\title{
WestVirginiaUniversity
}

THE RESEARCH REPOSITORY @ WVU

Graduate Theses, Dissertations, and Problem Reports

2003

\section{Effect of in-situ stresses on the stability of coal mine development workings}

\author{
Murali Mohan Gadde \\ West Virginia University
}

Follow this and additional works at: https://researchrepository.wvu.edu/etd

\section{Recommended Citation}

Gadde, Murali Mohan, "Effect of in-situ stresses on the stability of coal mine development workings" (2003). Graduate Theses, Dissertations, and Problem Reports. 1348.

https://researchrepository.wvu.edu/etd/1348

This Thesis is protected by copyright and/or related rights. It has been brought to you by the The Research Repository @WVU with permission from the rights-holder(s). You are free to use this Thesis in any way that is permitted by the copyright and related rights legislation that applies to your use. For other uses you must obtain permission from the rights-holder(s) directly, unless additional rights are indicated by a Creative Commons license in the record and/ or on the work itself. This Thesis has been accepted for inclusion in WVU Graduate Theses, Dissertations, and Problem Reports collection by an authorized administrator of The Research Repository @ WVU. For more information, please contact researchrepository@mail.wvu.edu. 


\title{
EFFECT OF IN-SITU STRESSES ON THE STABILITY OF COAL MINE DEVELOPMENT WORKINGS
}

\author{
Murali Mohan Gadde
}

\begin{abstract}
A Thesis submitted to the College of Engineering and Mineral Resources at West Virginia University in partial fulfillment of the requirements for the degree of
\end{abstract}

Master of Science in Mining Engineering

Approved by

Syd S. Peng, Ph.D., Committee Chairperson

Keith A. Heasley, Ph.D.

Yi Luo, Ph.D.

Department of Mining Engineering

Morgantown, West Virginia

2003

Keywords: coal, horizontal stress, development, entry, intersection 


\title{
ABSTRACT \\ EFFECT OF IN-SITU STRESSES ON THE STABILITY OF COAL MINE DEVELOPMENT WORKINGS
}

\author{
by Murali Mohan Gadde
}

Among the different types of ground control problems associated with underground coal mining, those related to in-situ stresses are the most common ones affecting the safety of a mining operation. As a result, this has been the focus of many ground control research works done in the recent years. More work has been done in this thesis to add additional information on the in-situ stress related ground control issues of the underground coal mine development workings.

Three-dimensional finite element modeling has been done to examine the Influence of the in-situ maximum horizontal stress angle on the stability of both the entry and the intersection. Distribution patterns of safety factors were used to explain the location of roof failure in the entry or the intersection. Also, the effect of in-situ stress ratios on the stability of development openings was studied. To make the work more general, both low and high insitu stress fields have been considered.

In general, the modeling results indicated that the entries oriented in the direction of the in-situ maximum horizontal stress were in the best condition while those oriented at $90^{\circ}$ were in the worst condition. For the intersections, the maximum and the minimum stability were seen at $0^{\circ} / 90^{\circ}$ and $45^{\circ}$ respectively. However, under some combinations of input conditions, the best or the worst conditions could be seen at other orientations as well. Based on these findings, layout design charts were prepared for both the entries and the intersections. It was also found that the change in the ground conditions with layout reorientation was more significant for the low in-situ stress fields than for the higher ones.

Distribution patterns of the maximum and the minimum principal stresses and safety factor revealed the causes for the change in the failure locations in the openings. The change in the average safety factor with the change in the ratio of the in-situ maximum horizontal to the vertical stress resembled a lognormal distribution curve. However, the effect of the ratio of the in-situ maximum horizontal to the minimum horizontal stress lacked such a clear trend for the different input combinations considered. 
To

My Parents 


\section{ACKNOWLEDGEMENTS}

At the outset, I would like to thank all my committee members for sparing some time amidst their busy schedules.

Special thanks are due to Dr. Keith A. Heasley and Dr. Yi Luo, my graduate committee members, for their insights and valuable advice. I appreciate your serving on my Master's committee and your suggestions were invaluable in shaping the final form of my thesis.

I would like to express my sincere and heart-felt sense of gratitude to Dr. Syd S. Peng, my research advisor and graduate committee chairman. Thank you for giving me an opportunity to work with you, and see and learn personally the qualities that made you an achiever. I always relish in sharing your intelligence and ever-present optimism. The multivaried fields of expertise that you've acquired are absolutely astounding and inspiring. Though this has been a short period of association, I feel l've matured much, both academically and personally as a result of being under your leadership and supervision. I am in no doubt that our continuing alliance will provide me bounty of opportunities to learn and emulate many of your traits that made you so successful.

I also appreciate the cooperation and the help received from my fellow students of the Mining Engineering Department, WVU. Individual credits are due to Dr. Khaled Morsy Mohamed for the many valuable discussions I have had with him and to Sergey Zagreba for his constant encouragement. Thanks are also due to my roommate, Pavan K Vedantam, for his support while writing this thesis. Aid of Ms. Karen Centofanti in administrative affairs is expressly acknowledged.

It is only fitting here that I recognize the contributions of a brilliant man, Dr. P. R. Sheorey, towards my career. I had the privilege of working with him for five years at Central Mining Research Institute (CMRI), India. I feel indebted to him for he taught me the intricacies of research when I began my research career. I would also like to thank the administration of CMRI for granting me the leave to pursue my higher studies here. Thanks are also owed to my colleagues at CMRI for their support and encouragement.

Finally, I come to my beloveds. I guess this is where words fail miserably. The journey from a modest background to this stage would not have been possible without the love, support, encouragement and scarifies of my parents and the family. In fact, I credit all the achievements in my life to my mother's confidence in my abilities more than my own. The patience and the sanguinity I learned from my dad have been invaluable in my life. I feel blessed to have such parents. The unconditional love and support of my brothers, Hari and Srinivas, and two vadinas helped me weather many tough times in my life successfully. Thank you all for being there whenever I needed help. 


\section{TABLE OF CONTENTS}

ABSTRACT

\section{CHAPTER 1}

INTRODUCTION

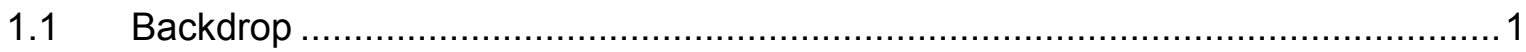

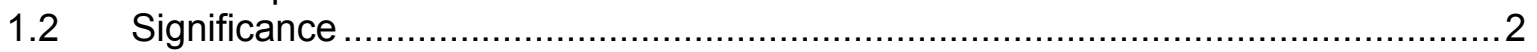

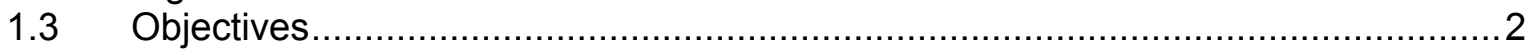

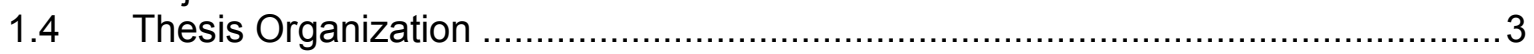

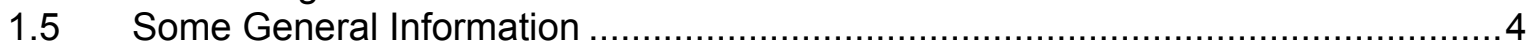

\section{CHAPTER 2}

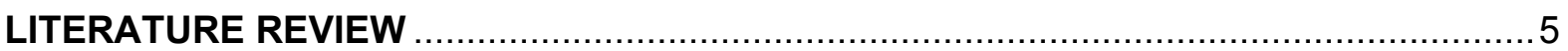

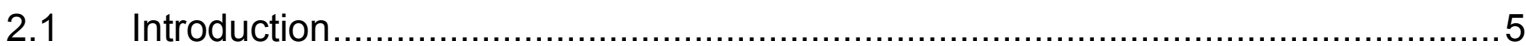

2.2 In-situ Stresses in the US Coal Fields ...................................................... 8

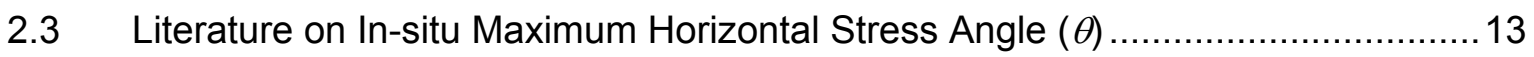

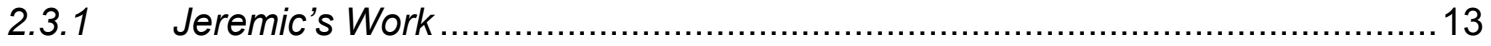

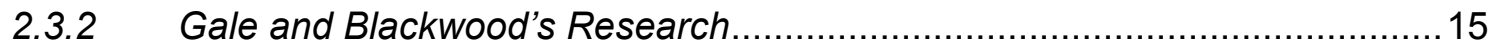

2.3.4 Wang and Stankus' Investigation ......................................................... 16

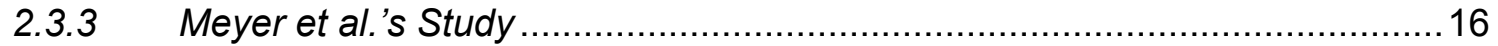

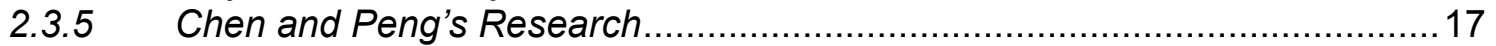

$2.4 \quad$ Works on Distribution Patterns ........................................................................... 19

2.5 Past Research on In-situ Stress Ratios...................................................... 21

2.6. Closing Remarks on Literature Review ........................................................ 22

\section{CHAPTER 3}

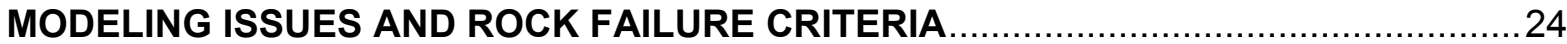

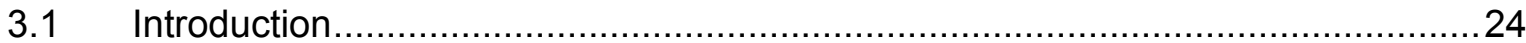

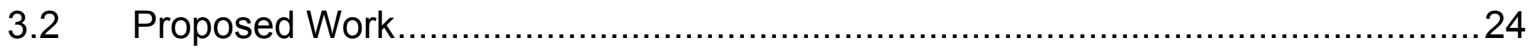

3.3 Application of In-situ Stresses in the Model ................................................... 30

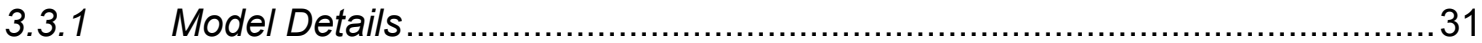

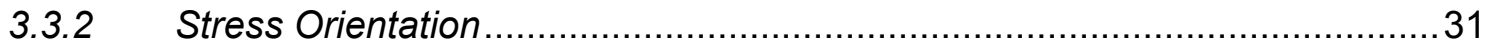

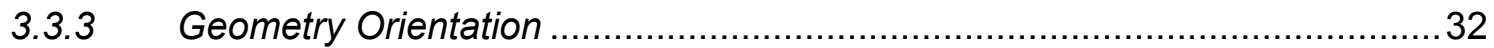

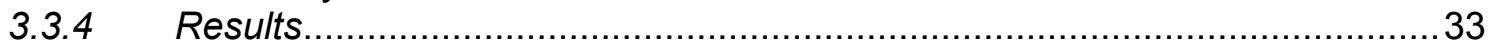

3.4 Rock Failure Criteria

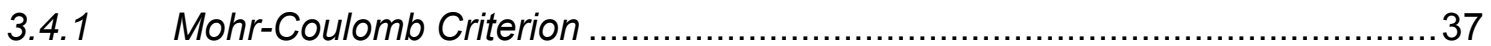

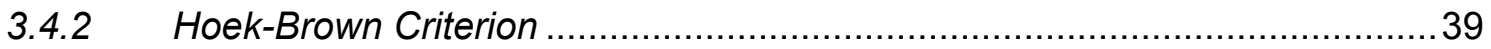

3.4.3 Comparison of Two Criteria ................................................................ 41

3.4.4 Effect of Intermediate Principal Stress ................................................... 42

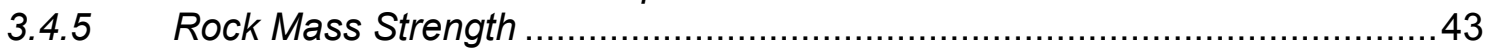




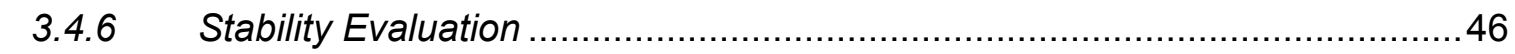

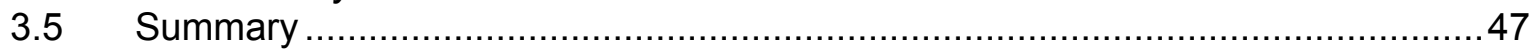

\section{CHAPTER 4}

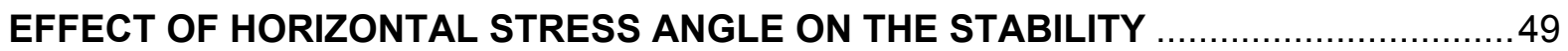

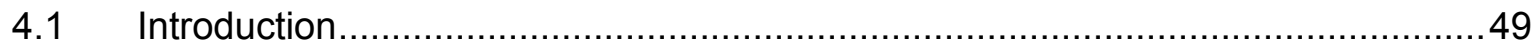

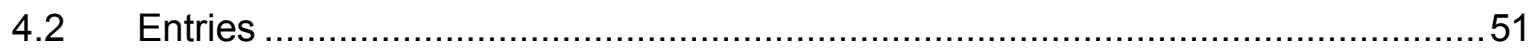

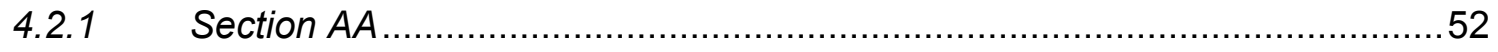

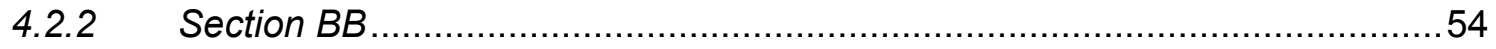

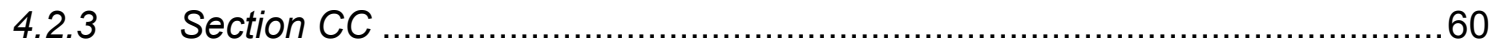

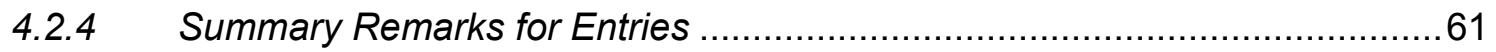

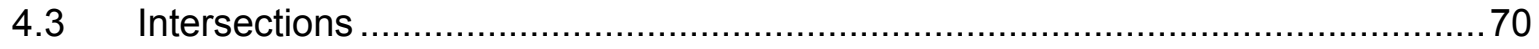

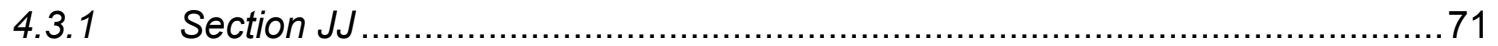

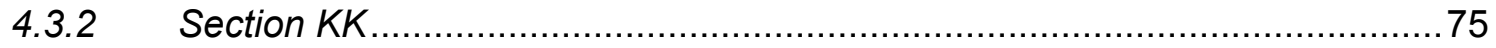

4.3.3 Summary Comments on Intersections .............................................. 75

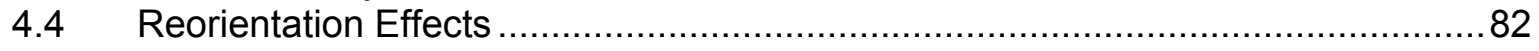

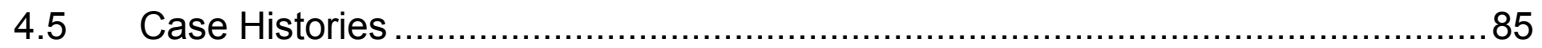

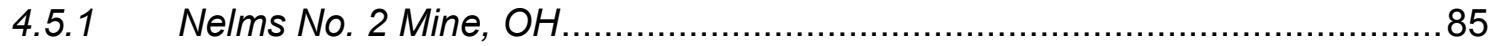

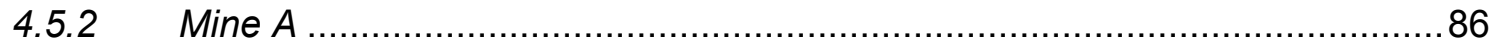

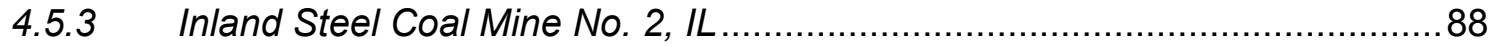

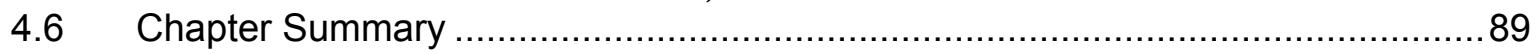

\section{CHAPTER 5}

DISTRIBUTION PATTERNS IN THE DEVELOPMENT WORKINGS $\ldots \ldots \ldots \ldots \ldots \ldots \ldots \ldots . . . \ldots 1$

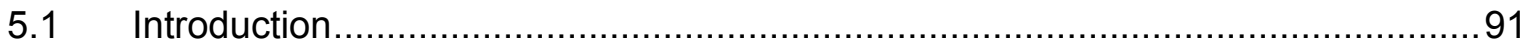

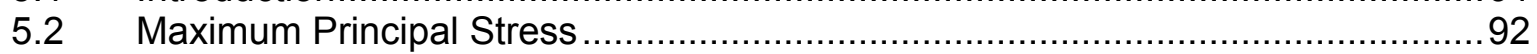

5.3 Minimum Principal Stress ....................................................................... 93

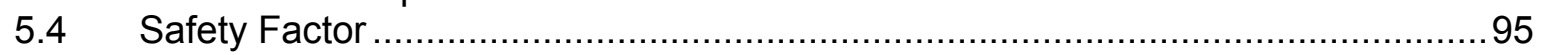

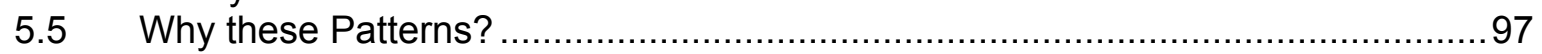

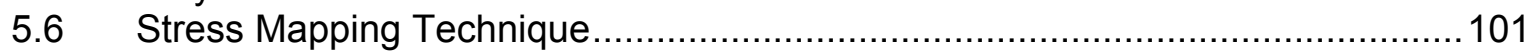

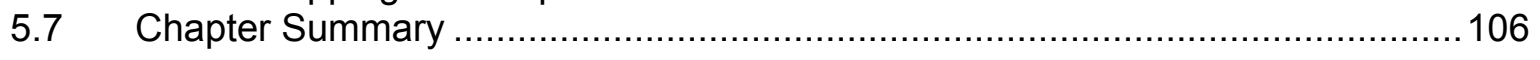

\section{CHAPTER 6}

INFLUENCE OF IN-SITU STRESS RATIOS ON THE ENTRY STABILITY ..................108

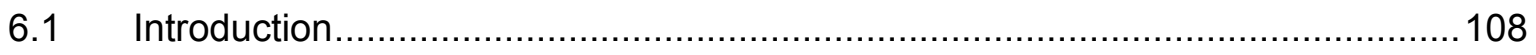

6.2 Influence of In-situ Maximum Horizontal to Vertical Stress Ratio (k)................. 109

6.2.1 Why $k$ Effect? ................................................................................. 113

6.2.2 Nature of Induced Stresses in the Immediate Roof ................................. 115

6. 3 Effect of In-situ Maximum Horizontal to Minimum Horizontal Stress Ratio (I) .....116

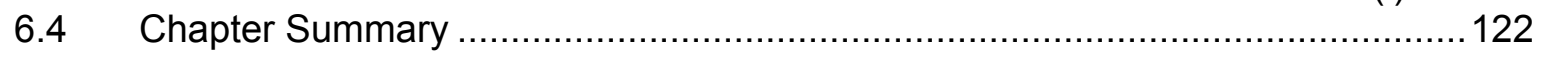

\section{CHAPTER 7}

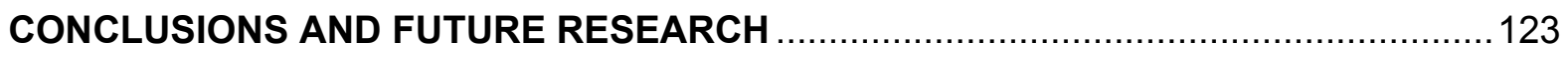

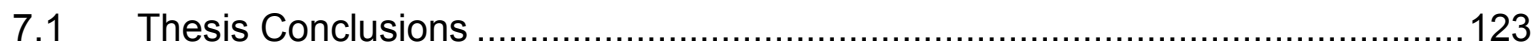

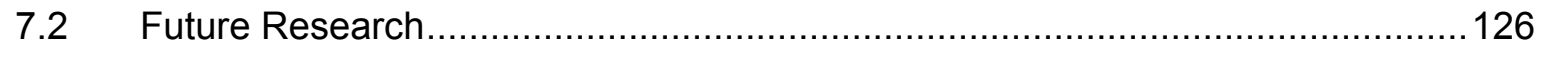

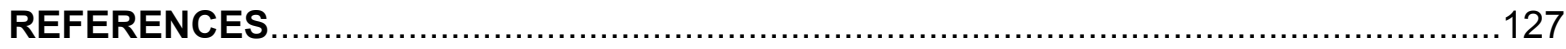




\section{LIST OF FIGURES}

Figure 2.1. The process of cutter roof failure [18] .................................................... 7

Figure 2.2. Direction of $\sigma_{\mathrm{hmax}}$ and associated stress regimes of North America [34] .......... 10

Figure 2.3. Variation of (a) $\boldsymbol{k}$ and (b) $I$ with depth obtained from field measurements in the US coal mines [26] ....

Figure 2.4. Direction of in-situ maximum horizontal stress (shown as $\sigma_{H}$ ) measured in the coal mines of (a) eastern and (b) western United States [26]

Figure 2.5. Roof failure by slip along bedding planes (top) and low angle shearing (below) for $\theta=90^{\circ}[22]$

Figure 2.6. Change in safety factor and percent of rock failure at the face with change in $\theta$ [14]. 15

Figure 2.7. Typical Von Mises stress change with $\theta$ at two points in the entry [39] ............16

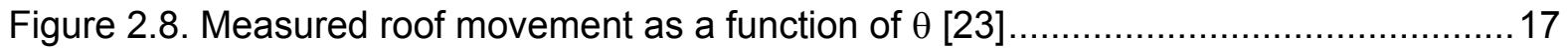

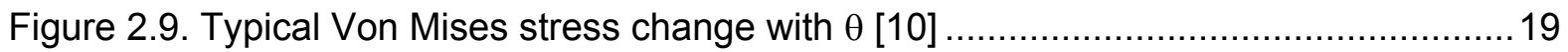

Figure 2.10. Position of roof failure in the entry for different orientations of $\sigma_{\mathrm{hmax}}[15] \ldots \ldots \ldots .20$

Figure 3.1. Model geometry and the location of cross-sections where results are obtained 27

Figure 3.2. Part of the lithology in the immediate vicinity of coal seam used in the models . 28

Figure 3.3. Modeled geometry with stress field rotated and entry aligned with coordinate axes.

Figure 3.4. Modeled geometry with entry rotated and stress field aligned with coordinate axes.

Figure 3.5. Comparison of (a) maximum principal stress and (b) minimum principal stress in the entry roof surface along line AA shown in Figure 3.3 and Figure 3.4. 34

Figure 3.6. Comparison of (a) maximum principal stress and (b) minimum principal stress in the entry roof surface along line BB shown in Figure 3.3 and Figure 3.4. 34

Figure 3.7. Comparison of (a) maximum principal stress and (b) minimum principal stress in the entry roof surface along line CC shown in Figure 3.3 and Figure 3.4 35

Figure 3.8. Comparison of (a) maximum principal stress and (b) minimum principal stress some distance into the roof at point $P$ shown in Figure 3.3 and Figure 3.4. 35

Figure 3.9. Comparison between measured and estimated compressive strengths for MohrCoulomb criterion 38

Figure 3.10. Comparison between measured and estimated tensile strengths for MohrCoulomb criterion 39

Figure 3.11. Comparison between measured and estimated compressive strengths using Hoek-Brown criterion

Figure 3.12. Comparison between measured and estimated tensile strengths using Hoek-

Brown criterion 
Figure 3.13. Comparison of performance of both criteria for a typical measured data set ...42

Figure 4.1. Location of cross-sections where results are obtained in the model ................50

Figure 4.2. Cutter roof failure along one rib side of an entry [2] .................................50

Figure 4.3. Change in average safety factors with $\theta$ (degrees) for different beds for $\boldsymbol{k}=0.3$ in cross-section AA.

Figure 4.4. Change in average safety factors with $\theta$ (degrees) for different beds for $\boldsymbol{k}=3.0$ in cross-section AA. 56

Figure 4.5. Relative frequency of observation of (a) highest and (b) lowest average safety factors for different in-situ maximum horizontal stress angles in the cross-section

AA.

Figure 4.6. Change in average safety factors with $\theta$ (degrees) for different beds for $\boldsymbol{k}=0.3$ in cross-section BB.

Figure 4.7. Change in average safety factors with $\theta$ (degrees) for different beds for $\boldsymbol{k}=3.0$ in cross-section BB.

Figure 4.8. Relative frequency of observation of (a) highest and (b) lowest average safety factors for different in-situ maximum horizontal stress angles in the cross-section BB.

Figure 4.9. Change in average safety factors with $\theta$ (degrees) for different beds for $\boldsymbol{k}=0.3$ in cross-section CC.

Figure 4.10. Change in average safety factors with $\theta$ (degrees) for different beds for $\boldsymbol{k}=3.0$ in cross-section CC.

Figure 4.11. Relative frequency of observation of (a) highest and (b) lowest average safety factors for different in-situ maximum horizontal stress angles in the cross-section CC.

Figure 4.12. Relative frequency of observation of highest and lowest average safety factors for different in-situ maximum horizontal stress angles for (a) $\boldsymbol{k}<1$ and (b) $\boldsymbol{k}>1$ in bed 1 .

Figure 4.13. Relative frequency of observation of highest and lowest average safety factors for different in-situ maximum horizontal stress angles for (a) $\boldsymbol{k}<1$ and (b) $\boldsymbol{k}>1$ in bed 2 . .68

Figure 4.14. Combined plot of relative frequency of observation of (a) highest and (b) lowest average safety factors for different in-situ maximum horizontal stress angles ....69

Figure 4.15. Design chart for the orientation of development entries in coal mines .............70

Figure 4.16. Change in average safety factors with $\theta$ (degrees) for different beds for $\boldsymbol{k}=0.3$ in cross-section $\mathrm{JJ}$.... 72

Figure 4.17. Change in average safety factors with $\theta$ (degrees) for different beds for $\boldsymbol{k}=3.0$ in cross-section $\mathrm{JJ}$. 73

Figure 4.18. Relative frequency of observation of (a) highest and (b) lowest average safety factors for different in-situ maximum horizontal stress angles in the cross-section JJ. 
Figure 4.19. Change in average safety factors with $\theta$ (degrees) for different beds for $\boldsymbol{k}=0.3$

in cross-section $\mathrm{KK}$

Figure 4.20. Change in average safety factors with $\theta$ (degrees) for different beds for $\boldsymbol{k}=3.0$

in cross-section KK. .77

Figure 4.21. Relative frequency of observation of (a) highest and (b) lowest average safety factors for different in-situ maximum horizontal stress angles in the cross-section $\mathrm{KK}$.

Figure 4.22. Relative frequency of observation of highest and lowest average safety factors for different in-situ maximum horizontal stress angles for (a) $\boldsymbol{k}<1$ and (b) $\boldsymbol{k}>1$ in bed 1 at the intersection. 79

Figure 4.23. Relative frequency of observation of highest and lowest average safety factors for different in-situ maximum horizontal stress angles for (a) $\boldsymbol{k}<1$ and (b) $\boldsymbol{k}>1$ in bed 2 at the intersection. 80

Figure 4.24. Combined plot of relative frequency of observation of (a) highest and (b) lowest average safety factors for different in-situ maximum horizontal stress angles in the intersection

Figure 4.25. Design chart for the orientation of intersections in coal mines 82

Figure 4.26. Design layout suggested for Nelms No.2 Mine [25]. 87

Figure 4.27. Recommended design layout for Mine A [39]. 87

Figure 4.28. Roof fall profiles near intersections before and after reorientation at Inland steel coal mine no.2 [9]

Figure 5.1. Distribution of maximum principal stress concentration zones in the immediate roof of the model

Figure 5.2. Maximum principal stress across the width in the entry $(a, b, c)$ and in the intersection (d, e, f).

Figure 5.3. Distribution of minimum principal stress concentration zones in the immediate roof of the model

Figure 5.4. Minimum principal stress across the width in the entry $(a, b, c)$ and in the intersection (d, e, f)...... 96

Figure 5.5. Distribution of lower safety factor zones in the immediate roof of the model......97

Figure 5.6. Safety factor stress across the width in the entry $(a, b, c)$ and in the intersection $(d, e, f)$. 98

Figure 5.7. Resultant deformation in the immediate roof of the model .............................99

Figure 5.8. Horizontal shear stress in the immediate roof coal bed 100

Figure 5.9. Shear stress in the horizontal plane in the black shale bed $1 \mathrm{ft}$ above the roof 100

Figure 5.10. Shear stress in the horizontal plane in the gray shale bed $9 \mathrm{ft}$ above the roof101

Figure 5.11. Stress mapping features and their disposition with respect to $\sigma_{\mathrm{hmax}}$ direction [31]

Figure 5.12. Induced principal stress directions in the intersection in the immediate roof.. 103 
Figure 5.13. Induced principal stress directions (a) near the face and (b) in the middle portion of the entry in the immediate roof (longitudinal axis of the entry is along 1axis)

Figure 5.14. Vertical displacement in the (a) roof and (b) floor along diagonals JJ and KK in the immediate roof.

Figure 6.1. Effect of the ratio of maximum horizontal to vertical in-situ stress, $\boldsymbol{k}$ on the average safety factors of different beds at cross-section AA shown in Figure 3.1.

Figure 6.2. Effect of the ratio of maximum horizontal to vertical in-situ stress, $\boldsymbol{k}$ on the average safety factors of different beds at cross-section BB shown in Figure 3.1.

Figure 6.3. Effect of the ratio of maximum horizontal to vertical in-situ stress, $\boldsymbol{k}$ on the average safety factors of different beds at cross-section CC shown in Figure 3.1.

Figure 6.4. Effect of the ratio of maximum horizontal to vertical in-situ stress, $\boldsymbol{k}$ on the average safety factors of different beds at cross-section JJ shown in Figure 3.1.

Figure 6.5. Effect of the ratio of maximum horizontal to vertical in-situ stress, $\boldsymbol{k}$ on the average safety factors of different beds at cross-section KK shown in Figure 3.1.

Figure 6.6. Maximum (sig1), minimum (sig3) principal stress and triaxial rock mass strength at the middle point in cross-section BB in the entry for different $\boldsymbol{k}$ values. 113

Figure 6.7. Maximum (sig1), minimum (sig3) principal stress and triaxial rock mass strength at the middle point in cross-section $\mathrm{JJ}$ in the intersection for different $\boldsymbol{k}$ values.

Figure 6.8. Minimum principal stress in the immediate roof coal evaluated at different locations in the mesh in the middle of the entry

Figure 6.9. Change in average safety factors with I for (a) bed 1 and (b) bed 2 at crosssection AA in the entry.

Figure 6.10. Change in average safety factors with I for (a) bed 1 and (b) bed 2 at crosssection BB in the entry.

Figure 6.11. Change in average safety factors with I for (a) bed 1 and (b) bed 2 at crosssection $\mathrm{CC}$ in the entry.

Figure 6.12. Change in average safety factors with I for (a) bed 1 and (b) bed 2 at crosssection $\mathrm{JJ}$ in the intersection.

Figure 6.13. Change in average safety factors with I for (a) bed 1 and (b) bed 2 at crosssection $\mathrm{KK}$ in the intersection.

Figure 7.1. Layout orientations and associated ground conditions with respect to $\sigma_{\text {hmax }}$ for (a) entry or crosscut and (b) intersection 


\section{LIST OF TABLES}

Table 3.1. Values of in-situ stress variables considered for the present work...............26

Table 3.2. Material and strength properties of different rocks used in the modeling.......28

Table 3.3. Details of data sets used for the regression analysis................................37

Table 3.4. Value of constant $m$ for different coal measure rocks obtained from regression analysis of the measured data.

Table 4.1. Percentage increase in the safety factors for different cross-sections in the entry for different stress fields with change in $\theta$.

Table 4.2. Percentage increase in the safety factors for different cross-sections in the intersection for different stress fields with change in $\theta$ 


\section{LIST OF SYMBOLS}

\begin{tabular}{|c|c|}
\hline a & Exponent in the Hoek-Brown rock mass failure criterion \\
\hline GSI & Geological Strength Index \\
\hline $\boldsymbol{k}$ & Ratio of the maximum in-situ horizontal to the vertical stress \\
\hline$l$ & Ratio of the in-situ maximum horizontal to the minimum horizontal stress \\
\hline$q$ & Mohr-Coulomb triaxial rock strength constant \\
\hline$R F$ & Uniaxial compressive strength reduction factor \\
\hline SF & Safety factor \\
\hline$s, m$ & Intact rock constants in the Hoek-Brown rock failure criterion \\
\hline$s_{r m}, m_{r m}$ & Rock mass constants in the Hoek-Brown rock mass failure criterion \\
\hline$\theta$ & In-situ maximum horizontal stress angle \\
\hline$\sigma_{c}$ & Uniaxial compressive strength of intact rock \\
\hline$\sigma_{c r m}$ & Uniaxial compressive strength of rock mass \\
\hline$\sigma_{\mathrm{hmax}}$ & In-situ maximum horizontal stress \\
\hline$\sigma_{\mathrm{hmin}}$ & In-situ minimum horizontal stress \\
\hline$\sigma_{t}$ & Uniaxial tensile strength of intact rock \\
\hline$\sigma_{t r m}$ & Uniaxial tensile strength of rock mass \\
\hline$\sigma_{\mathrm{v}}$ & In-situ vertical stress \\
\hline$\sigma_{1}$ & Maximum principal stress \\
\hline$\sigma_{2}$ & Intermediate principal stress \\
\hline$\sigma_{3}$ & Minimum principal stress \\
\hline $\begin{array}{l}\sigma_{1 \mathrm{i}}, \quad \sigma_{2 \mathrm{i}}, \\
\text { and } \sigma_{3 \mathrm{i}}\end{array}$ & Maximum, intermediate and minimum induced principal stresses \\
\hline
\end{tabular}




\section{CHAPTER}

\section{INTRODUCTION}

\subsection{Backdrop}

The stability of the rock mass surrounding an underground excavation depends on the loads to which it is subjected. To a large extent, the magnitude and the nature of redistributed loads on the rock mass are determined by the pre-mining or in-situ stress state at that point. Underground stress measurements show a lot of variability in the magnitude and the directions of the in-situ stresses in the US coal mines [26]*. Depending on the magnitude and the orientation of the in-situ stress field with respect to an entry, it might experience stable or unstable conditions. Among many kinds of ground control problems related to the in-situ stresses, a specific type of roof shear failure known as cutter failure is the common one plaguing the coal mining industry.

With the advent of the digital computer and tremendous advances in the numerical modeling techniques, it is now possible to incorporate complex geometric, material and boundary conditions in an analysis. Using the state-of-the-art analysis tools available at the time, it has been proven in the past that the magnitude and the direction of the in-situ maximum horizontal stress was the main factor responsible for most of the cutter failures. Though there are some excellent works available on this issue, much research needs to be done before a comprehensive understanding of the effect of in-situ stresses is developed. Work in this thesis is one effort in that direction.

In contrast to the past works, the current research considers the effect of both low and high horizontal in-situ stresses on the stability of coal mine development workings. Additionally, more detailed stability evaluations will be made at different

\footnotetext{
* Numbers in the square brackets refer to the references given at the end of the thesis
} 
points in the excavation by average safety factor estimation, which reflects the combined effect of the induced principal stresses. One major task of this work is evaluation of the orientation effects on the ground conditions of intersections by numerical modeling as very little has been done on this issue in the past.

\subsection{Significance}

Although knowledge of higher in-situ horizontal stresses has existed since the late 1970s, serious consideration of the influence of this factor in the stability analysis seems to have begun in the late 1980s. Prior to this period, most of the ground control problems were linked to high vertical stress. Now, with the advances in the in-situ stress measuring techniques that confirm the existence of high horizontal stresses, the roof instability in a majority of cases is ascribed to the high horizontal stresses. This can be witnessed by the deluge of publications on this subject. However, a complete study on the in-situ stress related ground control problems should consider both the high and the low in-situ stress fields as the stress measurements in the mines also show the existence of low horizontal stresses [26]. Besides, with increasing depth, the possibility of existence of the low horizontal stress increases as shown by the actual measurements [19].

Therefore, equal emphasis is placed in this research on the low horizontal insitu stress fields as much as on the higher ones. Further, the directional effects are also investigated for the low in-situ horizontal stresses. It is believed that such an approach will provide an all-embracing picture of the in-situ stress related problems.

\section{$1.3 \quad$ Objectives}

The number of factors accountable for ground control problems in a real mine situation are too many to incorporate in a research effort of this kind. Therefore, limits have been imposed on the number of variables and their range of magnitudes considered in this thesis to make the research manageable. However, these limits 
provide sufficient range to the magnitude of the variables to make modeling results meaningful for practical designs. The following are the broad objectives of this research endeavor:

a Consideration of all combinations of the magnitudes of the in-situ stresses; $\sigma_{h \max } \geq \sigma_{h \min } \geq \sigma_{v}, \sigma_{v} \geq \sigma_{h \max } \geq \sigma_{h \min }, \sigma_{h \max } \geq \sigma_{v} \geq \sigma_{h \min }$.

\# Investigation of the effect of the in-situ stresses on the stability of entries and intersections.

I Evaluation of the stability not only at a few points in the immediate roof surface but also to some distance into the entry or the intersection roof and at different locations.

a Consideration of the directional effects of in-situ horizontal stresses in both low and high stress environments.

z Providing feasible explanations for the distribution trends of rock failure observed in different parts of a development layout.

\# Enhancing knowledge on the effect of in-situ stress ratios on the stability of mine roof.

I Finally, developing layout design guidelines with respect to the direction of insitu maximum horizontal stress angle for entry and intersection in underground coal mines.

\subsection{Thesis Organization}

This thesis is organized into seven chapters. Chapter 2 is a review of the current knowledge on the in-situ stress related ground control problems. Different techniques adopted in the past to address this issue are discussed and shortcomings delineated. In Chapter 3 deliberations are made about some numerical modeling related issues and then ample details on selection of a suitable rock failure criterion for use in this work are provided. Chapter 4 outlines the results related to the effect of in-situ maximum horizontal stress direction on the stability of entry and intersection. Based on this work, guidelines are also developed for choosing proper 
development panel layout orientation. Comparison of the magnitudes and evaluation of bias in the distribution of induced principal stresses and safety factors as seen in the plan view of the development layout are the main themes of Chapter 5. Also, included in this chapter are discussions on the distribution trends vis-à-vis stress mapping technique. The effect of in-situ stress ratios on the stability of coal mine development workings is discussed in Chapter 6. Possible causes for the observed trends are also portrayed there. Chapter 7 provides a list of major conclusions of this work and also gives an outline of possible areas for future research work.

\subsection{Some General Information}

For terseness in this thesis, the ratio of the maximum in-situ horizontal to the vertical stress and the ratio of the in-situ maximum horizontal to the minimum horizontal stress are referred to by symbols $\boldsymbol{k}$ and $\boldsymbol{l}$, respectively. These two stress ratios are collectively called in-situ stress ratios. The distinction of low and high insitu stress fields in this work means $k<1$ and $k>1$, respectively. The angle between the direction of in-situ maximum horizontal stress and the longitudinal axis of the entry is called in-situ maximum horizontal stress angle and is most often

substituted by symbol $\theta$. The sign convention in this thesis is positive for compressive stresses and negative for tensile ones. 


\section{LITERATURE REVIEW}

\section{$2.1 \quad$ Introduction}

The detrimental effect of the in-situ stresses on the underground excavation stability has long been recognized and many significant works on this have been done in the past. These works encompass a broad range of underground mining activities involving both development and retreating works. A complete review of all these works is beyond the scope of this thesis. Since the present research is aimed at stability evaluations of development workings in underground coal mines, only important works related to this topic will be reviewed in this chapter.

Many factors contribute to the current in-situ stress state at a point in the earth's crust, e.g., plate tectonics, the earth's internal structure etc [6]. The interaction of all these parameters is so complex that no analytical methods are available to accurately estimate the in-situ stress state at a point in the earth's crust. Hence, often the only choice available is to measure the stress state in the field. Many methods are available for this purpose and each of them have their own advantages and limitations [6].

In coal mines of the United States over the last three decades, a number of stress measurements have been conducted mostly using the overcoring method [26]. In a majority of cases, these measurements indicate that the magnitude of insitu maximum horizontal stresses is more than the vertical stress in the coal mines of the eastern United States and is nearly equal to or less than the vertical stress in the mines of the western USA. A brief review is made in this chapter on the current knowledge of the in-situ stress state in the US coal mines and comparisons will also be made with the regional stress patterns.

Awareness of the influence of in-situ stresses, particularly, the existence and the effect of high in-situ horizontal stress, on roof stability was there in the coal mining industry even before actual underground stress measurements were made. 
In an excellent review on the in-situ stress related ground control problems in coal mines, Mark quoted a work by Roley that described a phenomenon called 'pressure cutting' in Illinois coal mines in the 1940s [26]. Later, many different types of rock failures were identified to be due to high in-situ maximum horizontal stresses. These are commonly known as cutters, guttering, kink roof, snap tops, etc. [26]. Of these roof failure types, the cutter roof failure seems to be more prevalent in the US coal mines, in general, and the Appalachian coal fields, in particular [18, 26]. High in-situ maximum horizontal stress related problems were also reported from Australia [14, 15] and the United Kingdom [27, 28].

Severity of roof control problems related to the high in-situ horizontal stresses gave an impetus to the research on the in-situ stresses related issues in the late 1970s [11, 4, 5, 3]. Many researchers worked on the problem of cutter roof failure and offered explanations based on field and analytical work [5, 24, 36, 18, 26]. Kripakov summarized the factors responsible for the cutters and also conducted numerical modeling to examine the causes for the cutter roof failure at a mine [24]. Using two dimensional finite element modeling, Kripakov inferred that the high shear stresses at the entry corner caused the cutters at the analyzed mine. He also lists hydraulic pressure, gas pressure and variations in temperature and humidity as contributors to the cutter roof failure [24].

Su and Peng using three dimensional finite element modeling and three case studies, investigated the intrinsic mechanism responsible for the cutter roof failures [36]. They divided the mechanisms into five categories: (1) effect of high vertical stress, (2) effect of high horizontal stresses, (3) effect of variation of material properties in coal and its immediate roof, (4) effect of large topographic relief, and (5) effect of bed separation and gas pressure. Their research also listed pillar size as a factor causing cutter roof failures.

Hill provided a definition for what constitutes a cutter roof failure and also a qualitative explanation of the process of its formation in the entry as shown in Figure 2.1 [18]. He also summarized the main factors responsible for the cutter roof failure and they were: the interaction of multiple entries, regional in-situ stresses, stress 
concentration beneath stream valleys, rock mass characteristics, and minor geological features.

Based on six case studies in the Northern Appalachian coal mines, Bauer concluded that high stress, surface topography and geological anomalies were causing the observed cutters in the mines studied [7].

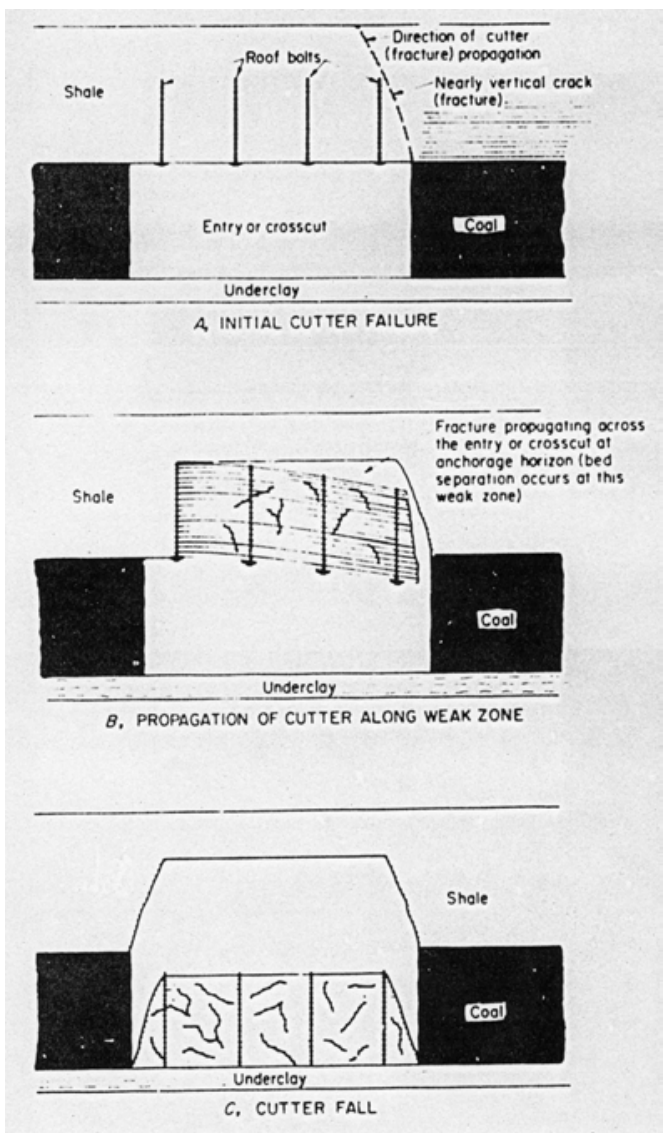

Figure 2.1. The process of cutter roof failure [18].

The suggested remedial measures to deal with the cutter roof problems include, change in support type and design patterns, employing sacrificial entries, reorientation of openings, yield pillars, advance and relief techniques, etc [18, 24, 13].

Broadly speaking, this review indicates a consensus among the researchers about the importance of the in-situ stresses and rock properties in causing the cutter roof failures. For this reason, it is vital to have an idea of the prevailing in-situ stress fields in the coal mines. Thus, the available knowledge on the in-situ stresses 
measured or inferred in the continental United States and also in the US coal mines is summarized in the next section. After that, important works related to the issues investigated in this thesis will be reviewed.

\subsection{In-situ Stresses in the US Coal Fields}

The stress state at any point in a continuum can be expressed by the six components of the stress tensor or by the three principal stresses and their directions. Often the in-situ stress state at a point in the Earth's crust is expressed in terms of its principal components with assumptions made about their directions [6]. Generally, one of the principal stresses is assumed to be in the vertical direction and its value is estimated by the weight of the overburden at that point. Actual stress measurements support this presumption about the magnitude of pre-mining vertical stress [19, 12]. The remaining two principal stresses are assumed to be in a horizontal plane but their magnitudes and directions are highly variable and no methods are available to estimate their values accurately without field measurements or observations.

Among many factors responsible for the current stress state at a point in the Earth's crust, tectonic stresses were found to be the most important one [6, 26]. Tectonic stresses are those stresses produced by the forces that drive plate tectonics [29]. According to the theory of the plate tectonics, the Earth's upper crust and mantle are divided into a number of moving plates and they interact with each other in the process of drifting. Depending on the relative movement of the plates with respect to each other, different types of stresses, e.g, compressive, extension, etc, are generated in them. It is also found that for the tectonic stress fields the three principal stresses lie in approximately horizontal and vertical planes, with the horizontal stress component almost always larger than the vertical component. Hence, for convenience only the direction of in-situ maximum horizontal stress is often recorded [40].

Based on the compilation of data from different sources, researchers at the World Stress Map Project produced stress map for the North American region as shown in Figure 2.2 [34]. This data came from earthquake focal mechanisms, 
borehole breakouts, in-situ stress measurements, fault slip analysis, etc. The stress regimes in this figure indicate the order of magnitude of principal stresses. The normal fault (NF) regime means $\sigma_{v}>\sigma_{h \max }>\sigma_{h \min }$, the strike-slip fault (SS) regime indicates $\sigma_{h \max }>\sigma_{v}>\sigma_{h \min }$ and the thrust faulting (TF) regime stands for $\sigma_{h \max }>\sigma_{h \min }$ $>\sigma_{\mathrm{v}}$. Regime $\mathrm{U}$ indicates unknown. The quality designations, $\mathrm{A}, \mathrm{B}$, and $\mathrm{C}$, shown in this figure indicate the quality ranking of the data and are mainly based on the number, the accuracy and the depth of the measurements [34].

Mark analyzed the significance of the World Stress Map to the in-situ stress measurements in the US coal mines [26]. Figure 2.2 is the latest update to the one used in Mark's paper. Though this map has more data points, the general remarks made by Mark seem to be still applicable. All coal mines in the eastern United States fall in the thrust fault regime with the general direction of $\sigma_{\mathrm{hmax}}$ in the east-northeast direction. Underground in-situ stress measurements in the eastern mines show compliance with these regional trends as shown in Figure 2.3 and Figure 2.4 [26].

In the Western United States, the regional stress field is the normal fault one. As per Mark, the coal mines here fall in three stress provinces and the high topography of the area was believed to be responsible for the extensional stress regime observed. Though the in-situ stress measurements in this region confirm to the regional trends in magnitude, there seems to be a lack of agreement in the direction as seen from Figure 2.3 and Figure 2.4.

From the in-situ stress measurements taken in the US coal mines, the following points are worth noting:

I Overcoring is the most popular method of measurement.

\# Data indicates higher in-situ horizontal stresses than the vertical stress. This trend is apparent for the eastern mines than the western mines.

4 The ratio of in-situ maximum horizontal to vertical stress $(\boldsymbol{k})$ varies between 0.3 and 10.23 .

Z The in-situ horizontal stress field is biaxial and the ratio of in-situ maximum horizontal to minimum horizontal stress $(l)$ varies from 1 to 10.48 . 


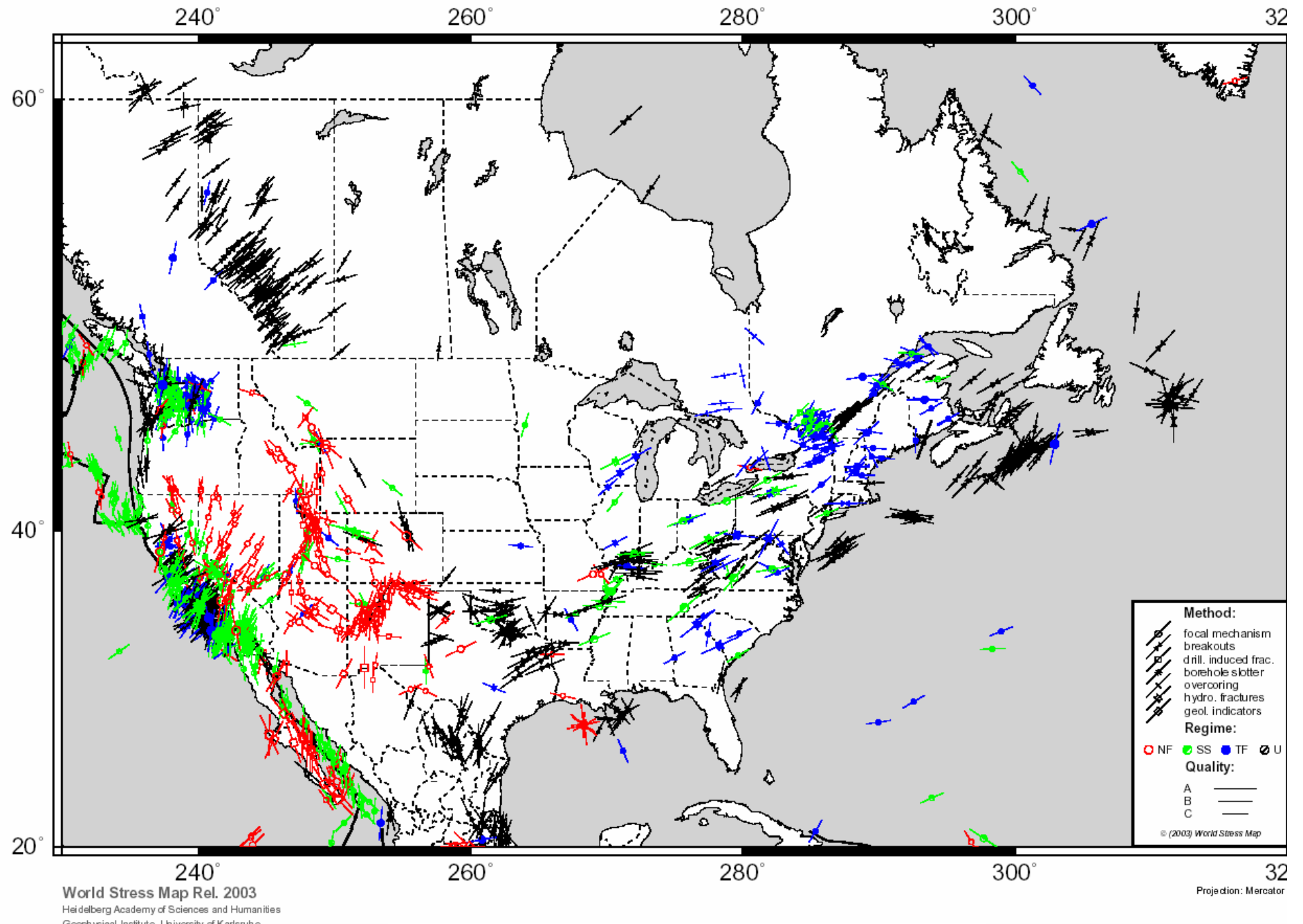

Figure 2.2. Direction of $\sigma_{h \max }$ and associated stress regimes of North America [34]. 
(a)

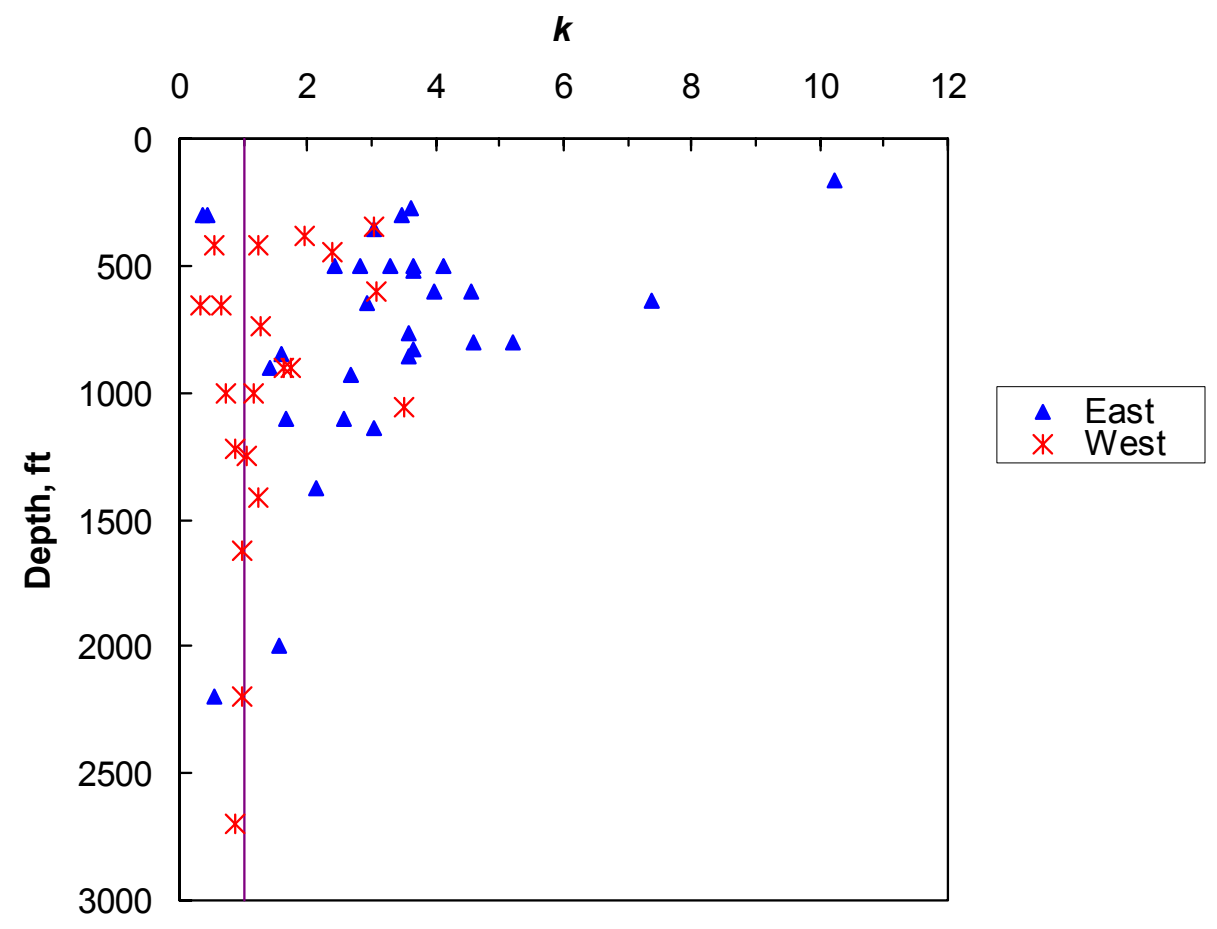

(b)

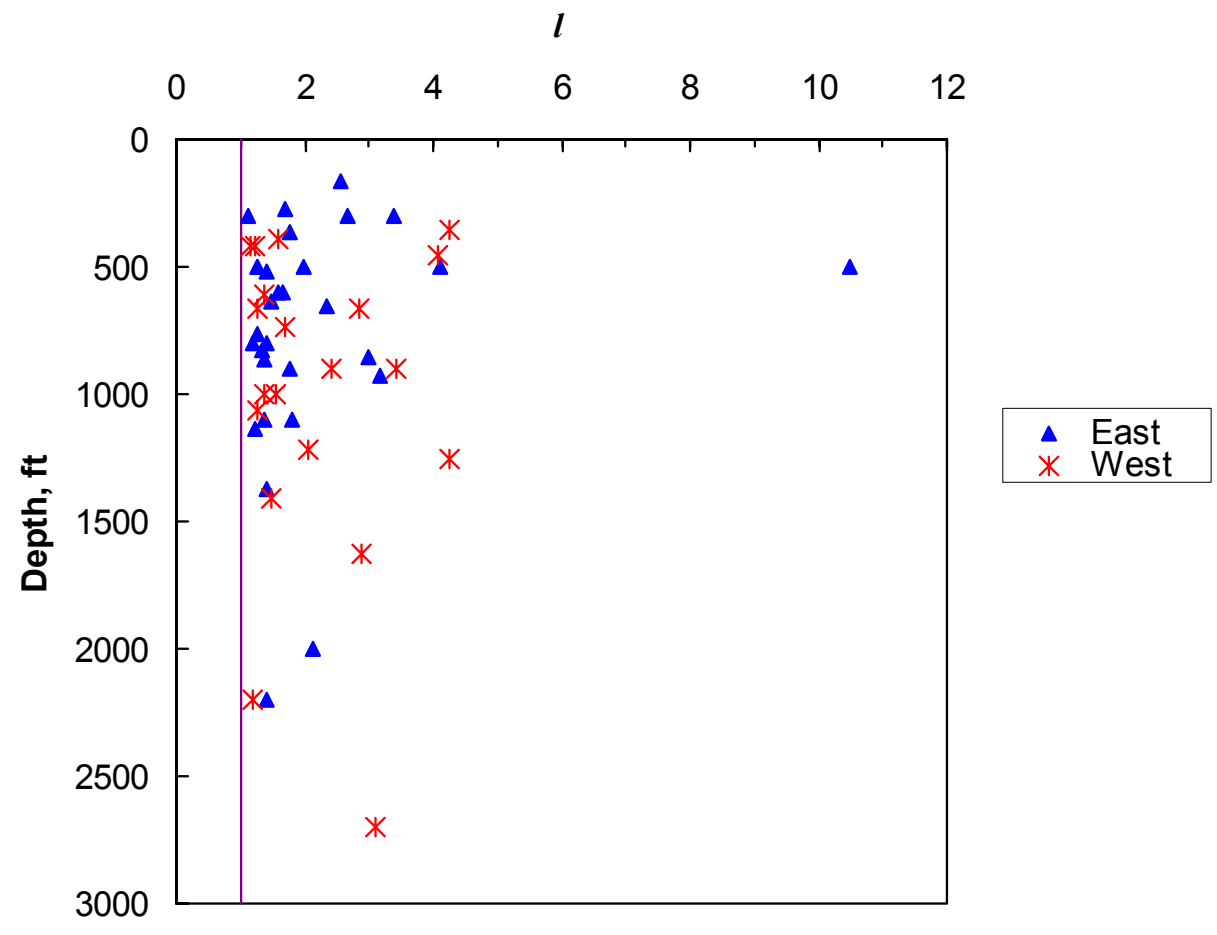

Figure 2.3. Variation of (a) $\boldsymbol{k}$ and (b) $\boldsymbol{l}$ with depth obtained from field measurements in the US coal mines [26]. 
(a)

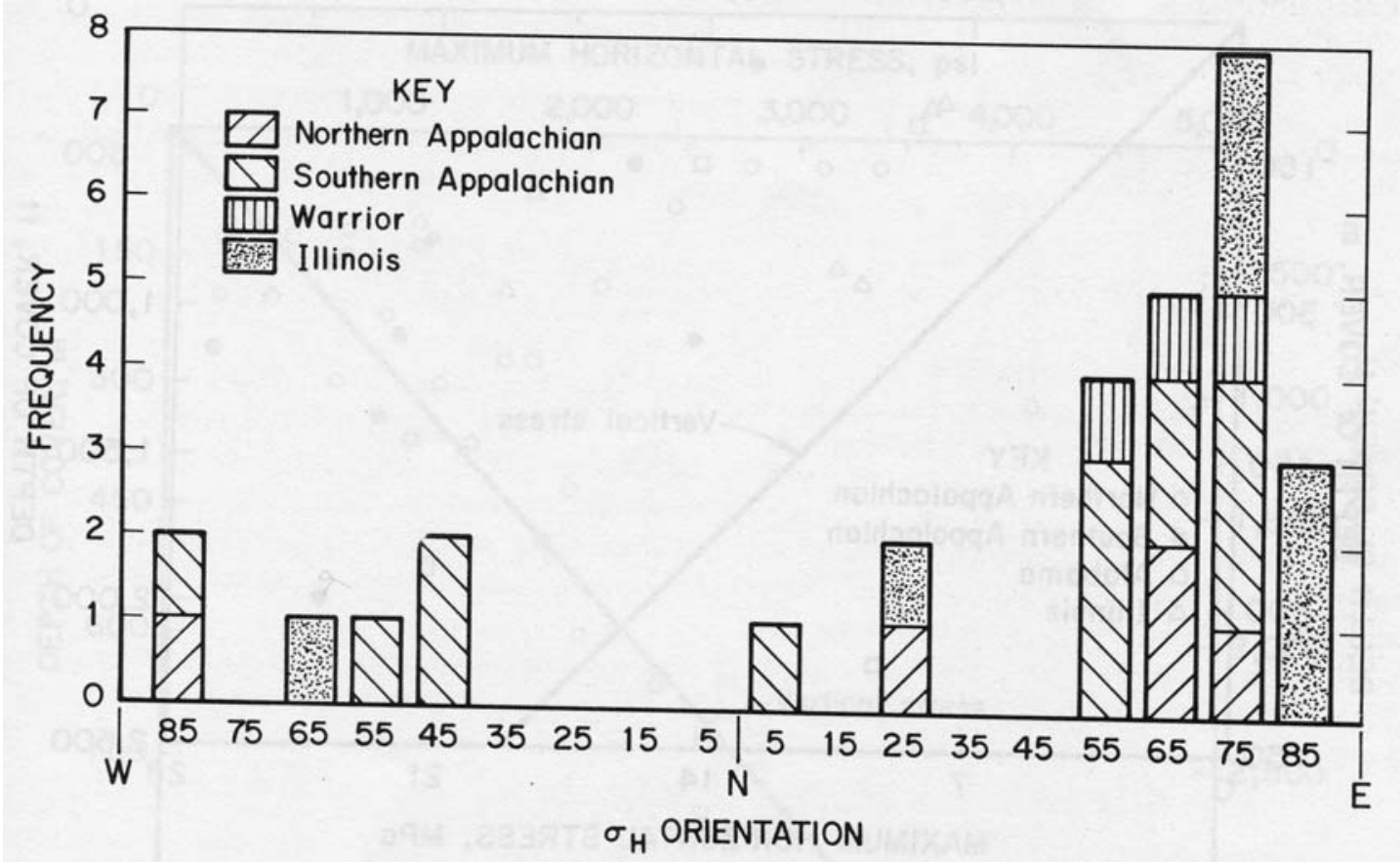

(b)

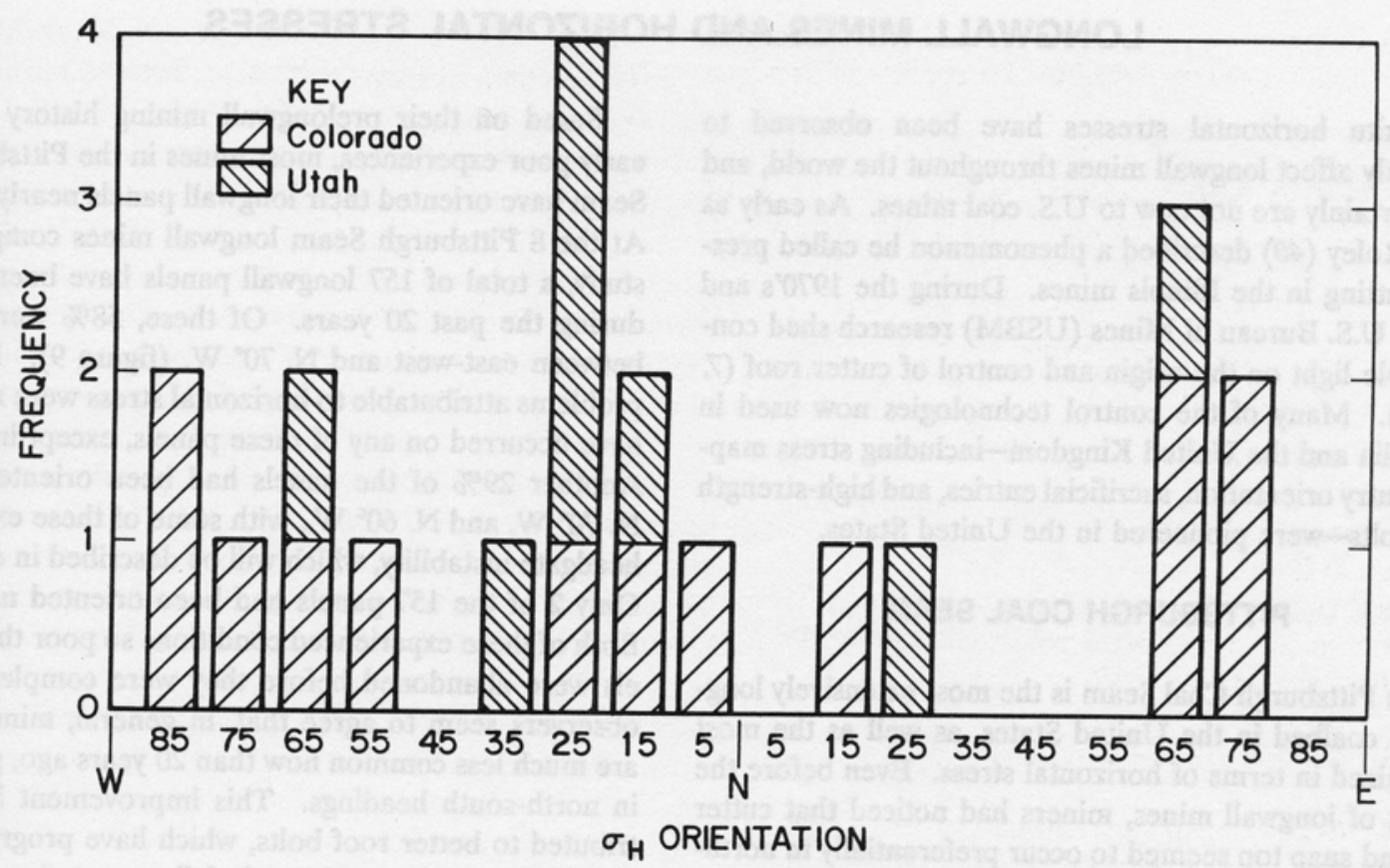

Figure 2.4. Direction of in-situ maximum horizontal stress (shown as $\sigma_{H}$ ) measured in the coal mines of (a) eastern and (b) western United States [26]. 


\subsection{Literature on In-situ Maximum Horizontal Stress Angle ( $\theta$ )}

Preference of rock failure as observed in a single set of openings (entry or crosscut) and also the location of failure across the entry or crosscut's width prompted the researchers to explore the influence of the in-situ maximum horizontal stress angle on this behavior. At Inland Steel coal company No. 2 mine in Illinois coal basin, persistent roof falls were noticed in the North-South openings while those oriented East-West experienced minimum problems [8, 9]. Investigations later revealed that these problems were mainly due to an East-West trending in-situ maximum horizontal stress and reorienting the openings reduced the number of falls considerably $[9,17]$.

Similar problems were reported by Lizak and Sembourski in Nelm's No.2 mine in Ohio [25] and by Wang and Stankus [39]. In both of these cases, the direction of openings with respect to the in-situ maximum horizontal stress was identified as the major cause of instability. Aggson also reported a case of roof failures in a West Virginia mine where roof failures were noticed in entries while crosscuts were stable [5]. Again, perpendicularity of entries with respect to $\sigma_{\mathrm{hmax}}$ was identified as the cause.

In-situ stress direction related problems were also noticed in the Australian and British coal mines and some works have been done in the past to tackle this problem [14, 15, 27, 28]. Though there are quite a few works on the issue of in-situ maximum horizontal stress angle effects, in the context of the current work, only those works that used some form of analysis methods - numerical or analytical - are reviewed in the subsequent discussions.

\subsubsection{Jeremic's Work}

This is one of the earliest works done on the effect of $\theta$ on the opening stability that employed some kind of semi-analytical approach [22]. Classical beam theories were used to explain the in-mine observations. From this analysis, roadways perpendicular to the lateral stress were reported to experience maximum 
instability and about $80 \%$ of roof falls were recorded in roadways in this condition. Two types of roof failures were hypothesized to take place in this condition as shown in Figure 2.5. Accelerated floor heave and extrusion of coal ribs into openings are other associated features for this condition.

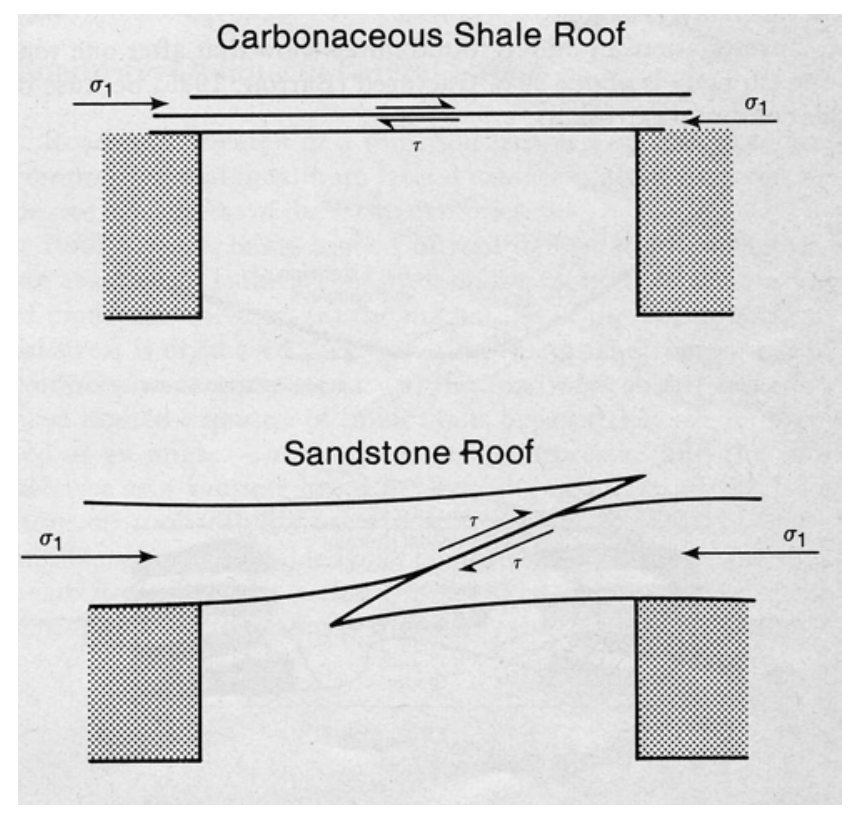

Figure 2.5. Roof failure by slip along bedding planes (top) and low angle shearing (below) for $\theta=90^{\circ}$ [22].

For roadways parallel to the maximum lateral tectonic stress, it was assumed that lateral extension would develop along its width [22]. It was concluded that roadways in this condition would experience better conditions than those at right angles to the lateral stress. Based on further analysis Jeremic concluded that the openings oriented at $45^{\circ}$ to the lateral stress were in the best conditions.

Although this work explained some broad field observations, it was very rudimentary in its approach. The beam theory equations used in the paper did not clearly explain the conditions reported for different orientations. Also, the description of lateral stresses was qualitative and how different magnitudes of these stresses would affect the stability was not clear from the analysis. 


\subsubsection{Gale and Blackwood's Research}

Three-dimensional boundary integral equation method was used in this research to investigate the effect of $\theta$ on the entry face stability [14]. A single entry model was created in a high in-situ stress field and results were evaluated at a few points $35 \mathrm{~cm}$ inside the roof at the face and $0.5 \mathrm{~m}$ ahead of it. Mohr-Coulomb failure criterion was used to estimate safety factors at these points.

The results of this analysis indicated that the safety factor decreases with increase in $\theta$ and has the minimum value at $90^{\circ}$. The rate of decrease is higher from $45^{\circ}$ onwards as shown in Figure 2.6. This figure also shows the percentage of roadway drivage affected by shear failure at the face area from two cases in Southern Coal Field, NSW, Australia. It was concluded that the observed conditions in the mine could be explained by the orientation of entry face with respect to $\sigma_{\mathrm{hmax}}$.

The results of this work are only applicable to the face area. However, as the number of points at which results were obtained was very limited, these results can not be extrapolated to the whole immediate roof influenced by the entry. Further, only single values of $\boldsymbol{k}$ and $\boldsymbol{l}$ have been considered in the analysis.

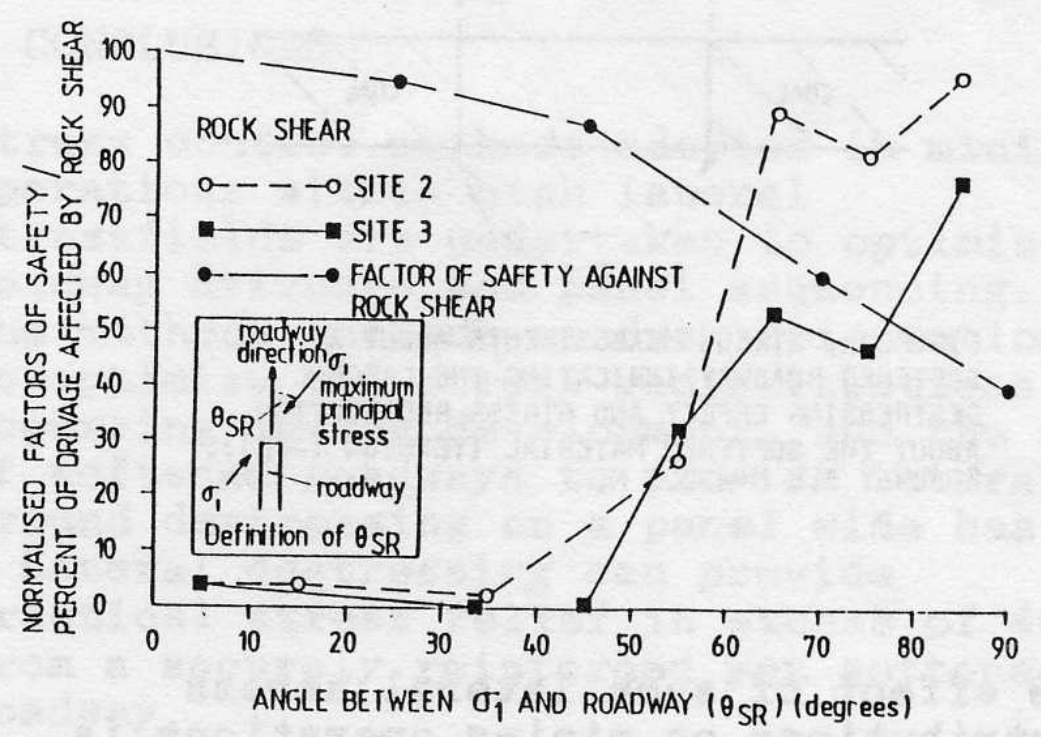

Figure 2.6. Change in safety factor and percent of rock failure at the face with change in $\theta$ [14]. 


\subsubsection{Wang and Stankus' Investigation}

This research was conducted to explain roof control problems at a room and pillar mine, Mine A [39]. Three-dimensional finite element method was used to simulate the problem. Only five three-entry longwall development models were studied for stress distributions with different $\sigma_{\mathrm{hmax}}$ orientations between $0^{\circ}$ and $90^{\circ}$ on $22.5^{\circ}$ increments. The $\boldsymbol{k}$ and $\boldsymbol{l}$ values used in the model were 10.9 and 2.57 respectively.

Description on Von Mises stress values obtained in the immediate roof surface at four points in the entry and four points in the crosscut was given and a typical plot is shown in Figure 2.7. Roof fall observations in the mine and the results of these five numerical models were used to construct a panel design layout. In my opinion the numbers of models run or the number of variables considered are too few to make any general conclusions as those made in this paper.

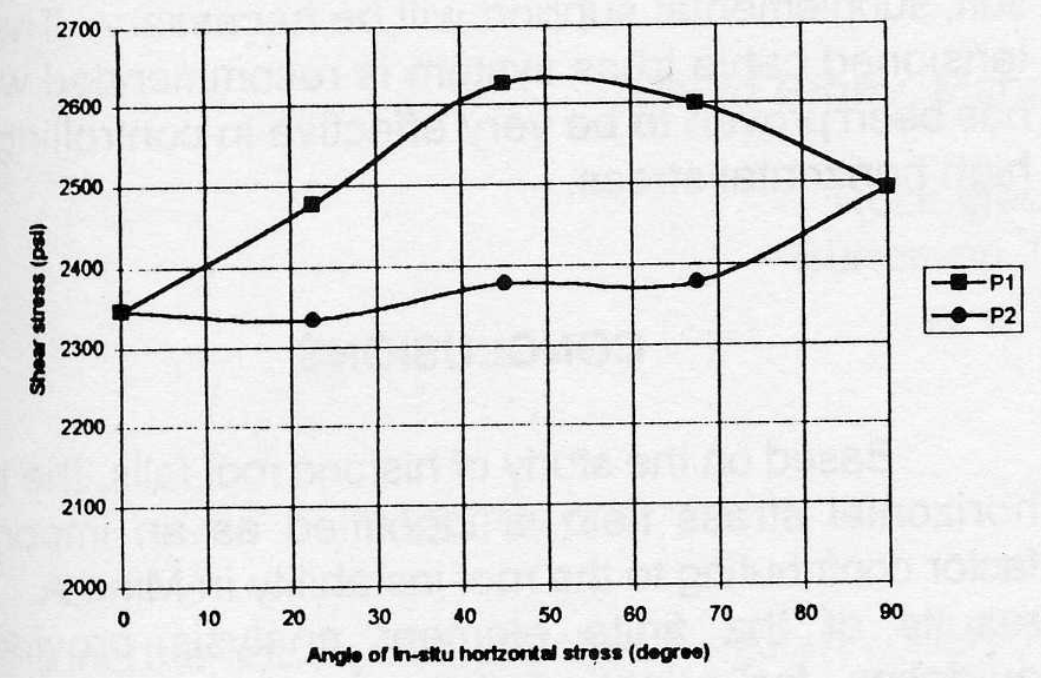

Figure 2.7. Typical Von Mises stress change with $\theta$ at two points in the entry [39].

\subsubsection{Meyer et al.'s Study}

This work was an extension of Gale and Blackwood's research and used three dimensional finite difference software, $\operatorname{FLAC}^{3 \mathrm{D}}$, for the modeling $[27,28]$. The 
same model data as that of Gale and Blackwood's were used in this work. Besides elastic analysis, elastic-plastic analysis was also conducted. Roadway convergence data obtained from the British coal mines was used to verify the results [23]. These field observations show that the convergence in the openings that make $90^{\circ}$ with $\sigma_{h \max }$ is more than in those that are aligned with $\sigma_{\mathrm{hmax}}$ as shown in Figure 2.8.

The field data used to verify the model results and the numerical method used to obtain them are the major differences between this research and Gale and Blackwood's. Broadly speaking, this research merely confirms the previous results obtained by Gale and Blackwood.

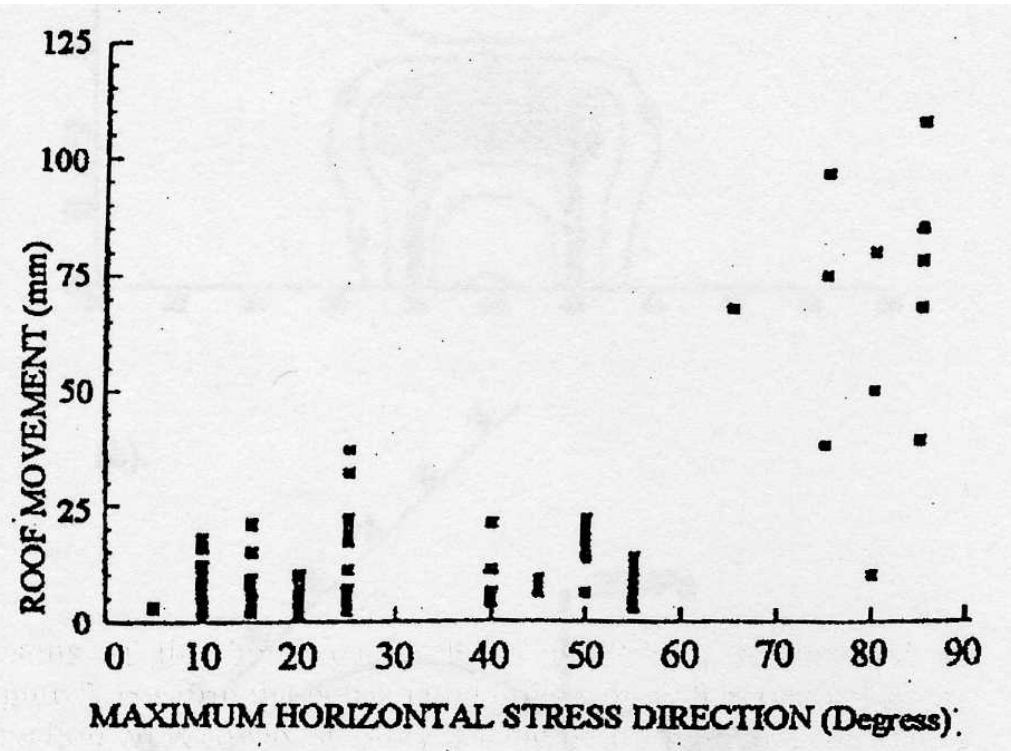

Figure 2.8. Measured roof movement as a function of $\theta$ [23].

\subsubsection{Chen and Peng's Research}

Chen [10] and Peng and Chen's research [32] on the effect of in-situ stress orientation on the entry stability is more elaborate than other works on the subject. Three dimensional finite element modeling was done for a typical three-entry longwall gate road system for the evaluation of in-situ stress effects on its stability. The model geometry and lithology were kept the same in all models with different ratios of $\sigma_{\mathrm{hmax}} / \sigma_{\mathrm{v}}$ and $\sigma_{\mathrm{hmax}} / \sigma_{\mathrm{hmin}}$. These in-situ stress fields were applied at different 
angles $\left(0^{\circ}\right.$ to $90^{\circ}$ in increments of $\left.15^{\circ}\right)$ with respect to the longitudinal axis of the gate entries.

Similar to the other works, the model results were analyzed at a few points in the immediate roof surface and Von Mises, major and minor principal stresses were obtained at these points. A typical plot of Von Mises stress change with $\theta$ is shown in Figure 2.9. Captions $\mathrm{P} 6$ to $\mathrm{P} 10$ in this figure indicate the location of points at which the Von Mises stresses were obtained in the immediate roof surface across the width of the entry with P6 and P10 located at the two ribs. From the analysis of the distributions of these three stresses in the entries, the following conclusions were drawn:

- For a single entry, the maximum Von Mises stress occurrs at $\theta=90^{\circ}$.

- For each entry in a three entry system, the $\theta$ value at which the maximum Von Mises stress occurs is not the same for different points in different crosssections.

- The stress distribution is asymmetrical across the cross-section of the entry for stress angles other than $0^{\circ}$ or $90^{\circ}$.

- In general, the maximum Von Mises stress occurs when stress angle equals to $60^{\circ}$.

- Limited study in the cross-cuts showed the maximum Von Mises stress occurs at stress angles between $60^{\circ}$ and $75^{\circ}$.

- Effect of $\sigma_{\mathrm{hmax}} / \sigma_{\mathrm{hmin}}$ evaluated at a single point near the rib, on the immediate roof line and in the middle portion of the entry showed the dependence of Von Mises stress on the stress angle, $\theta$.

- The properties of immediate roof only affect the magnitude of induced stress but not the pattern of stress distribution.

- For a specific set of input data analyzed, the sequence of development of entries showed no influence on the stress distributions. However, the sequence of development has some influence on the stresses in the crosscuts.

Even though this work is more detailed, the following shortcomings are observed: 
- It is not sufficient to study the stress state at a few points in the immediate roof surface as the stability of immediate roof to a certain height is important for ground control.

- The study doesn't cover the full range of $\sigma_{h \max } / \sigma_{v}$ and $\sigma_{h \max } / \sigma_{h \min }$ values observed in coal mines.

- Although the modeled geometry had intersections, nothing was said about the stability of intersections at different stress angles.

- The usefulness of the results has been severely limited by the way they were analyzed. The conclusions drawn based on Von Mises stress distribution alone may not indicate the stability of pressure dependent materials like rocks.

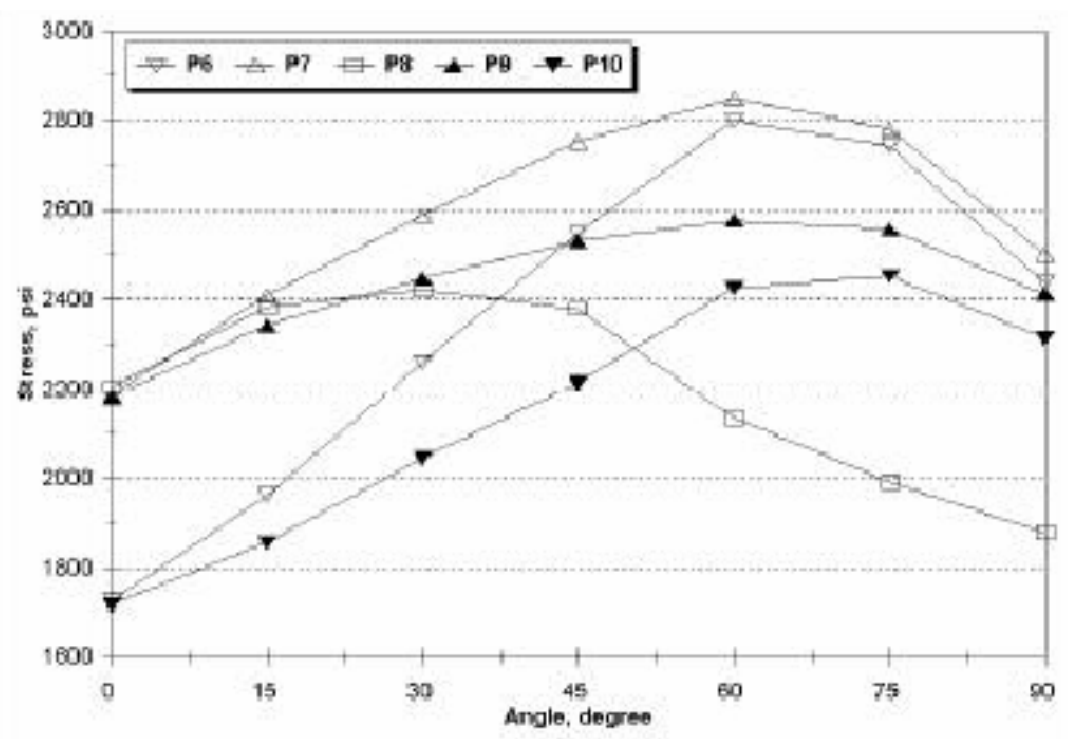

Figure 2.9. Typical Von Mises stress change with $\theta[10]$

\subsection{Works on Distribution Patterns}

The location of failure planes in the openings is highly variable for the in-situ stress orientation related roof instability. Even though changes in the location of the fracture plane in the entry have been noticed previously [18], no satisfactory explanations for this behavior seem to exist in the published literature. In the stress mapping technique of identifying the direction of in-situ maximum horizontal stress, 
the location of cutters in the openings or the intersections is used for deductions about the direction of $\sigma_{\mathrm{hmax}}[31]$. This interpretation of the direction of $\sigma_{\mathrm{hmax}}$ vis-à-vis cutter position is based on some simple rock mechanics principles rather than any rigorous analyses.

In the published literature, majority of the expositions available about the position of cutters in the entry are either based on field observations or limited numerical modeling $[14,27,28,31]$. The diagram shown in Figure 2.10 is the most common one used to explain the location of cutters in the opening. These figures were developed based on the research discussed in section 2.3.2. As noted there, this work is limited to the face area only and cannot explain the change in cutter locations behind the face. Further, as the modeling approach used in this research could only consider single material, the effect of presence of different rock layers in the roof on the failure locations shown in the Figure 2.10 is not known.

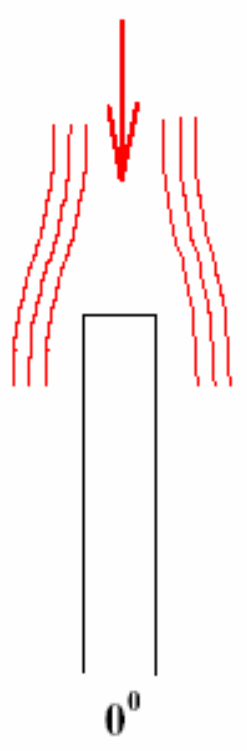

Good Condition

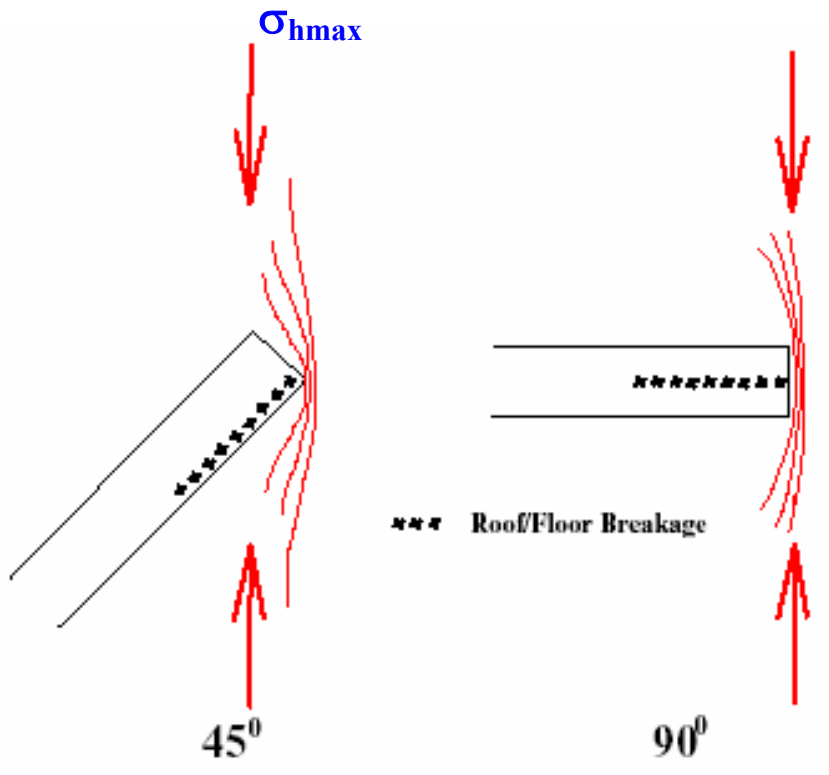

Roof/Floor Breakage Biased
Roof/Floor Breakage Center

Figure 2.10. Position of roof failure in the entry for different orientations of $\sigma_{\mathrm{hmax}}$ [15].

Roof failure types and their directional relation to $\sigma_{h \max }$ used in the stress mapping technique are shown in Figure 5.11. Inferences in this case are mainly 
based on field observations and some basic rock mechanics principles. Using threedimensional numerical modeling, Chen identified the probable position of cutters in the development workings [10]. The location of cutters in the entries and the intersection was derived from the distribution of induced Von Mises stresses. However, there was not enough explanation on how the cutter locations were derived from Von Mises stress distributions alone as the rock mass strength also depends on the average value of the induced principal stresses in this case.

\subsection{Past Research on In-situ Stress Ratios}

Since a major proportion of loads that act on an underground opening are related to the in-situ stresses, some works have been done in the past on the influence of relative magnitudes of the in-situ principal stresses on the stability of excavations $[5,10,16,36,37,38]$. Perhaps due to the limitations of numerical modeling facilities, most of these earlier works used two-dimensional geometries only. As a consequence, only the influence of in-situ maximum horizontal to vertical stress ratio, $\boldsymbol{k}$, was explored in a majority of the cases. The only three dimensional work found so far by the author of this thesis was that by Chen [10] and this was also the only research that considered the influence of in-situ maximum horizontal to minimum horizontal stress ratio, $l$.

Wang et al. used two dimensional finite element models to examine the nature and magnitude of induced stresses in the roof of three and seven layered materials [38]. They obtained the vertical and horizontal stresses in the roof and the rib for different $\boldsymbol{k}$ values. Aggson also used two dimensional finite element models to explain the shear roof failures observed in a West Virginia mine [5]. As an extension of this work, he also explored the effect of change in $\boldsymbol{k}$ on the roof stability. In both these works only qualitative interpretations on the nature and magnitudes of the induced stresses were made and except for some passing remarks nothing was said about the stability of roof with change in $\boldsymbol{k}$.

A two-dimensional boundary element method with Hoek-Brown rock mass failure criterion was used by Unal to investigate the influence of $\boldsymbol{k}$ on the roof stability 
[37]. His work shows that the height and mode of rock failure depends on the $\boldsymbol{k}$ value and for values above 0.8 the roof failure will be in complete shear. This work also shows that the height of rock failure decreases with increasing $\boldsymbol{k}$ up to a certain value and then increases with further increase in $\boldsymbol{k}$.

Though Chen's research on this topic was more complex, as it considered three-dimensional geometry, it was limited by the range of in-situ stress ratios considered [10]. He used only two $\boldsymbol{k}$ values and both of them were larger than 1. However, he considered a wide range of values for $l$. Similar to other works, his work was also restricted in its usefulness as only description on induced stresses at a few points in the roof surface was provided.

Besides the above observed limitations, the results of most of these works are applicable to the middle portion of the entry only. Because of the modeling space and the geometry used, they can not reflect the conditions at the face or around the intersections.

\subsection{Closing Remarks on Literature Review}

From the scrutiny on the past works in this chapter, the following important points emerge:

I Most of these works were limited by the range of values and the number of combinations of the input variables considered.

a The evaluation of stresses only along the immediate roof surface does not provide full picture of the roof stability as the effect of excavating coal reaches to some height inside the roof.

2. Examining the magnitude and nature of induced stresses in isolation is not sufficient to make inferences about the roof stability as the rock mass strength is another key factor that determines whether actual failure would take place or not. Hence both these issues - stress and strength - must be considered together. Besides, the stability of a point in the rock mass is determined by 
the combined effect of different components of stresses but not by any single component.

\# The range of values of stress ratios considered must reflect the ratios found in field measurements. As different combinations of $\boldsymbol{k}$ and $\boldsymbol{l}$ values were obtained in the field, as many combinations of $\boldsymbol{k}$ and $\boldsymbol{l}$ as possible must be considered in the modeling. 


\section{CHAPTER}

\section{MODELING ISSUES AND ROCK FAILURE
CRITERIA}

\subsection{Introduction}

This chapter mainly discusses the background issues related to the modeling methodology followed in this research. The true behavior of rock mass in-situ is very complex and any amount of available sophistication in the analysis procedures is far from sufficient to realistically simulate it. Simplifying assumptions about the rock behavior, model generation and input parameters must be made in order to make the problem solvable. However, these assumptions should not deviate too far from the actual behavior for an accurate analysis.

In this chapter, first, different input parameters and their range of values considered in the thesis are described. Then, important assumptions and conditions under which the results of the work are valid will be delineated. A major theme of the current work is related to the effect of in-situ maximum horizontal stress direction on the stability of development workings. Hence, alternative procedures to apply initial stresses in the models that are oriented differently from the global reference coordinate systems will be explored and compared. Often, numerical modeling is done to evaluate the stability of underground workings and the interpretation of stability depends on the failure criteria used for the purpose. Hence, detailed discussions are made in this chapter about the process of selecting realistic failure criterion for use in this analysis.

\subsection{Proposed Work}

The in-situ stress state at a point in the Earth's crust is most often given in terms of the three principal stresses. When expressed this way, assumptions are also made about the directions of the principal stress components. Generally, vertical stress $\left(\sigma_{v}\right)$ is assumed to be one of the principal stresses and the other two, 
in-situ maximum horizontal stress $\left(\sigma_{h \max }\right)$ and in-situ minimum horizontal stress $\left(\sigma_{\mathrm{hmin}}\right)$, are assumed to lie in a horizontal plane. The direction of these two horizontal stresses depends on many factors and no known methods are available to accurately predict them without field measurements or observations.

The stability of an excavation made in different in-situ stress fields is different. It depends both on the magnitude and the direction of the in-situ principal stresses. As shown in chapter 2, measurements in the underground coal mines show large variation in the magnitude of in-situ stresses. It has also been explained there that the direction of the in-situ horizontal stresses varies a lot as compared to the regional trends. Hence, it is important to consider the variation of both the magnitude and the direction of the in-situ stress field.

The variability in the magnitudes of $\sigma_{\mathrm{hmax}}$ and $\sigma_{\mathrm{hmin}}$ is generally expressed as two ratios, the ratio of in-situ maximum horizontal stress to vertical stress $(\boldsymbol{k})$ and ratio of in-situ maximum horizontal stress to minimum horizontal stress $(l)$. The effect of the direction of in-situ horizontal stresses is considered in terms of a variable, insitu maximum horizontal stress angle $(\theta)$. In this work, this angle is measured with respect to the longitudinal axis of an entry or crosscut as shown in Figure 3.1. Sometimes, the in-situ stress fields are referred to as low and high in this work and this distinction means $\boldsymbol{k}<1$ and $\boldsymbol{k}>1$ respectively.

To account for the factors mentioned above and also to limit the amount of work, the values of the variables listed in Table 3.1 have been considered in the current research. As most of the available literature on this work is for high in-situ stress fields, it is felt that some work must be done to examine the effect of low insitu stress fields as well. The values of $\boldsymbol{k}$ are chosen in such a way to cover both low and high in-situ stress fields. The measured in-situ stresses given in chapter 2 show the following combinations when their magnitudes are compared:

\footnotetext{
\# $\sigma_{\mathrm{v}}>\sigma_{\mathrm{hmax}}>\sigma_{\mathrm{hmin}}$ (e. g. Jim Walter Resources, AL. $\sigma_{\mathrm{v}}=2,420$ psi, $\sigma_{\mathrm{hmax}}=$ $\left.1,323 \mathrm{psi}, \sigma_{\mathrm{hmin}}=945 \mathrm{psi}\right)$,
} 
$\# \sigma_{h \max }>\sigma_{v}>\sigma_{h \min }$ (e. g. Island Creek, VA. $\sigma_{v}=2,200$ psi, $\sigma_{h \max }=3,400$ psi, $\left.\sigma_{\mathrm{hmin}}=1,590 \mathrm{psi}\right)$,

\# $\sigma_{\mathrm{hmax}}>\sigma_{\mathrm{hmin}}>\sigma_{\mathrm{v}}$ (e. g. Beckley \#2, WV. $\sigma_{\mathrm{v}}=365.75$ psi, $\sigma_{\mathrm{hmax}}=2,305$ psi, $\left.\sigma_{\mathrm{hmin}}=1,677 \mathrm{psi}\right)$.

Table 3.1. Values of in-situ stress variables considered for the present work.

\begin{tabular}{|c|l|}
\hline Variable & \multicolumn{1}{|c|}{ Values considered } \\
\hline $\boldsymbol{k}$ & $0.3,0.75,1.5$ and 3.0 \\
\hline $\boldsymbol{l}$ & $1,1.5$ and 2 \\
\hline$\theta$ & $0^{\circ}, 15^{\circ}, 30^{\circ}, 45^{\circ}, 60^{\circ}, 75^{\circ}$ and $90^{\circ}$ \\
\hline
\end{tabular}

The different combinations of $\boldsymbol{k}$ and $\boldsymbol{l}$ values given in Table 3.1 include all the three possible orders of magnitude for in-situ stresses given above. As per the effect of $\theta$, the magnitude of induced stresses will be the same for any $\theta$ and its supplement (e.g. $0^{\circ}$ and $180^{\circ}$ ). However, the distribution patterns will be exact mirror images of each other. Hence, $\theta$ is varied at $15^{\circ}$ increments between $0^{\circ}$ and $90^{\circ}$ only.

Though intersections are more susceptible to failures than entries, within the knowledge of the author there are no published numerical modeling works available on the effect of in-situ maximum horizontal stress angle on the stability of the intersection. Therefore, in this research, stability evaluations are made, not only for the entry, but also for the intersection. To accomplish this task, the geometry shown in Figure 3.1 has been used in all models.

In the models, the entry width and lithology have been taken as typical of Pittsburgh seam workings. Detailed geologic cross-section and material properties are shown in Figure 3.2 and Table 3.2, respectively. The working height in the models has been set at $7 \mathrm{ft}$ leaving $1 \mathrm{ft}$ of coal in the immediate roof. The entries are 


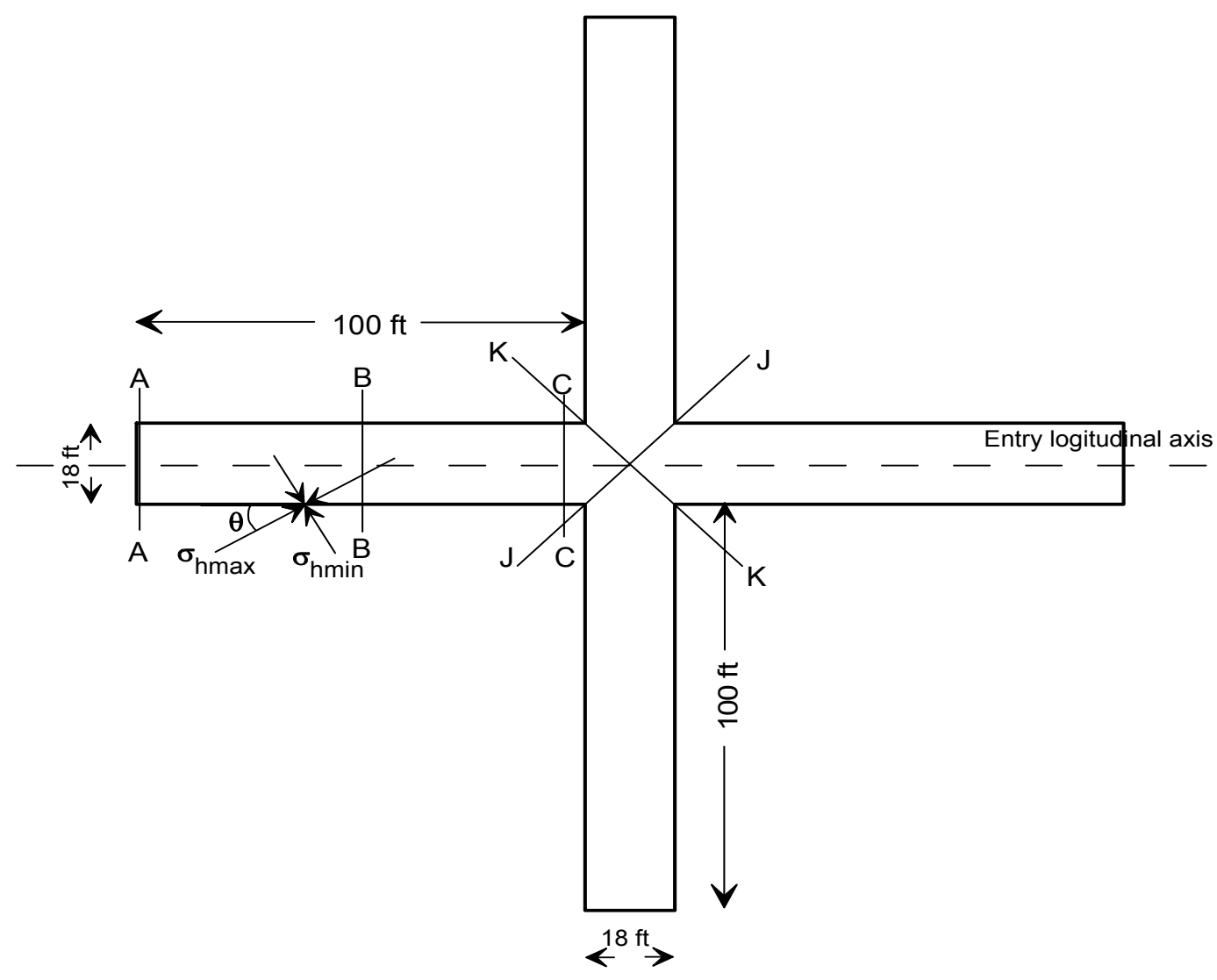

Figure 3.1. Model geometry and the location of cross-sections where results are obtained.

modeled $18 \mathrm{ft}$ wide at a depth of $800 \mathrm{ft}$. As explained later, average safety factors are evaluated up to a distance of $18 \mathrm{ft}$ inside the roof. From Figure 3.2, it is evident that there are six different beds within that distance. They are, $1 \mathrm{ft}$ of top coal, $2 \mathrm{ft}$ thick black shale, $6 \mathrm{ft}$ silty shale, $3 \mathrm{ft}$ gray shale, $2 \mathrm{ft}$ claystone and lower $4 \mathrm{ft}$ of limestone and these rock layers are subsequently referred to as bed 1 through bed 6 respectively.

Because the geometry, material and boundary conditions involved in the stability analysis are complex, no analytical solutions can be obtained for this problem. When the problem cannot be solved analytically, it is now a standard to use numerical procedures that provide an approximate and may be acceptable 
solutions. Of these, finite element method is by far the most popular one. Therefore, a commercial finite element package, ABAQUS [1] has been used in this work. This software can solve three dimensional problems with complex material and boundary conditions accurately.

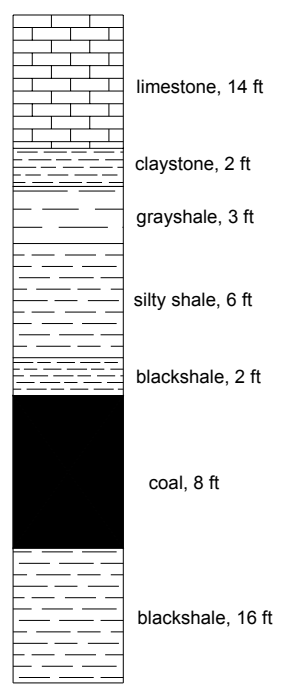

Figure 3.2. Part of the lithology in the immediate vicinity of coal seam used in the models.

\begin{tabular}{|c|c|c|c|c|c|}
\hline Rock Type & $\begin{array}{c}\text { Young's } \\
\text { Modulus } \\
\left(10^{6} \mathrm{psi}\right)\end{array}$ & $\begin{array}{c}\text { Poisson's } \\
\text { Ratio }\end{array}$ & $\begin{array}{c}\text { Uniaxial } \\
\text { Compressive } \\
\text { Strength } \\
(\mathrm{psi})\end{array}$ & $\begin{array}{c}\text { Strength } \\
\text { Used in } \\
\text { Models } \\
(\mathrm{psi})\end{array}$ & $\begin{array}{c}\text { Density } \\
\left(\mathrm{lb} / \mathrm{ft}^{3}\right)\end{array}$ \\
\hline Sandstone & 2.95 & 0.15 & 13,000 & 3,250 & 167.0 \\
\hline Sandyshale & 1.00 & 0.20 & 10,000 & 2,500 & 160.0 \\
\hline Claystone & 0.80 & 0.27 & 2,400 & 600 & 155.0 \\
\hline Blackshale & 0.30 & 0.27 & 3,000 & 750 & 150.0 \\
\hline Grayshale & 0.68 & 0.27 & 4,800 & 1,200 & 150.0 \\
\hline Siltyshale & 0.68 & 0.27 & 4,800 & 1,200 & 150.0 \\
\hline Coal & 0.36 & 0.34 & 3,600 & 900 & 87.6 \\
\hline Limestone & 2.50 & 0.30 & 10,000 & 2,500 & 165.0 \\
\hline
\end{tabular}

Table 3.2. Material and strength properties of different rocks used in the modeling. 
Due to the limitation of the available resources and to reduce the amount of work, some simplifying assumptions have been made in the geometry used for the mesh and also in the solution process of the finite element models as given below.

\# There are no interaction effects of adjacent entries. This means the pillars are big enough to isolate the effect of one entry or crosscut from the other.

a The crosscuts are developed at right angles to the entry as shown in Figure 3.1.

\# There is no separation or slip along the bedding planes that can affect the stress distributions significantly.

I The material is isotropic and homogeneously elastic in its behavior.

In the geometry that was used for the modeling, the model boundaries were placed at a distance of $100 \mathrm{ft}$ in all directions, which was approximately equal to five times the entry width. At this distance the boundary conditions were found to have negligible influence on the model results in the area of interest. The total dimensions of the meshed geometry were $418 \mathrm{ft} \times 418 \mathrm{ft} \times 208 \mathrm{ft}$. The geometry was meshed using 74,060 three-dimensional full integration linear finite elements and the mesh had 79,524 nodes. The minimum and the maximum dimensions of the elements in the immediate roof of the entry were $3 \mathrm{ft} \times 3 \mathrm{ft} \times 1 \mathrm{ft}$ and $6.6 \mathrm{ft} \times 3 \mathrm{ft} \times 3 \mathrm{ft}$ respectively.

In order to assess the effect of different input variables on the stability of entry roof, some parameter is required for comparison. Also, this parameter must be able to combine the effect of induced principal stresses on the stability. To meet these requirements, an average safety factor has been calculated for each individual bed that fall within a distance equal to the entry width inside the immediate roof. For each bed in the roof, this number is computed by averaging the safety factors at all integration points that fall between the two rib sides of the entry. Details pertaining to the definition of the safety factor are provided later in this chapter. 
For the purpose of the current work, the models were run in two steps and then the model output was analyzed and interpreted. Difference steps involved in this process are listed sequentially below.

7 The finite element model must be solved before any excavation is made in it to properly build the in-situ stresses in the model. To apply in-situ stresses that are oriented differently from the reference coordinate system, a special subroutine has been developed to apply stress transformations (explained in the next section) in the model.

a After the principal in-situ stresses in the desired direction were applied in the model, total length of the openings on the layout shown in Figure 3.1 was excavated in a single step and the model was solved again.

a The induced principal stresses were obtained at the cross-sections shown in Figure 3.1 .

Z Using a macro written in the MSEXCEL program, the Hoek-Brown local safety factors were evaluated at each integration point in the cross-section of interest.

7 Average safety factors were estimated for all beds within a distance of one entry width into the roof at each cross-section.

\subsection{Application of In-situ Stresses in the Model}

A general pre-mining horizontal stress field that is not aligned with the model global reference coordinate system could be applied in a numerical model in two different ways. One, by aligning the stress field with the model's global coordinate system and orienting the entries so as to make the desired angle with the stress field (geometry orientation) and second, by having entries aligned with the model's global coordinate system and transforming the pre-mining stress field into this coordinate system (stress orientation) for application as the boundary conditions. The second approach is definitely preferred to the first as it has some advantages provided the final results obtained by either approach are the same. The stress orientation 
approach gives the best mesh design and provides uniform mesh and hence less distortion in the model. It also simplifies the modeler's task to a great extent as the mesh generation is simpler.

Conceptually, it is not difficult to see that both of the above approaches would provide the same results for the same geo-mining conditions. In this analysis an attempt has been made to verify this by comparing results obtained using both of these approaches.

\subsubsection{Model Details}

The model parameters have been chosen arbitrarily as this exercise is only intended to compare two different methods of stress application.

$\begin{array}{lll}\text { Number of entries } & : & \text { one } \\ \text { Entry width } & : & 19.68 \mathrm{ft} \\ \text { Entry length } & : & 196.86 \mathrm{ft} \\ \text { Depth of cover } & : & 180.45 \mathrm{ft} \\ \text { Working height } & : & 9.84 \mathrm{ft} \\ \begin{array}{l}\text { Max. horizontal-to-vertical } \\ \quad \text { stress ratio }\end{array} & & \\ \begin{array}{l}\text { Max. horizontal-to-min. } \\ \quad \text { horizontal stress ratio }\end{array} & : & 1.5 \\ \begin{array}{l}\text { Vertical stress } \\ \text { Angle between max. } \\ \quad \text { horizontal stress and the } \\ \quad \text { entry's long axis }\end{array} & : & 3.1 \times \text { Depth, psi } \\ \end{array}$

\subsubsection{Stress Orientation}

For the present analysis, stress transformations are required only in the horizontal plane (X-Y plane) as the vertical axes (Z) are the same. Further, we only need to deal with the principal stresses in the reference coordinate system as the 
pre-mining stresses are assumed to be the principal stresses. The following are the stress transformation equations used to obtain the stress field in a new coordinate system that makes an angle $\theta$ with the old one [21]. If $X^{\prime}, Y^{\prime}$ represent the new coordinate system and $\mathrm{X}, \mathrm{Y}$ represent the old one, then

$$
\begin{aligned}
& \sigma_{X^{\prime}}=\sigma_{1} \cos ^{2} \theta+\sigma_{2} \sin ^{2} \theta \\
& \sigma_{Y^{\prime}}=\sigma_{1} \sin ^{2} \theta+\sigma_{2} \cos ^{2} \theta \\
& \tau_{X^{\prime} Y^{\prime}}=-\frac{\sigma_{1}}{2} \sin 2 \theta+\frac{\sigma_{2}}{2} \sin 2 \theta
\end{aligned}
$$

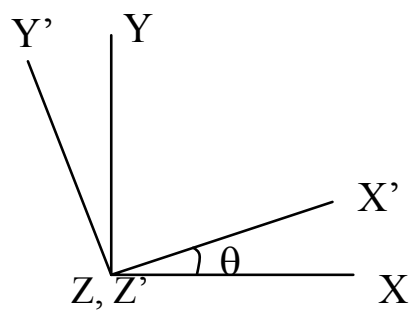

$\sigma_{X^{\prime}}, \sigma_{Y^{\prime}}$ in the above equations are the normal stresses in the $X^{\prime}$ and the $Y^{\prime}$ directions and $\tau_{X^{\prime} Y^{\prime}}$ is the shear stress in the $X^{\prime} Y^{\prime}$ plane. The plan view of the model geometry used for the analysis at the seam level is shown in Figure 3.3. The pre-mining stresses for this model have been obtained using the stress transformation equations above.
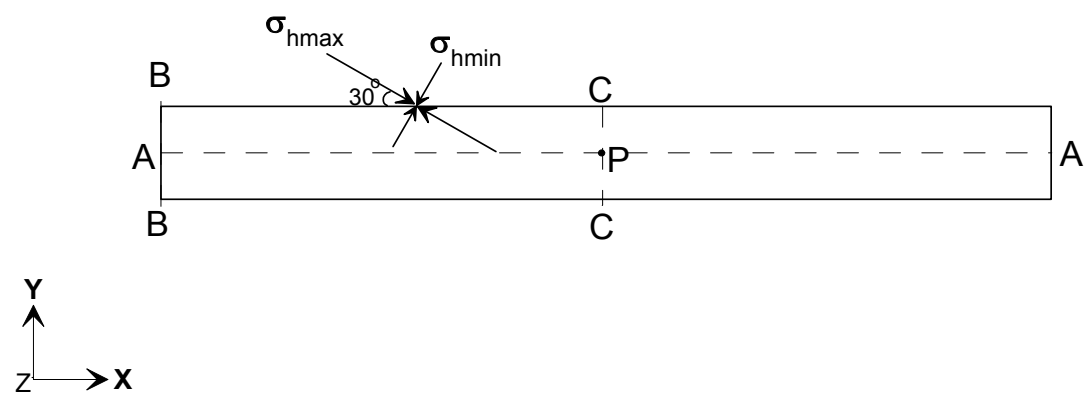

Figure 3.3. Modeled geometry with stress field rotated and entry aligned with coordinate axes.

\subsubsection{Geometry Orientation}

In this case of geometry orientation, the entry is oriented $30^{\circ}$ to the $\mathrm{X}$-axis and the pre-mining stresses are applied in the global $X, Y$ directions. That is, the global $X$ 
and $Y$ axes have been assumed to be the principal stress directions. The model geometry is shown in Figure 3.4 below.

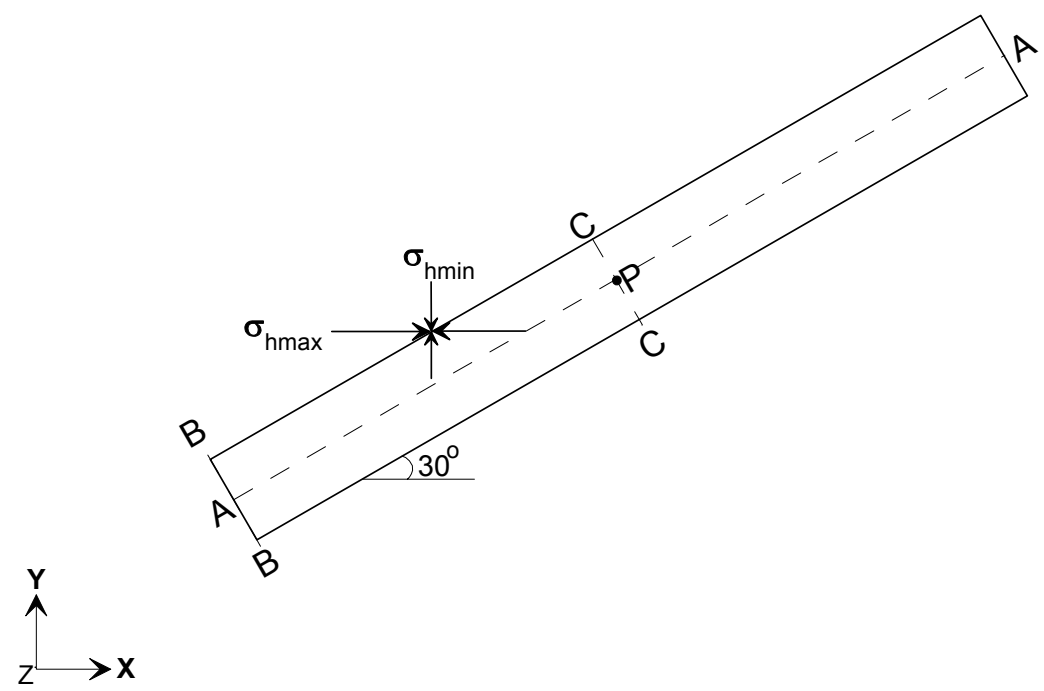

Figure 3.4. Modeled geometry with entry rotated and stress field aligned with coordinate axes.

\subsubsection{Results}

From the above description of the models, it is apparent that the values of the individual components of the stress tensor in the horizontal plane will be different. However, the principal stresses which are invariants of the stress tensor must have the same value and direction with respect to the entry axis for both cases. Further, for stability analysis using any failure criterion, it is the principal stresses that are required, not the individual coordinate components of stress tensor. Hence, a comparison of principal stresses at different locations of the immediate roof above the entry has been made below. Comparisons have been made along some selected lines in the entry roof surface and to some distance inside the roof at a point as shown in Figure 3.3 and Figure 3.4 and the results are shown in Figure 3.5 to Figure 3.8. 
(a)

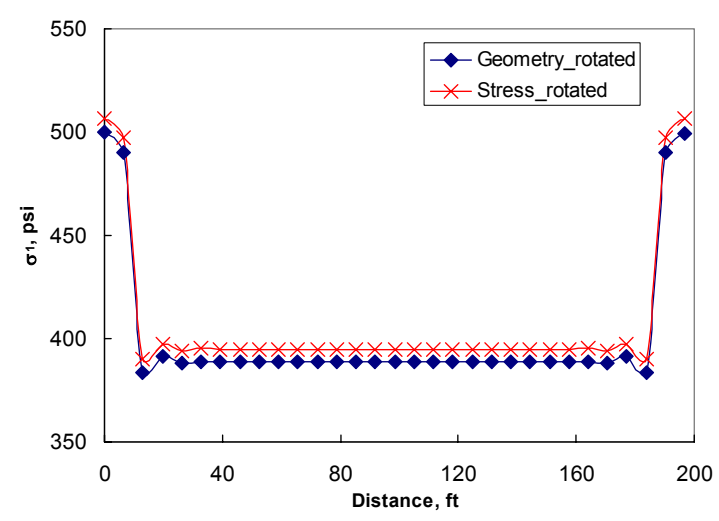

Figure 3.5. Comparison of (a) maximum principal stress and (b) minimum principal stress in the entry roof surface along line AA shown in Figure 3.3 and Figure 3.4.

(a)

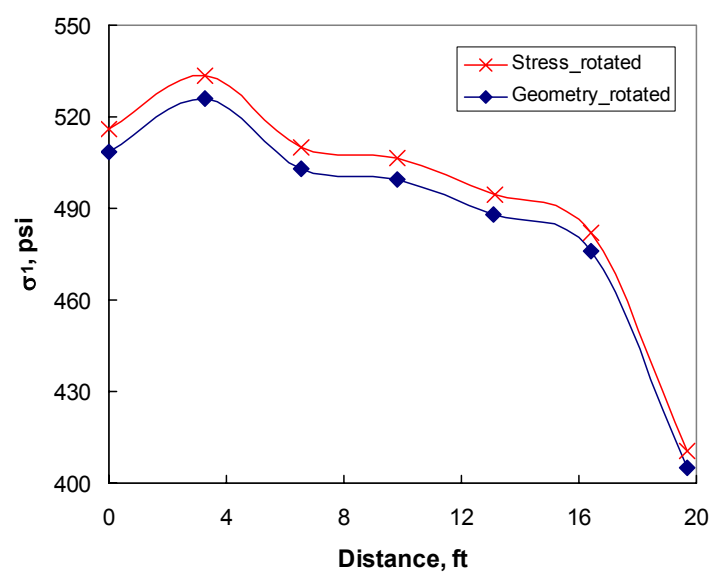

Figure 3.6. Comparison of (a) maximum principal stress and (b) minimum principal stress in the entry roof surface along line BB shown in Figure 3.3 and Figure 3.4. (b)

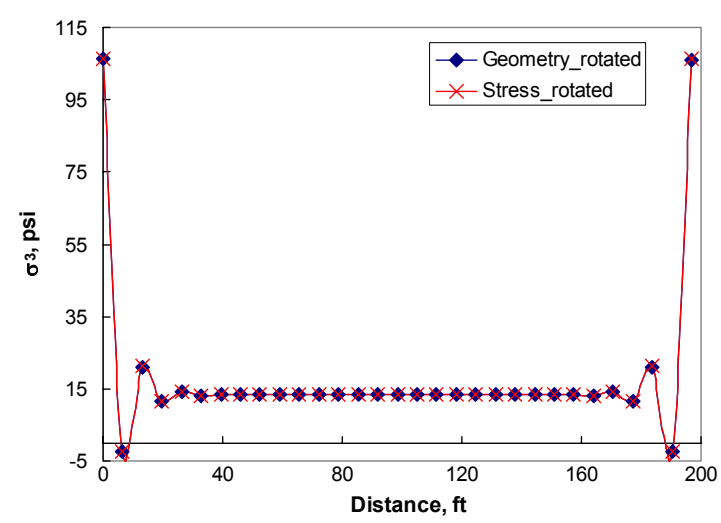

(b)

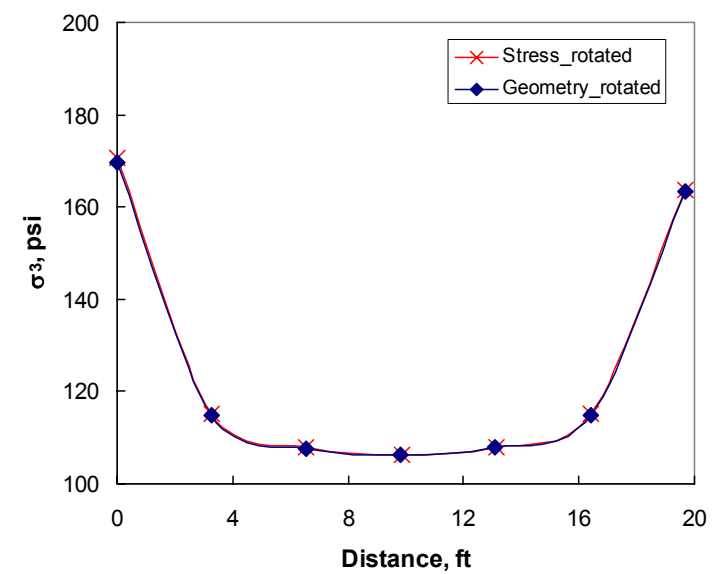


(a)

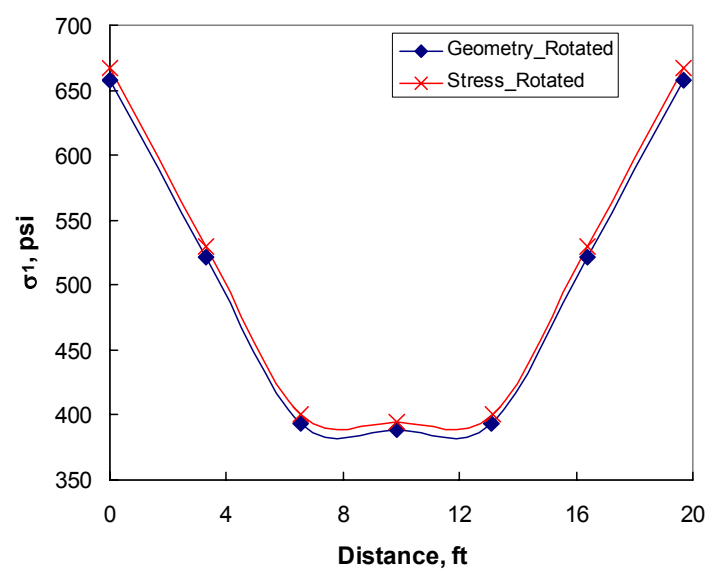

Figure 3.7. Comparison of (a) maximum principal stress and (b) minimum principal stress in the entry roof surface along line CC shown in Figure 3.3 and Figure 3.4.

(a)

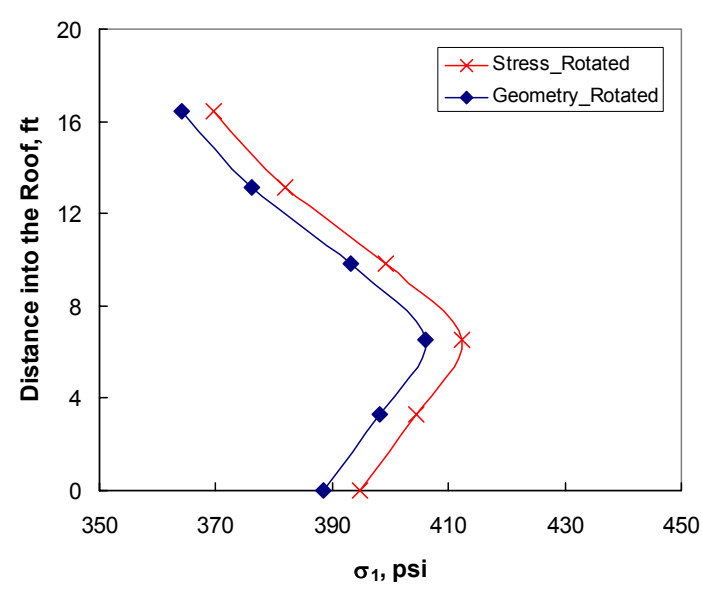

Figure 3.8. Comparison of (a) maximum principal stress and (b) minimum principal stress some distance into the roof at point $P$ shown in Figure 3.3 and Figure 3.4 . (b)

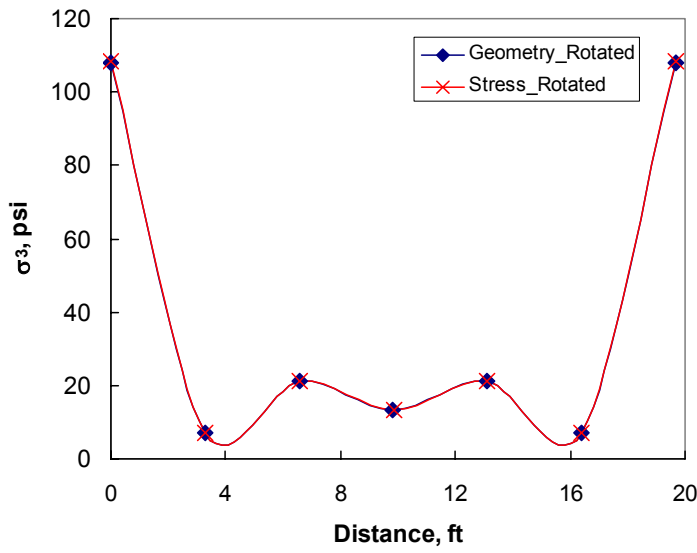

(b)

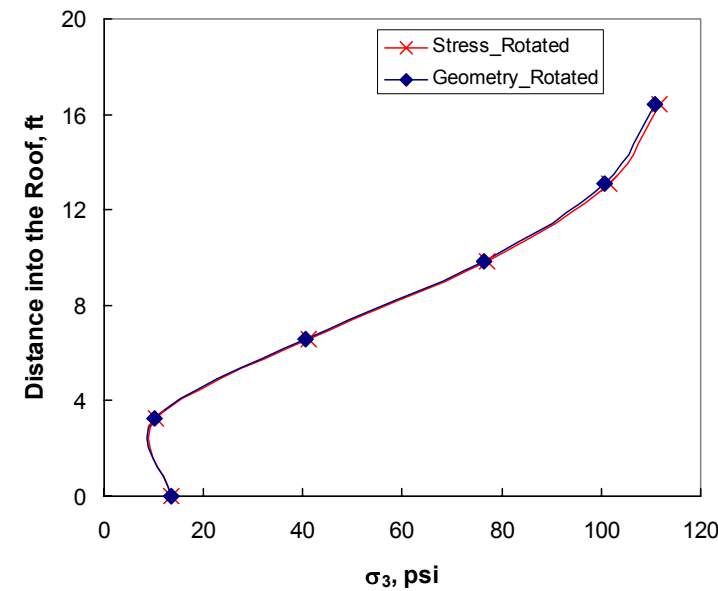


From this comparison of principal stresses at different locations of the entry, it is clear that both approaches provide the same results within the limitations imposed by the mesh design. As may be seen from the above graphs, the major principal stress is slightly different in these two approaches (maximum difference is about 10 psi) as it happens to lie in the horizontal plane where the mesh design is different in both situations. However, since the minor principal stress is in the vertical direction where the mesh is exactly the same, the values obtained through these approaches are identical. Based on this study it is apparent that either way of applying stresses has the same influence on the induced stresses around the entry. Hence, for its obvious advantages, the stress orientation method will be used for subsequent studies in this work.

\subsection{Rock Failure Criteria}

Once a numerical model has been run and relevant output data obtained, the next step in the analysis involves choosing a proper rock failure criterion for stability evaluation. Many such criteria are available in the literature and a full discussion of all of them is beyond the scope of this work. Only two criteria that are used in the practical designs are examined for application in the present work. The selected ones are Mohr-Coulomb [21] and Hoek-Brown criterion [19, 20].

Besides its historical importance, the linear Mohr-Coulomb criterion is very simple to use and more popular for elastic-plastic analysis as compared to the nonlinear Hoek-Brown criterion. However, it is now a well established fact that rocks behave non-linearly in a triaxial stress state and this behavior is well represented by the Hoek-Brown criterion [19]. Unfortunately, it is not easy to formulate elastic-plastic analysis procedures for the Hoek-Brown criterion and hence most of the general purpose numerical packages do not have provision for analysis using this criterion despite its wide spread use in the rock mechanics community.

The selection of a rock failure criterion is very critical to the interpretation of model results as a poor selection may result in incorrect conclusions. The best way to choose proper failure criterion is to examine the performance of a criterion by 
fitting it against tested data. For this purpose, available triaxial test data of coal measure rocks in the US have been gathered [33]. The data base includes 50 sets of testing on different rock types and the details are given in Table 3.3.

Table 3.3. Details of data sets used for the regression analysis.

\begin{tabular}{|c|c|}
\hline Rock Type & Number of data sets \\
\hline Sandstone & 11 \\
\hline Shale & 7 \\
\hline Coal & 17 \\
\hline Siltstone & 6 \\
\hline Limestone & 5 \\
\hline Others & 4 \\
\hline
\end{tabular}

Along with the triaxial test data, uniaxial compressive and tensile strength values have been collected wherever available. The suitability of a criterion is examined interms of its ability to predict the uniaxial compressive and tensile strengths besides the index of determination values. After performing regression analysis on test data, estimates of uniaxial compressive and tensile strengths have been made after some manipulations on the criterion equations as explained below. Then the estimated values are compared with the tested values to evaluate its predictive capability. In the following sections details of this process are discussed.

\subsubsection{Mohr-Coulomb Criterion}

The Mohr-Coulomb criterion is written in principal stress space as

$$
\sigma_{l}=\sigma_{c}+q \sigma_{3}
$$


where $\sigma_{l}$ and $\sigma_{3}$ are the major and the minor principal stresses, respectively; $\sigma_{c}$, the uniaxial compressive strength and $q$ a constant sometimes known as triaxial constant.

The intercept value in equation (3.1) directly gives the estimated uniaxial compressive strength value and the tensile strength $\left(\sigma_{t}\right)$ is obtained by setting $\sigma_{l}=0$ and $\sigma_{3}=\sigma_{t}$ and then solving equation (1) for $\sigma_{t}$. This gives

$$
\sigma_{t}=-\frac{\sigma_{c}}{q}
$$

Figure 3.9 and 3.10 below show comparison between measured and estimated strengths for this criterion.

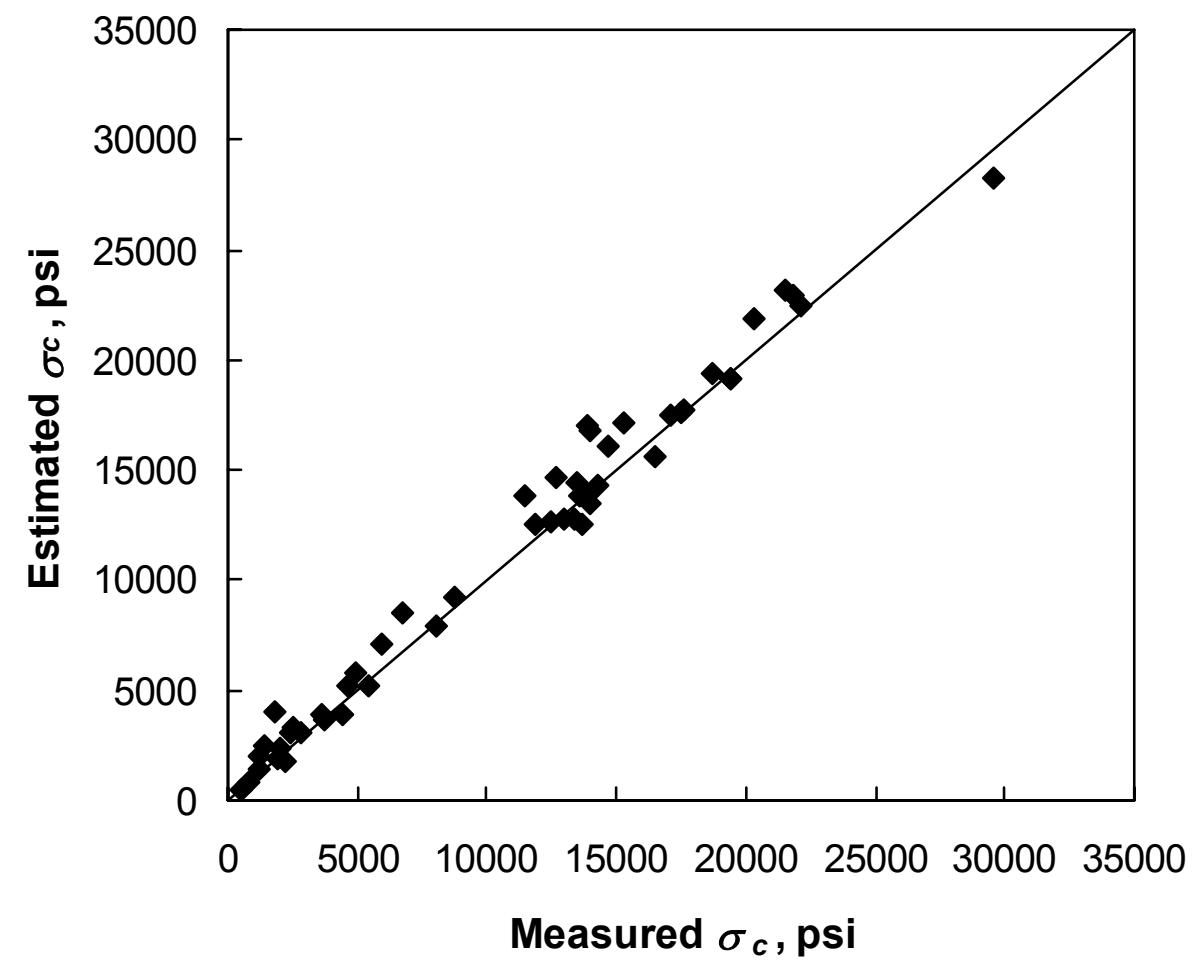

Figure 3.9. Comparison between measured and estimated compressive strengths for Mohr-Coulomb criterion. 


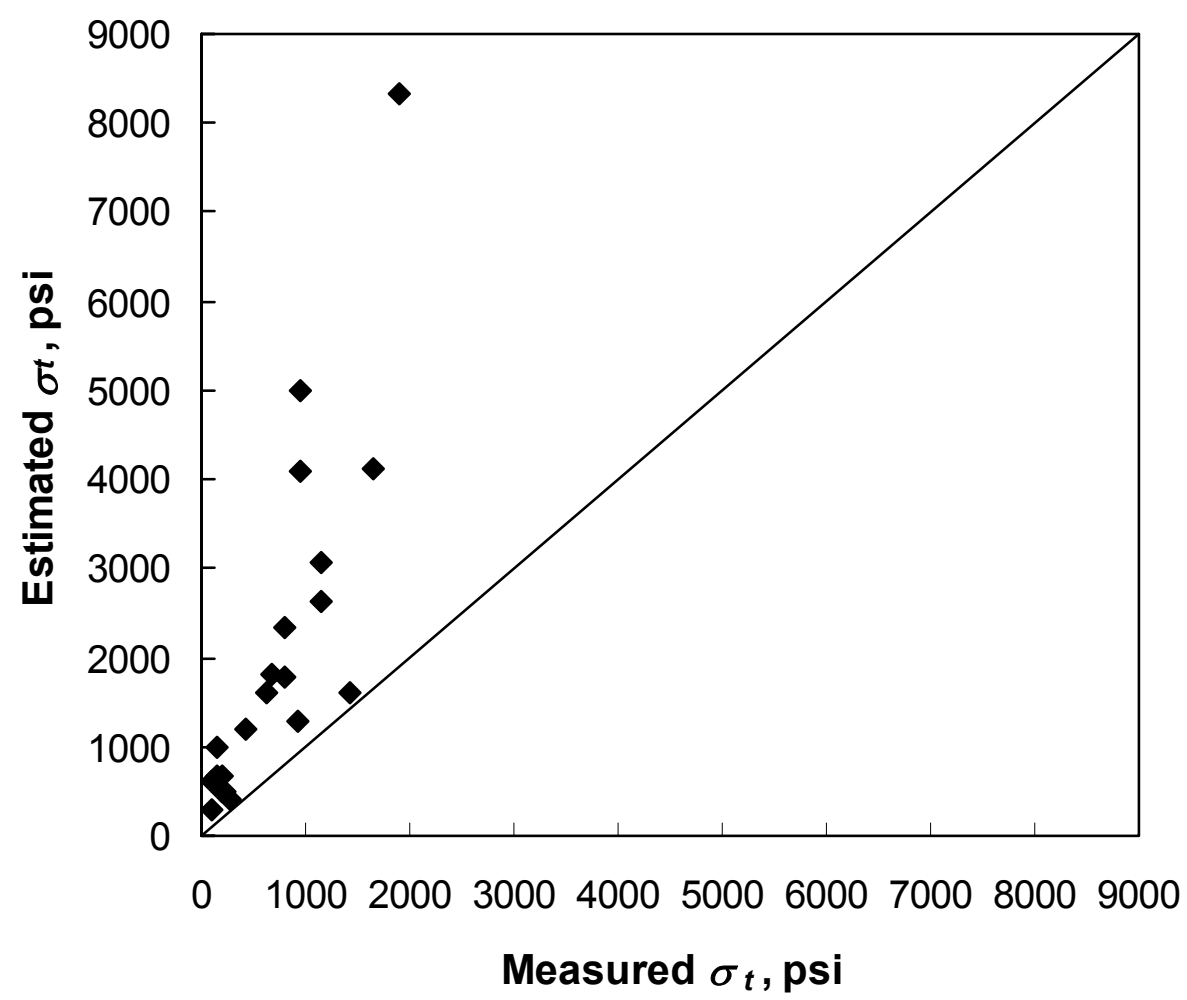

Figure 3.10. Comparison between measured and estimated tensile strengths for Mohr-Coulomb criterion.

Figure 3.10 clearly shows that the Mohr-Coulomb criterion over estimates the uniaxial tensile strength significantly and to take care of the tensile strength overestimation, it is often used with a tension cut-off [21]. By imposing the tension cut-off, the Mohr-Coulomb criterion is applied only up to a minimum principal stress value equal to the uniaxial tensile strength of the rock and not beyond. If the numerical analysis package, like ABAQUS, doesn't have provision for incorporating tension cut-off, considerable over estimation of stability occurs in the portions of the model that are under tension and some ways must be devised to deal with this situation.

\subsubsection{Hoek-Brown Criterion}

This criterion has two forms, one for intact rock and one for the rock mass. Though the equation for the rock mass has undergone several changes since the 
time of inception $[19,20]$, the intact rock criterion has remained unchanged and is given as

$$
\sigma_{1}=\sigma_{3}+\sqrt{\left(m \sigma_{3} \sigma_{c}+s \sigma_{c}^{2}\right)}
$$

Where $\quad \sigma_{1}=$ strength of the rock at a confinement of $\sigma_{3}$

$$
\begin{aligned}
& \sigma_{c}=\text { uniaxial compressive strength of rock } \\
& m=\text { triaxial constant for the rock } \\
& s=1 \text { for intact rock }
\end{aligned}
$$

For this criterion, the regression process directly yields $\sigma_{c}$ and $m$ values. By setting $\sigma_{l}=0$ and $\sigma_{3}=\sigma_{t}$ in equation (3.2) and solving for $\sigma_{t}$ gives the estimated tensile strength as

$$
\sigma_{t}=-\frac{\sigma_{c}}{2}\left(\sqrt{m^{2}+4}-m\right)
$$

Comparison of the measured and estimated strengths is given below in Figures 3.11 and 3.12.

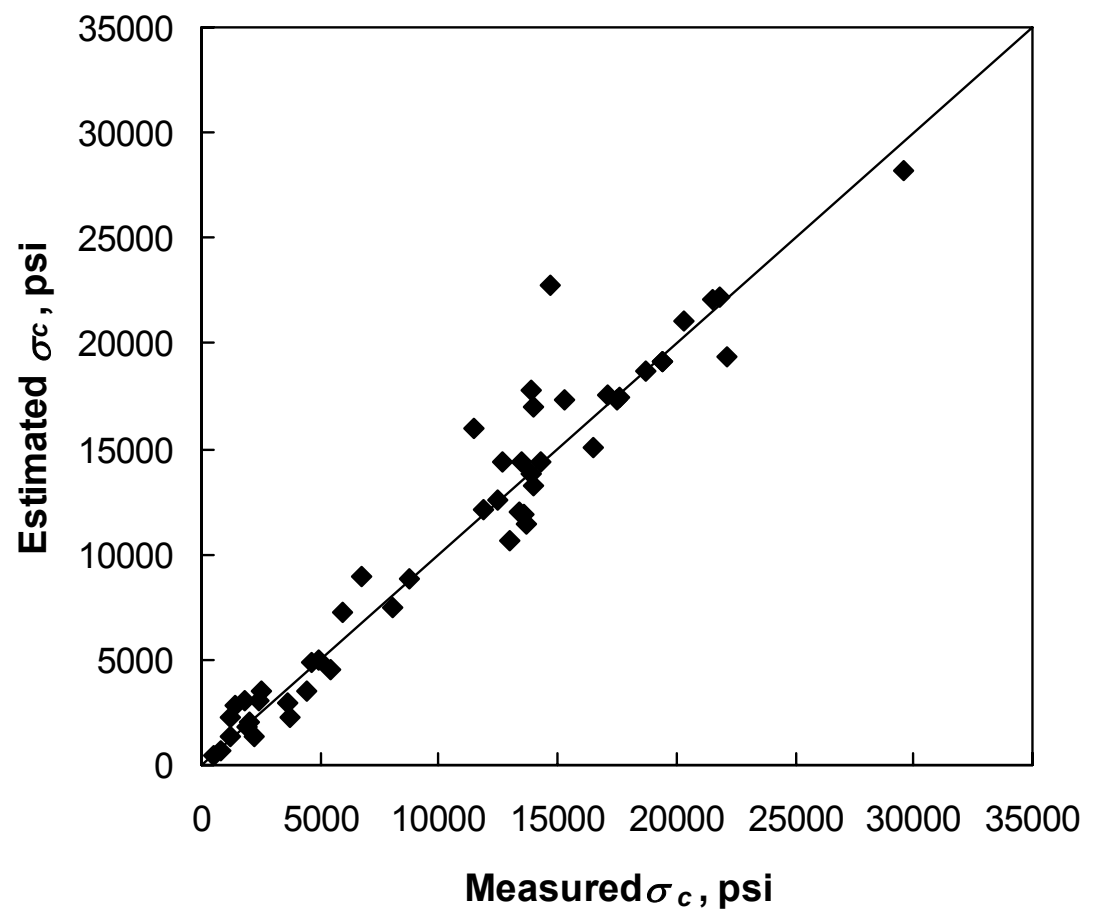

Figure 3.11. Comparison between measured and estimated compressive strengths using Hoek-Brown criterion. 


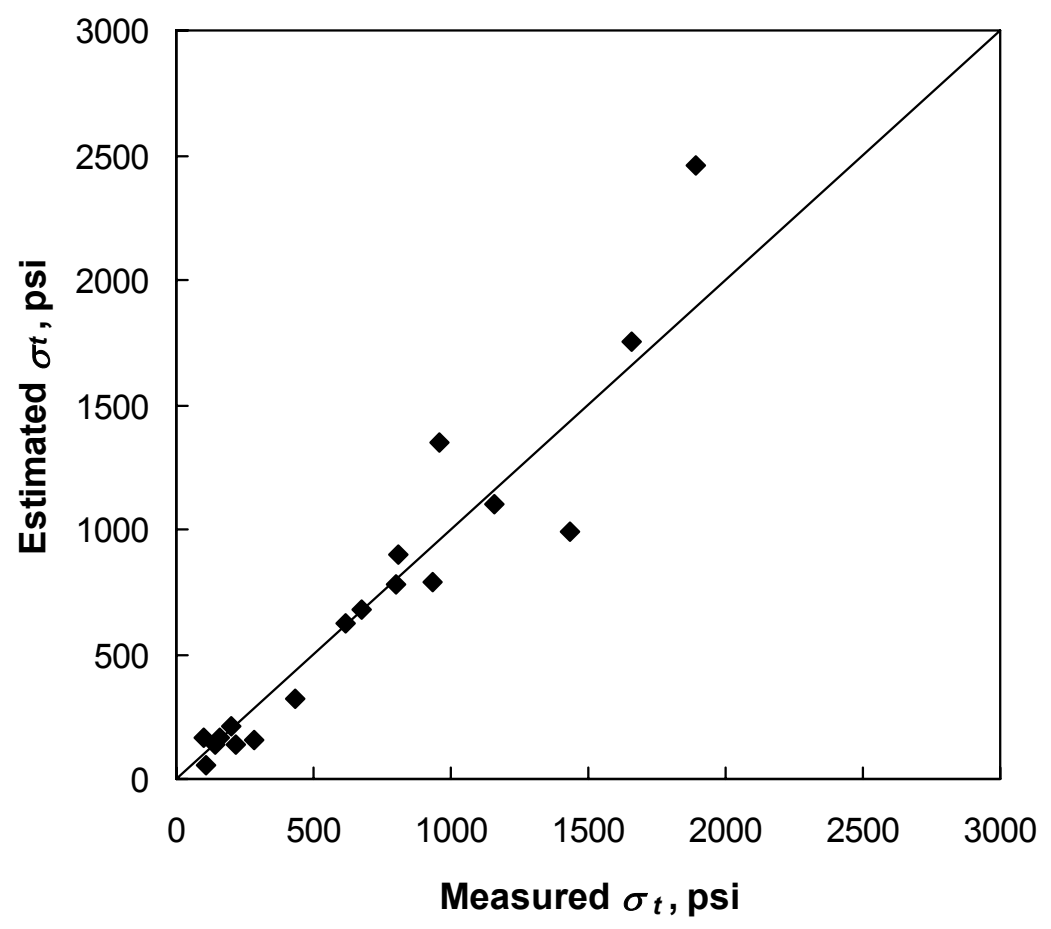

Figure 3.12. Comparison between measured and estimated tensile strengths using Hoek-Brown criterion

These plots clearly show that the Hoek-Brown criterion performs well in both compressive and tensile regions. Comparison of Figure 3.9 and Figure 3.11 indicates a slightly better fit for the Mohr-Coulomb criterion.

\subsubsection{Comparison of Two Criteria}

For an easy understanding of the behavior of these criteria, a common plot is produced in Figure 3.13 for a typical set of measured data.

From this figure the following points are noticeable:

\# Within the limits of the tested confining pressures both criteria perform comparably well in the compressive region.

I In the tensile region, the non-linear criterion behaves in a more realistic manner than the linear one. This trend has been observed for all the data sets. 
\# Though the tension cut-off takes care of overestimation of uniaxial tensile strength, some overestimation of strength still exists in the tensile quadrant for the Mohr-Coulomb criterion.

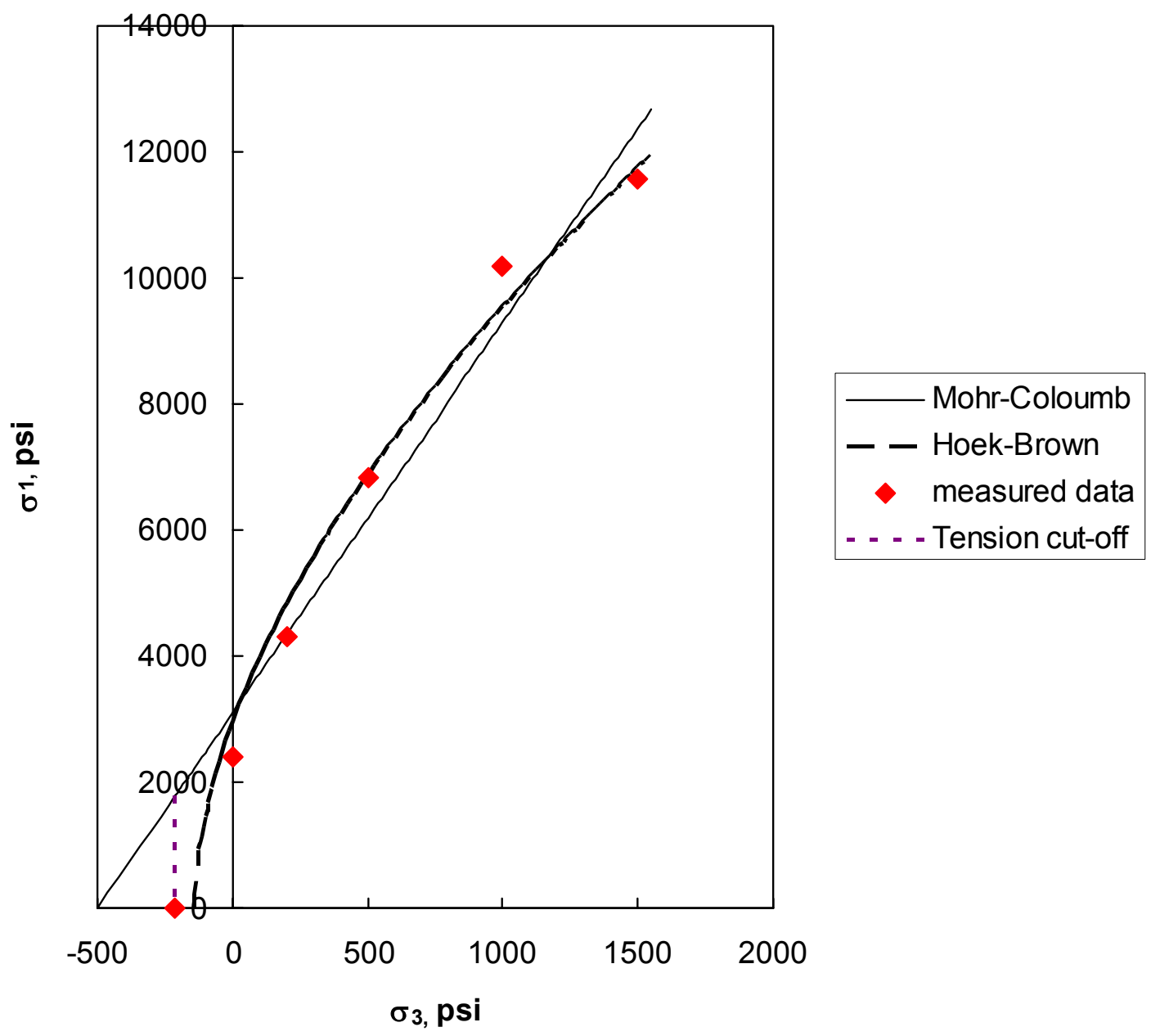

Figure 3.13. Comparison of performance of both criteria for a typical measured data set.

\subsubsection{Effect of Intermediate Principal Stress}

It is important to realize that both the Mohr-Coulomb and Hoek-Brown criteria are independent of intermediate principal stress $\left(\sigma_{2}\right)$. The very few available polyaxial test results do not provide a clear picture of the influence of intermediate principal stress on the strength of rock [35] and hence no attempt is made to consider its effect for stability estimation in this work. Further, all the published polyaxial tests 
were conducted on hard rocks and it is not clear whether soft sedimentary rocks typical of coal measures would exhibit similar behavior.

Some people use the polyaxial Drucker-Prager failure criterion for elastic-plastic analysis of geological materials. In the absence of the effect of intermediate principal stress, the Drucker-Prager Criterion has the same form as that of the Mohr-Coulomb criterion with different constants. In fact the constants in both criteria are intertransformable. Hence all the foregoing discussions on the Mohr-Coulomb criterion are applicable to triaxial Drucker-Prager criterion as well.

\subsubsection{Rock Mass Strength}

Based on the above discussion, it is clear that the Hoek-Brown failure criterion well represents the intact coal measure rocks' behavior in both compressive and tensile quadrants of stress space. Moreover, this is the most popular failure criterion that provides strength estimates for the rock mass as well. For these reasons this criterion will be used for the stability analysis in the present work. The strength of the rock mass is generally less than the strength of intact rock due to the presence of discontinuities, both microscopic and macroscopic. Therefore, it is expedient to use rock mass failure criterion for designs. The Hoek-Brown failure criterion for rock mass has the following form [20]

$$
\sigma_{1}=\sigma_{3}+\sigma_{c}\left(m_{r m} \frac{\sigma_{3}}{\sigma_{c}}+s_{r m}\right)^{a}
$$

where subscript $\mathrm{rm}$ indicates the rock mass value of the parameter. For undisturbed rock masses

$$
m_{r m}=m \exp \left(\frac{G S I-100}{28}\right)
$$




$$
s_{r m}=\exp \left(\frac{G S I-100}{9}\right)
$$

where GSI is an index that reflects the quality of rock mass. The value of $a$ in equation (3.4) is also dependent on the quality of the rock mass. However, for the typical qualities of rock mass in coal mines it can be taken as 0.5 .

Any rock mass failure criterion should only be used when the rock mass strength behavior is isotropic, which means either the rock mass has no significant weakness planes in it or no single weakness plane controls the strength failure [19]. No rock mass in-situ can meet these requirements exactly. However, it has been shown that if the rock contains four or more discontinuity sets at different orientations, then the rock mass strength behavior is nearly isotropic $[19,21]$.

Coal measure rocks generally have one major discontinuity set, which is the bedding plane and in the majority of cases these bedding planes are either horizontal or near horizontal in their disposition. Sometimes a few joint sets and other kinds of local structures, e.g., slickensides are also observed in the mines. Hence, it is important to understand the effects of these discontinuities on the strength of the rock mass before deciding to use any isotropic rock mass failure criterion.

The effect of a single discontinuity on the strength of rock has been thoroughly investigated both theoretically and experimentally [19, 21]. These studies show that the failure will take place along the discontinuity for some combination of principal stresses if it is oriented at a certain angle with reference to the major principal stress, the minimum stability occurs at about $30^{\circ}$. It has also been shown that the discontinuity would not control the failure strength if it was oriented at $0^{\circ}$ or $90^{\circ}$ with the major principal stress. In these situations, failure will be through the rock itself.

If the spacing of discontinuities oriented along the direction of a coal mine entry exceeds the width of the entry and any discontinuities across the entry have persistence more than the width of the entry, then the only discontinuities of concern for the stability of the entry are the bedding planes. Since these bedding planes are 
most often horizontal or near horizontal, from the foregoing discussions it is clear that they will not control the strength value of the rock. However, these discontinuities will affect the stress distribution in the rock because of separation and slip along them.

From the above discussions, it is apparent that the presence of bedding planes in coal measure rocks generally affects the stress distribution in the rock surrounding the entry and has less influence on the strength of the rock mass. This can be seen from underground observations of roof falls. Most of the roof falls in coal mines take place because of failure through the rock itself rather than along discontinuities though the limit of this failure zone may be determined by them. Based on these considerations and performance when fitted to the measured data, it seems reasonable to use the isotropic Hoek-Brown rock mass failure criterion for stability evaluations in coal mine entry design.

The reduction factors in equations (3.5) and (3.6) are derived for heavily jointed rock masses. If these equations are used for coal measure rocks, then the rock mass strength estimates will be too low. This is due to the fact that the coal measure rocks most often have a single major set of discontinuity and under the conditions explained above their strength is not significantly controlled by the presence of discontinuities. The reduction in strength of these rocks is mainly due to the size effect and hence, it is sufficient to use strength reduction factors obtained from experience instead of rock mass classification index related approaches like those given in equations (3.5) and (3.6) developed for civil engineering structures.

As discussed above, it is not proper to estimate the rock mass parameters of Hoek-Brown failure criterion in terms of GSI for coal measure rocks and as an alternative, uniaxial compressive strength reduction factor $(R F)$ is employed for the estimation of rock mass parameters. As no direct forms of equations (3.5) and (3.6) are available in terms of $R F$, a hypothetical value of $G S I$ is estimated that will give the same uniaxial compressive strength reduction factor as that given by $R F$. This $G S I$ value is then used to estimate the rock mass parameters and for convenience they are re-written in terms of $R F$ as 


$$
\begin{aligned}
& s_{r m}=R F^{2} \\
& m_{r m}=m \exp \left[\frac{9 \log (R F)}{14}\right]
\end{aligned}
$$

Equations (3.7) and (3.8) are used in the failure criterion (equation 3.4) for the estimation of triaxial rock mass strength. The values of $m$ are obtained from the regression analysis and its mean values for different rock types encountered in the US coal mines are given Table 3.4.

The $m$ values obtained from the regression analysis for limestone were highly variable ranging between 22 and 333. Further, only five data sets of limestone were available for analysis. Considering this, the $m$ value for limestone in the Table 3.4 was taken from published literature and not from the regression analysis done in this work [35].

Table 3.4. Value of constant $m$ for different coal measure rocks obtained from regression analysis of the measured data.

\begin{tabular}{|l|l|}
\hline Rock Type & $m$ value \\
\hline Sandstone & 17.1666 \\
\hline Coal & 17.6256 \\
\hline Shale & 9.8608 \\
\hline Siltstone & 11.7984 \\
\hline Limestone & 10.5487 \\
\hline
\end{tabular}

\subsubsection{Stability Evaluation}

As discussed before, most of the available general purpose finite element numerical software packages do not have provision for elastic-plastic analysis using the Hoek-Brown failure criterion. Although the finite element program, ABAQUS, 
used in this work can model rock behavior as Mohr-Coulomb elastic-plastic material, it has no provision to impose tension cut-off. The author and his colleagues are in the process of developing some means to incorporate tension cut-off for the MohrCoulomb model in ABAQUS. Hence, in this work, the stability evaluations are made using the conventional safety factor approach. When applied to the output of a numerical analysis, these are called local safety factors as they represent the condition of only a small portion of the modeled region.

The local safety factor of an element is defined as

When $\sigma_{3 i}>-\sigma_{t r m}$

$$
S F=\frac{\sigma_{3 i}+\sigma_{c}\left(m_{r m} \frac{\sigma_{3 i}}{\sigma_{c}}+s_{r m}\right)^{a}}{\sigma_{1 i}}
$$

When $\sigma_{3 i}<-\sigma_{t r m}$ or $\sigma_{1 i}, \sigma_{2 i}, \sigma_{3 i}<0$

$$
S F=\frac{-\sigma_{t r m}}{\sigma_{3 i}}
$$

subscript $i$ in above equations (3.9) and (3.10) indicates the principal stress values obtained from the model output and $\sigma_{t r m}$ is obtained from equation (3.3) with corresponding values for the rock mass.

\subsection{Summary}

Different methods of applying in-situ stresses in the finite element models have been compared and it was found that the stress orientation method is much 
simpler and accurate way of initializing stresses in the model. It was also shown that it provides same results as geometry orientations.

Typical Pittsburgh seam geo-mining conditions will be used for the proposed research. In-situ stress fields have been chosen so as to represent the measured stresses fairly well while limiting the amount of work. Different assumptions made in the analysis and limitations of the work have also been outlined.

The Hoek-Brown rock failure criterion was shown to perform well in both compressive and tensile regions of the stress space. As the finite element program, ABAQUS doesn't have provisions for elastic-plastic analysis using Hoek-Brown criterion or Mohr-Coulomb criterion with tension cut-off to estimate the rock mass stability; it was decided to use elastic modeling with safety factor method of stability evaluation in this research. 


\section{CHAPTER}

\section{EFFECT OF HORIZONTAL STRESS ANGLE ON
THE STABILITY}

\subsection{Introduction}

Field measurements in the US coal mines indicate that the in-situ horizontal stress field is most often biaxial and sometimes the difference between the two components could be quite large [26]. Unless designed specifically, a development entry in a coal mine could meet the in-situ horizontal stress field at any angle. In this case, under certain conditions, the deleterious effects of high horizontal stress on the entry stability are seen from the bias of rock failure observed in the entries. The mode and location of failure zones in the entry or intersection depend to a large extent upon the angle between the in-situ maximum horizontal stress and the longitudinal axis of the entry and this angle is referred to as in-situ maximum horizontal stress angle $(\theta)$ in this work. This angle is measured with respect to the longitudinal axis of the entry as shown in Figure 4.1, which is reproduced from Figure 3.1 for convenience. Depending on the magnitude of this angle, failure may be seen in only one set of openings (entries or crosscuts) and/or at a certain location within the entry cross-section, e.g., on one rib side as seen in Figure 4.2.

The detrimental effect of $\theta$ on the entry stability is a major cause of concern for the mine operators in the U.S. coal mines. In fact a few mines were abandoned as the safety and the economy of the operation were jeopardized by this problem. Roof failures associated with high in-situ horizontal stresses are commonly known as cutters, gutters, kink roof, etc [26]. A lot of work has been done on the roof failures associated with high horizontal stresses with the objective of understanding the mechanism and devising control methods for this type of roof failure as discussed in chapter 2 .

Of the many factors that contribute to cutter roof failure, the in-situ maximum horizontal stress has been identified as an important one. It has also 


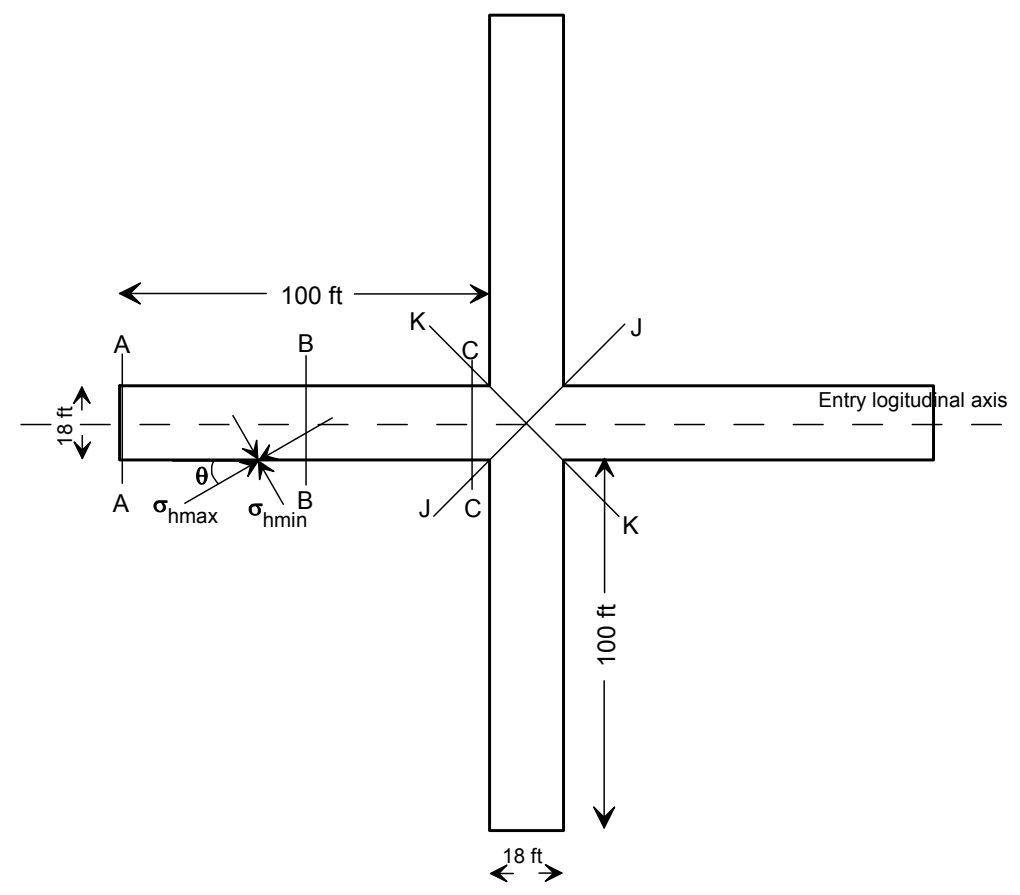

Figure 4.1. Location of cross-sections where results are obtained in the model.

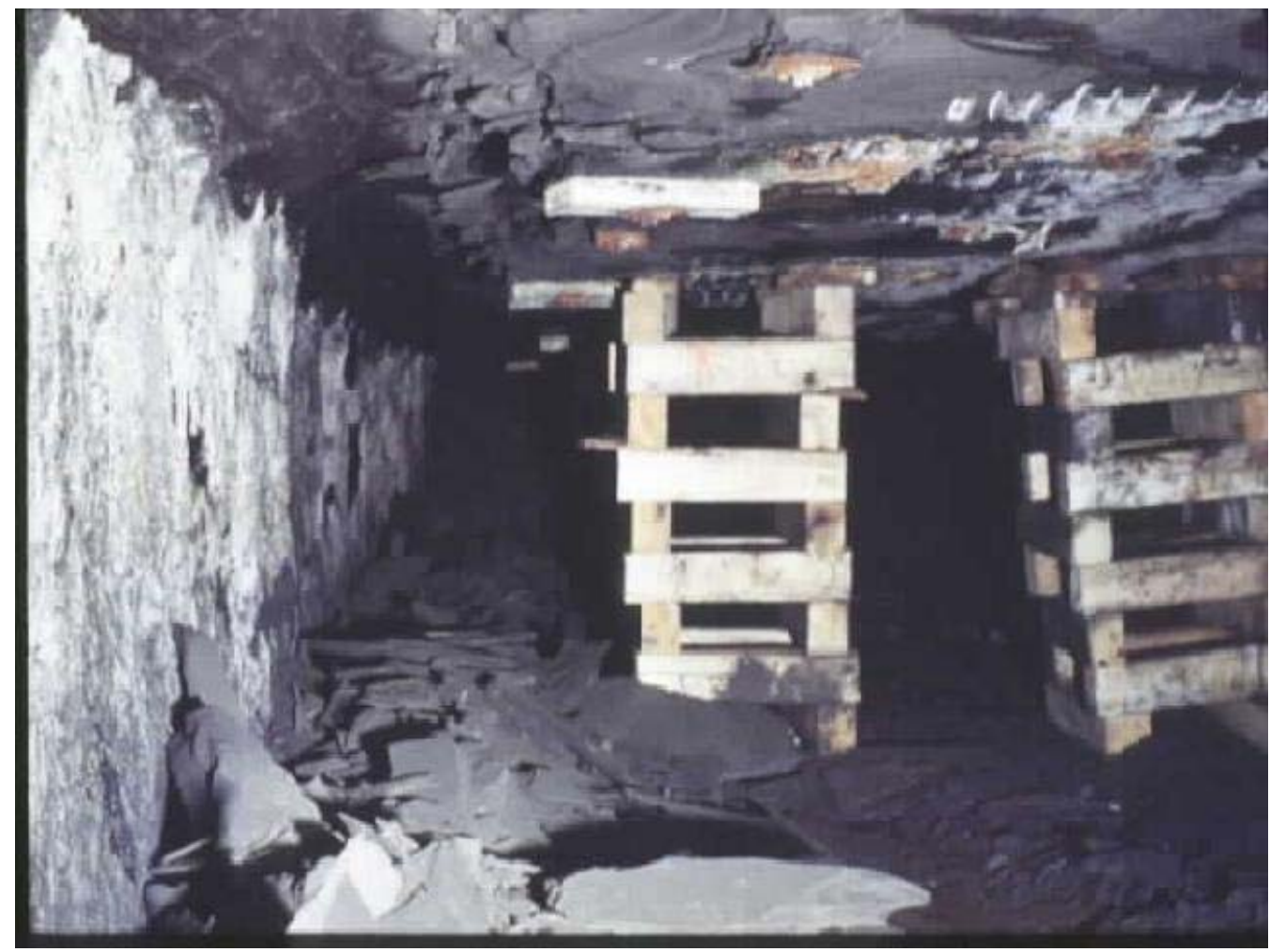

Figure 4.2. Cutter roof failure along one rib side of an entry [2]. 
been found that the entries oriented at right angles to the in-situ maximum horizontal stress would suffer the most while those oriented in the direction of it would have less cutter problems. A full discussion on the works that address the issue of the

directional effects of $\sigma_{\text {hmax }}$ has already been presented in chapter 2 . As mentioned there, more research is required to develop full understanding of the effect of in-situ stresses on the roof stability. Hence, further work is done in this thesis to explore the effects of different input parameters and also to evaluate results at different locations in the coal mine development entries. Model details and other relevant issues discussed in chapter 3 are used for this work. Discussions in this chapter are limited to the influence of the in-situ maximum horizontal stress angle on the stability of entry and intersection.

\subsection{Entries}

The first part of this work is aimed at evaluating the stability of roof at different points in the development entries. The formation of entries in underground coal mines is a sequential process that involves excavation of coal by machines or explosives in stages. Analysis of the stability of the active working area, referred to as the face area, is a difficult problem as three dimensional geometric effects need to be considered besides other parameters that affect the stability. To make matters worse, this face is one of the most likely areas to receive the maximum impact of horizontal in-situ stresses. Therefore, the researcher is often forced to resort to complex three dimensional numerical modeling methods to understand the problem. In fact, many of the cutter roof problems happen at the face area soon after the roof is exposed.

It is not uncommon to find cutters developing a little behind the face area or near the intersection area. Therefore, any study on this subject should consider the ground response at different locations along the entry in relation to the face to get a full picture of its stability. Also, the influence of removal of coal reaches to some distance into the roof and the response of rock to these stress redistributions must be evaluated at least to some distance into the roof. To accommodate the above two 
requirements, three cross-sections are selected in the entry at locations shown in Figure 4.1. It may be noticed that these cross-sections are chosen in such a ways to represent conditions at the face, in the middle of entry (which is free of influence of the face or the intersection) and near the intersection.

The procedure described in chapter 3 to evaluate safety factors using HoekBrown rockmass failure criterion is used to estimate its value at each integration point in the mesh in the cross-section of interest. These values are evaluated to a distance equal to the width of the entry $(18 \mathrm{ft})$ inside the roof. It is assumed that the major stress redistributions take place within this distance. For the lithology used in this analysis (Figure 3.2), six different rock layers fall within the distance considered.

To get a single representative number that can express the stability of each of these beds, and also to compare results among different models, an average safety factor has been calculated for each individual beds. For each bed in the roof, this number is computed by averaging the safety factors at all integration points that fall between the two rib sides of the entry. Further discussions about the stability of any cross-section are made in terms of the average safety factor for all of the beds. Changes in the average safety factor with change in $\theta$ for different beds in the roof at different cross-sections shown in Figure 4.1 are obtained from the numerical models and the results are presented in the following sections.

\subsubsection{Section AA}

Change in the average safety factors for different beds - that fall within a distance of $18 \mathrm{ft}$ from the roof line as shown in Figure 3.2 - with change in the in-situ maximum horizontal stress angle, $\theta$ are shown in Figure 4.3 and Figure 4.4 for one low and one high in-situ stress fields respectively. Similar trends were noticed for other $\boldsymbol{k}$ values. These figures also show the effect of the ratio of in-situ maximum horizontal to minimum horizontal stress, $\boldsymbol{l}$ on the average safety factor. At angles other than $0^{\circ}$ and $90^{\circ}$ the stresses and safety factor distributions were asymmetric across the entry width. Because of the importance of stress distribution patterns in the entry, detailed discussions are made on this topic later in chapter 5. 
Two general trends are seen in the variation of the average safety factors with change in $\theta$ as seen from Figure 4.3 and Figure 4.4. In one case, the average safety factor of a bed continuously reduces with increasing $\theta$ indicating decreased stability at higher angles of $\theta$. In the other case, there was no consistent trend in the safety factor distribution and was more variable. Further, these variations showed no general patterns even for a single bed. It appears that the effect of $\theta$ depends on the location of the bed inside the roof, the ratio of maximum horizontal to vertical stress and the ratio of maximum horizontal to minimum horizontal stress.

These observations clearly indicate that the stability of the face area is dependent on a combination of parameters, e.g. properties of different beds, and it is not always true that the worst stability is noticed at an in-situ maximum horizontal stress angle of $90^{\circ}$. To summarize the effect of $\theta$ on the entry stability in this crosssection, relative frequency plots for the highest and the lowest average safety factors are made and shown in Figure 4.5. In these plots, the relative frequency indicates the fraction of observations that show the highest or lowest average safety factors for certain $\theta$ among the total number of observations. For every combination of $\boldsymbol{k}$ and $l$ and for each bed, values of $\theta$ are noted at which the highest and the lowest average safety factors were obtained. When the relative frequency is estimated for a certain cross-section, the numerator is estimated by counting the number of times the best or the worst conditions are noticed for each of the $\theta$ values for all six beds combined. Similarly, when it is estimated for low or high in-situ stress fields for a bed, the total number of times the maximum or minimum stability noticed is counted with all cross-sections combined together.

From Figure 4.5 it is obvious that the most stable orientation for the face area is aligning the entry with the direction of in-situ maximum horizontal stress though there is a small fraction that shows better orientation at $90^{\circ}$. However, the effect is not as clear for the least stable condition. Even though more cases of worst stability are noticed at $90^{\circ}$ orientation, we can also see fairly good proportions that show minimum stability for angles between $30^{\circ}$ and $75^{\circ}$. 


\subsubsection{Section $B B$}

Section BB is located in the middle portion of the entry which is normally free of effects of the face or the intersection. In fact, from the models run in this work it was seen that the effect of face vanishes at about 10-15 ft outby while the influence of intersection can be seen up to a maximum distance of $30 \mathrm{ft}$. One important observation about stress distribution in this section is the near symmetry across the width for any in-situ maximum horizontal stress angle. Further details on this will be given in the next chapter.

The average safety factor distribution for the roof beds for the same $\boldsymbol{k}, \boldsymbol{l}$ and $\theta$ as that of section AA are shown in Figure 4.6 and Figure 4.7. These plots show more inconsistency in the average safety factor distribution as compared to section AA. The effect of in-situ maximum horizontal stress is more predominant on the stability of this portion of the entry as seen from the safety factors in the immediate two roof beds for $\boldsymbol{k}<1$ and $\boldsymbol{k}>1$. At low in-situ horizontal stresses, the immediate portion of the roof is more stable when the entry is oriented at right angles to the direction of the in-situ maximum horizontal stress. For high in-situ horizontal stresses, the opposite is true in general.

This behavior of the immediate roof is due to the change in the nature and/or the magnitude of induced stresses. For $\boldsymbol{k}<1$, the immediate two layers of the roof were in tension or under very low compression and with increasing $\theta$, as more horizontal stress is applied, the magnitude of tensile induced stresses decreased and/or minimum compressive stresses increased.

As the rock mass strength increases with increasing confining pressure, this increase in minimum principal stress with increase in $\theta$ made these beds more stable. For the case when $\boldsymbol{k}>1$, the induced stresses in a major portion of the roof were compressive and with increasing $\theta$ both the maximum and minimum compressive stresses increased though at different rates. As the rate of increase of minimum principal stress was less than the maximum one, the rock stability decreased and in some cases resulted in shear failure. Therefore, depending on the 


\section{$\underline{\text { Bed } 1}$}

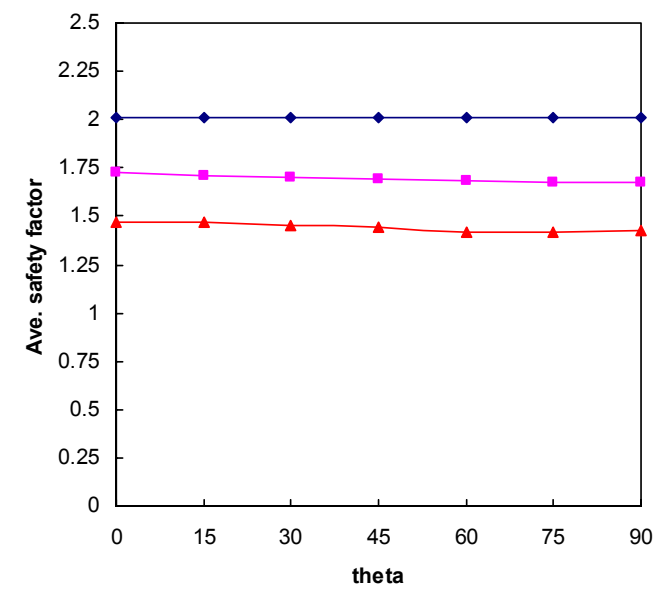

\section{$\underline{\text { Bed2 }}$}

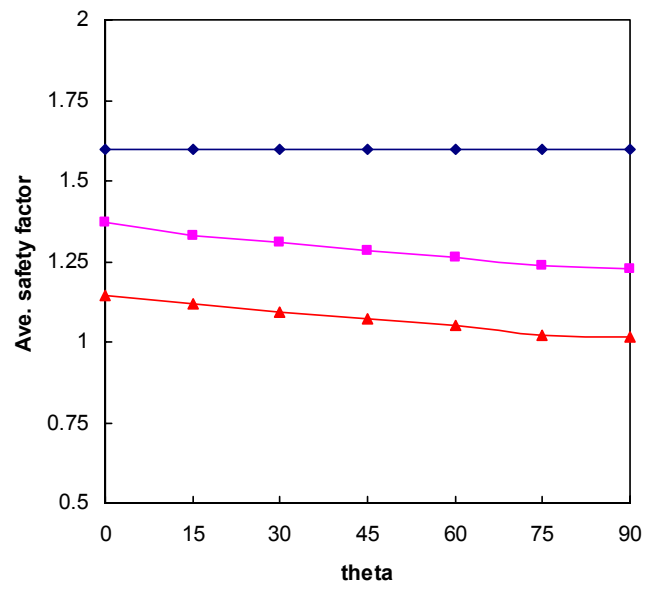

\section{$\underline{\text { Bed } 3}$}

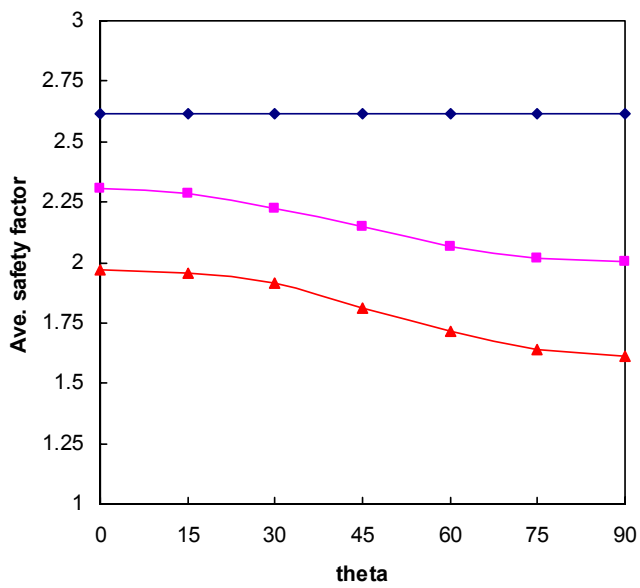

\section{$\underline{\operatorname{Bed} 4}$}

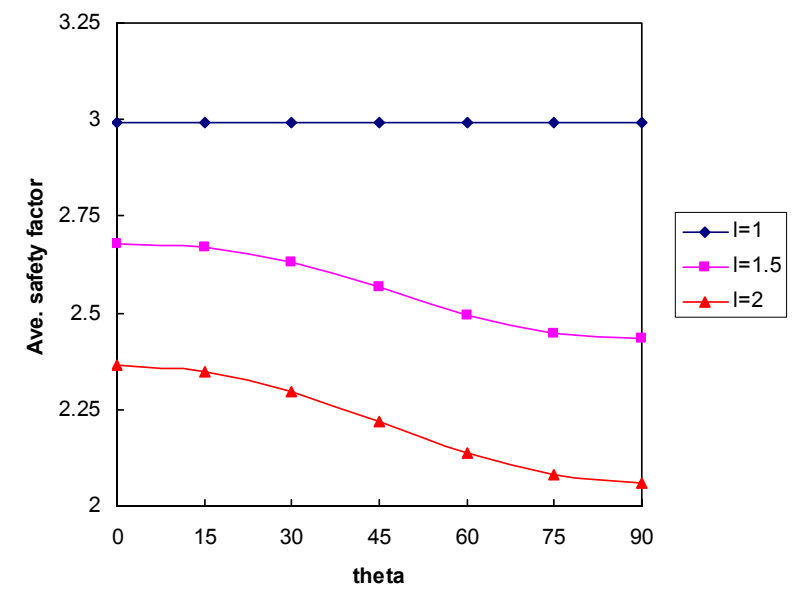

\section{$\underline{\text { Bed } 5}$}

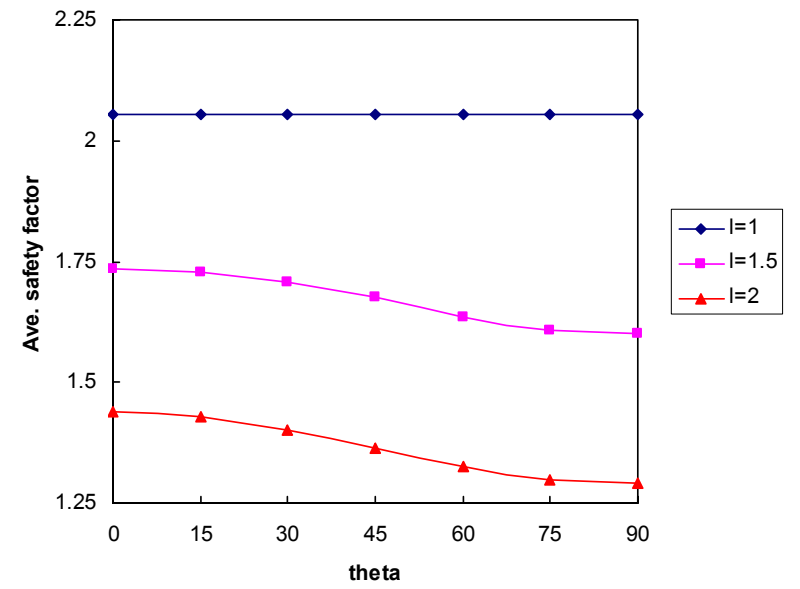

\section{Bed 6}

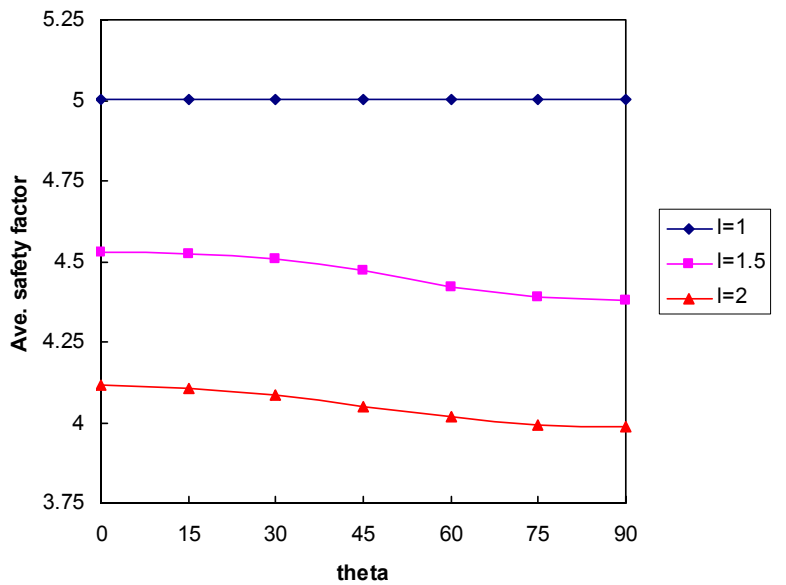

Figure 4.3. Change in average safety factors with $\theta$ (degrees) for different beds for $\boldsymbol{k}=0.3$ in crosssection AA. 
$\underline{\text { Bed } 1}$

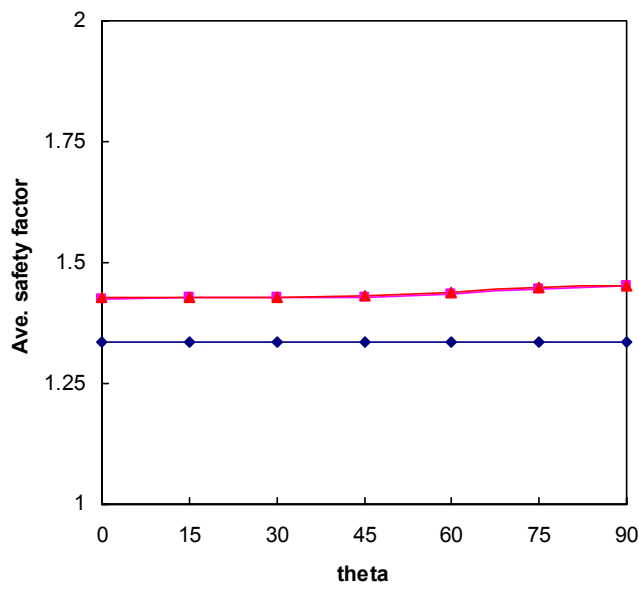

\section{Bed 2}

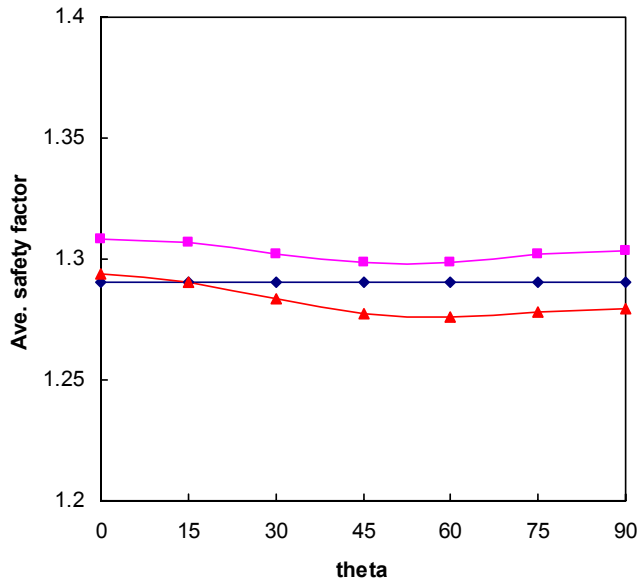

$\underline{\text { Bed } 3}$

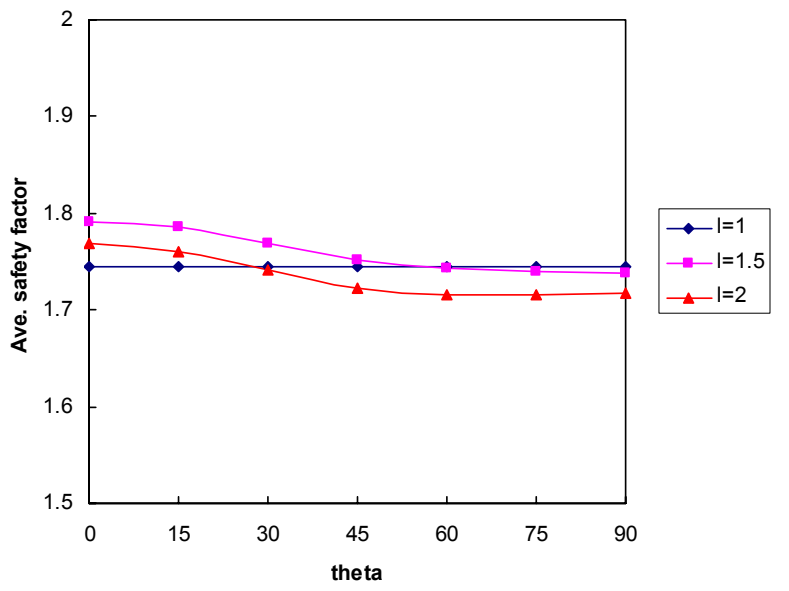

$\underline{\text { Bed } 4}$

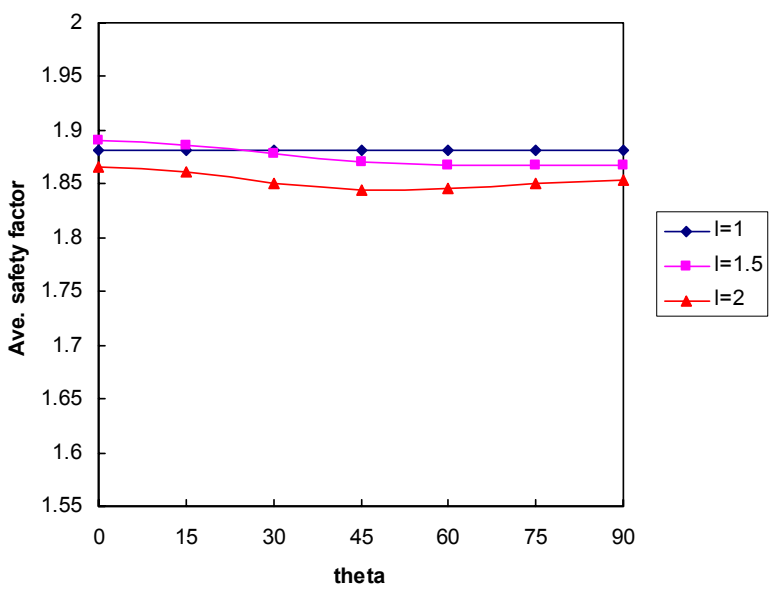

\section{$\underline{\text { Bed } 5}$}

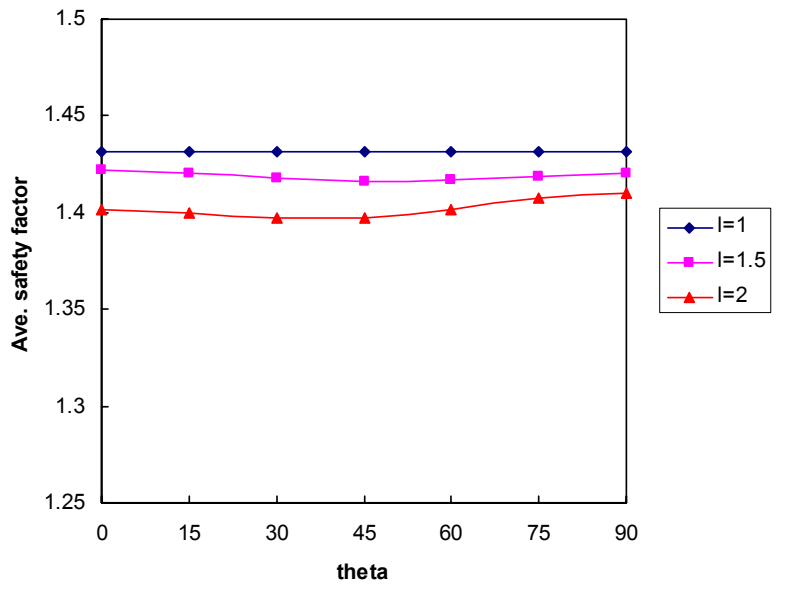

\section{Bed 6}

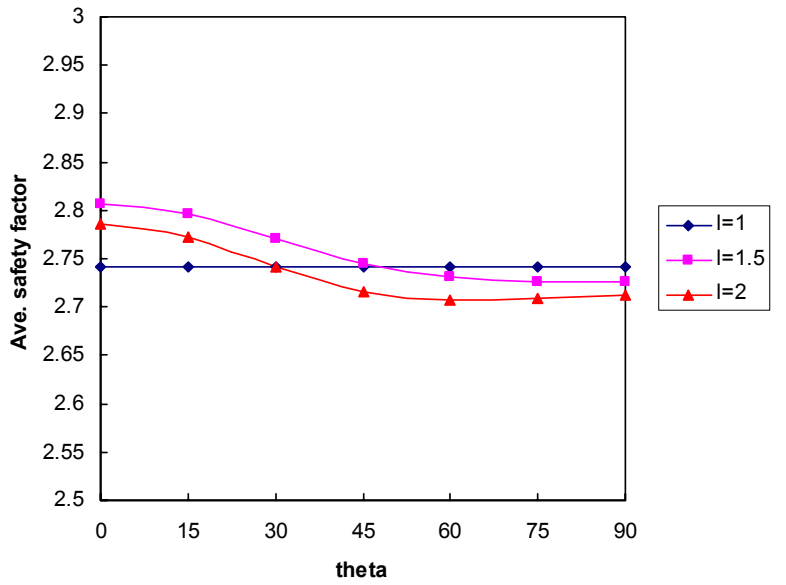

Figure 4.4. Change in average safety factors with $\theta$ (degrees) for different beds for $\boldsymbol{k}=3.0$ in crosssection AA. 
(a)

Highest Average Safety Factor

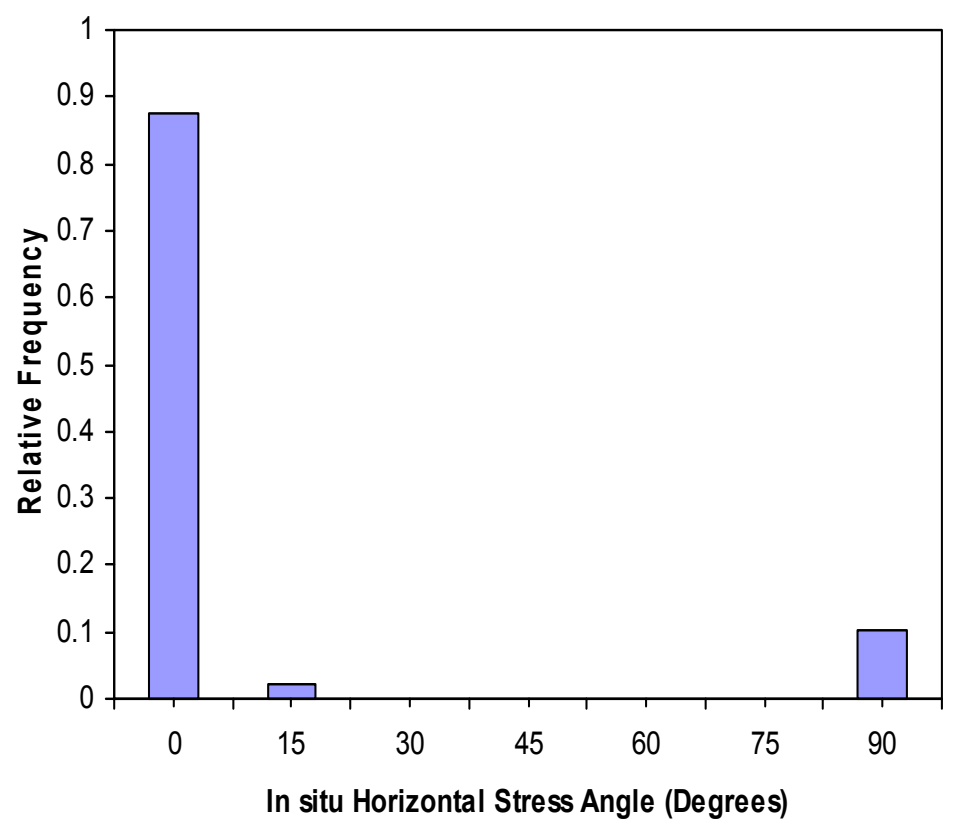

(b)

Lowest Average Safety Factor

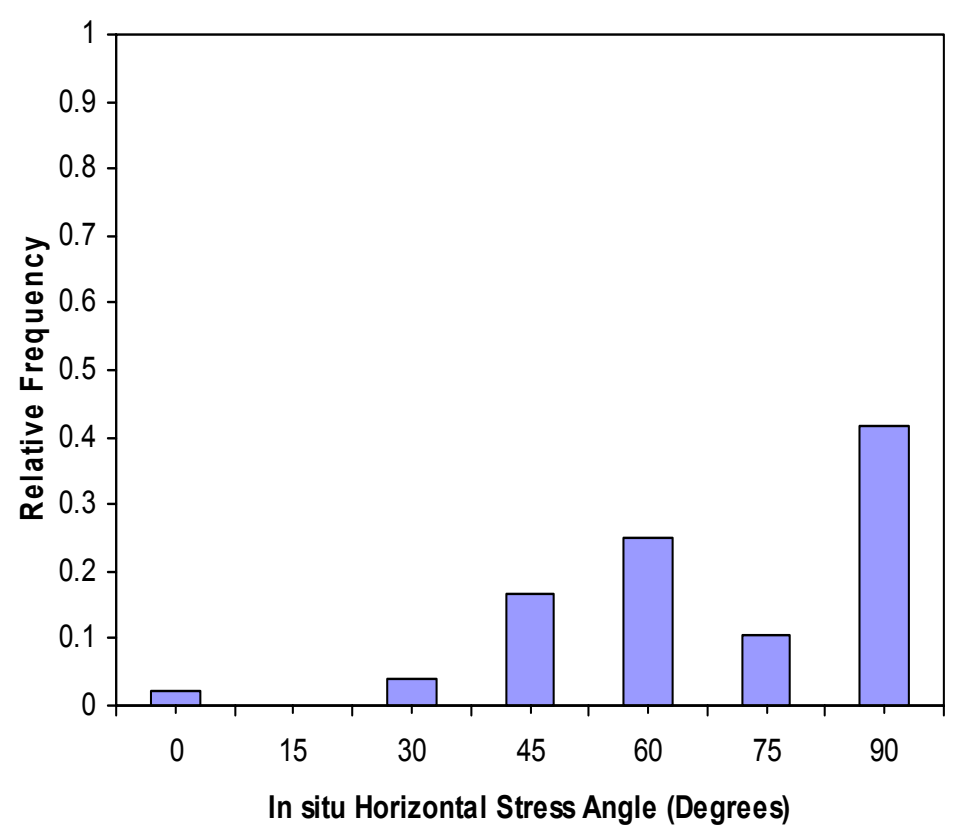

Figure 4.5. Relative frequency of observation of (a) highest and (b) lowest average safety factors for different in-situ maximum horizontal stress angles in the cross-section AA. 


\section{$\underline{\text { Bed } 1}$}

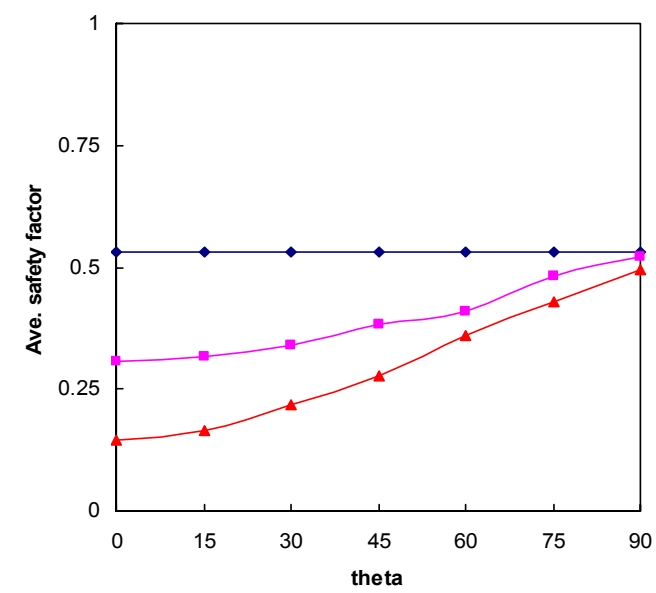

\section{$\underline{\text { Bed } 2}$}

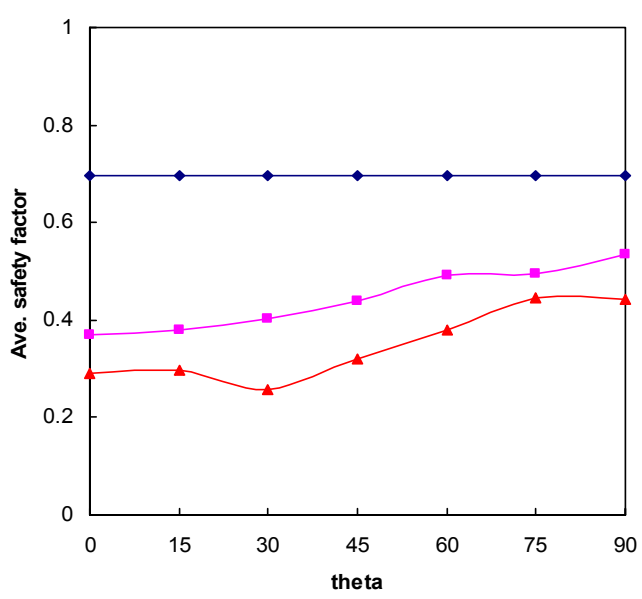

$\underline{\text { Bed } 3}$

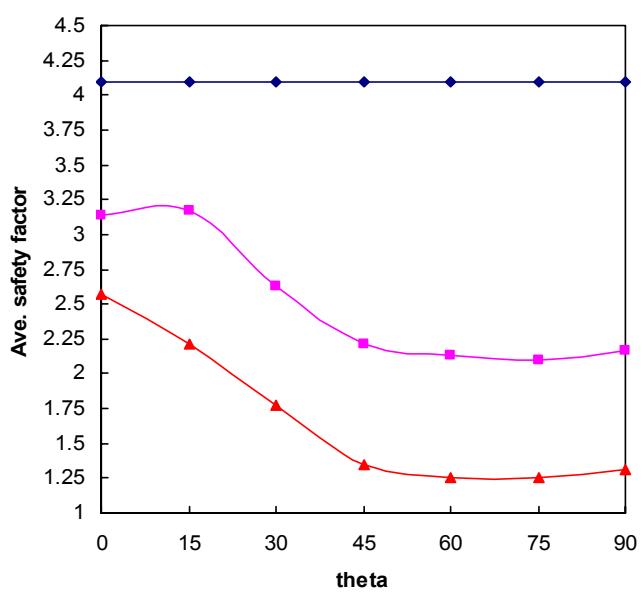

\section{$\underline{\operatorname{Bed} 4}$}

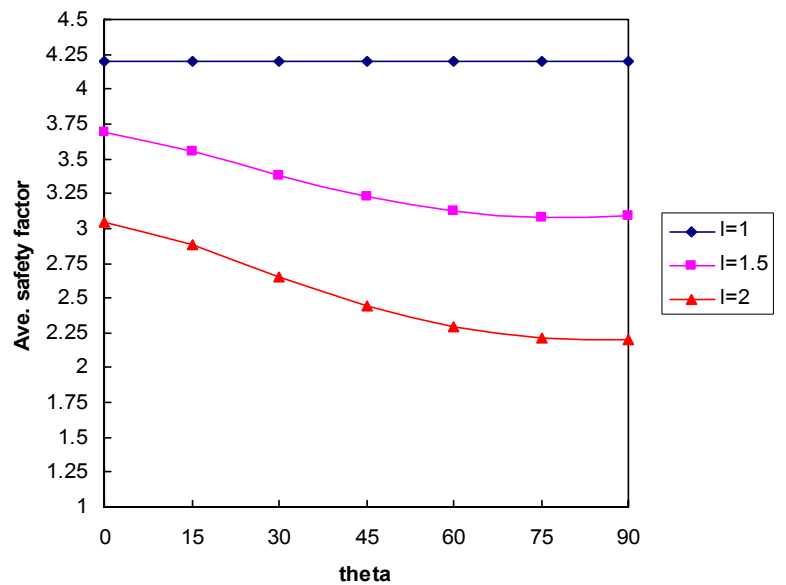

\section{$\underline{\text { Bed } 5}$}

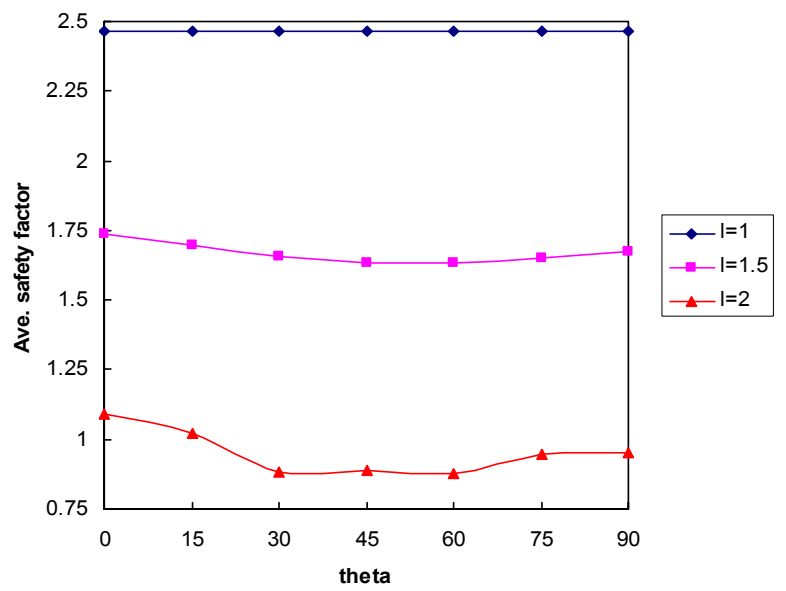

\section{Bed 6}

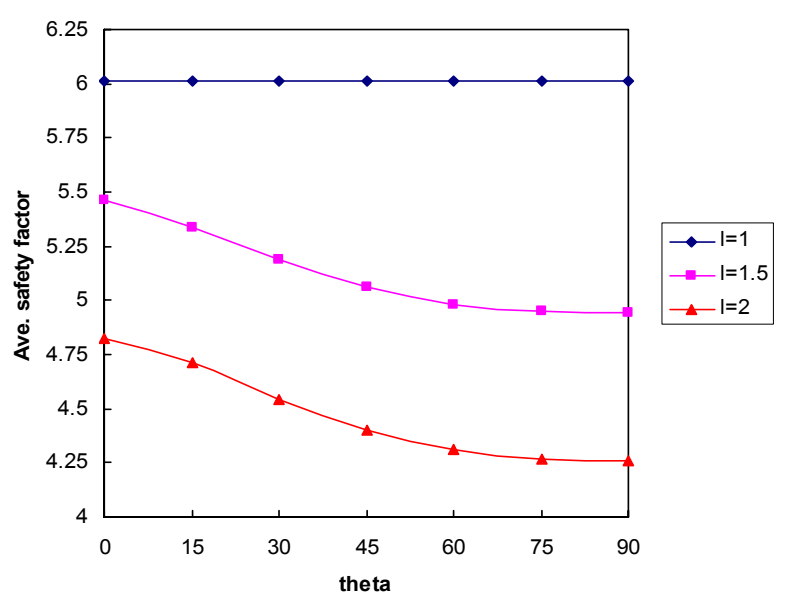

Figure 4.6. Change in average safety factors with $\theta$ (degrees) for different beds for $\boldsymbol{k}=0.3$ in cross-section BB. 
$\underline{\text { Bed } 1}$

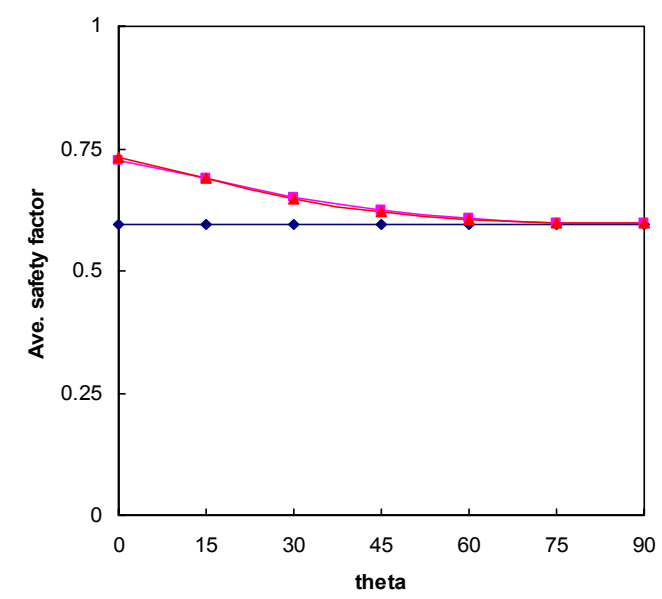

$\underline{\text { Bed } 2}$

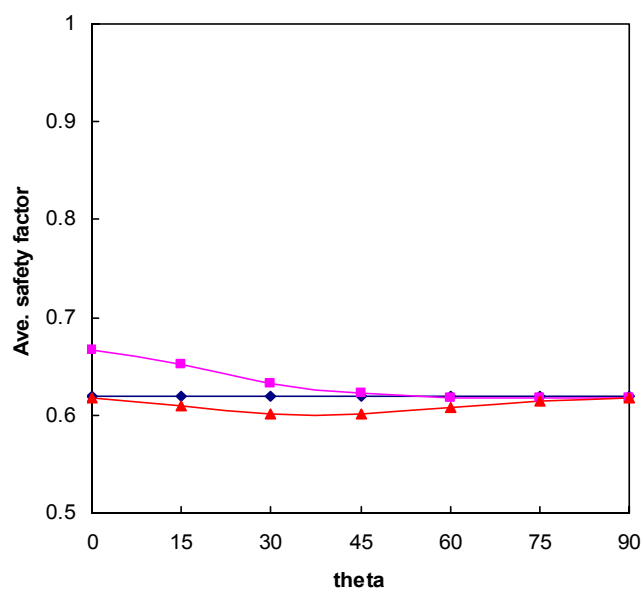

$\underline{\text { Bed } 3}$

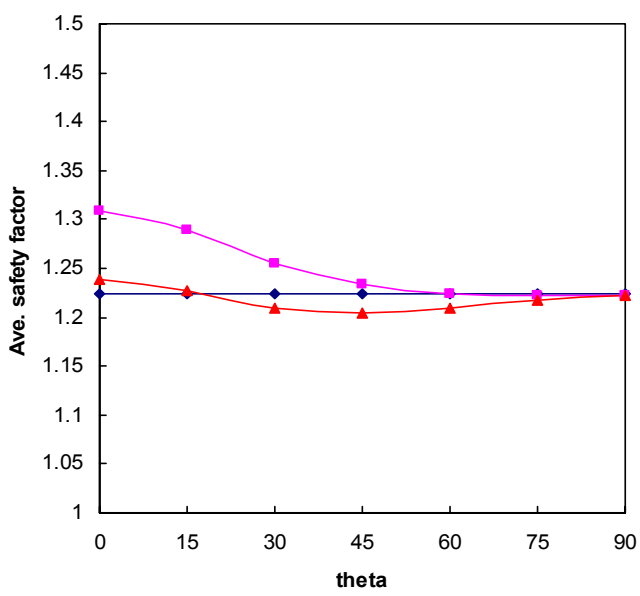

\section{$\underline{\operatorname{Bed} 4}$}

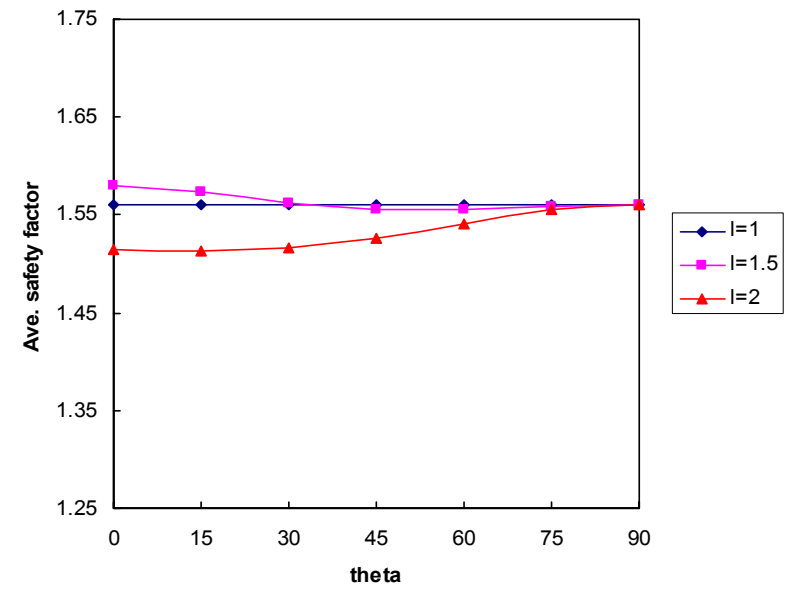

\section{Bed 5}

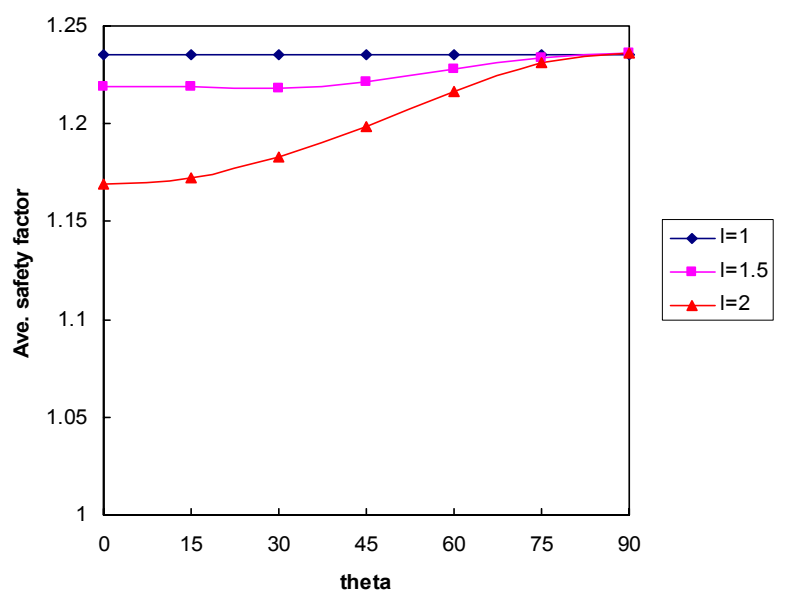

\section{Bed 6}

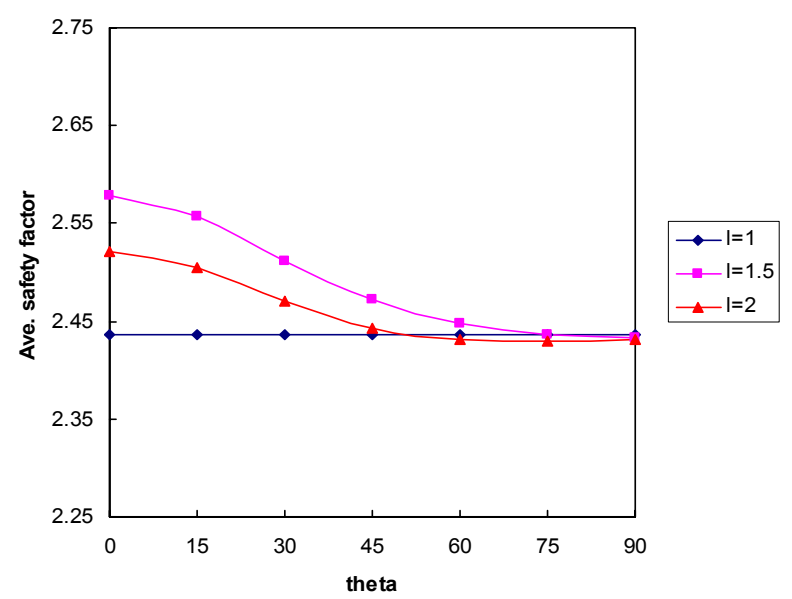

Figure 4.7. Change in average safety factors with $\theta$ (degrees) for different beds for $\boldsymbol{k}=3.0$ in cross-section BB. 
change in the magnitude and/or nature of the induced principal stresses, different beds exhibited different behavior as shown in these figures.

Similar to section AA, relative frequency plots are produced for this section also. These plots for the highest and the lowest average factors are shown in Figure 4.8. The following points are worth noting from this:

\# Maximum stability is still shown for $\theta=0^{\circ}$. However, as compared to section $A A$, there is a decrease in the number of cases that show maximum stability for this orientation.

7. Minimum stability occurs when $\theta=90^{\circ}$ and the relative frequency for this case is less than that for section AA.

I While the above two general trends are still maintained, the number of cases that show maximum stability at $90^{\circ}$ increased for this section. Most of these observations are for $\boldsymbol{k}<1$.

7. Minimum stability is noticed for all angles between $0^{\circ}$ and $90^{\circ}$ and the relative frequency increased for $0^{\circ}, 15^{\circ}, 30^{\circ}$ and $75^{\circ}$ orientations as compared to section $A A$.

\subsubsection{Section CC}

The average safety factor distributions shown from Figure 4.9 to Figure 4.10 indicate almost similar trends observed in cross-section BB though with different magnitudes. However, there is one major difference between these two sections. It is in the stress distribution across the width. There is a significant bias in the stress distribution toward the rib from which the in-situ maximum horizontal stress is acting in the model. More details will be given in a later chapter.

The relative frequencies of the maximum and minimum stability orientations are given in Figure 4.11. The following differences are noticed when compared with section $\mathrm{BB}$ :

\# Maximum stability is noticed for $\theta=0^{\circ}$ and $90^{\circ}$ with the relative frequency of the former being more than the latter. The fraction of most stable cases reduced for $0^{\circ}$ and increased for $90^{\circ}$ as compared to BB. 
\# The least stable direction is at right angles to the in-situ maximum horizontal stress and minimum stability can occur at other orientations as well except at $45^{\circ}$.

\subsubsection{Summary Remarks for Entries}

From the foregoing discussions it is clear that the orientation of an entry with respect to the direction of the in-situ maximum horizontal stress has a substantial effect on its stability. This, however, depends on other factors as well. The best and the worst orientations are determined by the location of the cross-section, location of the bed in the immediate roof and more importantly the ratio of in-situ maximum horizontal stress to vertical stress and the ratio of in-situ maximum horizontal to minimum horizontal stress.

Of the factors investigated, the ratio of in-situ maximum horizontal to vertical stress was found to have the highest influence in determining the stable and unstable entry orientations with respect to in-situ horizontal stress field. Therefore, further inquiry is made to explore the effect of this ratio in combination with the orientation effects on the stability of roof. Since, it is the first few feet of the immediate roof that is important for the ground control, only beds 1 and 2 are examined in this case (in fact, it is in these two beds the effect of $\boldsymbol{k}$ is seen more remarkably).

Figures 4.12 and 4.13 show the relative frequency distributions for bed 1 and bed 2 for all three cross-sections combined. The plots are separated into $\boldsymbol{k}<1$ and $\boldsymbol{k}$ $>1$. From these plots the following points are the most notable ones:

I For both immediate roof beds, when the vertical stress is more than both of the in-situ horizontal stresses, the maximum stability is achieved when the entry is oriented at right angles to the direction of the in-situ maximum horizontal stress. 
(a)

Highest Average Safety Factor

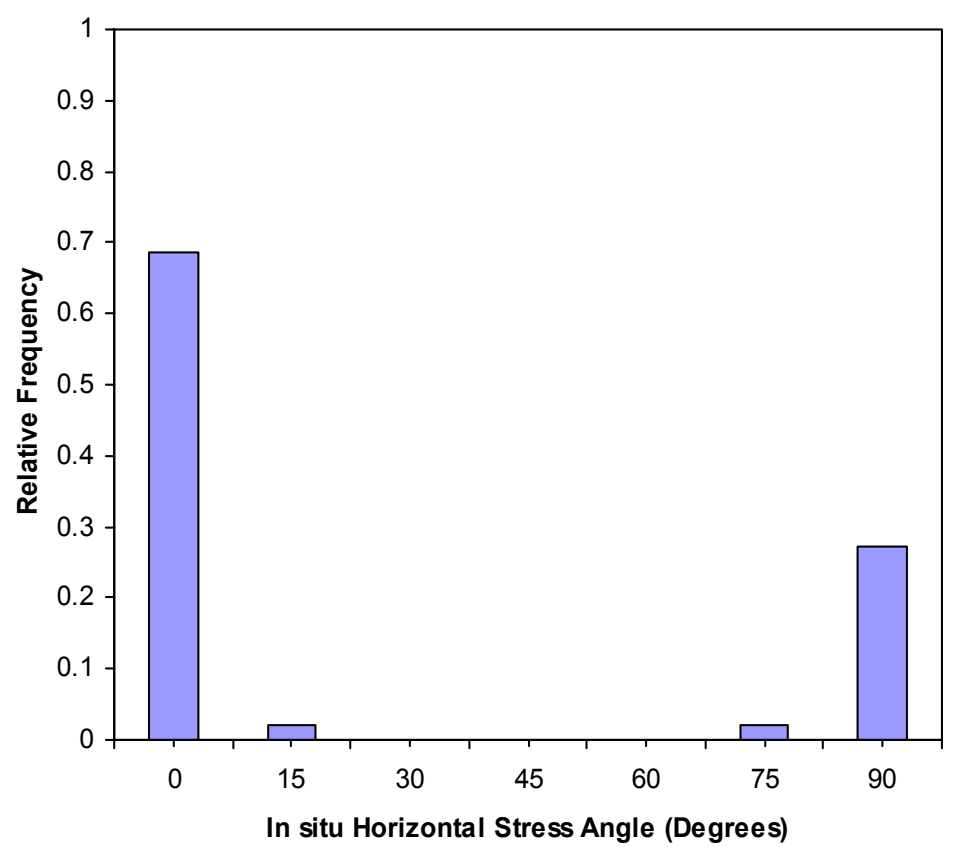

(b)

Lowest Average Safety Factor

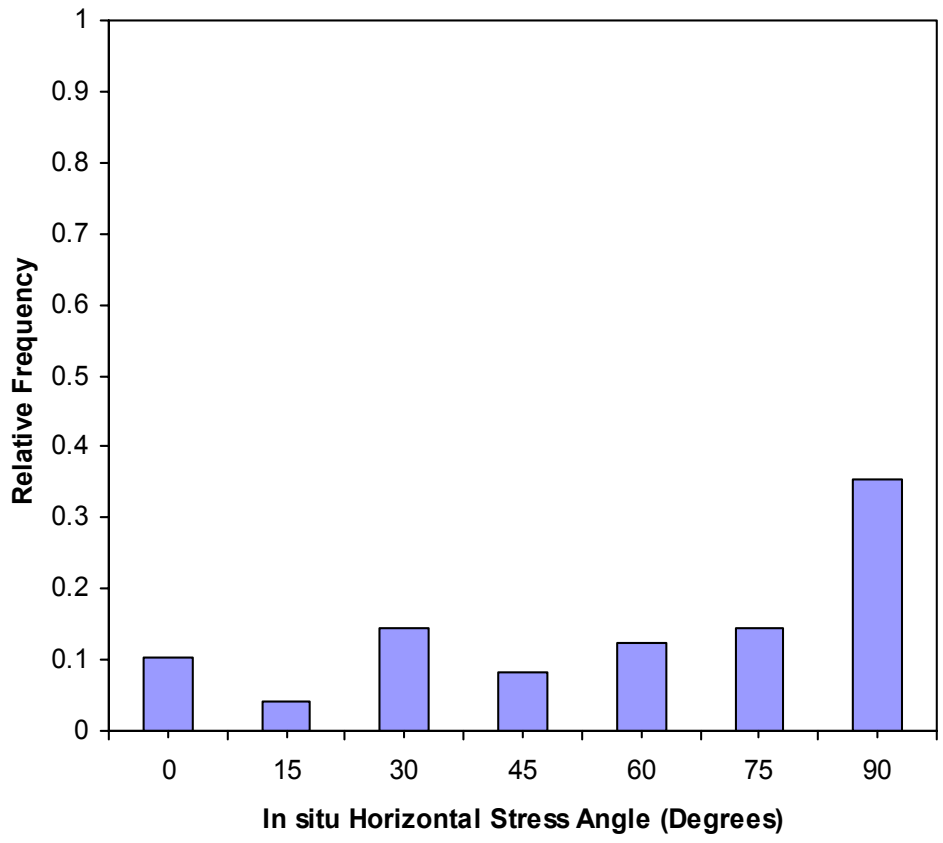

Figure 4.8. Relative frequency of observation of (a) highest and (b) lowest average safety factors for different in-situ maximum horizontal stress angles in the cross-section BB. 
$\underline{\text { Bed } 1}$

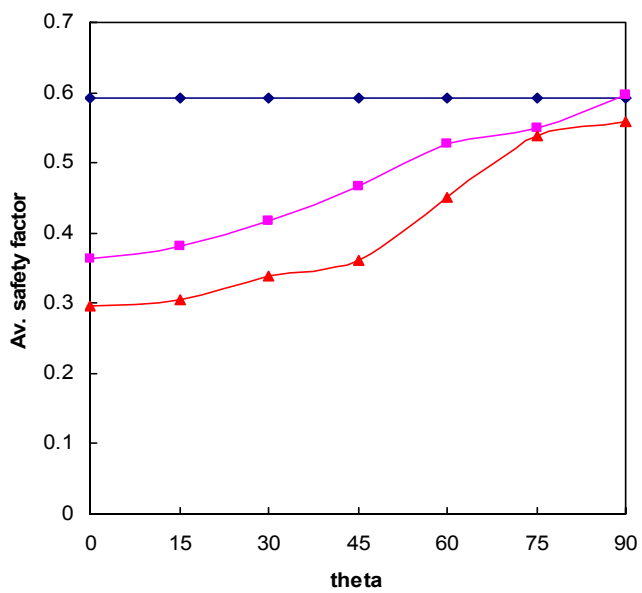

$\underline{\text { Bed } 2}$

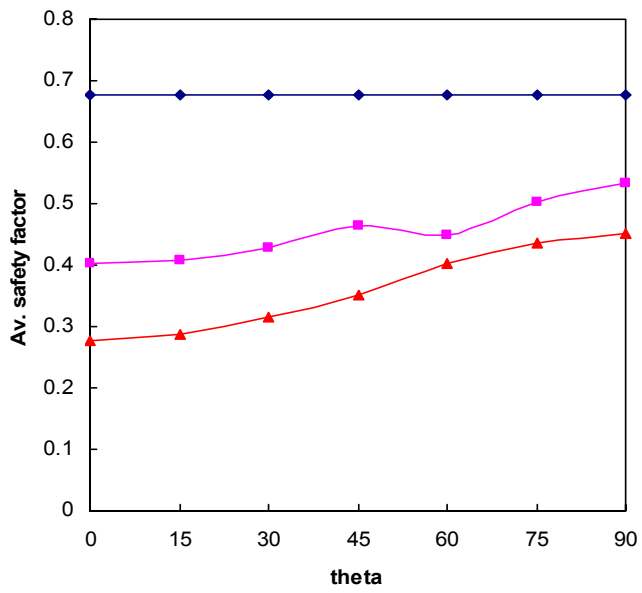

$\underline{\text { Bed } 3}$

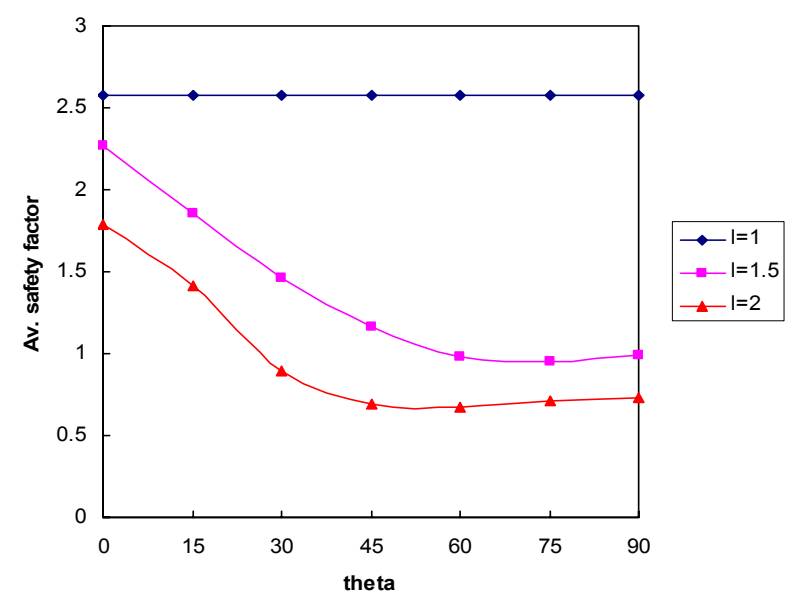

\section{$\underline{\operatorname{Bed} 4}$}

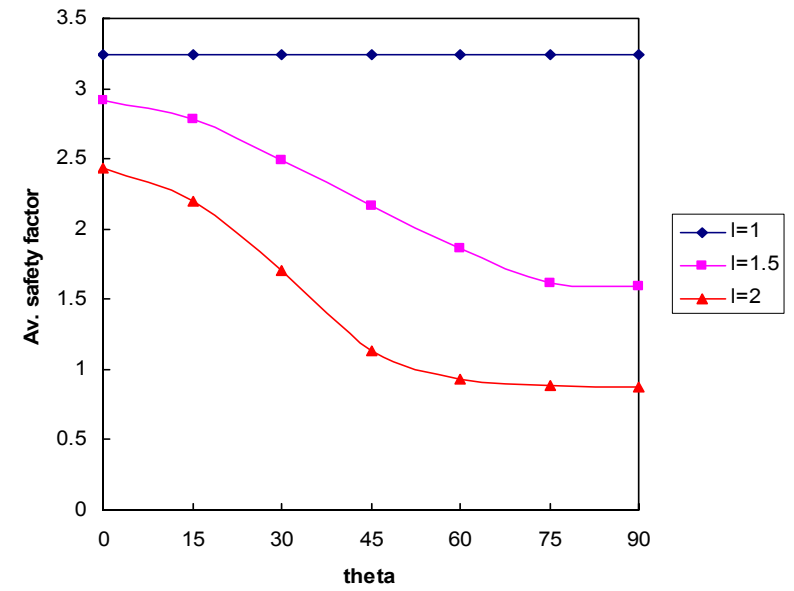

\section{Bed 5}

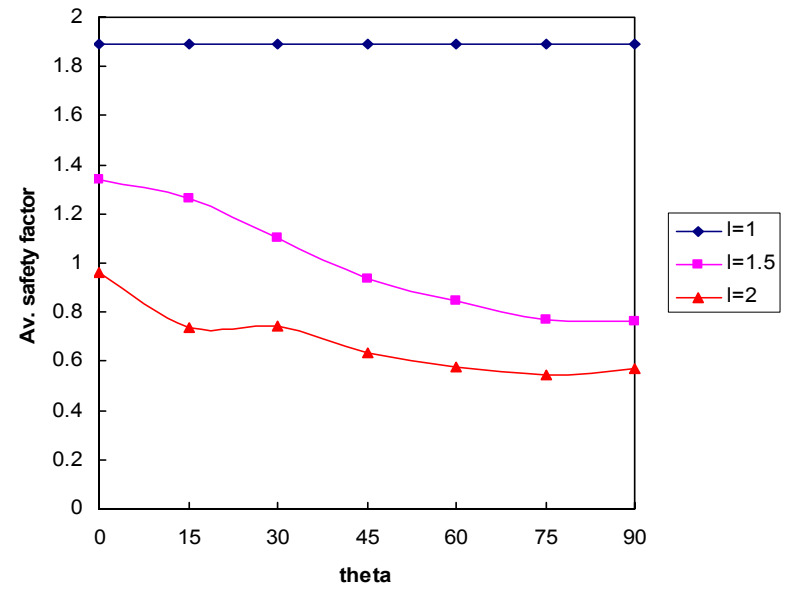

\section{$\underline{\text { Bed } 6}$}

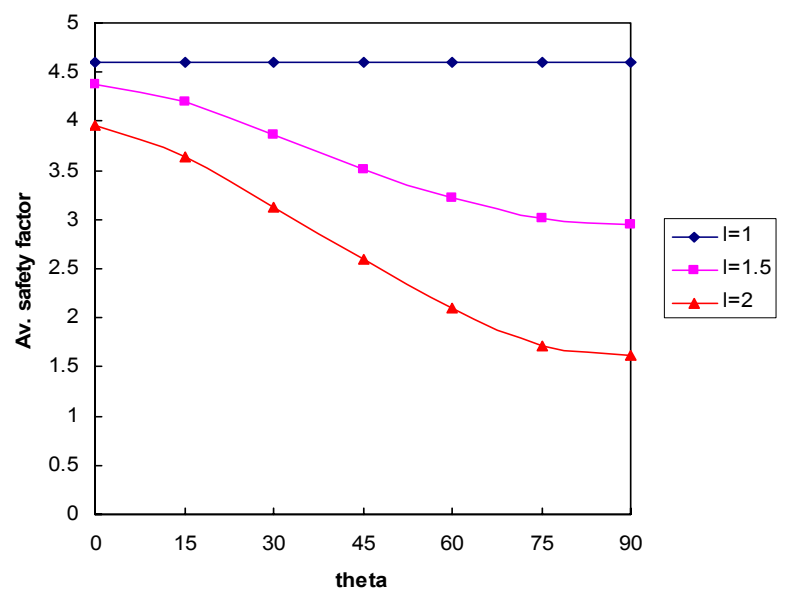

Figure 4.9. Change in average safety factors with $\theta$ (degrees) for different beds for $\boldsymbol{k}=0.3$ in cross-section CC. 
$\underline{\text { Bed } 1}$

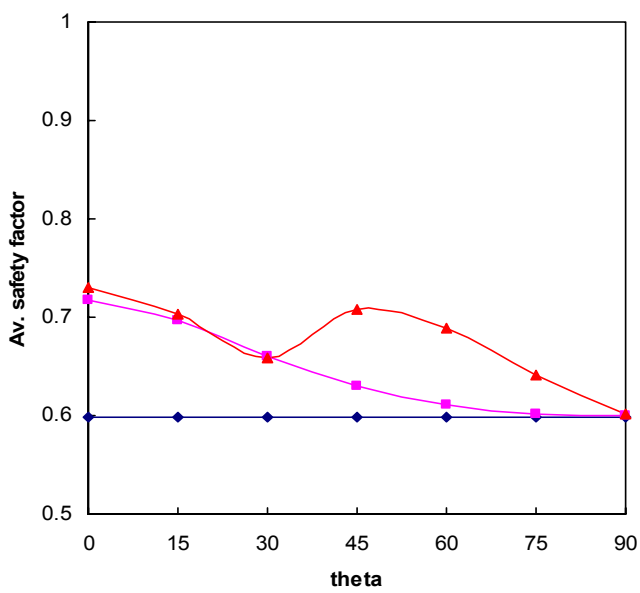

Bed 2

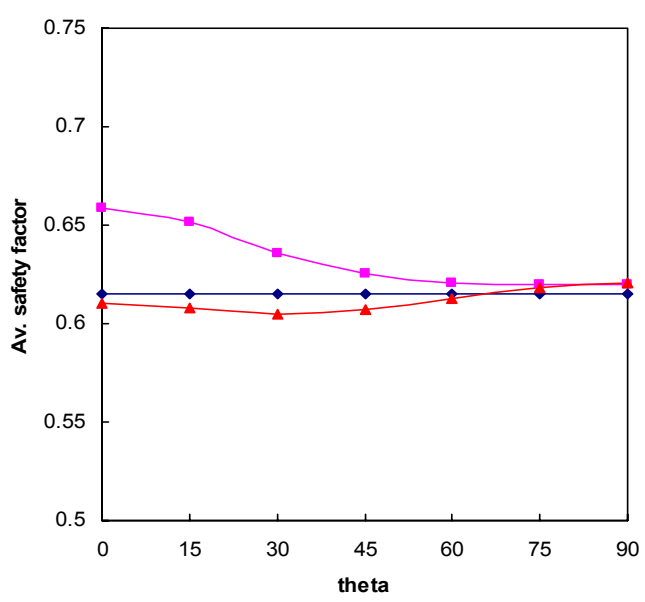

Bed 3

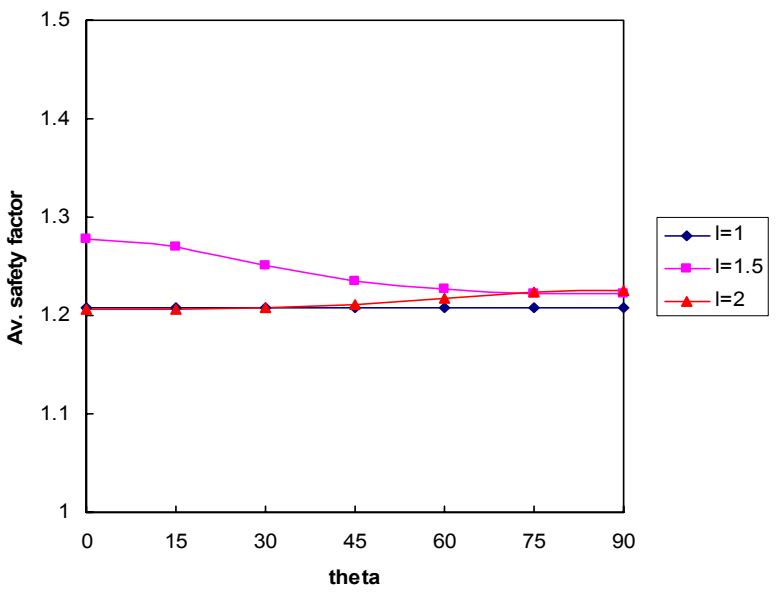

$\underline{\operatorname{Bed} 4}$

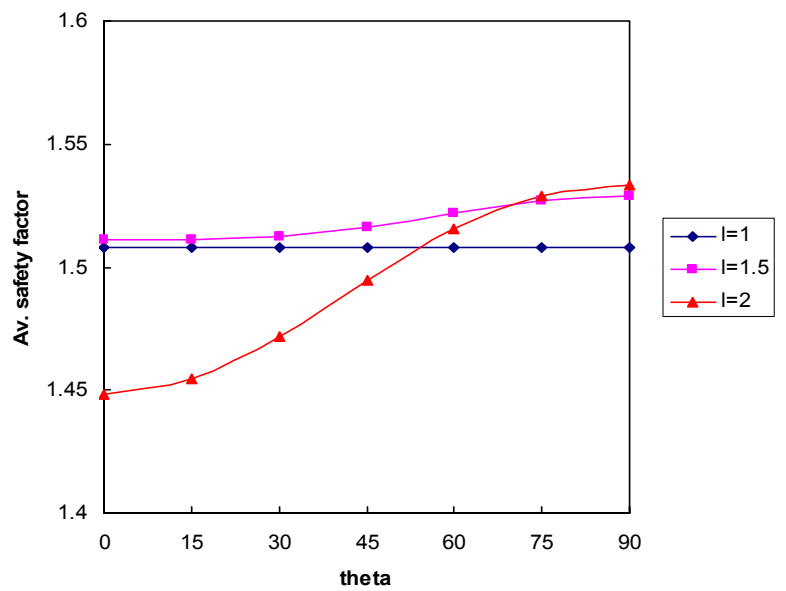

Bed 5

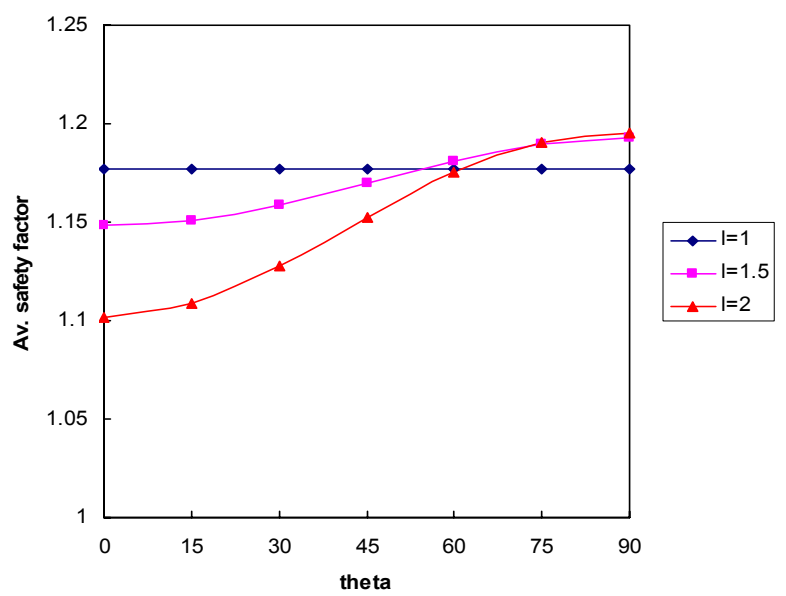

$\underline{\text { Bed } 6}$

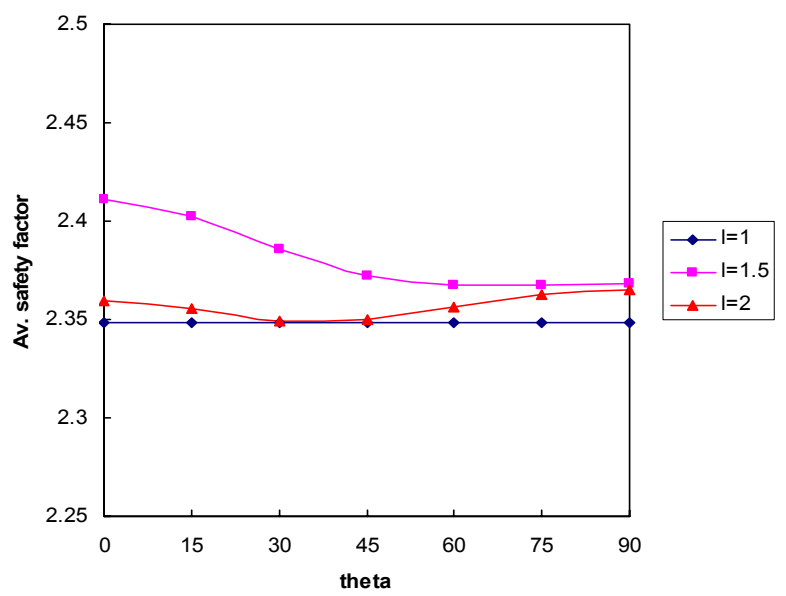

Figure 4.10. Change in average safety factors with $\theta$ (degrees) for different beds for $\boldsymbol{k}=3.0$ in cross-section CC. 
(a)

Highest Average Safety Factor

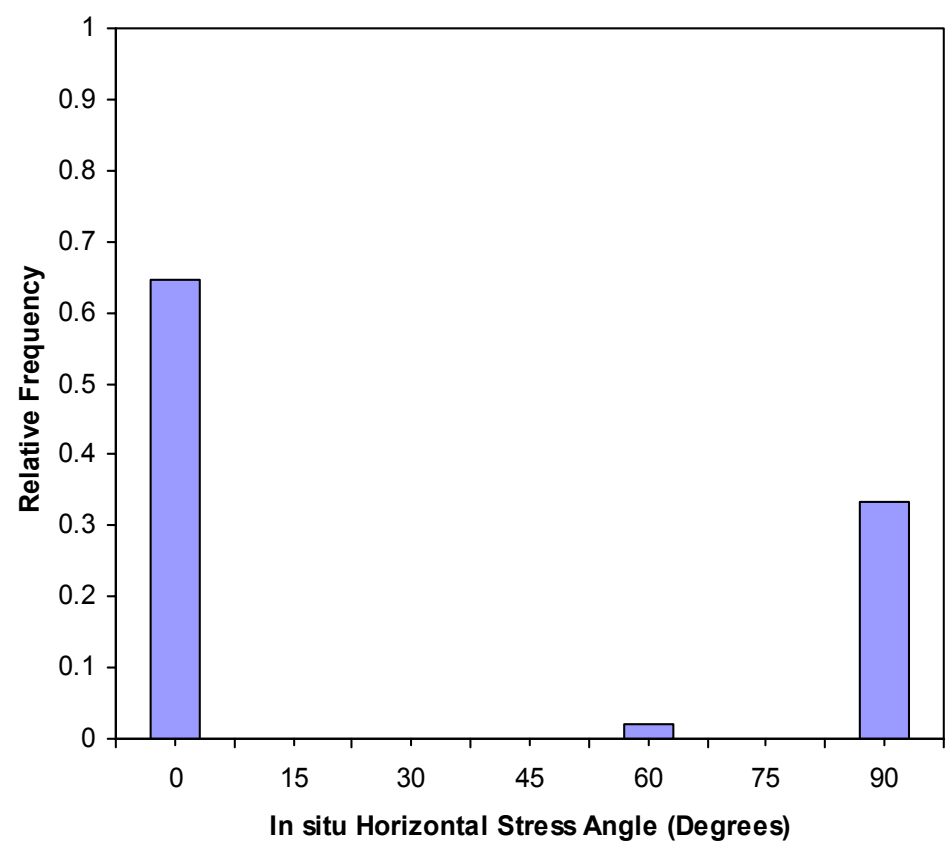

(b)

Lowest Average Safety Factor

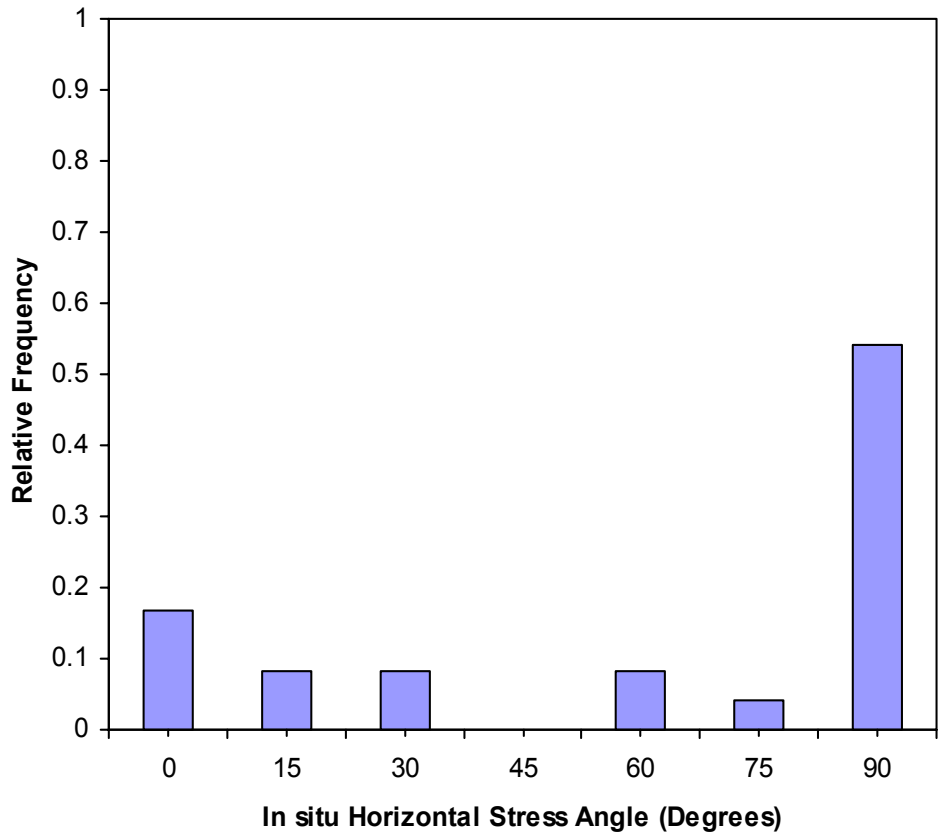

Figure 4.11. Relative frequency of observation of (a) highest and (b) lowest average safety factors for different in-situ maximum horizontal stress angles in the cross-section CC. 
\#When $\boldsymbol{k}<1$, entries oriented in the direction of $\sigma_{\mathrm{hmax}}$ will have least stability in a majority of cases. Minimum stability could also be noticeable at other orientations.

2 When $\boldsymbol{k}>1$, the entries are in the least stable orientation if $\theta=90^{\circ}$ and in the best stable direction if $\theta=0^{\circ}$. Stability problems may exist for orientations other than $90^{\circ}$ though at a lower frequency.

When all cross-sections, beds and input variables are combined for the entries the relative frequency diagram shown in Figure 4.14 is obtained. From this figure the following inferences can be drawn:

I In a general sense, for the maximum stability of the entry it must be oriented in the direction of $\sigma_{h \max }$. Though in some case $90^{\circ}$ orientation will yield most stable entry.

\# The orientation at which least stability is obtained is not as clear as the maximum stability. However, at right angles to the direction of $\sigma_{h \max }$, in a majority of cases minimum stability is noticed.

Based on the research in this thesis, for the lithology considered, design chart shown in Figure 4.15 is developed to choose the best layout for development entries. The ground conditions for different orientations shown in this chart match exactly with those given by Lizak and Sembourski [25] and software program AHSEM [2] developed mostly based on field observations and simple rock mechanics principles. However, research in this thesis provides some rational basis for the classification of ground conditions for different $\theta$ values shown in this chart.

Further, the descriptions of roof conditions given in the design chart are only relative to the prevailing conditions at the mine. This basically means adverse ground conditions may exist for any orientation of $\sigma_{\mathrm{hmax}}$ if the rock mass strength is lower compared to the induced stress field. However, within those adverse conditions relative improvements in the stability could be seen if the entries are designed as per the chart in Figure 4.15. 
(a)

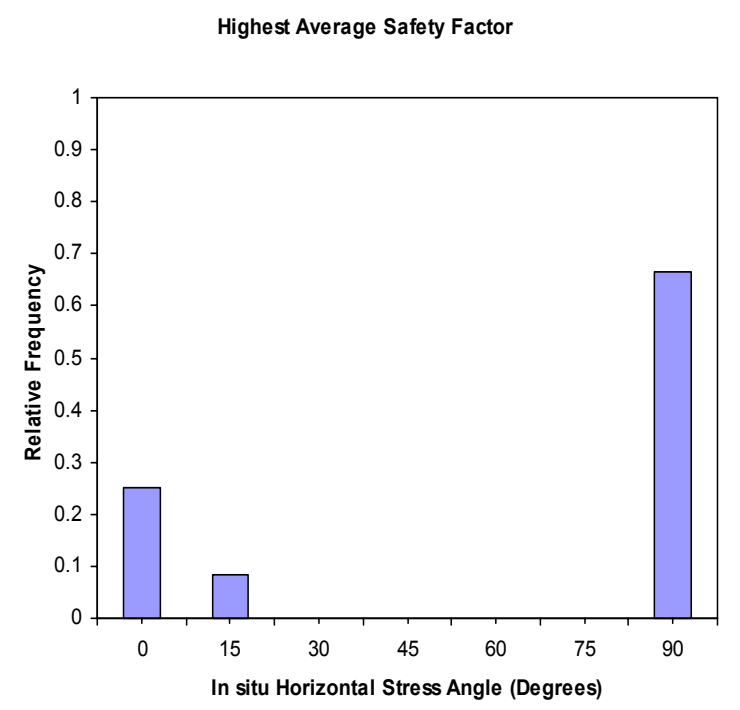

Lowest Average Safety Factor

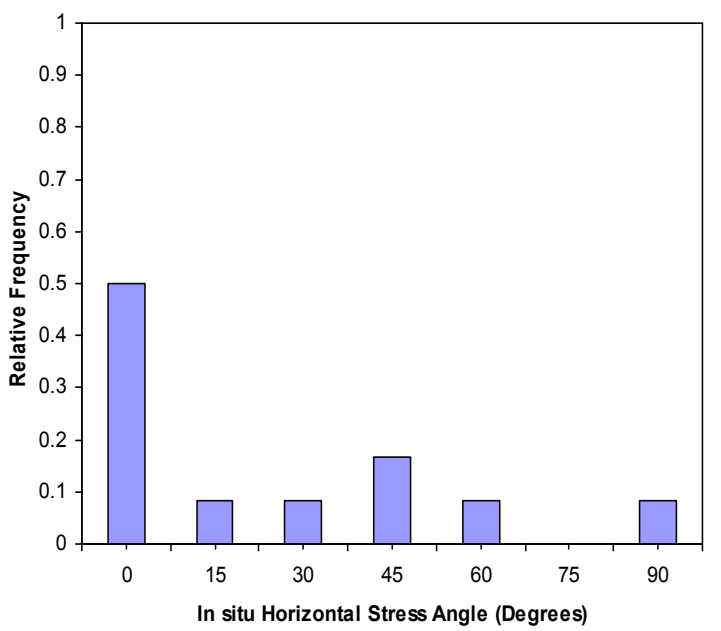

(b)

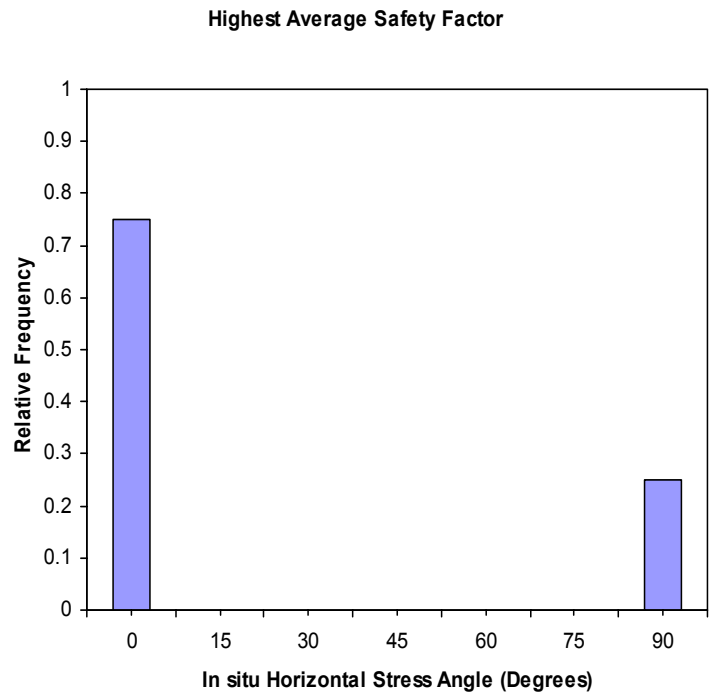

Lowest Average Safety Factor

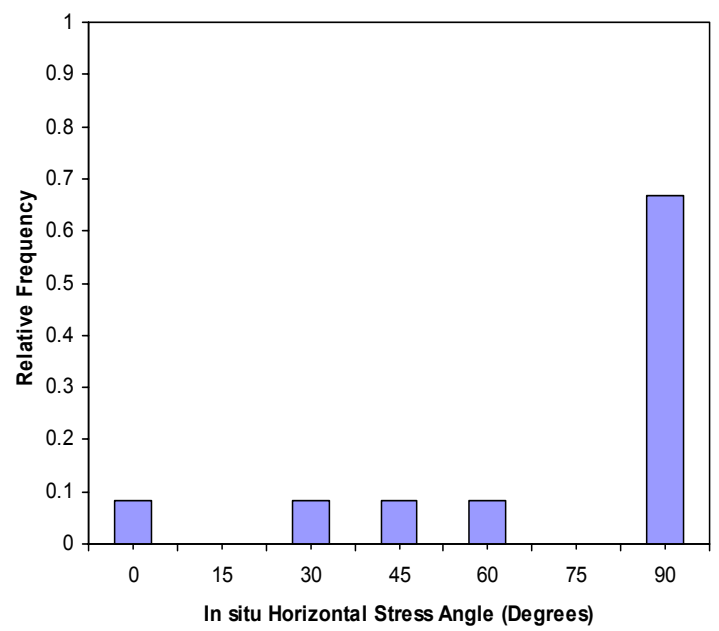

Figure 4.12. Relative frequency of observation of highest and lowest average safety factors for different in-situ maximum horizontal stress angles for (a) $\boldsymbol{k}<1$ and (b) $\boldsymbol{k}>1$ in bed 1 . 
(a)

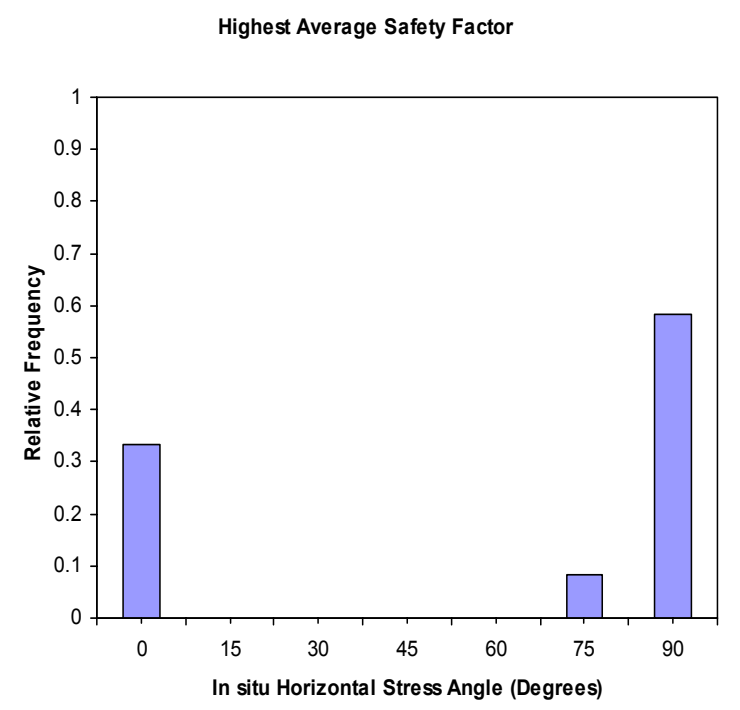

Lowest Average Safety Factor

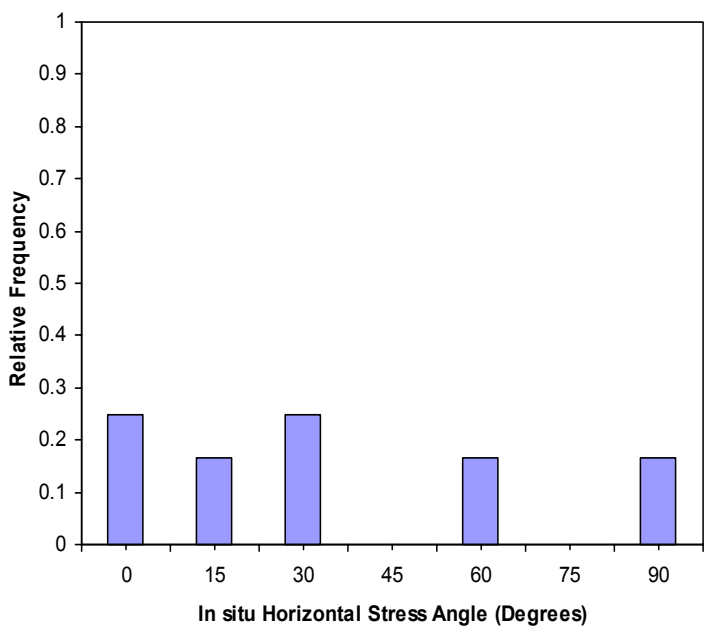

(b)
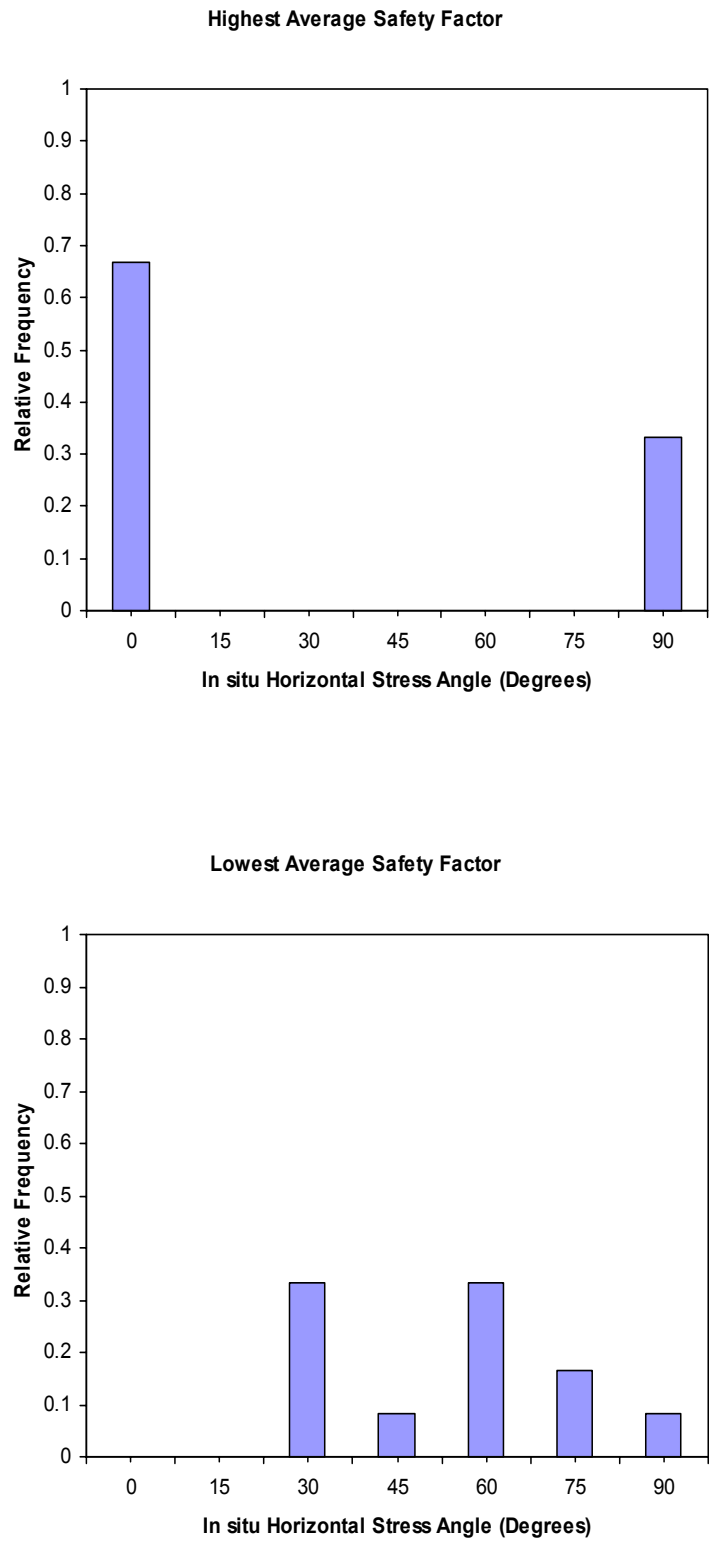

Figure 4.13. Relative frequency of observation of highest and lowest average safety factors for different in-situ maximum horizontal stress angles for (a) $\boldsymbol{k}<1$ and (b) $\boldsymbol{k}>1$ in bed 2 . 
(a)

Highest Average Safety Factor

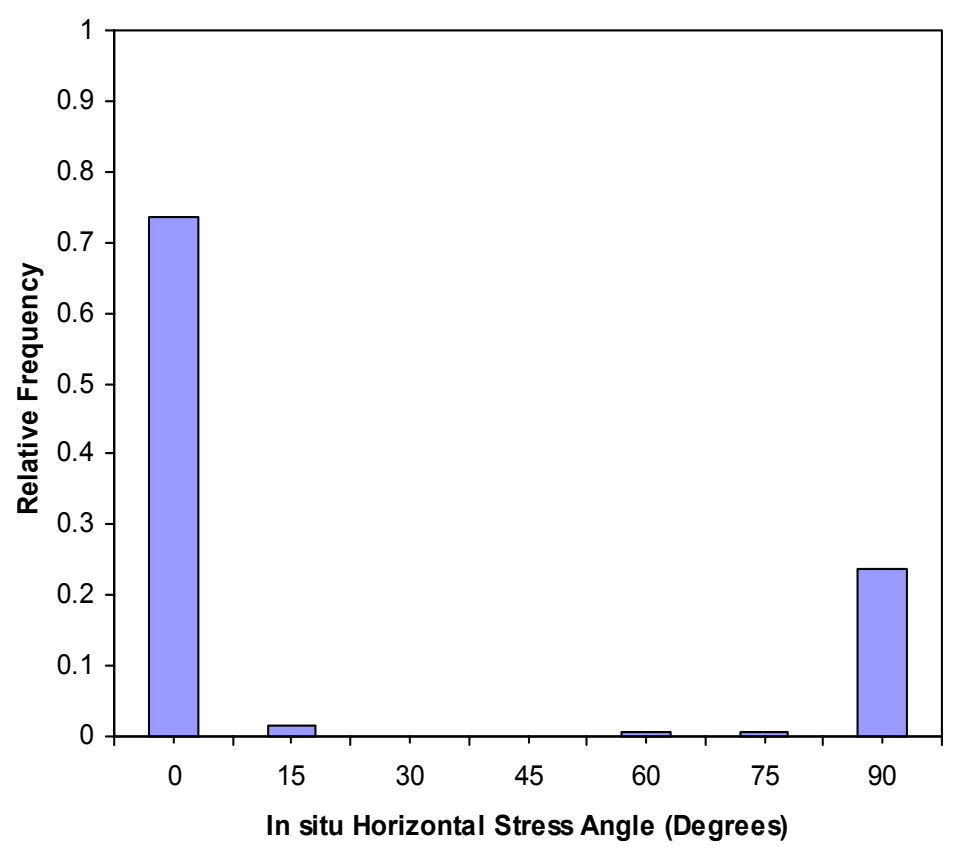

(b)

Lowest Average Safety Factor

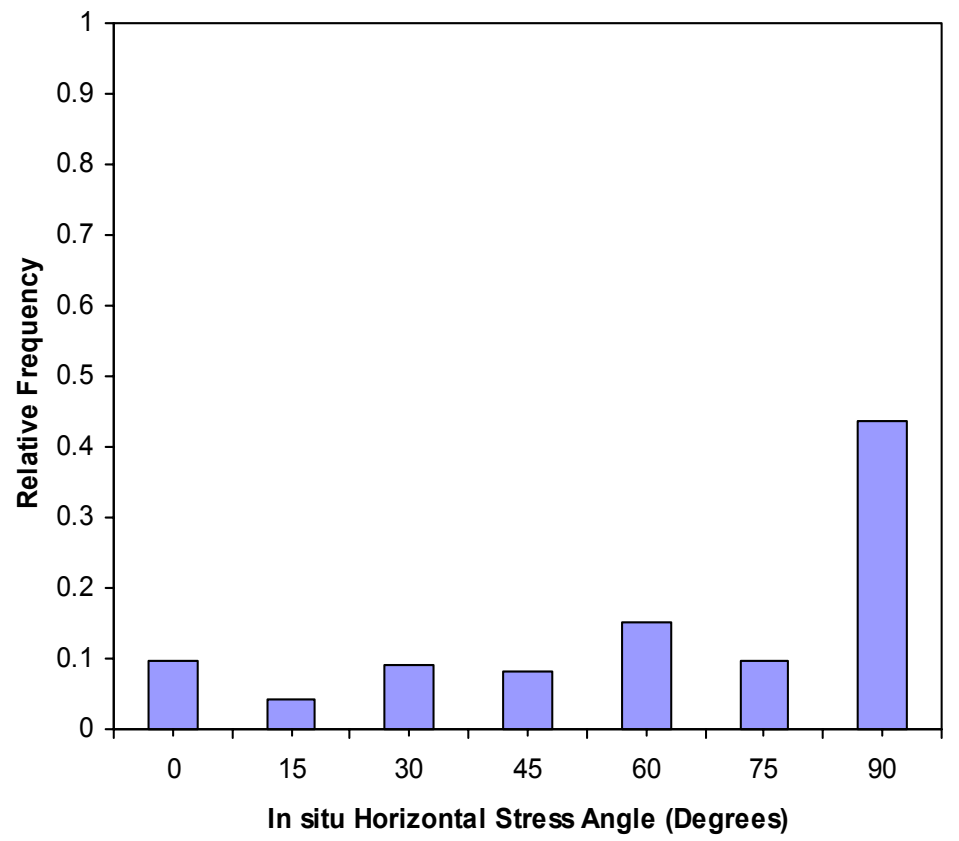

Figure 4.14. Combined plot of relative frequency of observation of (a) highest and (b) lowest average safety factors for different in-situ maximum horizontal stress angles. 


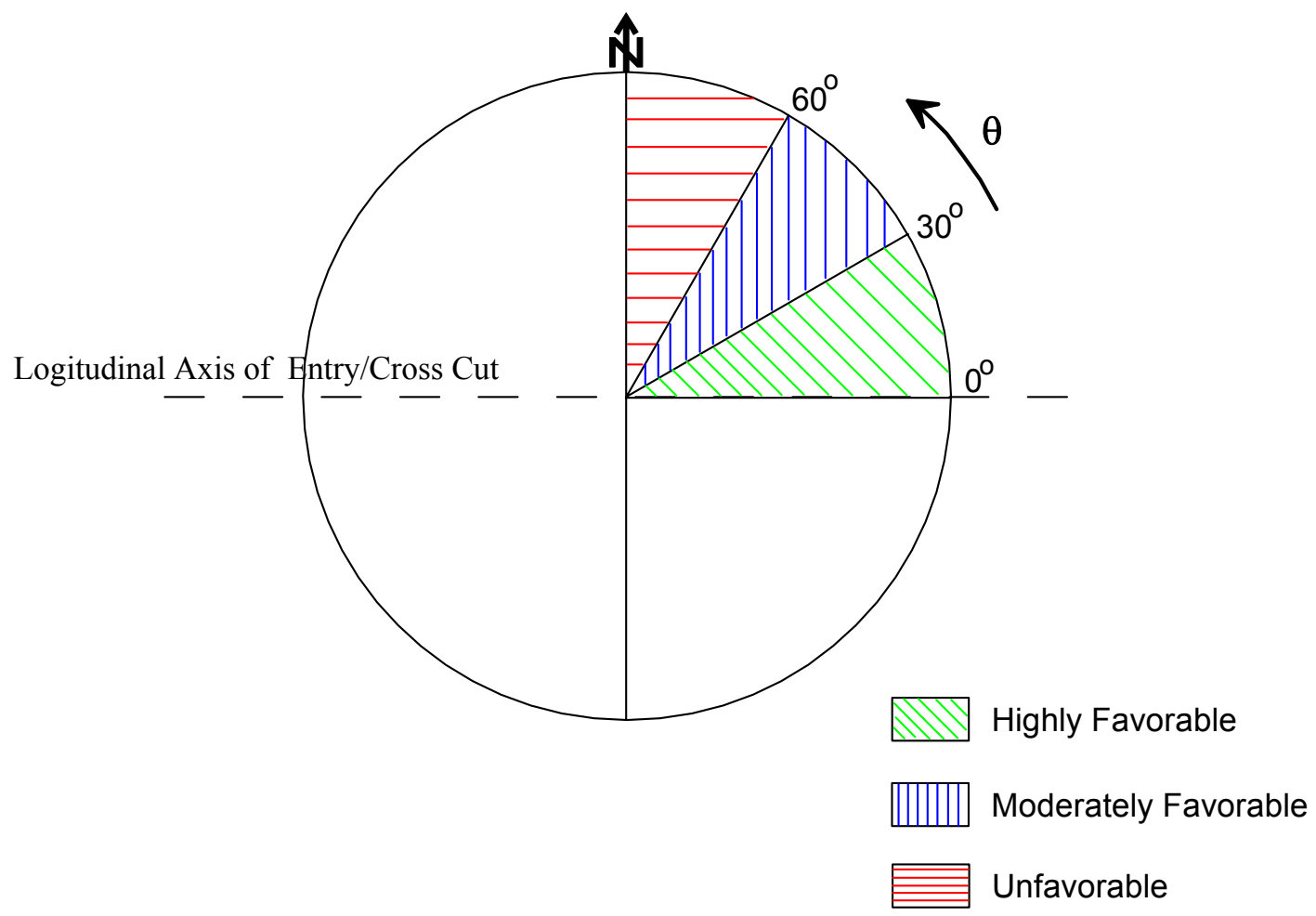

Figure 4.15. Design chart for the orientation of development entries in coal mines.

\subsection{Intersections}

Intersections are the most critical parts of a coal mine development layout. On a per unit linear footage basis, intersection are 8-10 times more susceptible to failures than entries [30]. Despite this, there are only limited numbers of works done on this subject. Further, these works were mostly site-specific or limited by the input variables considered. There were only some sporadic attempts made in the past to analyze the stability of intersections using numerical modeling [16]. This dearth of analytical research on the subject is mainly because of the complex three dimensional effects that need to be considered for the intersection stability analysis. As far as the author is aware, there are no available published numerical modeling works that deal with the effect of in-situ maximum horizontal stress angle on the stability of intersections. 
The next step of the research in this thesis tries to address the issue of the effect of in-situ maximum horizontal stress angle on the stability of intersections. Since, a four way intersection is more unstable than a three way intersection, only the former one is analyzed in this work. It is a tradition in coal mine ground control research to analyze the stability of an intersection along its two diagonals as they represent its maximum spans. The geometry and the two diagonal sections, JJ and

$\mathrm{KK}$, at which the results are obtained, are shown in Figure 4.1. Since the geometry is symmetric along these two diagonal sections, the magnitude of stresses and safety factors will be the same for any $\theta$ and its complement. This means, the safety factors along these diagonal will have same magnitudes for $\theta=0^{\circ}$ and $90^{\circ}$, for example. However, it was noticed that the directions of induced principal stresses are different in these two cases and are closer to the in-situ principal stress directions.

\subsubsection{Section JJ}

Similar to different sections in the entry, average safety factors for all beds within a distance equal to one entry width from the roofline were obtained for section $\mathrm{JJ}$ in the intersection. The change in safety factors with change in the direction of insitu maximum horizontal stress are shown in Figure 4.16 to Figure 4.17.

The relative frequency of occurrence of highest and lowest average safety factors for different $\theta$ values are shown in Figure 4.18. From these figures, the following points are noted:

I The maximum stable orientation in general is $0^{\circ}$ or $90^{\circ}$. Though in some cases other orientations may also yield best conditions.

I The orientation for which this cross-section has lowest stability is $45^{\circ}$. Again, as noted in different locations in the entry, under some combinations of in-situ stresses and for certain locations in the roof, least stability can be noticed for other orientations as well. 
$\underline{\text { Bed } 1}$

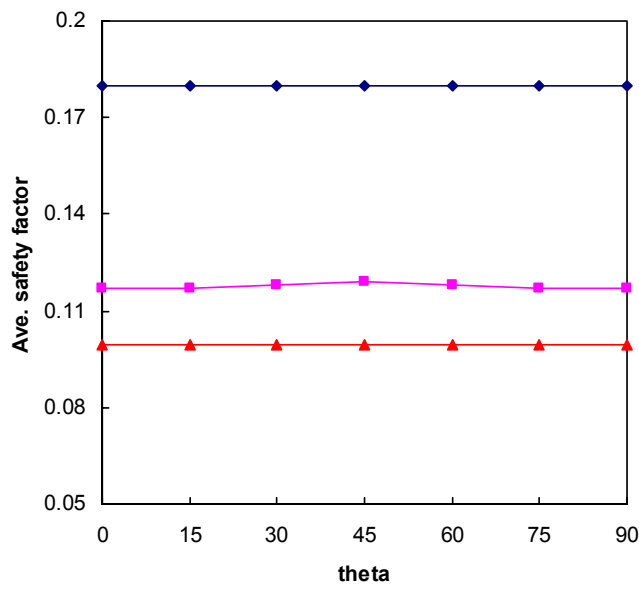

Bed 2

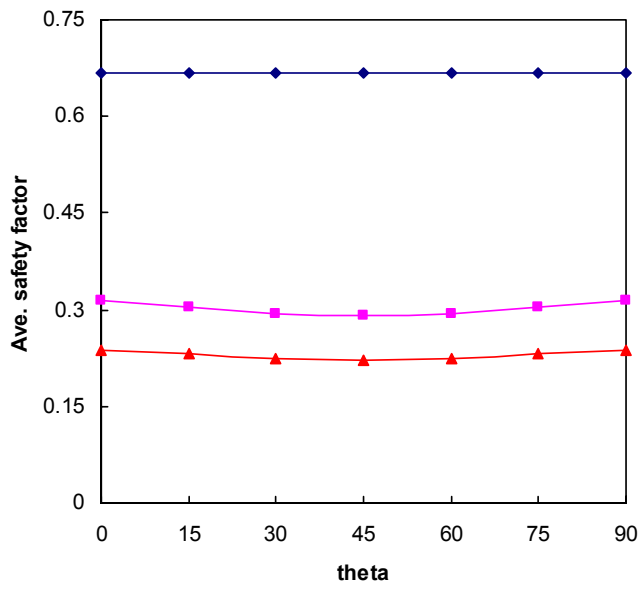

$\underline{\text { Bed } 3}$

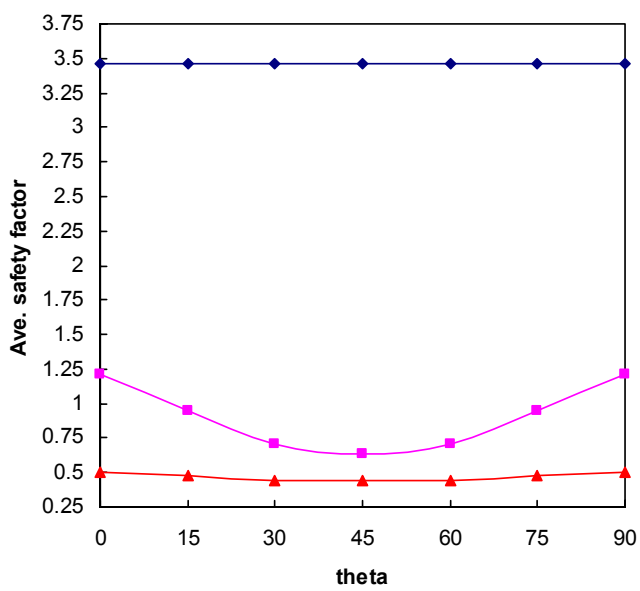

$\underline{\text { Bed } 4}$

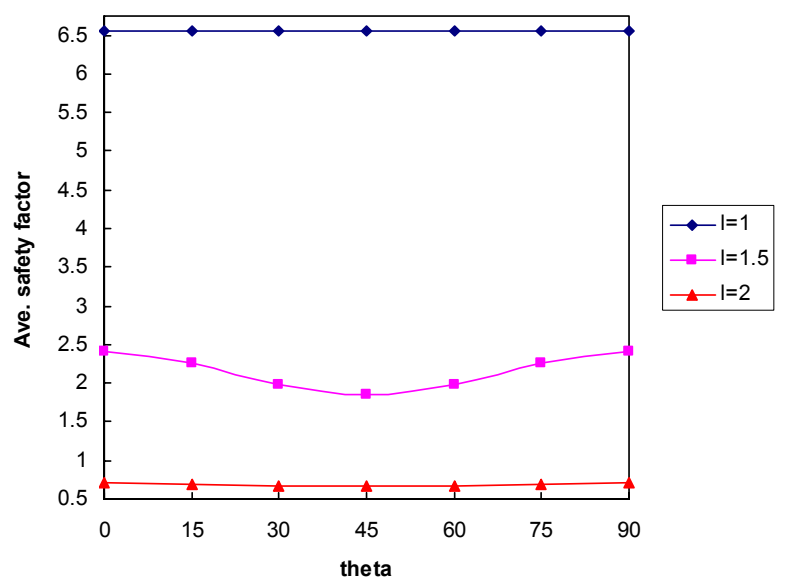

$\underline{\text { Bed } 5}$

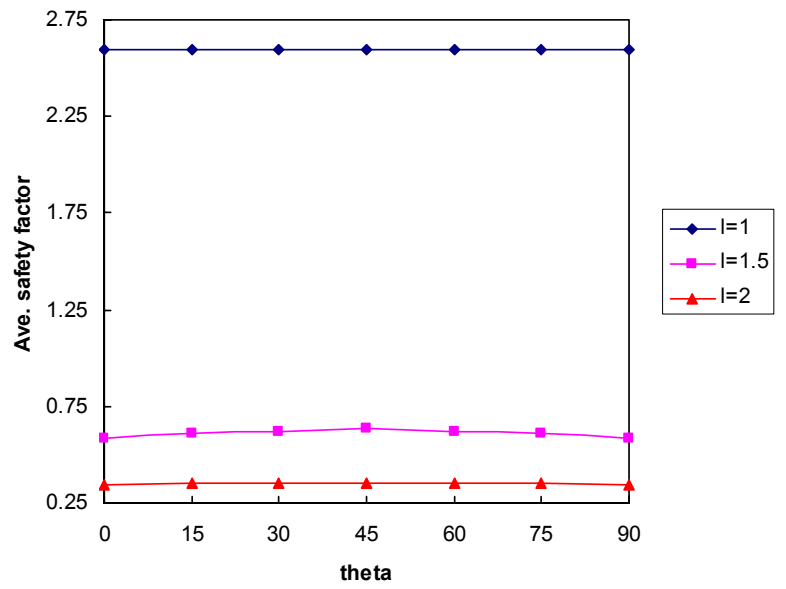

$\underline{\text { Bed } 6}$

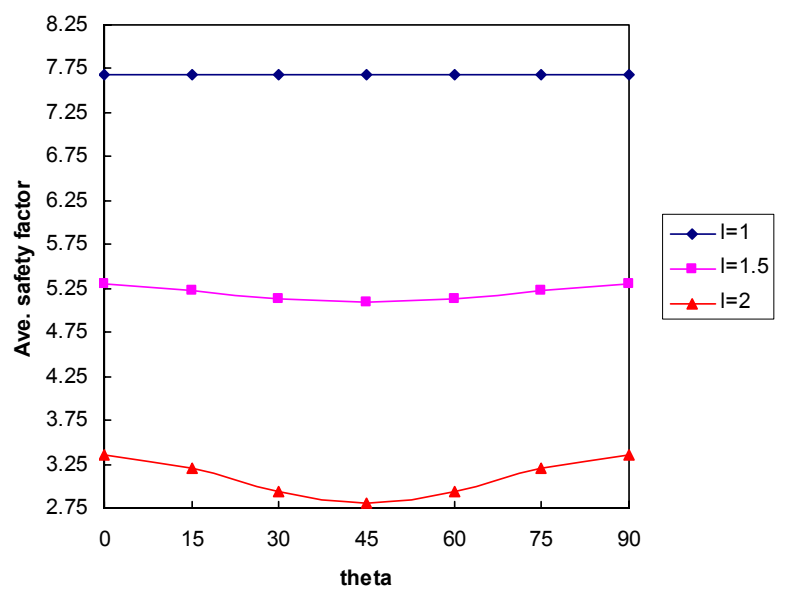

Figure 4.16. Change in average safety factors with $\theta$ (degrees) for different beds for $\boldsymbol{k}=0.3$ in cross-section JJ. 


\section{$\underline{\text { Bed } 1}$}

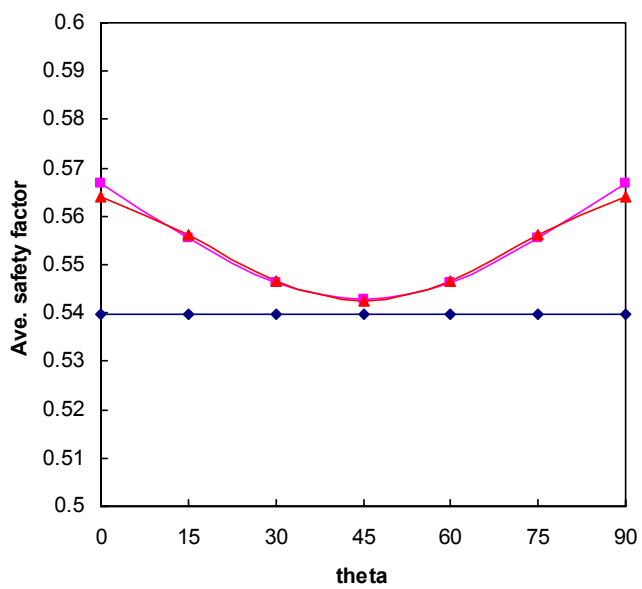

\section{Bed 2}

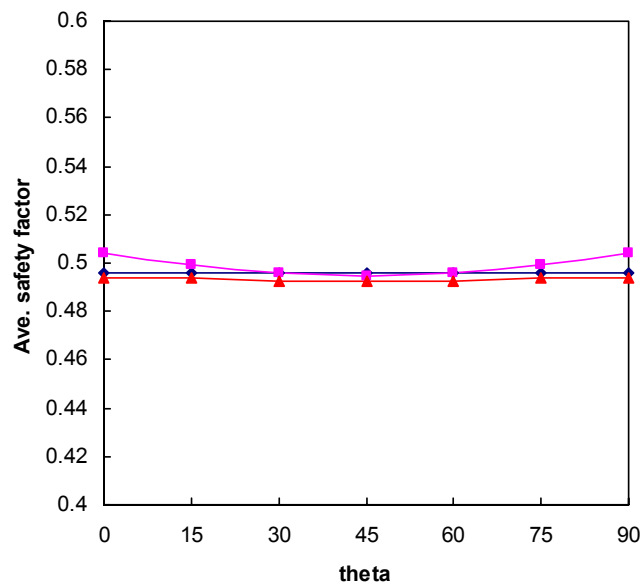

\section{Bed 3}

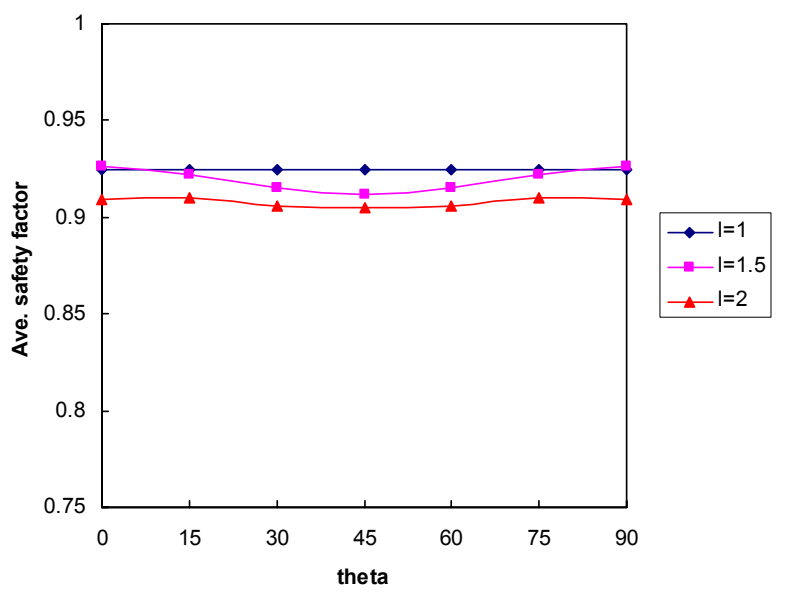

\section{$\underline{\operatorname{Bed} 4}$}

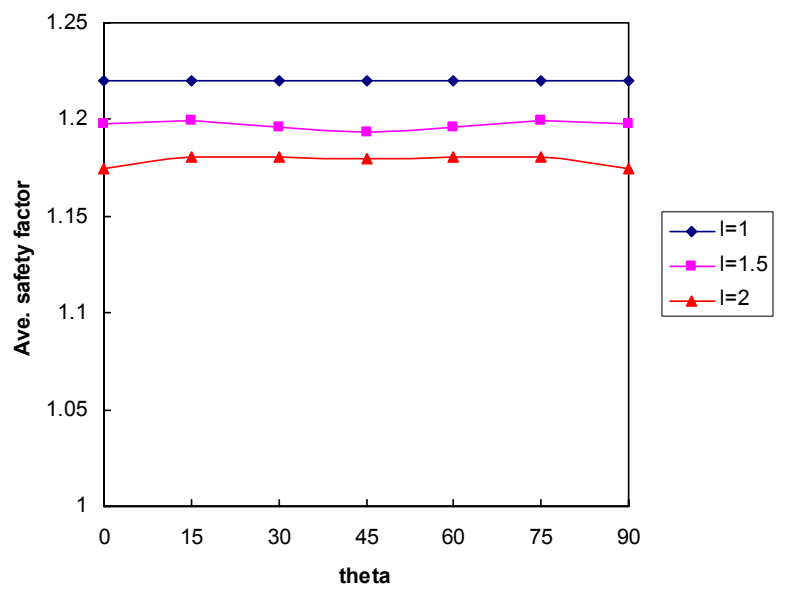

$\underline{\text { Bed } 5}$

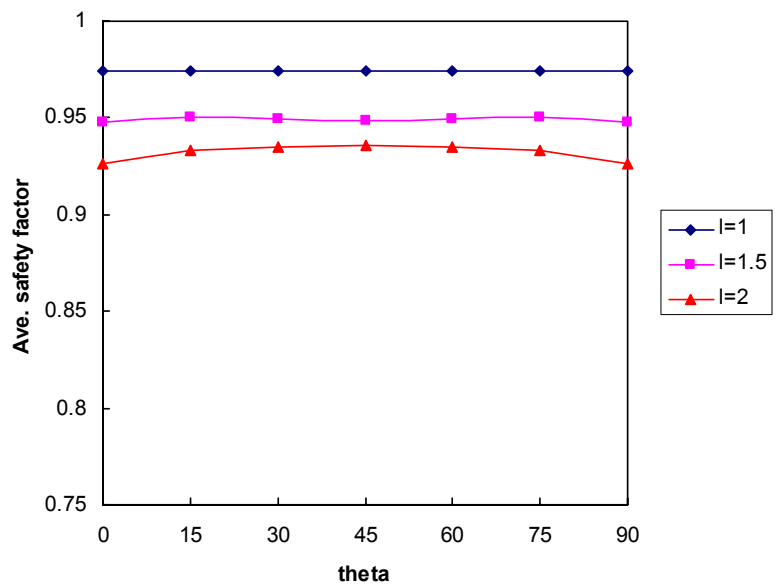

\section{Bed 6}

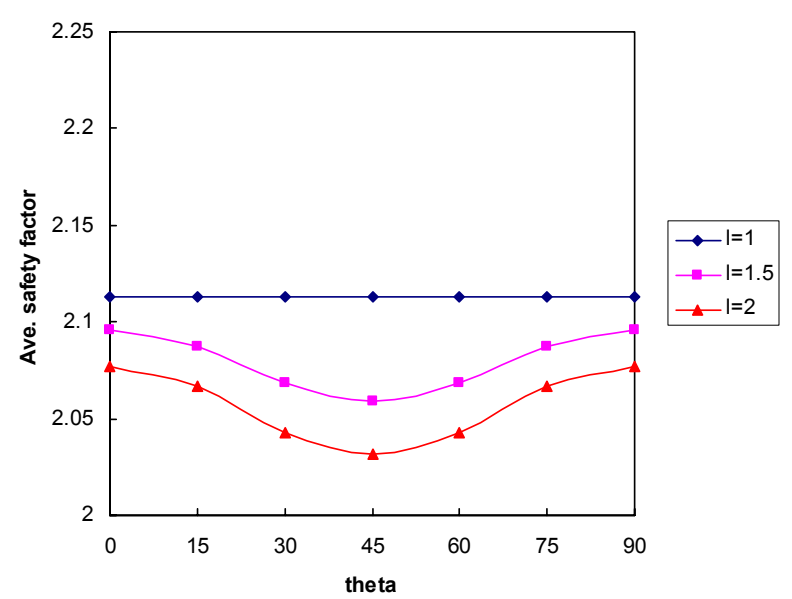

Figure 4.17. Change in average safety factors with $\theta$ (degrees) for different beds for $\boldsymbol{k}=3.0$ in cross-section JJ. 
(a)

Highest Average Safety Factor

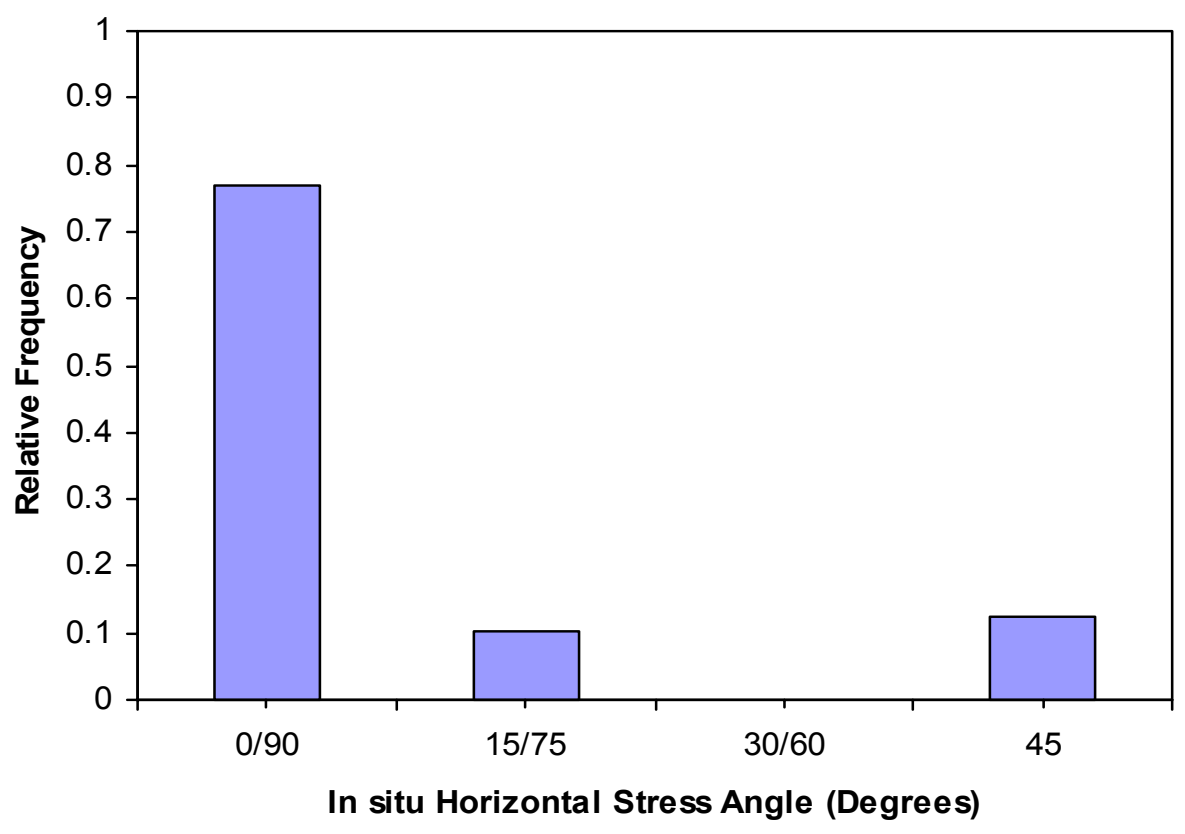

(b)

Lowest Average Safety Factor

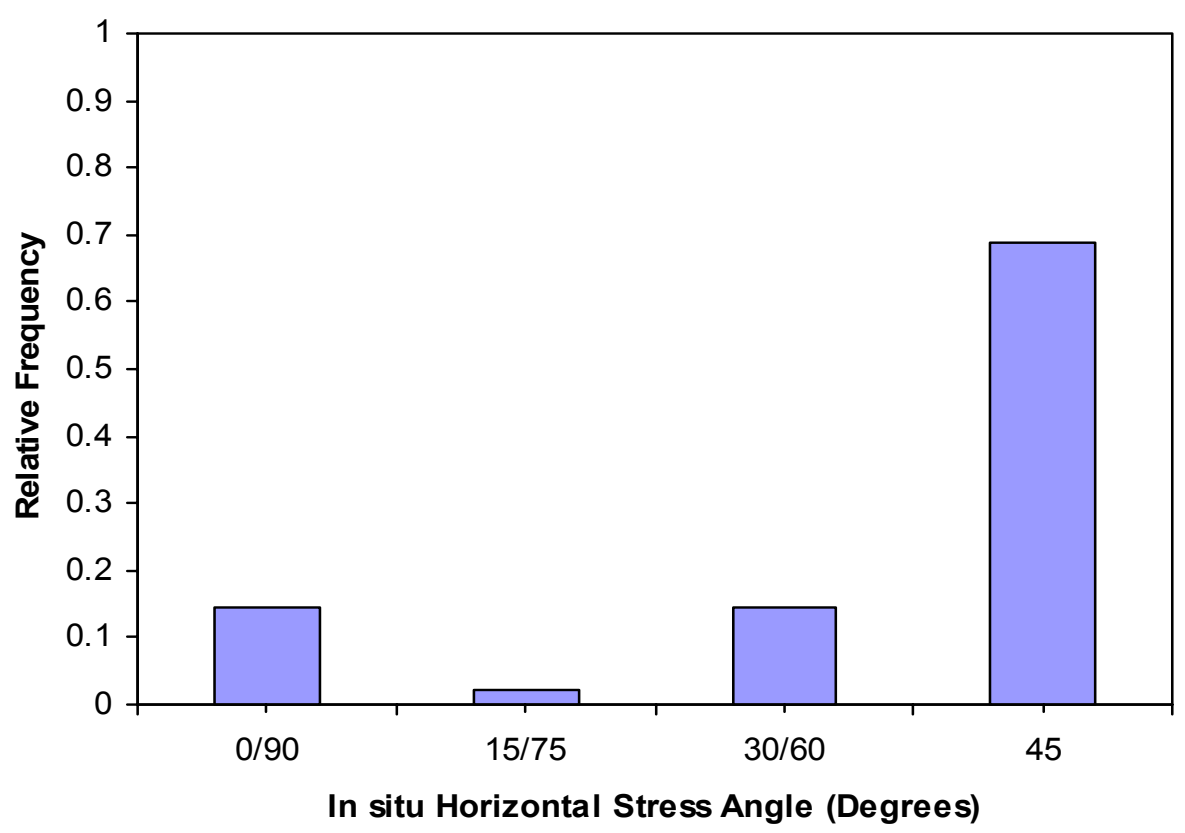

Figure 4.18. Relative frequency of observation of (a) highest and (b) lowest average safety factors for different in-situ maximum horizontal stress angles in the cross-section JJ. 


\subsubsection{Section $K K$}

Plots similar to those above are given in Figure 4.19 through Figure 4.21 for diagonal section KK. The first two of these show the variation of average safety factor while the last one shows the relative frequency of the highest and the lowest safety factors. The following are the observations from these figures.

\# There is no clear trend for the maximum stable direction. However, $0^{\circ}$ and $90^{\circ}$ directions have a little more relative frequency than other orientations.

a For the least stable orientation, there are only three directions in this case. This condition is seen at $0^{\circ}, 90^{\circ}$ and $45^{\circ}$. Another interesting feature is the percent of minimum stability at $45^{\circ}$ is a little less than $0^{\circ}$ and $90^{\circ}$.

\subsubsection{Summary Comments on Intersections}

Results in this work underscore the point that the stability of an entry and an intersection are totally different and must be treated so. Unlike the entries, there are no significant changes in the best or least stable orientations for the intersections between high and low in-situ stress fields and they follow the general trends discussed above. This is demonstrated in Figure 4.22 and Figure 4.23. This means, for the intersections, all in-situ stress regimes, i.e. both low and high horizontal insitu stress, have similar effects with regard to $\theta$.

The summary frequency diagram given in Figure 4.24 shows the general trends for the stability of intersection. These are:

a The most stable orientation for the intersection is $0^{\circ}$ or $90^{\circ}$ and the least one is $45^{\circ}$.

a For other orientations, under certain conditions maximum or minimum stability is possible. 


\section{$\underline{\text { Bed } 1}$}

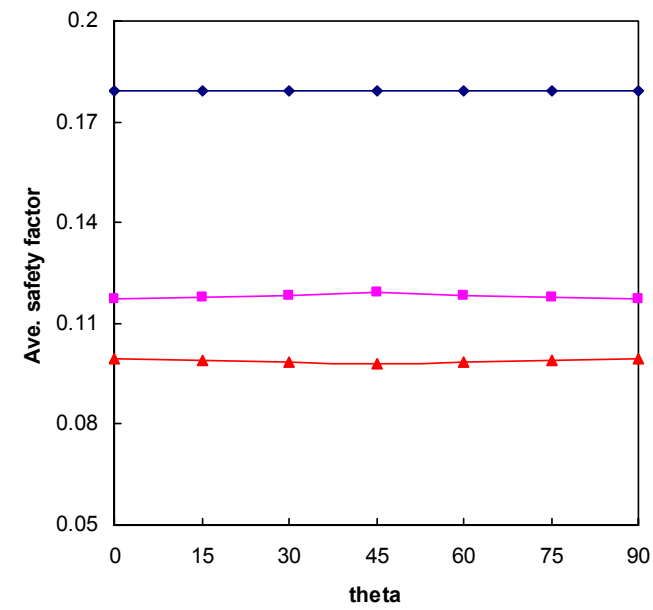

$\underline{\text { Bed } 2}$

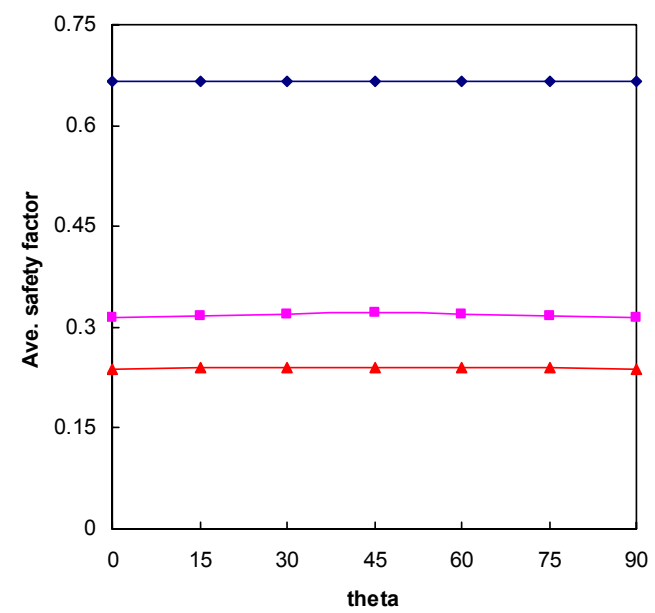

Bed 3

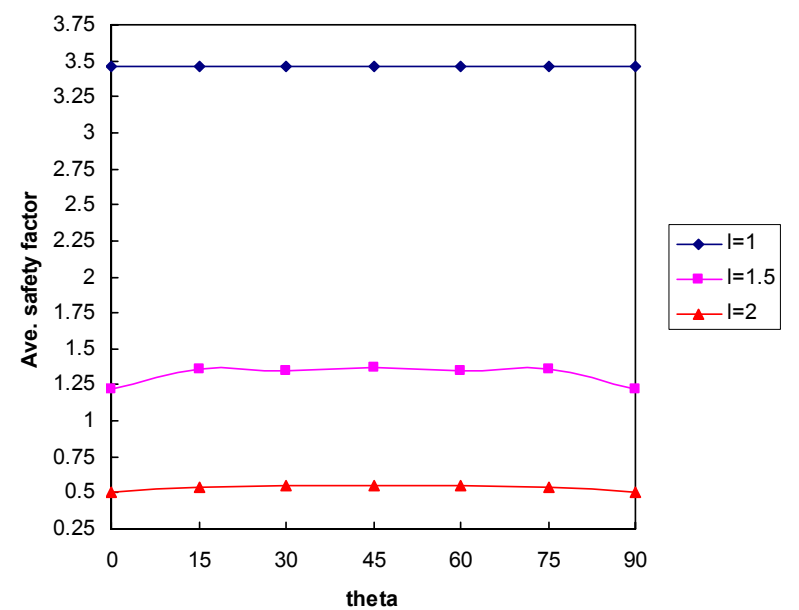

\section{Bed 4}

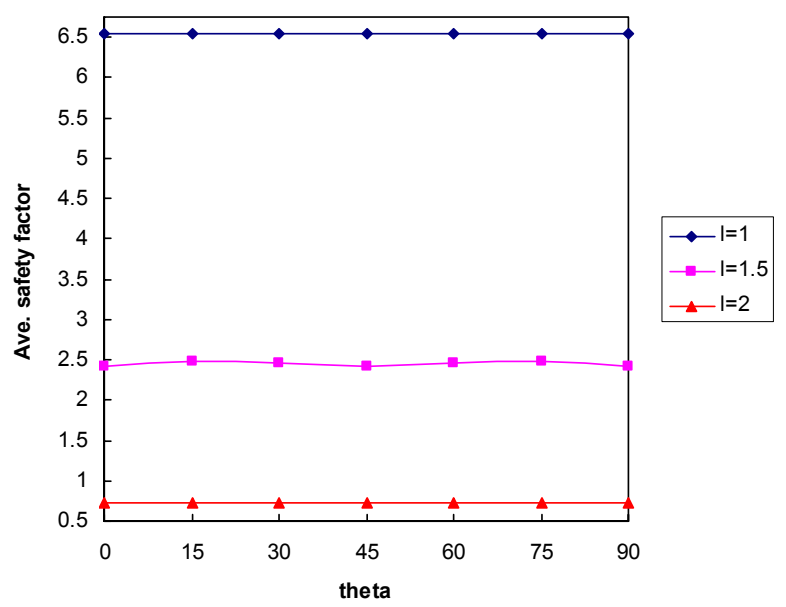

\section{$\underline{\text { Bed } 5}$}

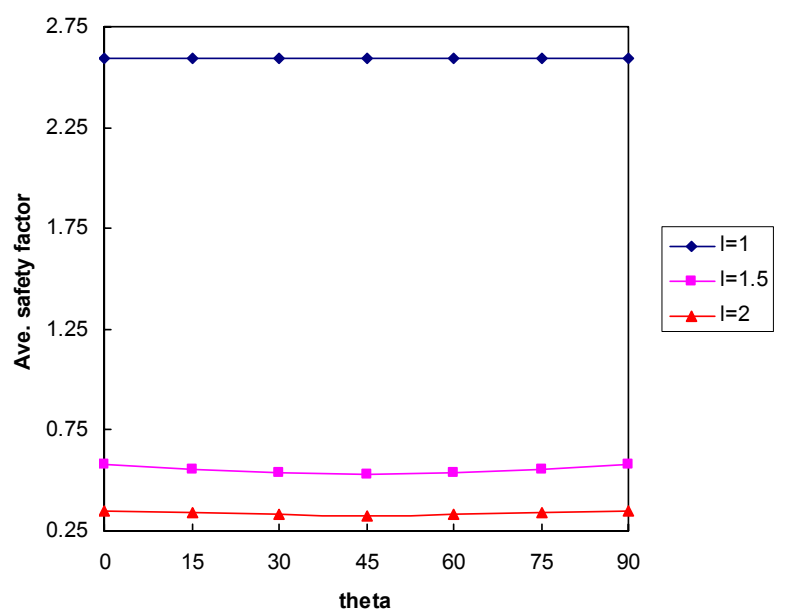

\section{Bed 6}

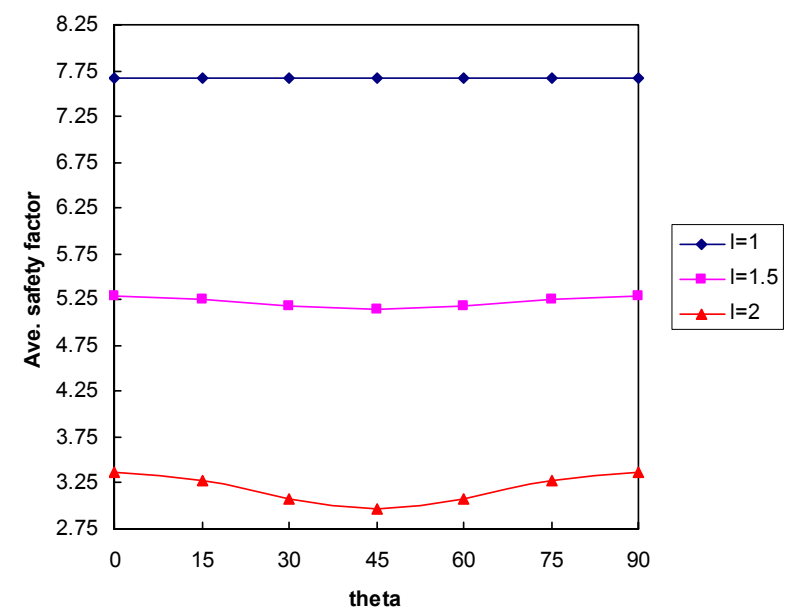

Figure 4.19. Change in average safety factors with $\theta$ (degrees) for different beds for $\boldsymbol{k}=0.3$ in cross-section KK. 


\section{Bed 1}

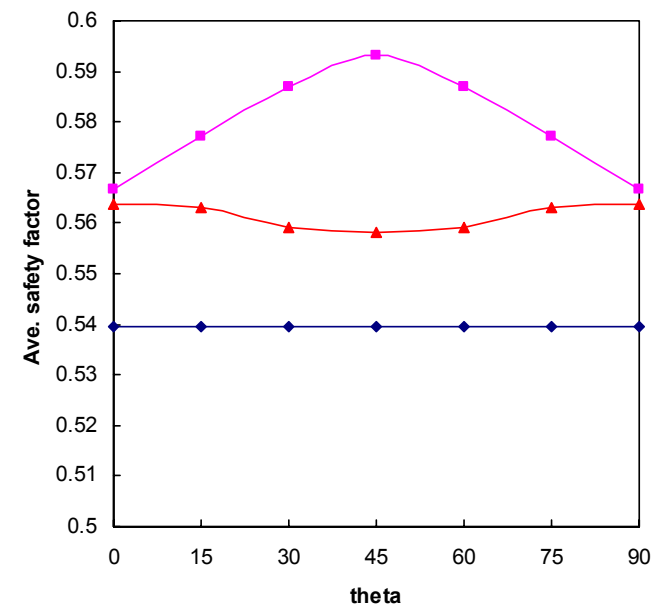

\section{$\underline{\text { Bed } 2}$}

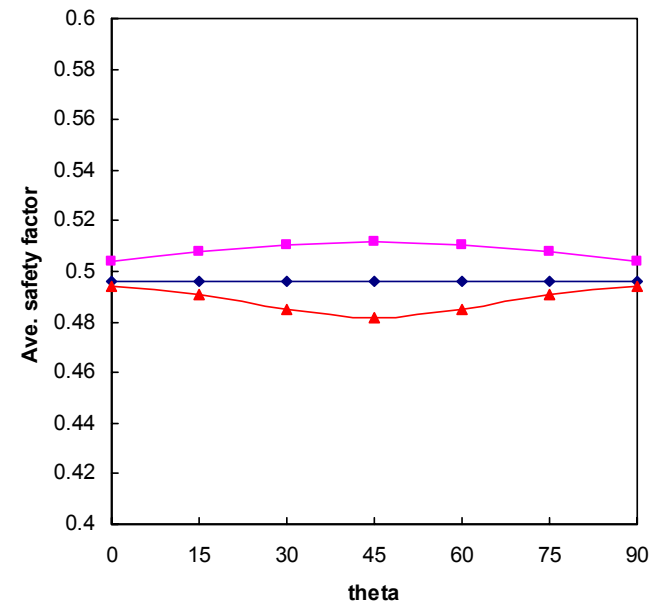

$\underline{\text { Bed } 3}$

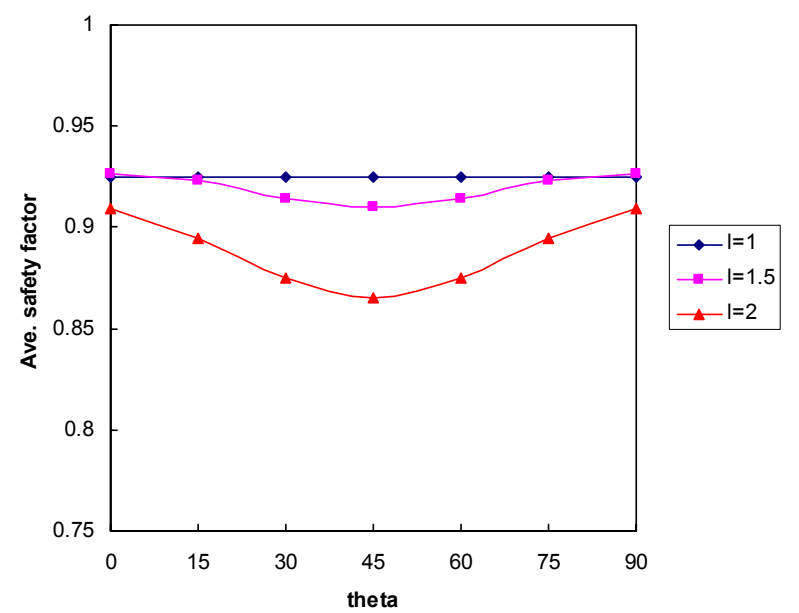

\section{$\underline{\text { Bed } 4}$}

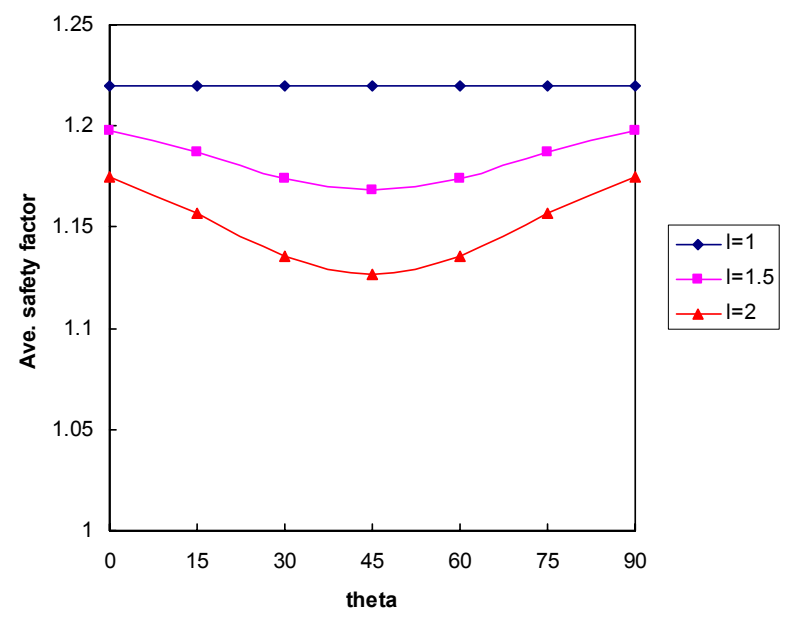

\section{$\underline{\text { Bed } 5}$}

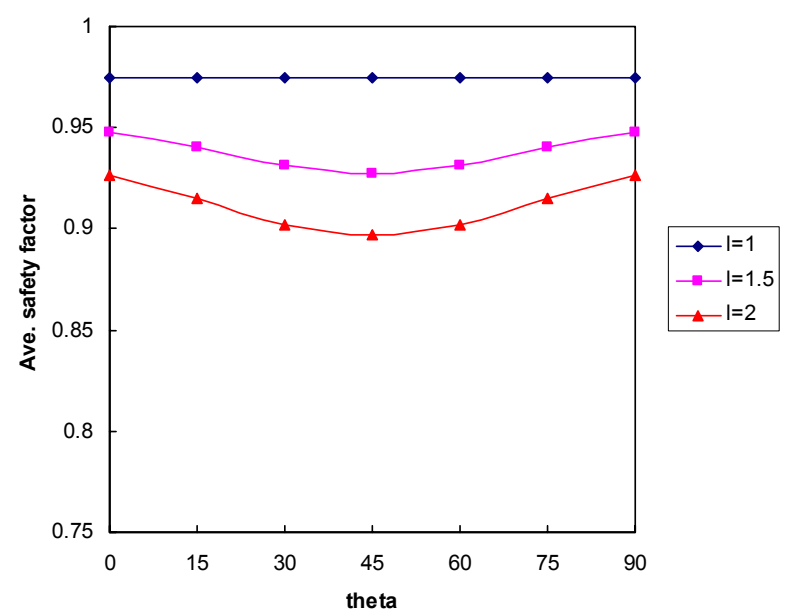

\section{$\underline{\text { Bed } 6}$}

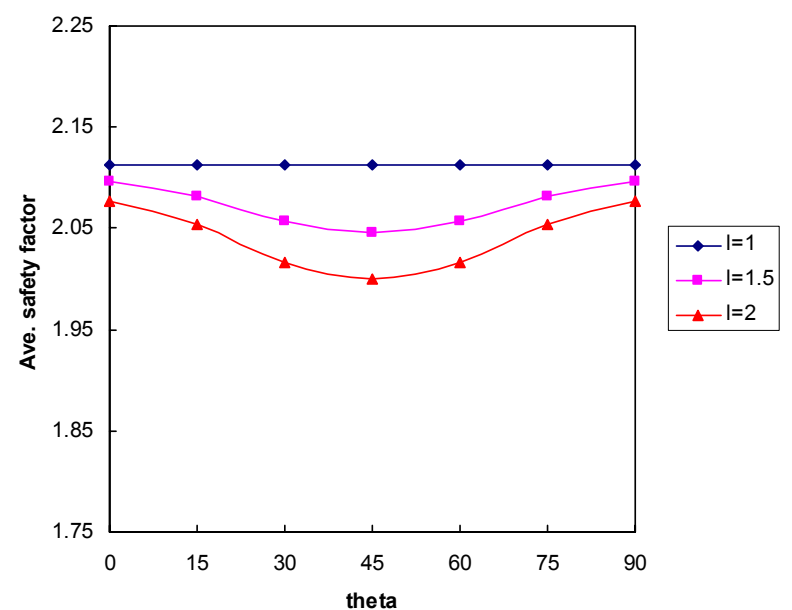

Figure 4.20. Change in average safety factors with $\theta$ (degrees) for different beds for $\boldsymbol{k}=3.0$ in cross-section KK. 
(a)

Highest Average Safety Factor

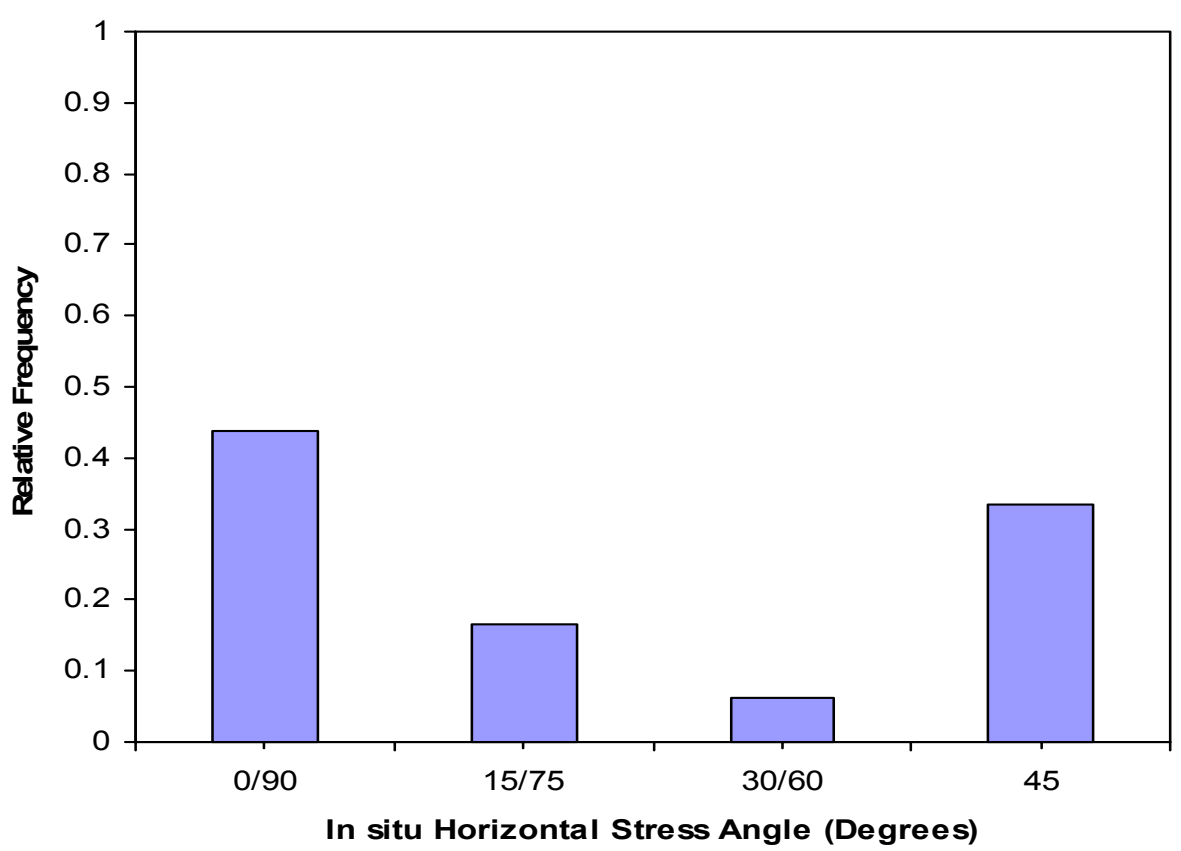

(b)

Lowest Average Safety Factor

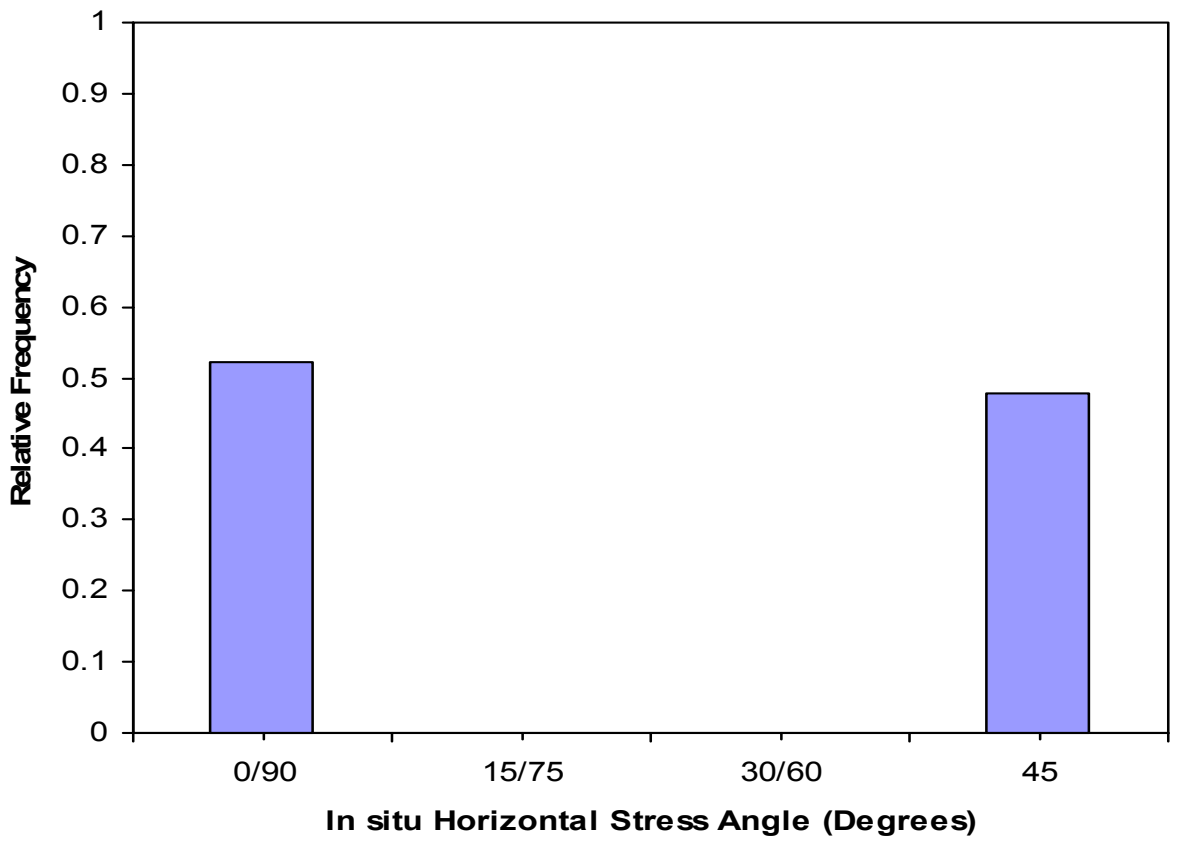

Figure 4.21. Relative frequency of observation of (a) highest and (b) lowest average safety factors for different in-situ maximum horizontal stress angles in the cross-section KK. 
(a)
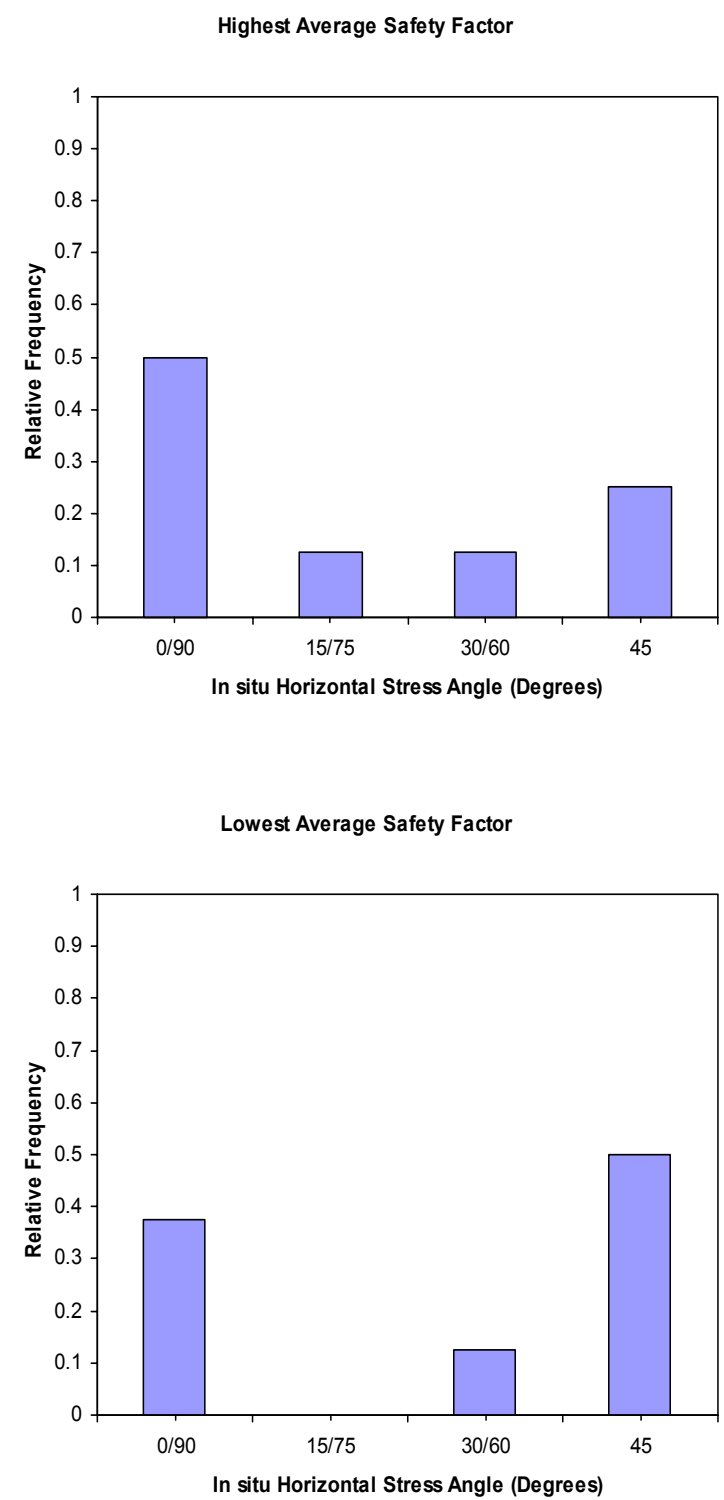

(b)

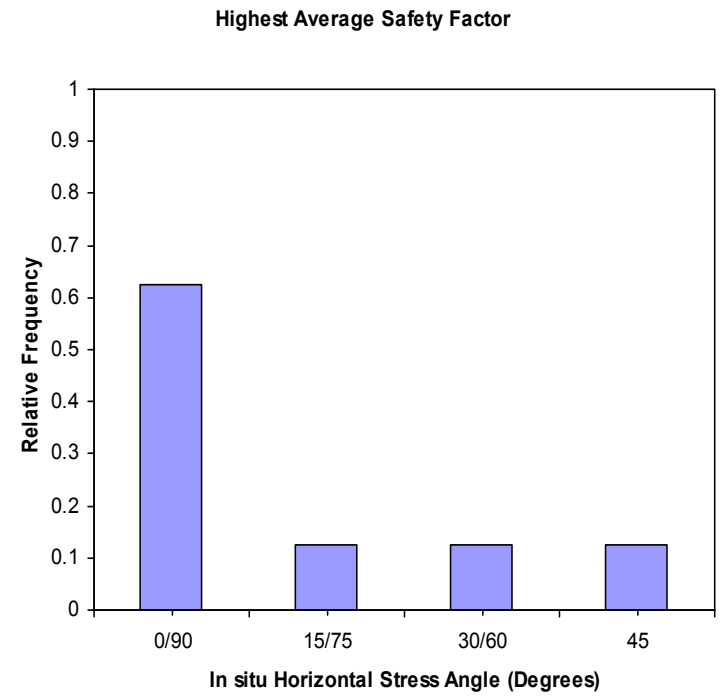

Lowest Average Safety Factor

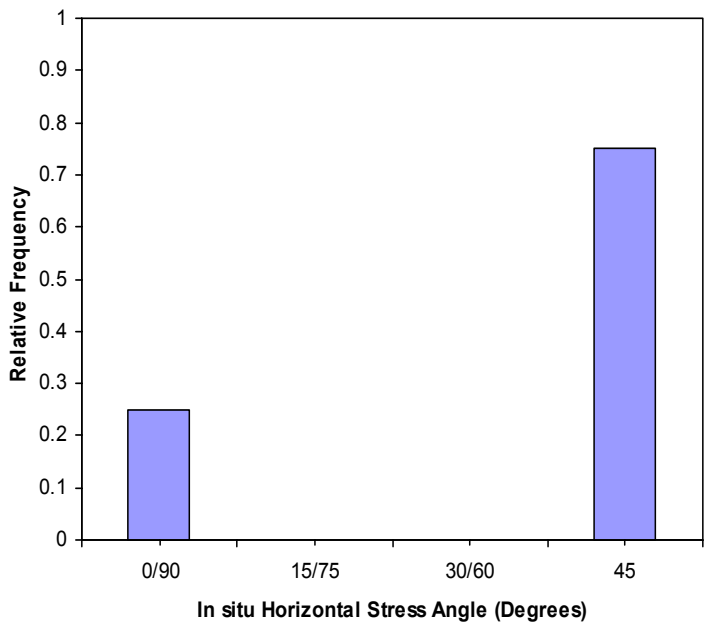

Figure 4.22. Relative frequency of observation of highest and lowest average safety factors for different in-situ maximum horizontal stress angles for (a) $\boldsymbol{k}<1$ and (b) $\boldsymbol{k}>1$ in bed 1 at the intersection. 
(a)

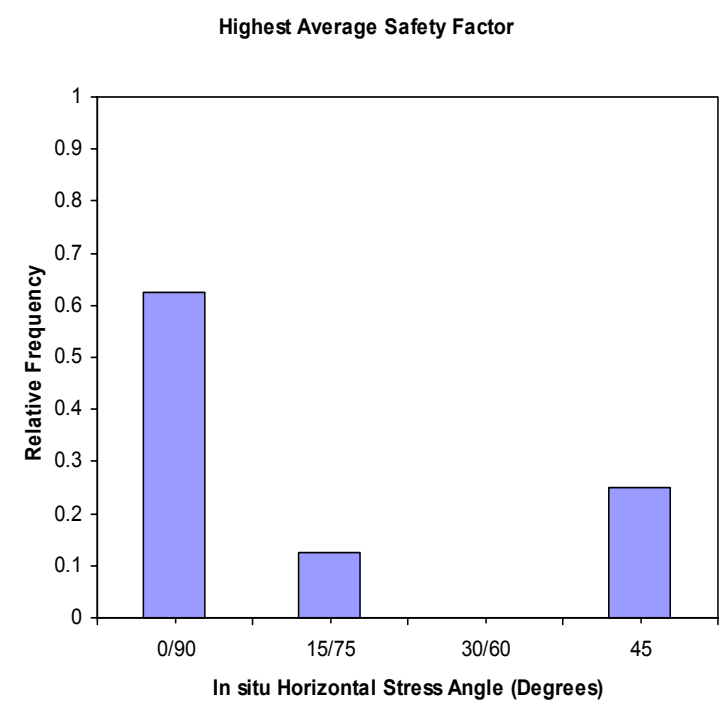

Lowest Average Safety Factor

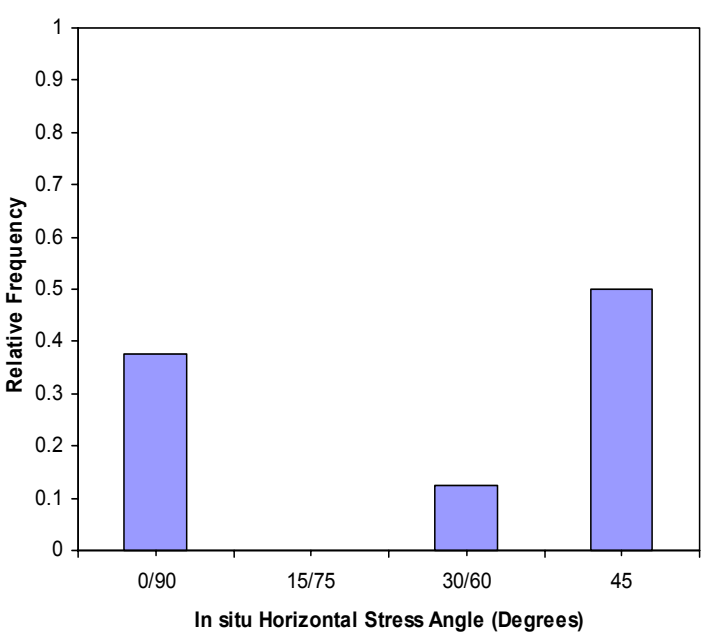

(b)
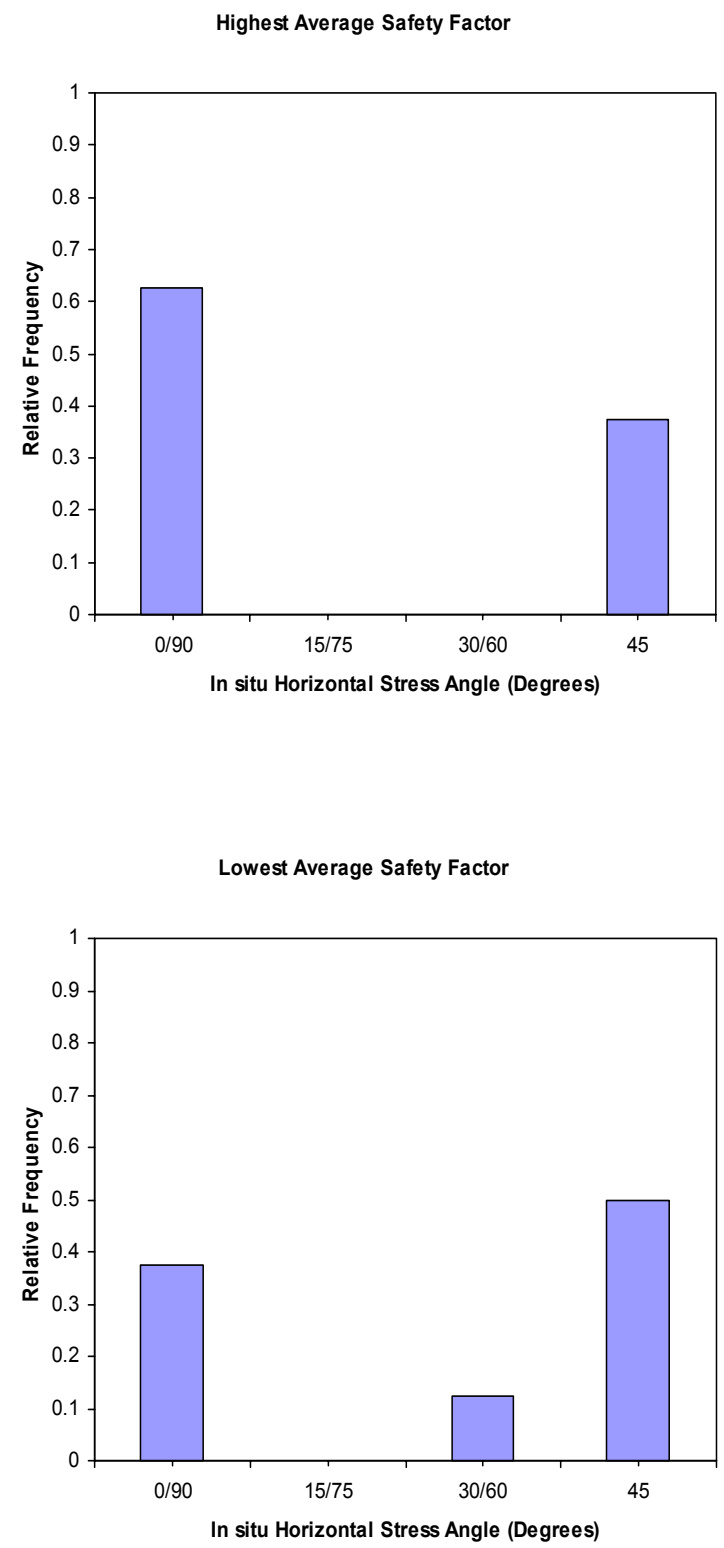

Figure 4.23. Relative frequency of observation of highest and lowest average safety factors for different in-situ maximum horizontal stress angles for (a) $\boldsymbol{k}<1$ and (b) $\boldsymbol{k}>1$ in bed 2 at the intersection. 
(a)

Highest Average Safety Factor

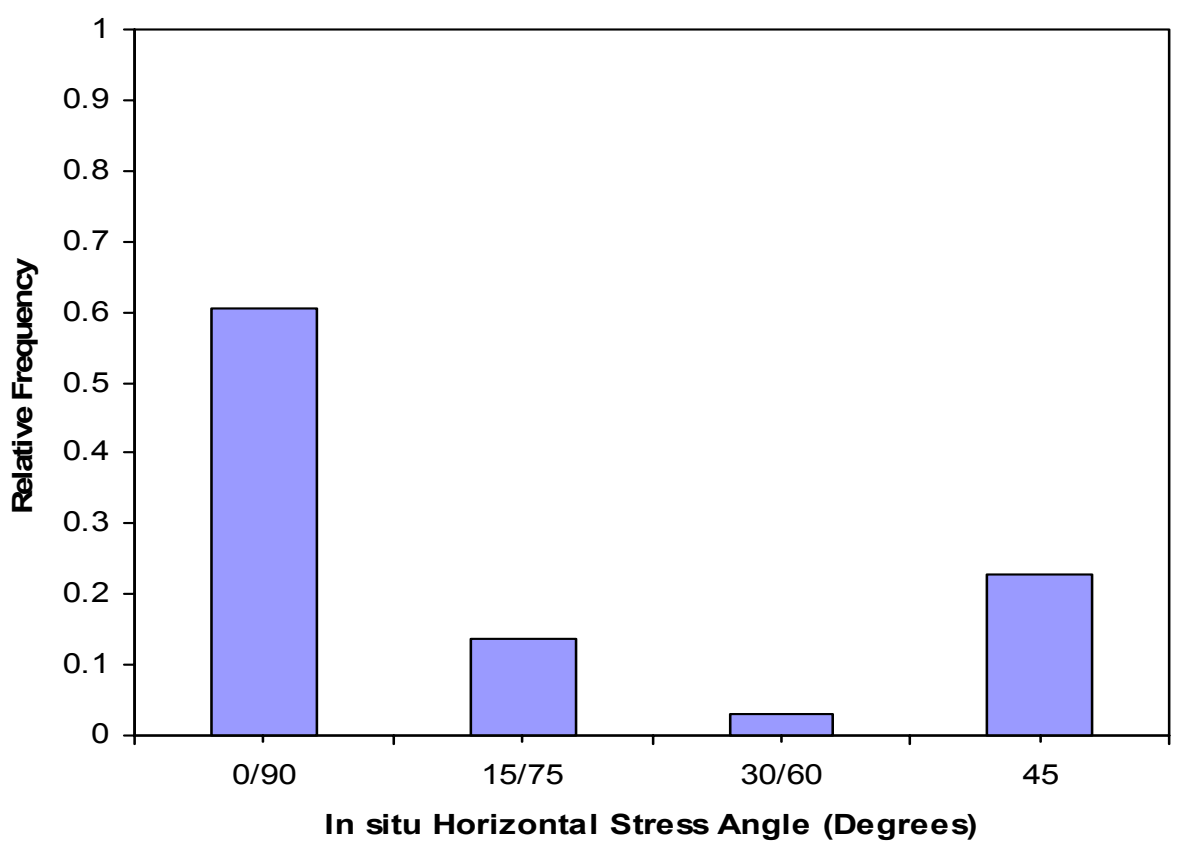

(b)

Lowest Average Safety Factor

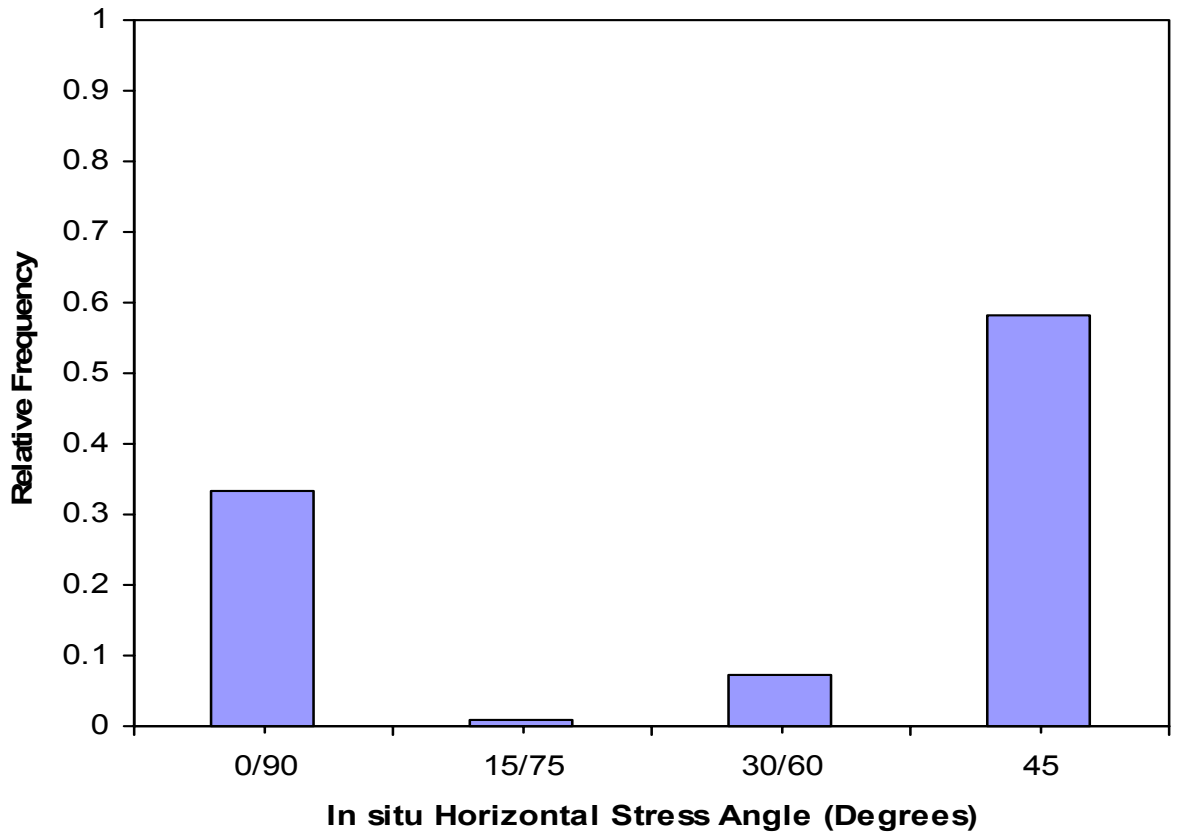

Figure 4.24. Combined plot of relative frequency of observation of (a) highest and (b) lowest average safety factors for different in-situ maximum horizontal stress angles in the intersection. 
Based on the above discussions, the design chart shown in Figure 4.25 is developed for choosing proper orientation for the intersections with respect to the maximum horizontal stress. As explained above the average safety factor has the same value for any $\theta$ and its complement. Therefore, the ground conditions chart below has symmetry at a $\theta$ value of $45^{\circ}$.

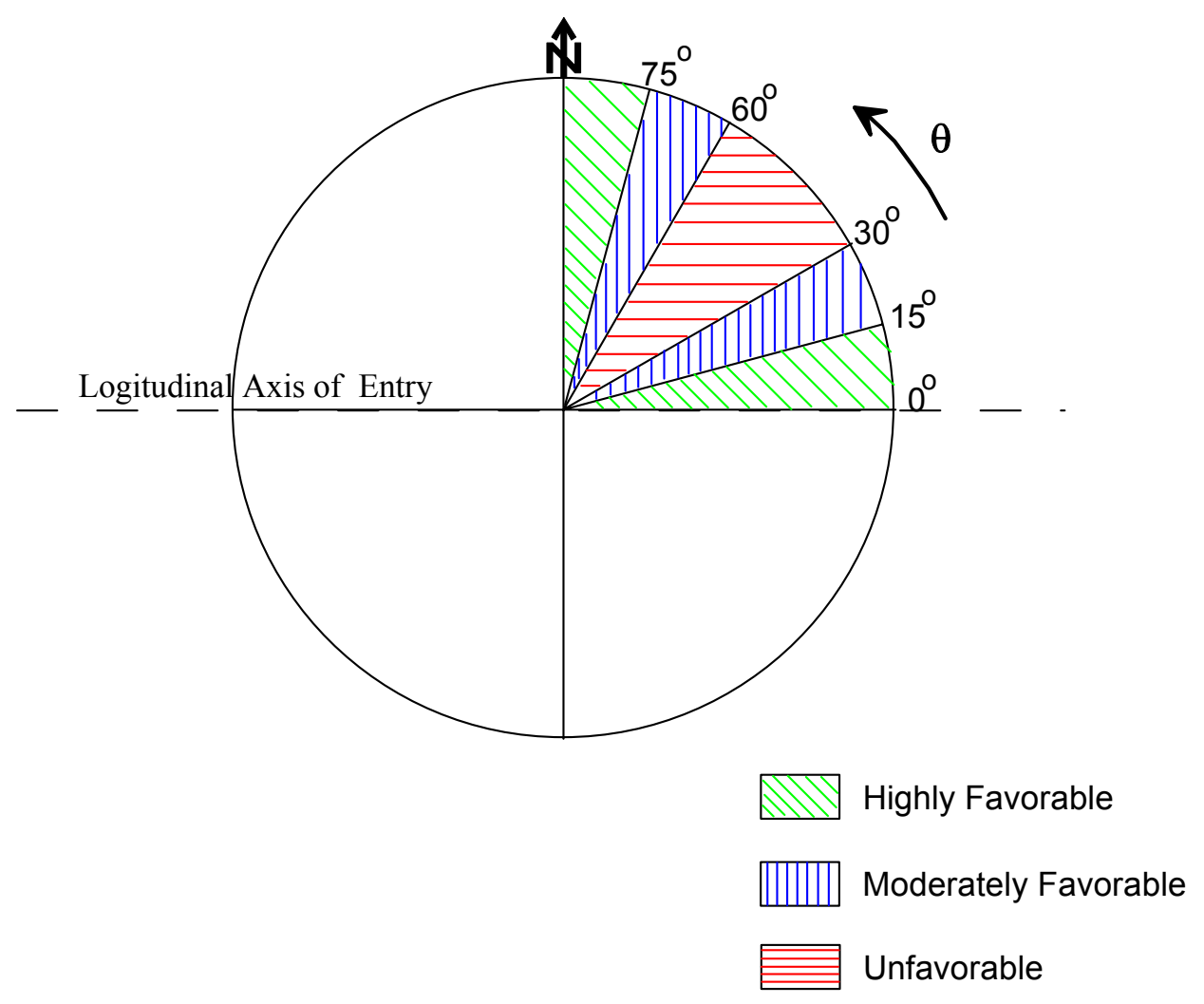

Figure 4.25. Design chart for the orientation of intersections in coal mines.

\subsection{Reorientation Effects}

When the directional effects of in-situ horizontal stresses are noted in a mine, the most frequent and the popular remedial measure adopted is the entry reorientation. As explained above, changing the direction of an entry or intersection does have some influence on its stability. However, in some instances it was also 
noted that the improvement in ground conditions with reorientation was not substantial.

Based on the results obtained in the present work an analysis has been made to see the percentage improvement that can be realized by changing an entry or intersection's orientation. This is done by comparing the best and the worst average safety factors obtained from the models run for different combinations of input. The results are summarized in Table 4.1 and 4.2. These tables show the maximum and the minimum percentage increase obtained for different beds under different combinations of in-situ stress fields. The percentage increase was calculated as

$\%$ increase $=\frac{(\max \text { imum average safety factor }- \text { min imum average safety factor })}{\min \text { imum average safety factor }} \times 100$

For each bed, the minimum and maximum safety factors in the equation 4.1 were picked up based only on their arithmetic value and irrespective of the $\theta$ value at which they were noticed. After the percentage of increase was calculated for all sections for every combination of input values, they were grouped in to low and high in-situ stress fields. Among these grouped values, the lowest and the highest \% increases were noticed and reported in Tables 4.1 and 4.2.

From these tables, for the geo-mining conditions considered, the following points are notable:

(a) For $\boldsymbol{k}>1$,

I At the face area, the percentage of improvement realized by reorientation is less than $10 \%$. However, in the mid portion and near the intersection, the improvement in the entry condition is substantial in the immediate roof beds.

II In the intersection, the change is less than $7 \%$. 
(b) For $\boldsymbol{k}<1$

\# Surprisingly, the effect of reorientation seems much more apparent for low horizontal stress fields. This is true for both entries and intersections. In fact, the percentage improvement can reach as high as about $236 \%$ for the entry and about $90 \%$ for the intersection.

These findings were totally unforeseen and further analysis into the nature and magnitude of the induced stresses supported these trends. To summarize, the very high gains for low in-situ horizontal stress fields is mainly because of the reduction in the tensile induced minimum principal stress with change in $\theta$. Since rock is very weak in tension even a small reduction in tension value makes lot of difference to its strength. On the other hand the near compressive and/or compressive minimum principal stresses for $\boldsymbol{k}>1$ changed very little with orientation and so did the triaxial rock mass strength. However, it is not clear whether the same trends will be noticed for different lithologies or geo-mining conditions. Further work is required to gain more insights into this issue.

Table 4.1. Percentage increase in the safety factors for different cross-sections in the entry for different stress fields with change in $\theta$.

\begin{tabular}{|c|c|c|c|c|c|c|c|}
\hline \multirow{2}{*}{$\begin{array}{c}\text { Bed } \\
\text { Number }\end{array}$} & \multirow{2}{*}{$\begin{array}{l}\text { Stress } \\
\text { field }\end{array}$} & \multicolumn{2}{|c|}{ Section AA } & \multicolumn{2}{|c|}{ Section BB } & \multicolumn{2}{|c|}{ Section CC } \\
\hline & & $\begin{array}{l}\text { Minimum } \\
\% \\
\text { increase }\end{array}$ & $\begin{array}{l}\text { Maximum } \\
\% \\
\text { increase }\end{array}$ & $\begin{array}{l}\text { Minimum } \\
\% \\
\text { increase }\end{array}$ & $\begin{array}{l}\text { Maximum } \\
\% \\
\text { increase }\end{array}$ & $\begin{array}{l}\text { Minimum } \\
\% \\
\text { increase }\end{array}$ & $\begin{array}{l}\text { Maximum } \\
\% \\
\text { increase }\end{array}$ \\
\hline \multirow{2}{*}{ BED1 } & $k<1$ & 3.149 & 3.772 & 39.606 & 236.555 & 28.204 & 88.499 \\
\hline & $k>1$ & 1.713 & 5.679 & 17.424 & 22.813 & 14.671 & 21.545 \\
\hline \multirow{2}{*}{ BED2 } & $k<1$ & 4.679 & 12.860 & 7.395 & 72.969 & 7.323 & 62.663 \\
\hline & $k>1$ & 0.756 & 6.328 & 2.759 & 9.898 & 2.654 & 8.164 \\
\hline \multirow{2}{*}{ BED3 } & $k<1$ & 3.324 & 22.261 & 17.991 & 104.867 & 22.716 & 164.599 \\
\hline & $k>1$ & 3.072 & 9.021 & 2.859 & 13.322 & 1.569 & 14.468 \\
\hline \multirow{2}{*}{ BED4 } & $k<1$ & 2.394 & 14.594 & 16.655 & 38.711 & 27.490 & 176.535 \\
\hline & $k>1$ & 1.097 & 6.628 & 1.583 & 6.169 & 1.163 & 7.834 \\
\hline \multirow{2}{*}{ BED5 } & $k<1$ & 0.957 & 11.462 & 6.152 & 24.349 & 17.349 & 76.088 \\
\hline & $k>1$ & 0.402 & 4.234 & 1.453 & 5.779 & 2.626 & 8.518 \\
\hline \multirow{2}{*}{ BED6 } & $k<1$ & 0.762 & 3.467 & 10.486 & 25.682 & 25.232 & 145.607 \\
\hline & $k>1$ & 2.921 & 4.396 & 3.698 & 10.106 & 0.676 & 15.728 \\
\hline
\end{tabular}


Table 4.2. Percentage increase in the safety factors for different cross-sections in the intersection for different stress fields with change in $\theta$.

\begin{tabular}{|c|c|c|c|c|c|}
\hline \multirow{2}{*}{$\begin{array}{c}\text { Bed } \\
\text { Number }\end{array}$} & \multirow{2}{*}{$\begin{array}{c}\text { Stress } \\
\text { field }\end{array}$} & \multicolumn{2}{|c|}{ Section JJ } & \multicolumn{2}{|c|}{ Section KK } \\
\hline & & $\begin{array}{l}\text { Minimum } \\
\% \\
\text { increase }\end{array}$ & $\begin{array}{l}\text { Maximum } \\
\% \\
\text { increase }\end{array}$ & $\begin{array}{l}\text { Minimum } \\
\% \\
\text { increase }\end{array}$ & $\begin{array}{l}\text { Maximum } \\
\% \\
\text { increase }\end{array}$ \\
\hline \multirow{2}{*}{ BED1 } & $\mathrm{k}<1$ & 0.193 & 58.182 & 1.629 & 28.850 \\
\hline & $k>1$ & 3.950 & 6.941 & 0.994 & 6.028 \\
\hline \multirow{2}{*}{ BED2 } & $\mathrm{k}<1$ & 5.486 & 31.150 & 0.619 & 7.279 \\
\hline & $\mathrm{k}>1$ & 0.313 & 3.581 & 1.567 & 5.714 \\
\hline \multirow{2}{*}{ BED3 } & $\mathrm{k}<1$ & 5.454 & 90.712 & 6.361 & 12.603 \\
\hline & $k>1$ & 0.611 & 4.197 & 0.967 & 5.063 \\
\hline \multirow{2}{*}{ BED4 } & $\mathrm{k}<1$ & 2.144 & 30.773 & 1.666 & 5.450 \\
\hline & $k>1$ & 0.449 & 2.200 & 0.452 & 4.253 \\
\hline \multirow{2}{*}{ BED5 } & $\mathrm{k}<1$ & 3.214 & 9.483 & 0.733 & 10.155 \\
\hline & $k>1$ & 0.284 & 2.041 & 0.493 & 3.333 \\
\hline \multirow{2}{*}{ BED6 } & $\mathrm{k}<1$ & 5.067 & 20.169 & 1.207 & 13.014 \\
\hline & $k>1$ & 1.779 & 2.843 & 1.381 & 3.851 \\
\hline
\end{tabular}

\subsection{Case Histories}

There are many published case histories that illustrate the effect of in-situ maximum horizontal stress angle on the stability of development workings. However, for the sake of examining the validity of the findings in this work only three cases of roof failures in the development workings have been chosen and described below.

\subsubsection{Nelms No. 2 Mine, $\mathrm{OH}$}

At Nelms No.2 North reserve, a nine entry mains system, with entries oriented due North, experienced roof falls outby the face about a month after being developed [25]. The entries and crosscuts were $18 \mathrm{ft}$ wide. The crosscuts were developed at $90^{\circ}$ and $60^{\circ}$ to the entries. There was no reduction in the roof falls even after the support system was changed. A detailed geologic mapping of the area did not show any major structures responsible for these preferred failures in the NorthSouth entries. Therefore, the above average in-situ horizontal stresses were recognized as the culprit [25]. 
Underground in-situ stress measurements showed that the in-situ maximum horizontal stress was oriented $N 69^{\circ} \mathrm{E}$ with a magnitude of 2 to 3 times the vertical stress. Based on these findings, entry reorientation was recommended with a modified support system. Though the exact bearing of reoriented entries was not specified [25], it was clear from the mine map that the entries made smaller angle with $\sigma_{\mathrm{hmax}}$ in the new direction. It was also reported that the conditions improved and number of roof falls reduced significantly with these changes.

From this description, it may be noticed that the roof falls were taking place at an orientation of $69^{\circ}$ and it lies in the unfavorable zone indicated in Figure 4.15. It is also interesting to compare the design layout prepared for this mine based on field observations as shown in Figure 4.26 with the chart in Figure 4.15. The layout based on field observations match exactly with that developed from numerical modeling in this work. Similar design chart is also used in the software program, AHSEM, developed by NIOSH [2]. In the later case, no details were given as to how this design layout was developed.

\subsubsection{Mine A}

This is a case of room-and-pillar mine at a shallow depth experiencing roof falls in entries developed in some directions [39]. Based on a careful analysis of roof fall data, geologic factors had been eliminated as the cause and in-situ horizontal stresses were identified as the factor responsible for the falls. Out of 73 roof falls, 33 took place in entries oriented at $52^{\circ}$ and 37 in entries oriented at $68^{\circ}$ with $\sigma_{\mathrm{hmax}}$.

Based on only five three dimensional models, a design layout diagram has been prepared as shown in Figure 4.27. There are only two ground conditions in this chart and the angle ranges are also different as compared to Figure 4.15. However, the actual ground conditions observed in the mine could be explained from Figure 4.15. Entries in $52^{\circ}$ direction fall in the moderately favorable direction where some 


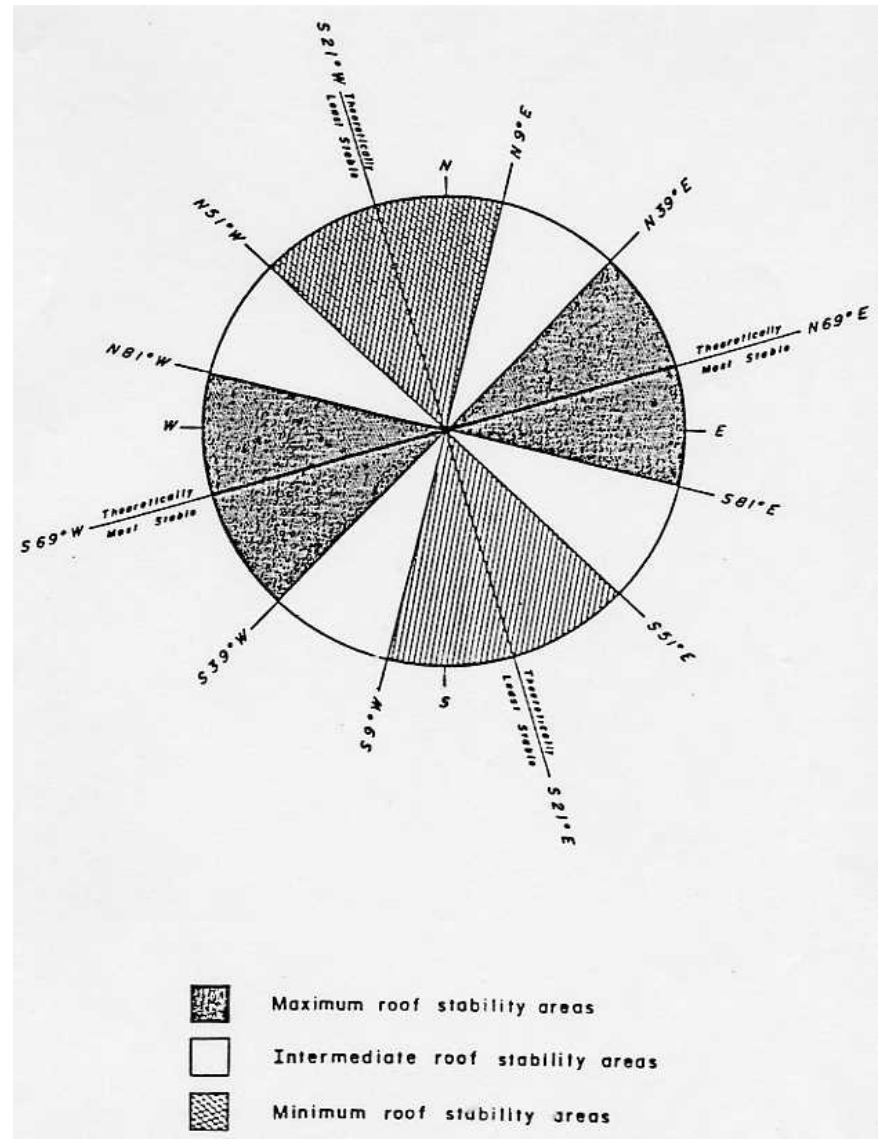

Figure 4.26. Design layout suggested for Nelms No.2 Mine [25].

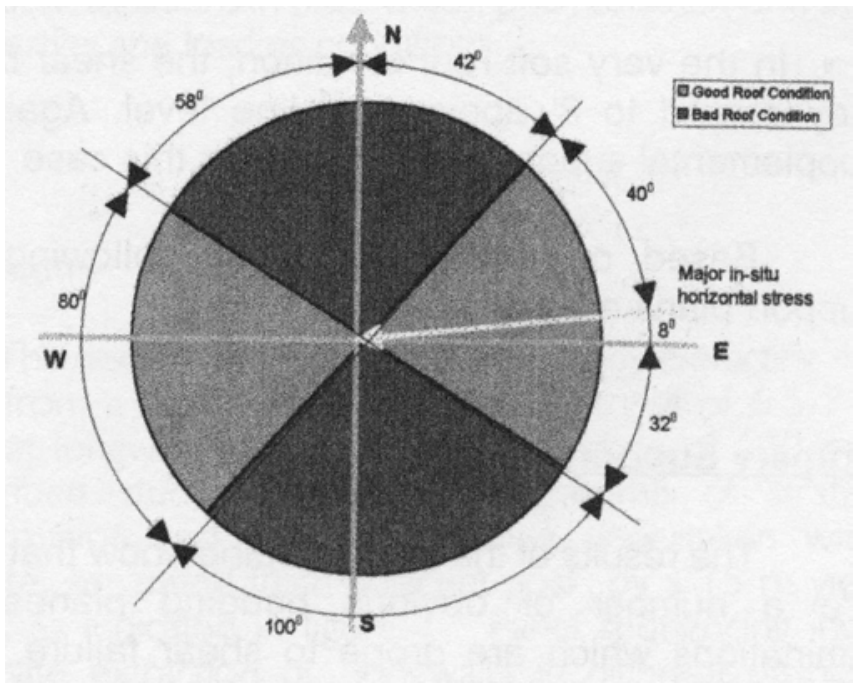

Figure 4.27. Recommended design layout for Mine A [39]. 
roof falls could be expected. And entries in $62^{\circ}$ direction are in the unfavorable direction as indicated by more roof falls.

\subsubsection{Inland Steel Coal Mine No. 2, IL}

Inland Steel Coal Company No. 2 mine is a room-and-pillar operation extracting Harrisburg-Springfield \#5 seam at a depth of $950 \mathrm{ft}[8,9,17]$. The immediate roof is Dykersburg shale that has variable geological structure. Roof falls in the mine resulted in run of mine reject as high as $50 \%$ and caused many delays to the production. Most of the roof falls were taking place in entries oriented in the North-South direction. The roof failed immediately after the box cut to a height of 2 to $4 \mathrm{ft}$. However, widening it further didn't cause any more falls. Besides this, failures were also taking place outby the face. The height of these outby falls was approximately 6-15 ft.

Based on field observations, the entries were reoriented by $45^{\circ}$, thus making the mining directions as Northeast-Southwest and Northwest- Southeast. In-situ stress measurements later [17] showed the magnitude of $\sigma_{\mathrm{hmax}}$ as $2700 \mathrm{psi}$ acting in easterly direction. This reorientation reduced the total number of failures in the mine. However, there was not much change in the outby falls. These falls took more circular shape as shown in Figure 4.28 and were restricted to intersections.

From these descriptions it is clear that more roof failures were taking place at the face in entries oriented at $90^{\circ}$ from $\sigma_{\text {hmax }}$ direction and were eliminated when the direction was changed to $45^{\circ}$. This behavior is explainable from Figure 4.15. However, this reorientation put the intersections in more unfavorable direction than before as seen from Figure 4.25 and hence the fall area increased and assumed circular shape. This case corroborates the finding that the reorientation will have very little influence on the condition of intersections for $\boldsymbol{k}>1$ as roof falls were noticed both before and after reorientation in the intersections. 


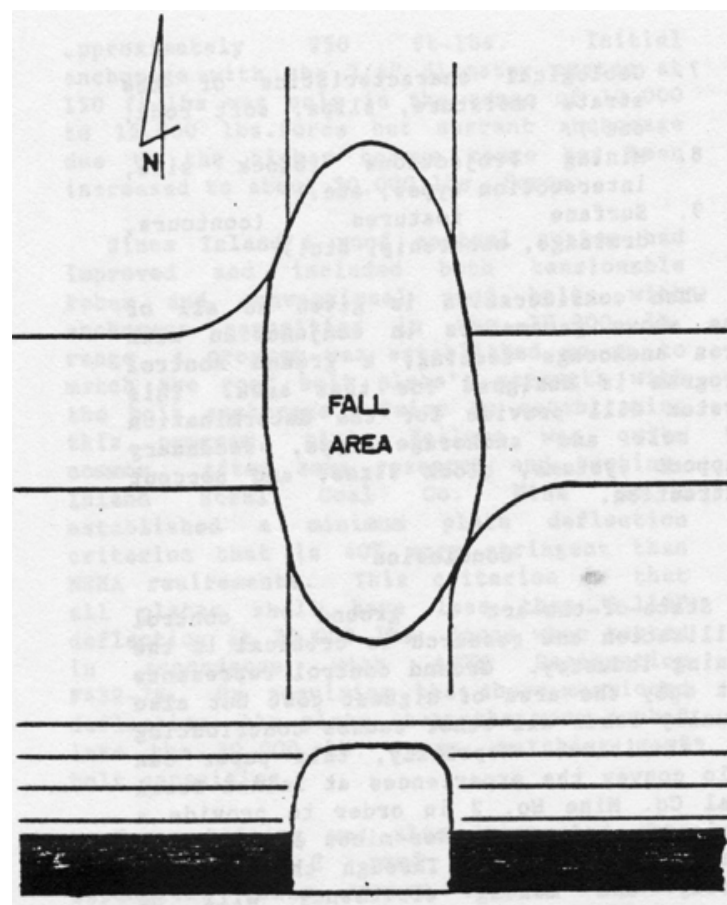

TYPICAL NORTH-SOUTH FALL

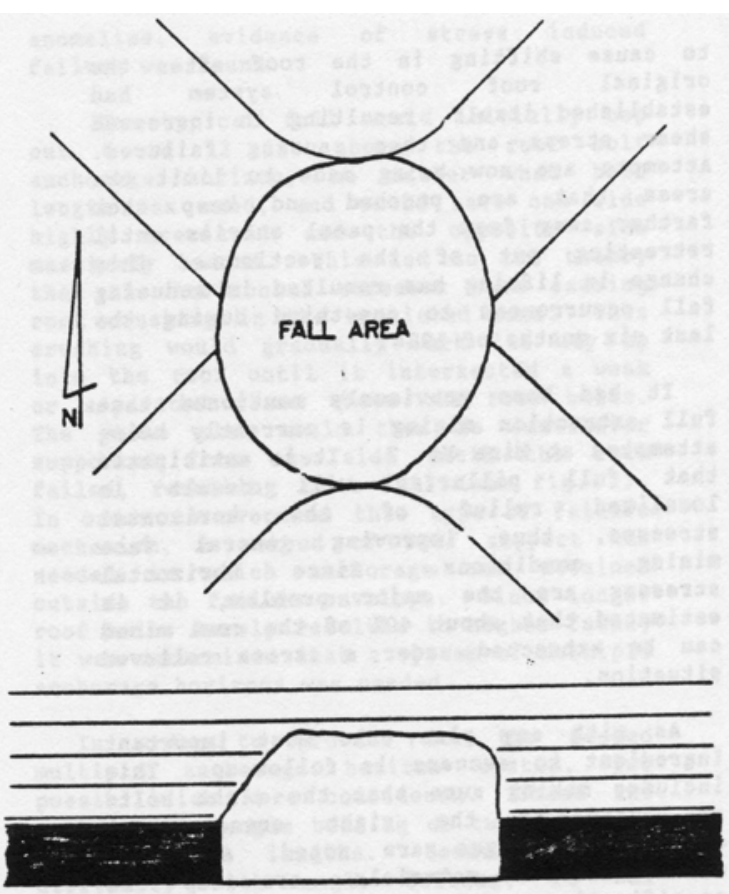

TMPICAL NORTHEAST-SOUTHWEST FALL

Figure 4.28. Roof fall profiles near intersections before and after reorientation at Inland steel coal mine no.2 [9].

\subsection{Chapter Summary}

For the lithology and the other parameters considered in this work, the following are the significant observations with regard to the influence of the in-situ maximum horizontal stress angle on the development workings' stability:

\# In general, the entries are most stable when they are oriented in the direction of $\sigma_{\mathrm{hmax}}$ and have least stability when oriented at $90^{\circ}$. However, depending on the values of $\boldsymbol{k}, \boldsymbol{l}$ and the location of bed in the roof and the location of the cross-section, minimum and maximum stability can be seen at other orientations as well.

II Intersections have the least stability for $\theta=45^{\circ}$ and best stability at $0^{\circ}$ or $90^{\circ}$ orientation. Again, depending on the mining conditions discussed in the 
previous sections, minimum and maximum stability may be seen at other orientations also.

\# The orientation effects depend on the in-situ maximum horizontal stress angle, ratio of maximum horizontal to vertical stress, ratio of maximum horizontal to minimum horizontal stress, location of the cross-section in the layout and the location of the bed in the roof.

a For the lithology considered in this research, it was seen that the reorientation effects were more substantial for $\boldsymbol{k}<1$ than for $\boldsymbol{k}>1$.

\# In general, roof behavior noticed in the case histories corroborated the findings in this chapter. 


\section{CHAPTER}

\section{DISTRIBUTION PATTERNS IN THE DEVELOPMENT WORKINGS}

\subsection{Introduction}

Directional roof falls in the entries is perhaps the most important and readily recognizable attribute of the in-situ high horizontal stress related ground control problems. As seen from the discussions in chapter 4, preferential failures in a single set of openings (entry or crosscut) could be explained by its orientation with respect to the $\sigma_{\text {hmax }}$ direction. However, often it is noticed that the rock failure has certain bias even across the entry width or within intersections. Some plausible explanations have been offered for this behavior and they pinpoint concentration of stresses in those portions of the entry or intersection as the factor responsible for this [14]. This concentration occurs when the entry or intersection meets the in-situ horizontal stress field at a certain angle and is developed in a certain sequence.

Further, it is also noticed that the bias in rock failure across the entry width also changes at different locations along the entry axis. The failure locations at the face and some distance outby the face were found to be different on some occasions. Some cutters running across the intersections were also observed underground. Explanations were offered about this erratic behavior based on field observations and some fundamental rock behavior principles. In fact, it is this inconsistent rock failure patterns that are exploited in the in-situ stress mapping technique to determine the directions of the horizontal in-situ stress field based on simple field observations [31].

The next aspect of investigation in this thesis is centered on the distribution of stresses and safety factor in the entry and intersection with the objective of finding some feasible explanation for the asymmetric failure patterns observed. It must be noted that the detailed distributions given in subsequent discussions are obtained in the top coal layer at a distance of about $0.2 \mathrm{ft}$ from the roofline. Beds higher in the 
roof were observed to exhibit similar behavior. The stress distribution patterns shown in the following sections are obtained by comparing the magnitudes of the variable of interest at two points that are mirror images with respect to the center line of the entry for any cross-section, e.g., maximum principal stress at the two ribs of the entry.

\subsection{Maximum Principal Stress}

The maximum principal stress distribution has noticeable asymmetry in the areas shown in Figure 5.1 for in-situ maximum horizontal stress angles other than $0^{\circ}$ and $90^{\circ}$. At the face area the stress gets concentrated on the side where the stress can pass into solid coal without going through the excavated area of the entry. This concentration is continued to a distance of about 5 to $10 \mathrm{ft}$ and then there is no noticeable asymmetry in the maximum principal stress distribution.

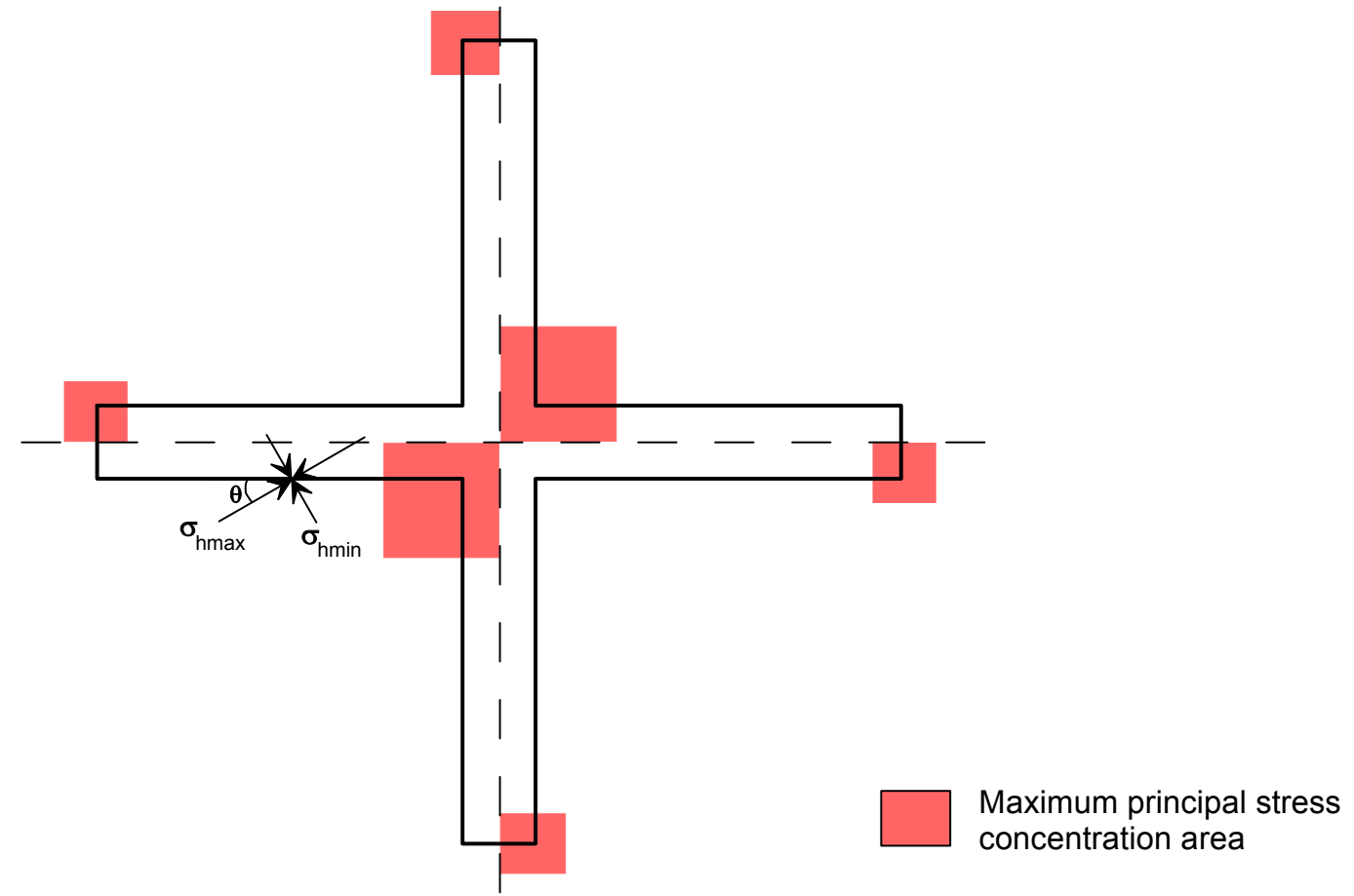

Figure 5.1. Distribution of maximum principal stress concentration zones in the immediate roof of the model. 
As the intersection is approached, bias in maximum principal stress distribution is noticed with higher values on the opposite side to that at the face. This zone begins at a distance as far as $30 \mathrm{ft}$ from the intersection with the general range being 10 to $30 \mathrm{ft}$. Within the intersection, the high stress zones are seen in line with the in-situ maximum horizontal stress. The same patterns are noticed in the other parts of the model as shown in Figure 5.1.

The maximum principal stress plots shown in Figure 5.2 at different crosssections in the entry right up to the middle of the intersection clearly shows the above discussed patterns. These results were obtained for $\boldsymbol{k}=3.0, \boldsymbol{l}=1.5$ and $\theta=$ $30^{\circ}$. It may also be noted that the stress values at different cross-sections in the intersection beyond the entry width were obtained in the roof of the crosscut shown in Figure 3.1. It must however be noted that the difference in the values of the maximum principal stress is higher near the intersection than at the face area.

The patterns depicted in the above figure were consistent and clearly noticeable for $\boldsymbol{k}$ values more than 1. For $\boldsymbol{k}$ less than 1, though in some cases the above patterns were noticed they were not as clearly discernable as for $\boldsymbol{k}>1$. Distributions in this case were mixed and lacked a general pattern. This is probably one reason why ground control problems related to low in-situ horizontal stresses do not have as distinguishable features as high horizontal stress related failures seen in the mine.

\subsection{Minimum Principal Stress}

The minimum principal stress did not show as clear a pattern as the maximum principal stress. The minimum induced principal stress distributions shown in Figure 5.3 are highly approximate and the shaded areas indicate high compressive or tensile minimum principal stress as compared to their counterparts in the other half of the entry. They follow the same general patterns as the maximum

principal stress. Again, the patterns, though approximate, were better seen for $\boldsymbol{k}>1$ than for $\boldsymbol{k}<1$.

Comparison of minimum principal stress along different cross-sections of the entry and intersection are shown in Figure 5.4. 
(a)

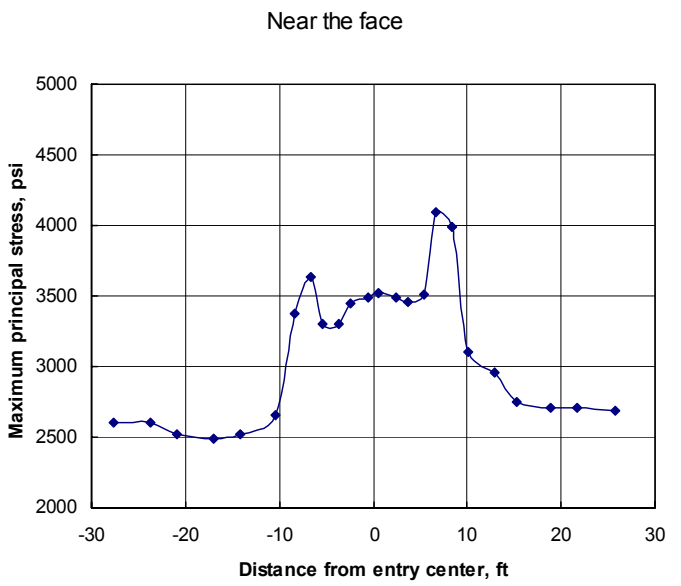

(b)

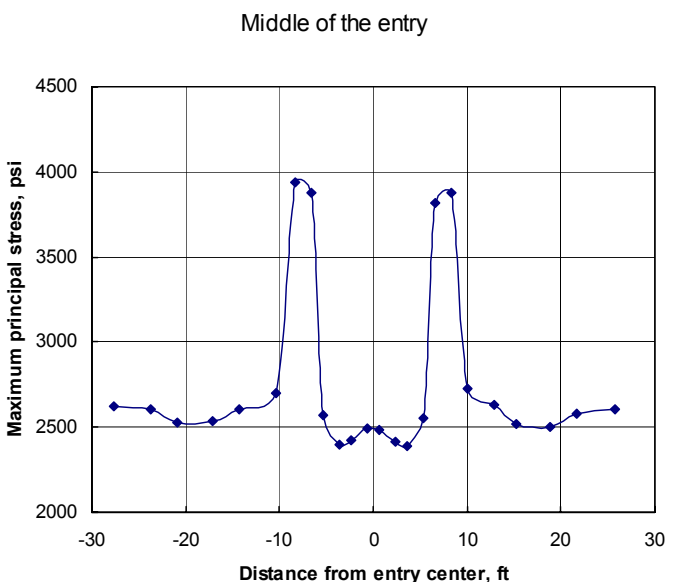

(c)

Near intersection

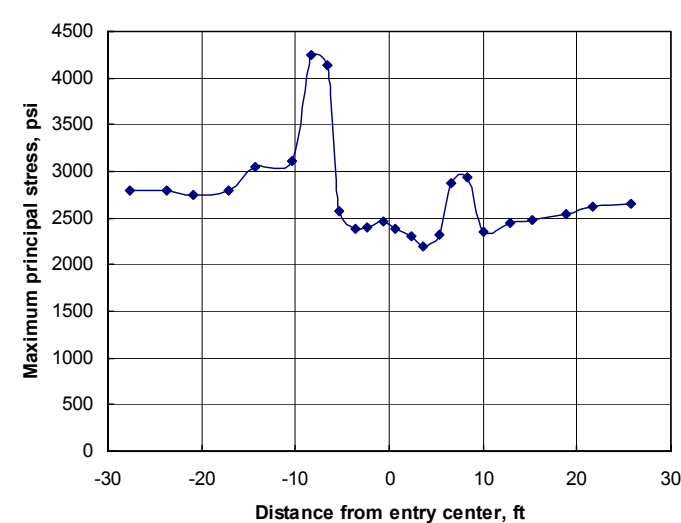

(d)

First $1 / 3$ rd of intersection

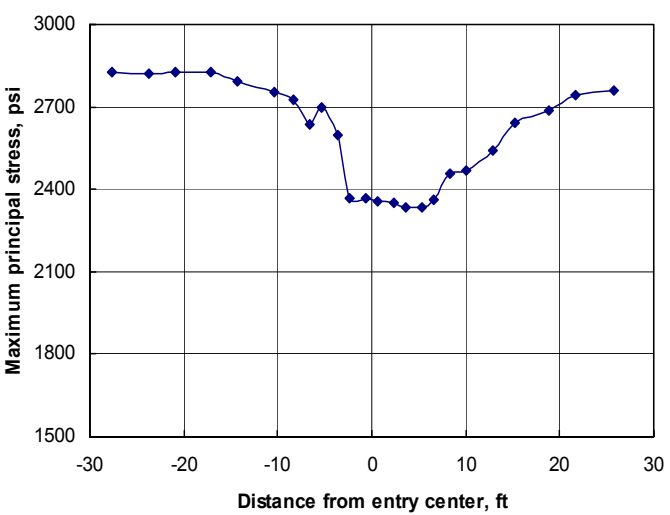

(e)

Near Middle of the intersection

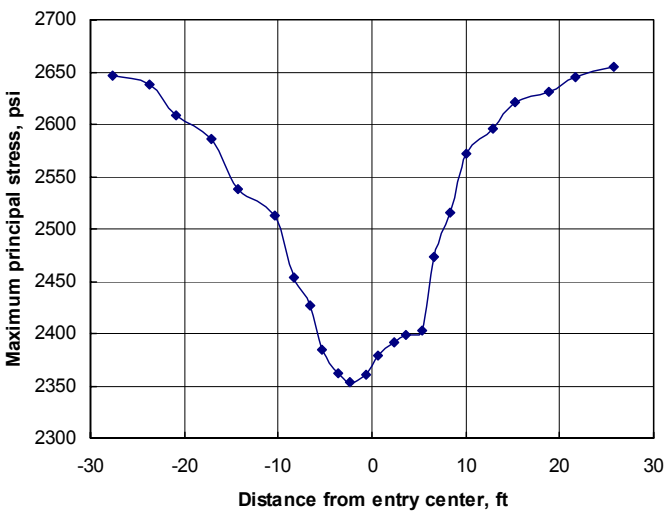

(f)

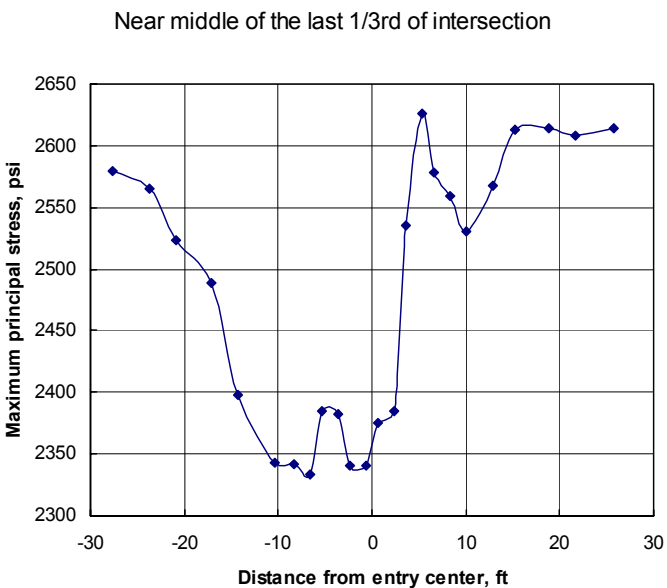

Figure 5.2. Maximum principal stress across the width in the entry $(a, b, c)$ and in the intersection $(d, e, f)$. 


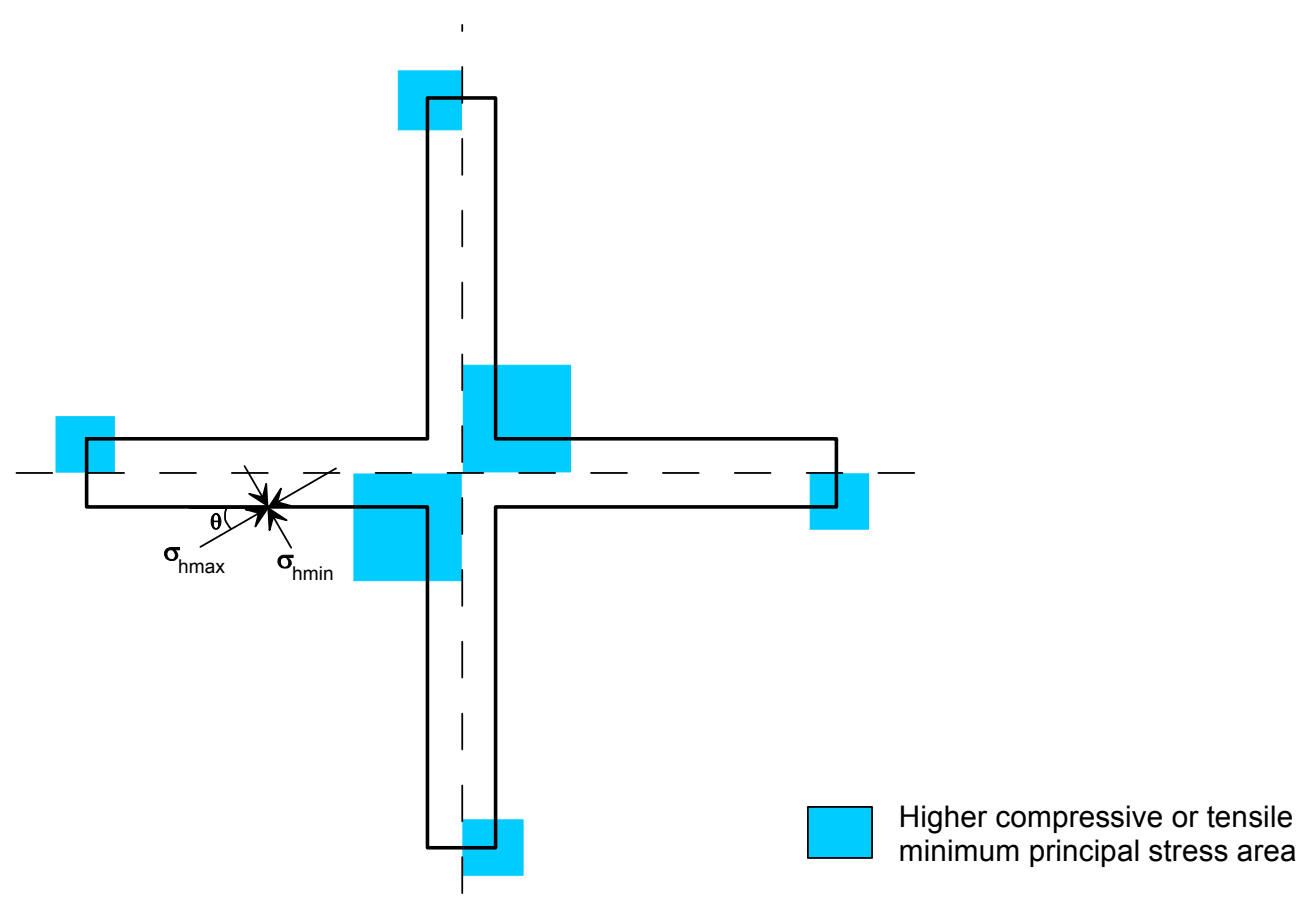

Figure 5.3. Distribution of minimum principal stress concentration zones in the immediate roof of the model.

\subsection{Safety Factor}

Hoek-Brown safety factors for the immediate roof show the pattern given in Figure 5.5. The shaded zones indicate lower safety factor values than corresponding points in the other half of the entry. The distribution of lower safety factors within the intersection are not very clear and so are for $k<1$. In those cases, they must be taken as approximate and reflect the patterns shown by higher percentage of points where results are obtained in the model.

It was observed that the distributions within the entry portion were very clear for $\boldsymbol{k}>1$ and mixed for $\boldsymbol{k}<1$. The difference in the magnitudes was found to be highest for the corner points and kept decreasing towards the centre of the entry as shown in Figure 5.6. Also, the irregular pattern of safety factors in the intersection is mainly due to the fact that for these plots the stresses were obtained in the roof of the crosscut for points that fall beyond the width of the intersection. As a result, both the magnitude and the nature of the minimum principal stress changed as shown in Figure 5.4 causing the observed change in the safety factor. 
(a)

Near the face

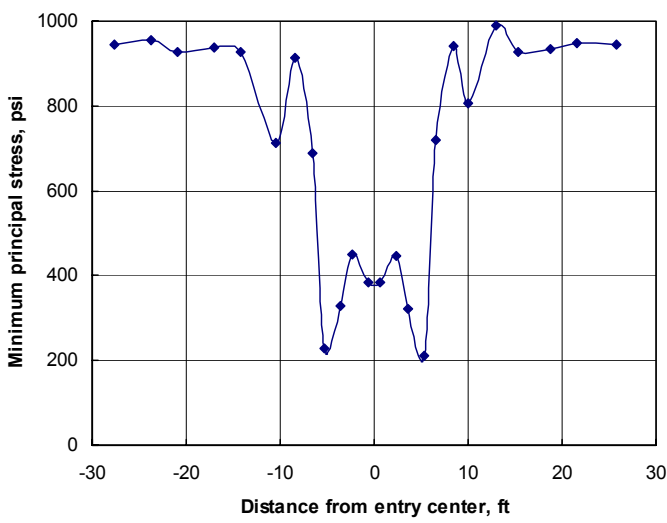

(b)

Middle of the entry

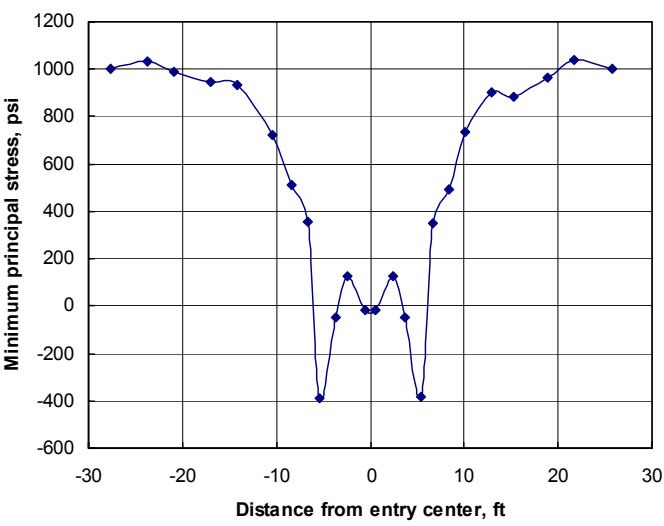

(c)

Near intersection

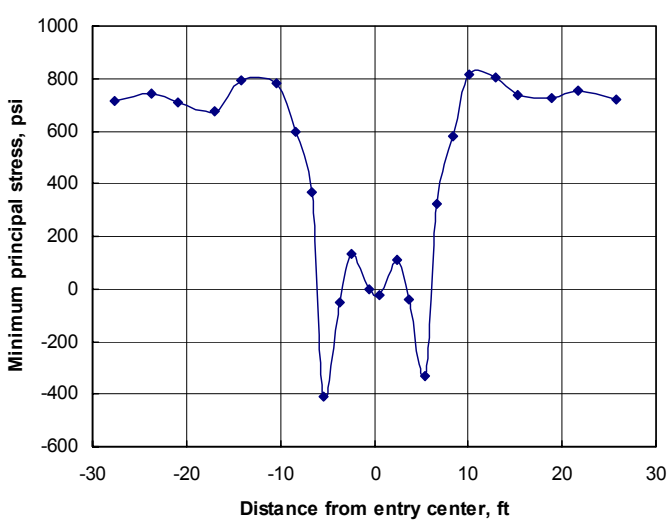

(d)

First $1 / 3$ rd of intersection

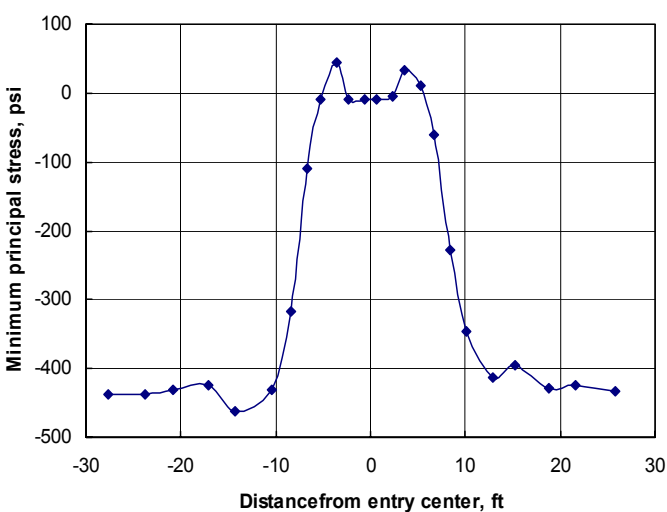

(e)

Near Middle of the intersection

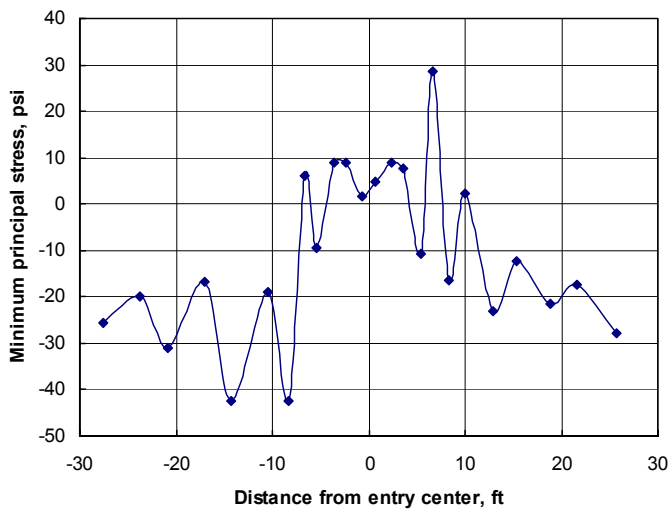

(f)

Near middle of the last $1 / 3$ rd of intersection

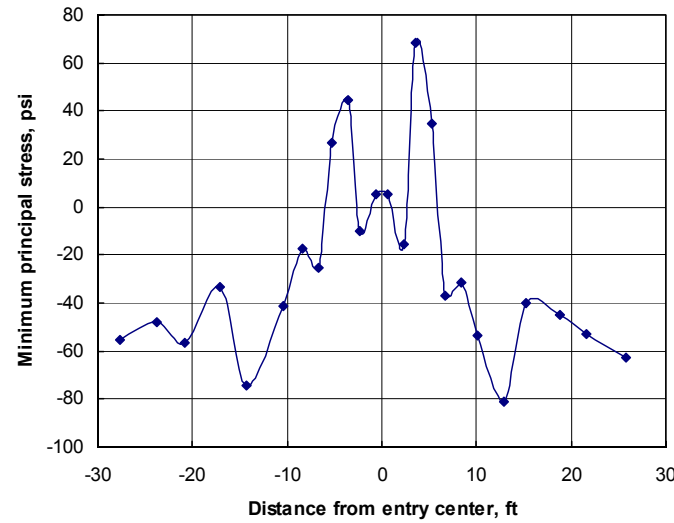

Figure 5.4. Minimum principal stress across the width in the entry $(a, b, c)$ and in the intersection (d, e, f). 


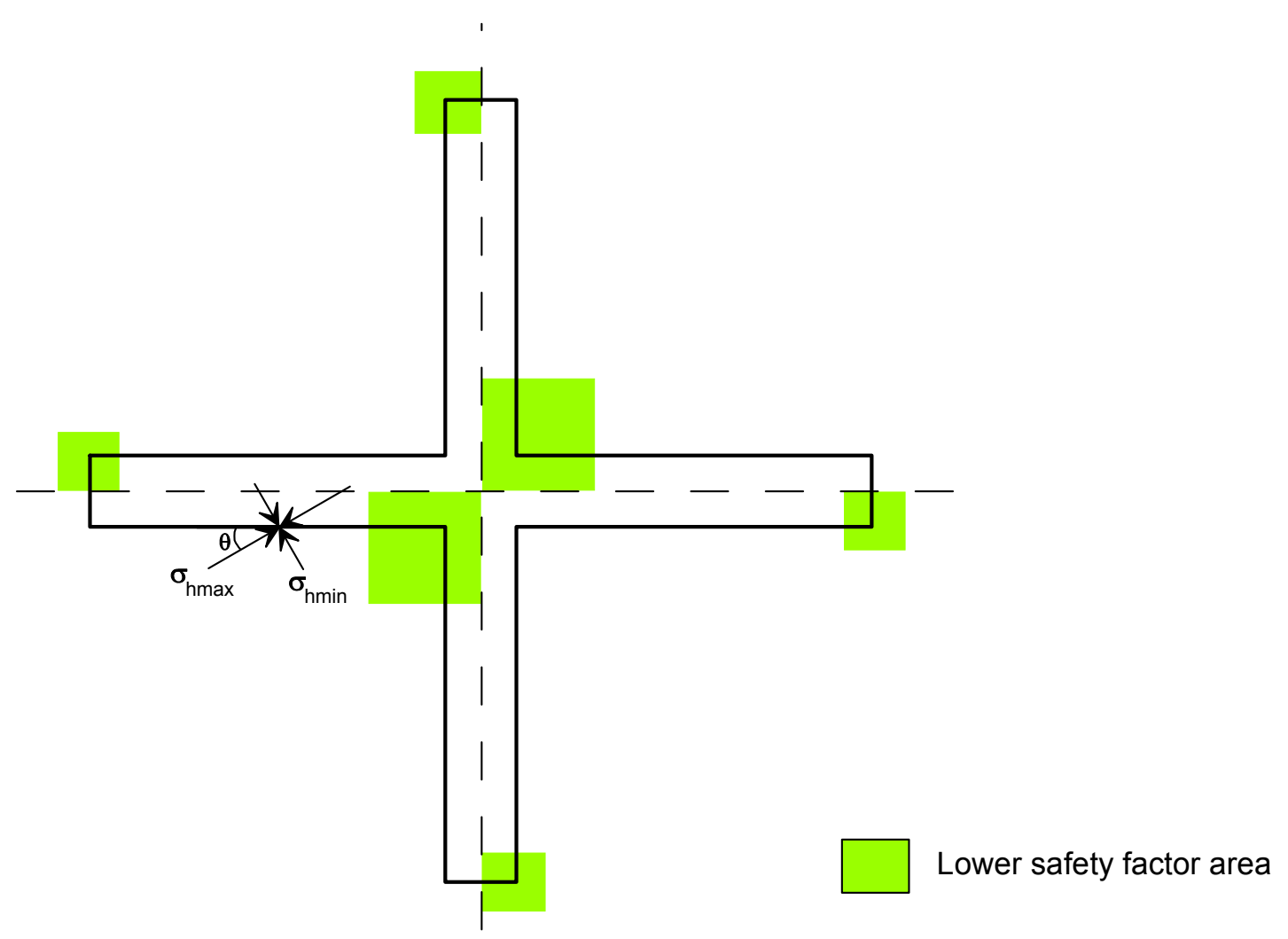

Figure 5.5. Distribution of lower safety factor zones in the immediate roof of the model.

\subsection{Why these Patterns?}

Recognizing the mechanisms responsible for the type of distributions observed above is very important and hence an effort has been made to find some logical basis for this. Toward this end, the resultant displacement patterns in the immediate roof are observed. A typical plot of deformed mesh is shown in Figure 5.7. These deformations were obtained for $\boldsymbol{k}=2.0, I=1.5$ and $\theta=30^{\circ}$.

From this figure it may be seen that the rock mass on either side of the entry is moving in opposite directions with different magnitudes resulting in a highly skewed geometry. This shear seems to take place in such a way to concentrate the deformations on the solid side of the face where the in-situ maximum horizontal stress can pass through without entering into the void space of the entry. These differential movements are higher near the face and have almost the same magnitude for the elements some distance outby the face. 
(a)

Near the face

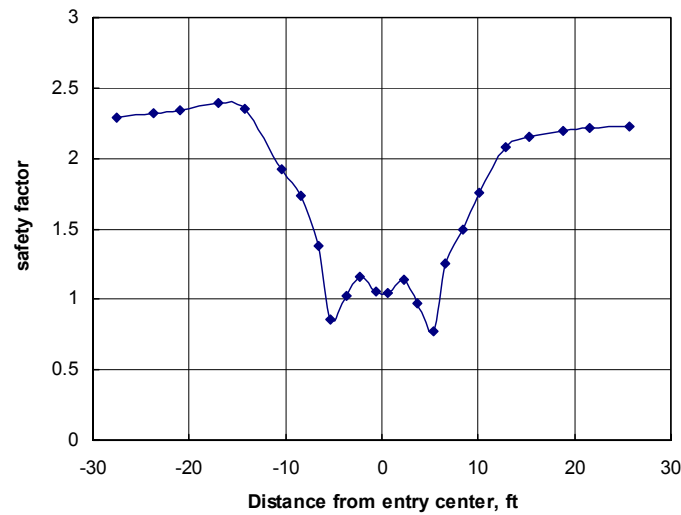

(b)

Middle of the entry

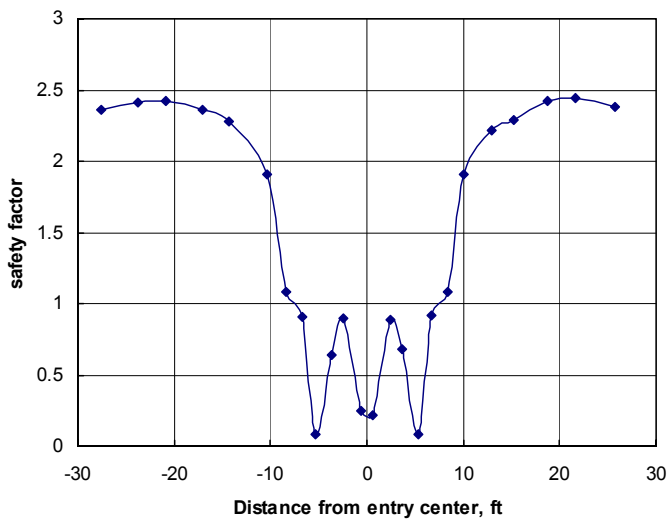

(c)

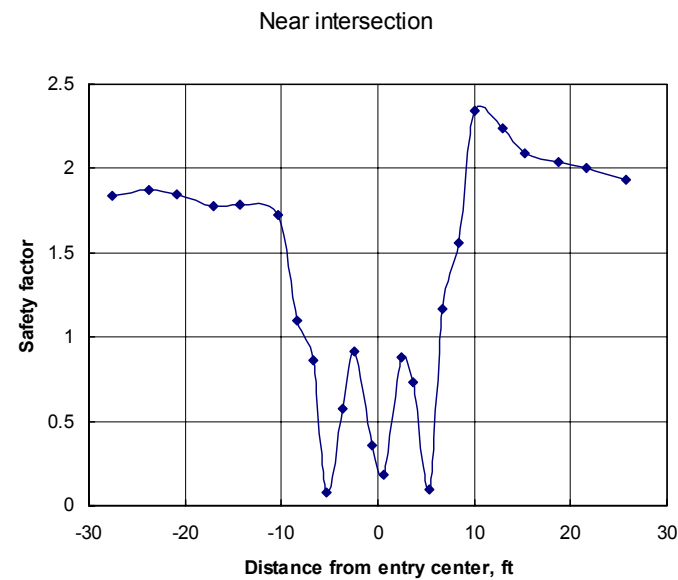

(d)

First $1 / 3$ rd of intersection

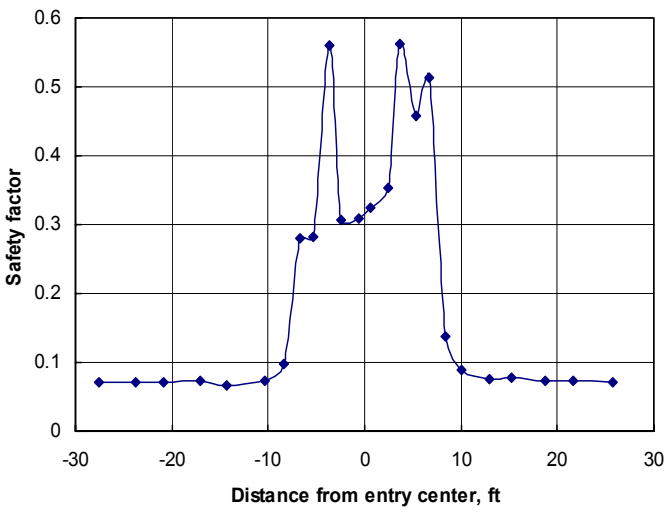

(e)

Near Middle of the intersection

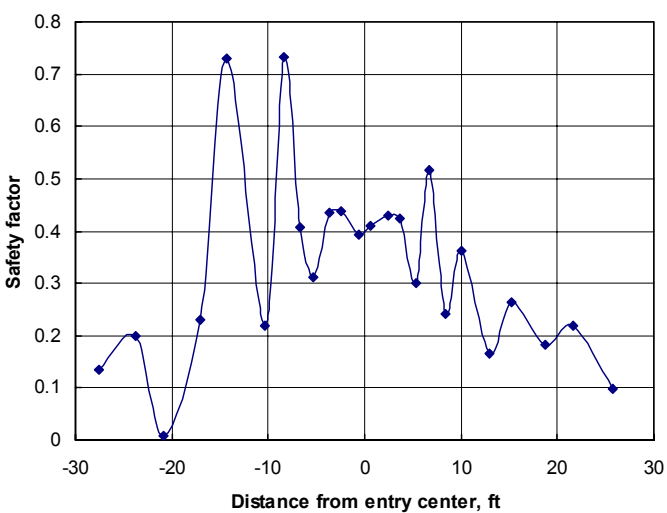

(f)

Near middle of the last $1 / 3$ rd of intersection

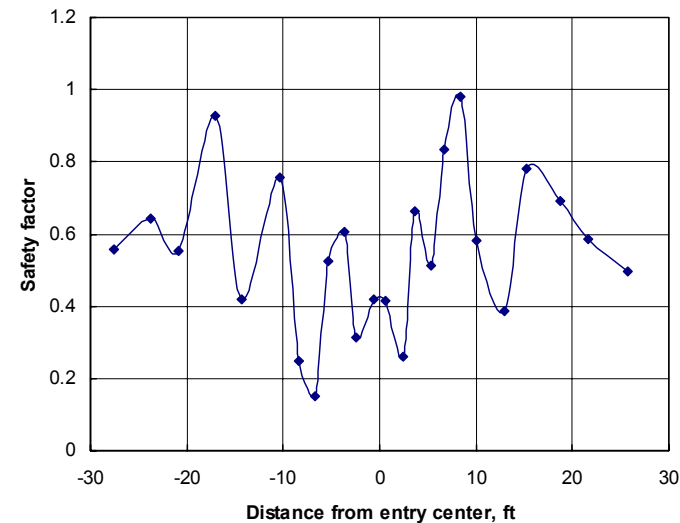

Figure 5.6. Safety factor stress across the width in the entry $(a, b, c)$ and in the intersection $(d, e, f)$. 


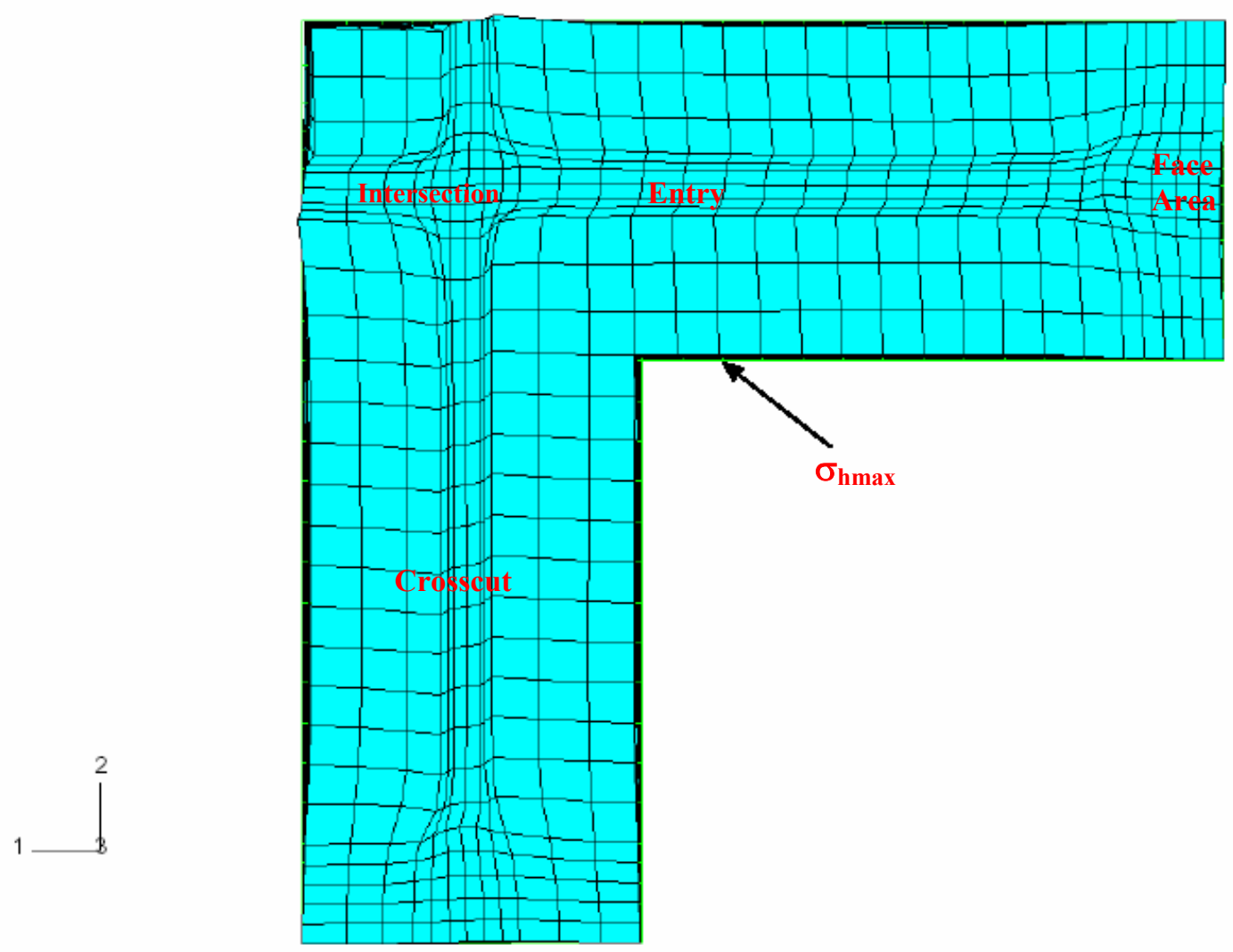

Figure 5.7. Resultant deformation in the immediate roof of the model.

In the intersection, there is more resultant movement along the diagonal aligned nearly in the direction of $\sigma_{\mathrm{hmax}}$ than the other diagonal. As a result of this movement more shear stress is developed in this direction than the other one. The effect of these movements can be more clearly seen in the distribution of horizontal shear stress in different beds in the roof. Figure 5.8 to 5.10 shows shear stress distributions at different heights inside the roof. Also, the horizontal shear stress distributions provide an approximate summary of the principal stress patterns in the roof. These figures further reinforce the distributions obtained above and also show that with increasing distance into the roof there is more compliance with the patterns depicted above. These plots in conjunction with the deformation patterns shown in Figure 5.7 explain the reason for the distribution patterns described in the previous sections. 


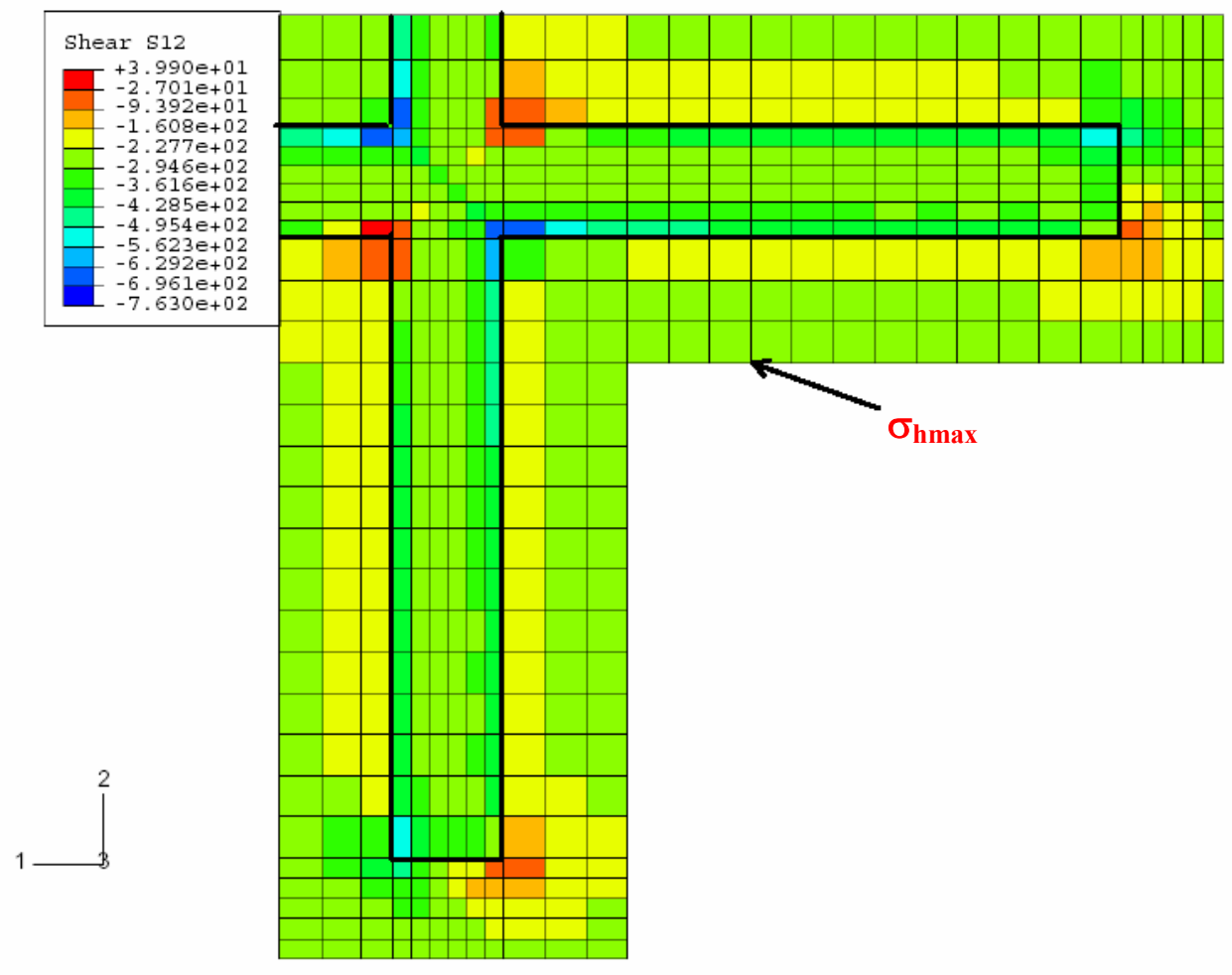

Figure 5.8. Horizontal shear stress in the immediate roof coal bed.

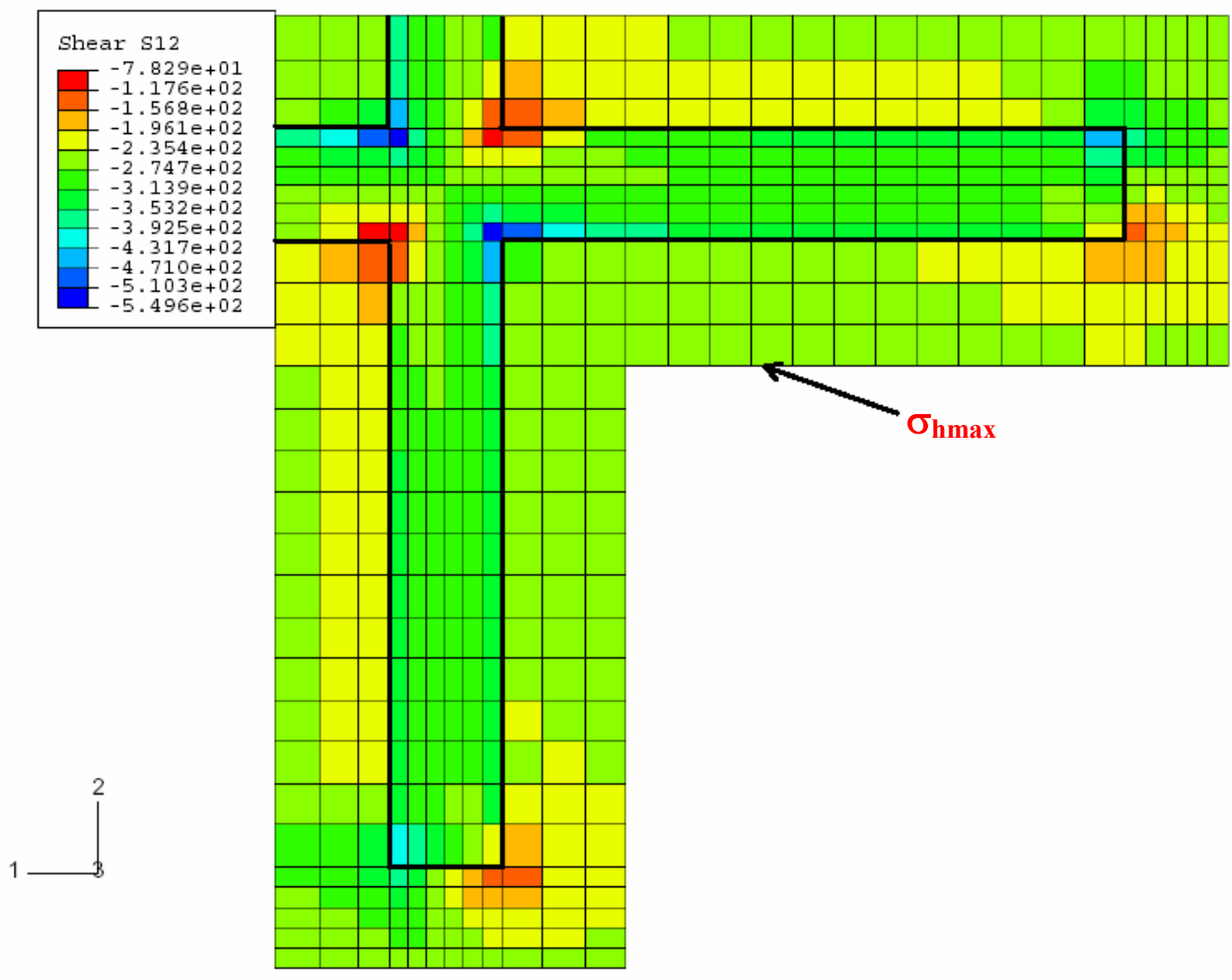

Figure 5.9. Shear stress in the horizontal plane in the black shale bed $1 \mathrm{ft}$ above the roof. 


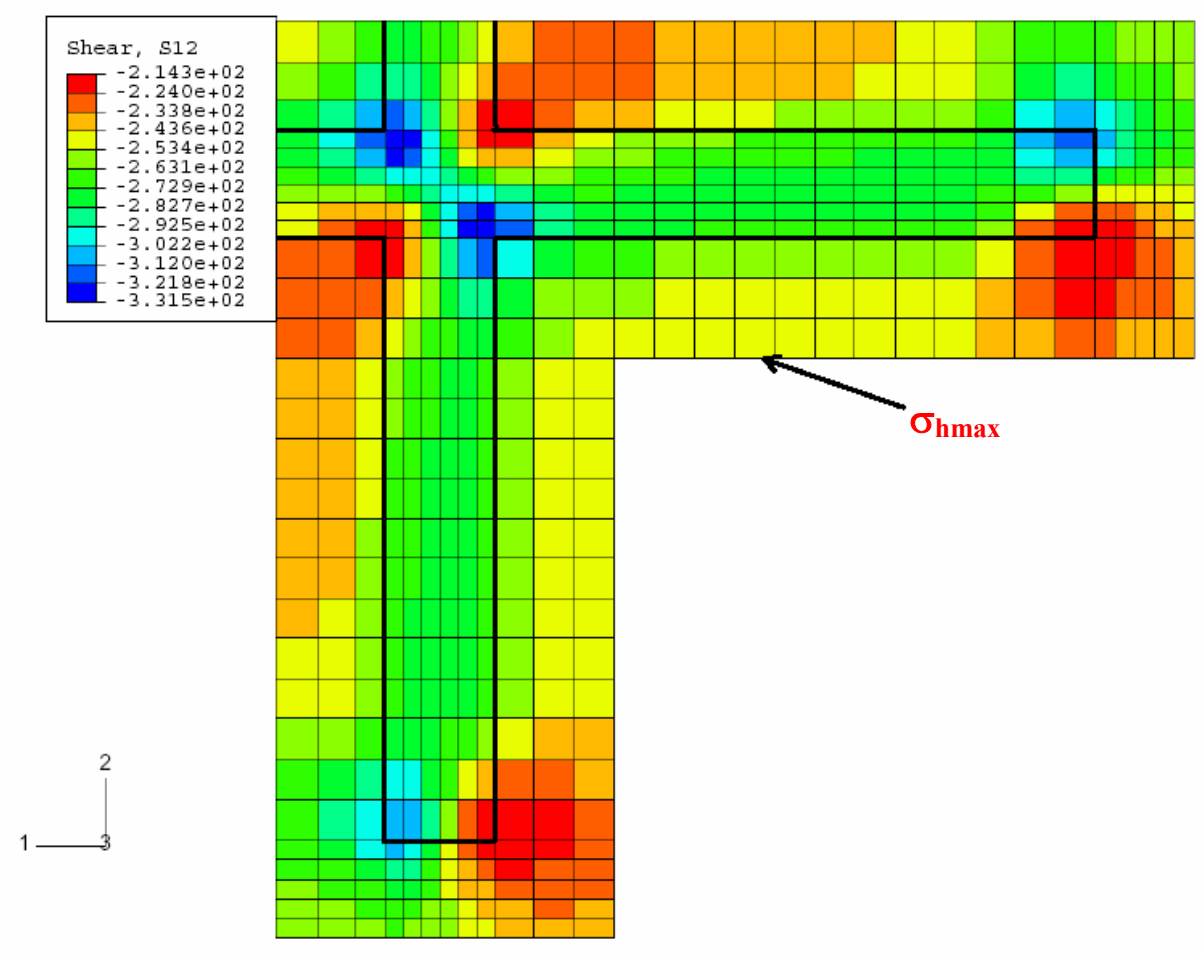

Figure 5.10. Shear stress in the horizontal plane in the gray shale bed $9 \mathrm{ft}$ above the roof.

\subsection{Stress Mapping Technique}

Stress mapping is a simple and inexpensive method of estimating approximate directions of the horizontal in-situ stress field [31]. This prediction is done based on underground mapping of stress induced failures in the mine. Figure 5.11 shows the most commonly observed stress related failure and deformation features and their disposition with respect to the in-situ maximum horizontal stress direction. Comparison of the cutter position within and near the intersection area predicted in this work with the stress mapping technique show completely opposite patterns. To understand the reasons for this discrepancy, the basic assumptions in both works needs to be understood and compared.

Inference of the directions of $\sigma_{h \max }$ based on cutter positions in the intersection area is based on two major principles in the stress mapping technique [31]. These principles are reproduced here for ready reference. 


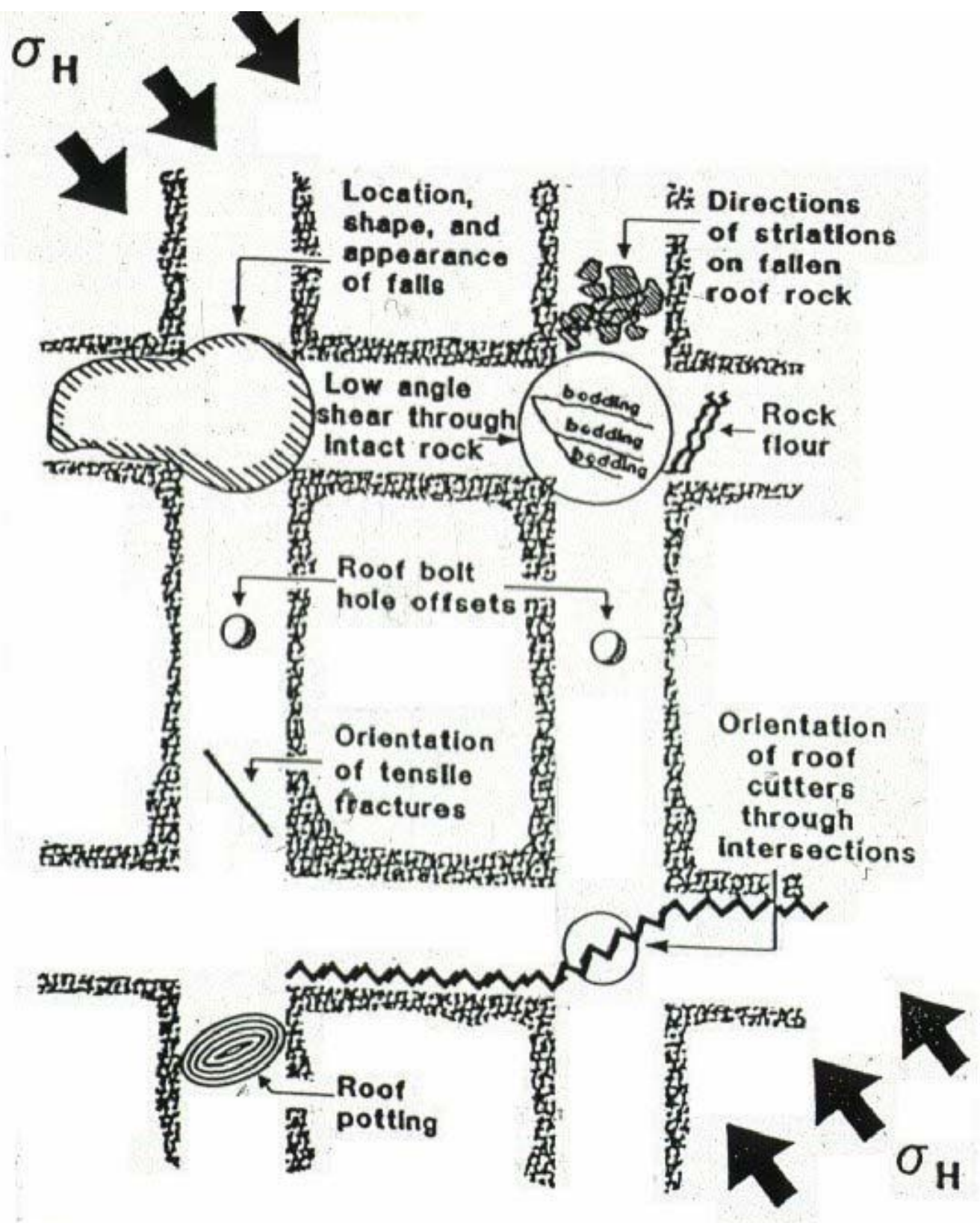

Figure 5.11. Stress mapping features and their disposition with respect to $\sigma_{\mathrm{hmax}}$ direction [31].

"The direction of failure is in the direction of the minor principal horizontal stress and 90 deg to the major principal stress".

"Where permitted to do so, such as crossing intersections and failures across openings, major failure features, such as cutters and bottom heave, will try to be aligned in the direction of the minimum principal stress and perpendicular to the major principal stress. Roof potting and shear failures will exhibit this trend at all times". 
Although the failure patterns observed in borehole breakouts were used to support the first principle given above, it is not completely clear from the paper how this principle was developed [31]. Shear failure in a circular borehole as seen in the borehole breakouts happens in the direction of minimum applied principal stress mainly because of its special shape that causes the induced maximum principal stress to concentrate at those points [21]. For a different geometry, the location of stress concentrations will be different. Therefore, it may not be logical to extend the circular hole analogy to the intersection as the geometry and loading conditions are entirely different.

Besides, it also seems that in the stress mapping method the directions of induced principal stresses are assumed to remain unchanged from their pre-mining directions. This assumption to a large extent is correct within the intersection where the induced principal stresses are oriented nearly in the direction of in-situ stresses as shown in Figure 5.12. However, probably due to difference in the geometry, it was noticed from the models that the induced principal stresses get reoriented in the entry as seen from Figure 5.13.

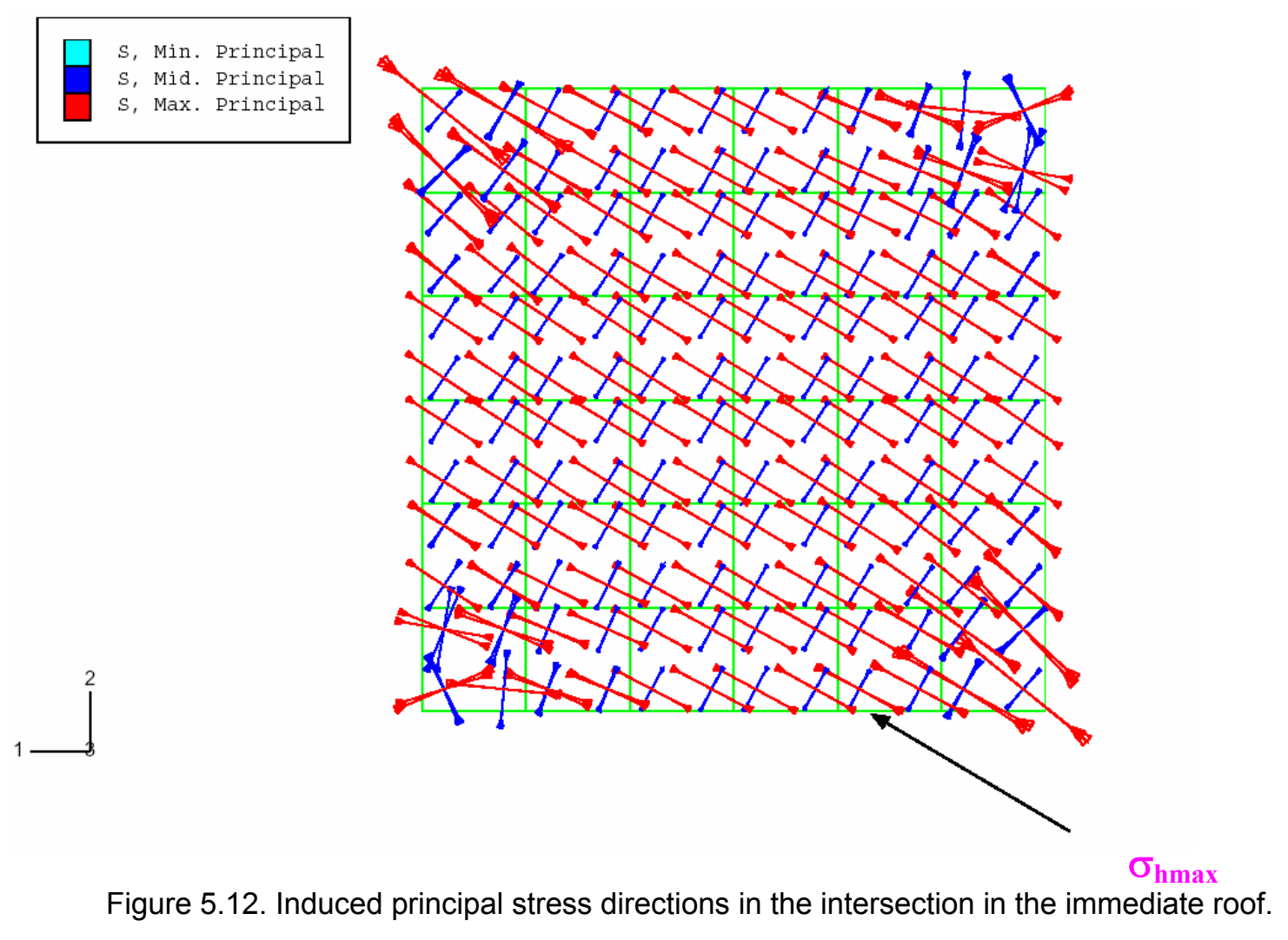


(a)
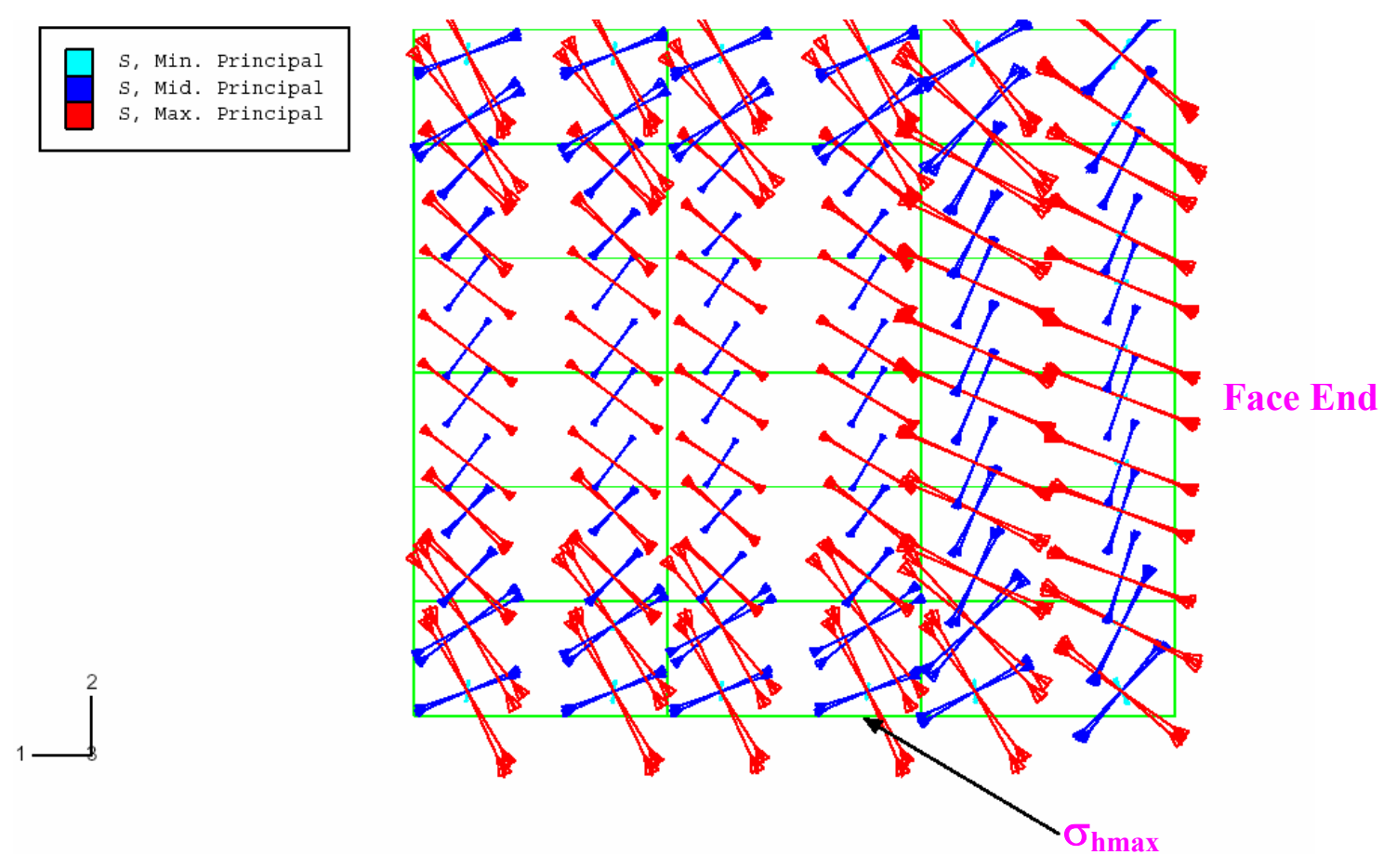

(b)
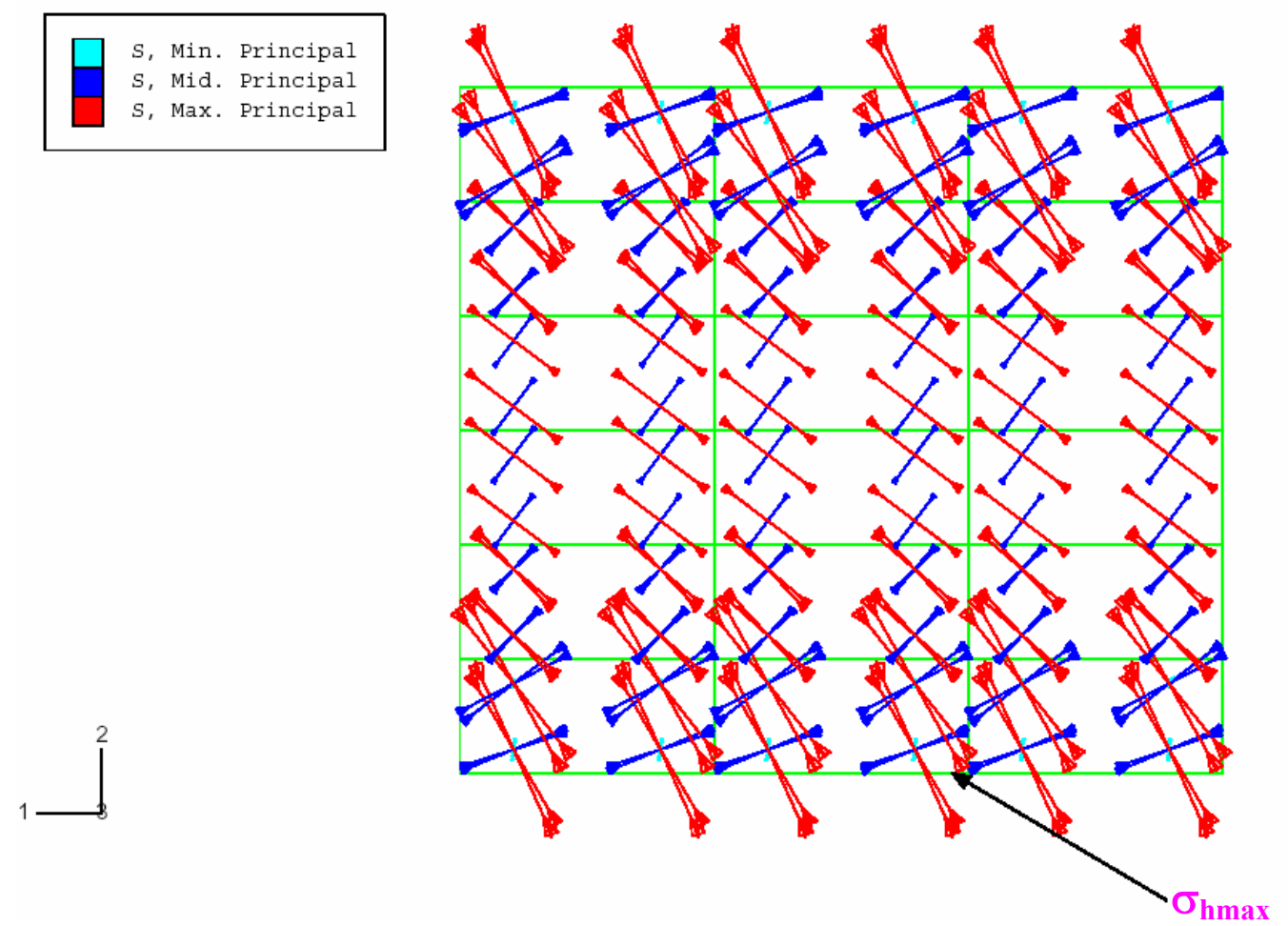

Figure 5.13. Induced principal stress directions (a) near the face and (b) in the middle portion of the entry in the immediate roof (longitudinal axis of the entry is along 1-axis). 
It is now a very well proven experimental fact that the shear failure surface in the rock lies in general at an angle of $45^{\circ}-\phi / 2$ ( $\phi$, angle of internal friction of the rock) from the direction of major principal stress and not at right angles as assumed in the stress mapping technique [21]. Hence, for general in-situ stress field and excavation geometry, the actual direction of cutters in the entry or intersection depends on the direction of induced principal stresses and they are not always perpendicular to $\sigma_{\mathrm{hmax}}$ as indicated in Figure 5.11.

Coming back to the patterns derived in this work, as noted in section 5.4, the safety factor distributions in the intersections are only approximate and low safety factors exist in the other half of the intersection also for some combinations of input variables. The actual failure in the mine is progressive and starts at the weakest point in the rock mass and then propagates in the least resistant path. This process is extremely difficult to simulate in a numerical model. Therefore, the patterns given in Figure 5.5 should only be taken as those demonstrated by a majority of points and exceptions to this may occur under the conditions discussed below.

The modeling process adopted here does not consider the step-by-step process of forming an actual entry in the mine or the sequence of rock cutting in a single step. This may have influenced the patterns obtained in this work. This happens probably under two conditions. One, when failure occurs at the face area immediately after its exposure. When this happens, there is a release of stresses in that direction and the concentrations seen on the opposite rib side near the intersection area may no longer exist. Two, when the rock near the face area doesn't fail immediately after the exposure but was loaded to near its failure load. In that case failure will take place after some time lag due to time dependent effects and change in loading conditions. In this instance also, the failure will continue on the same rib side as that near the face area and will not change to opposite rib side as depicted in this work.

It is therefore clear that the patterns obtained in this work for areas near the intersection are possible only if the in-situ rock mass strength of the roof lies somewhere between the induced stress states experienced at the face and near the 
intersection. That is, the rock strength is high enough to withstand the stresses near the face but lower than that required to resist stresses near the intersection.

As the major differences in patterns when compared with stress mapping technique are seen near the intersection, it is also interesting to compare the floor heave patterns described in the second principle of the stress mapping technique. This is done by comparing vertical displacements obtained along the two diagonals of the intersection. Typical roof and floor displacements obtained from the models are shown in Figure 5.14. Diagonal $\mathrm{JJ}$ is nearly in the direction of $\sigma_{\mathrm{hmax}}$ while $\mathrm{KK}$ is nearly at right angles to it as shown in Figure 3.1. It may be noticed in Figure 5.14 that the difference in the vertical displacement is reducing as the center of the diagonals is approached. This is expected as the points get closer to each other as one moves towards the center of the intersection and in fact the value of the displacement will be exactly the same for both the diagonals at their midpoint. These figures confirm the fact that the maximum roof or floor movements take place along the lines perpendicular to $\sigma_{h \max }$ direction as assumed in the stress mapping technique.

Based on the above discussions, it is clear that the apparent discrepancy in the failure patterns observed near the intersection area between the present work (as seen from the lower safety factor zones) and the stress mapping technique is mainly due to the assumptions in the modeling approach adopted here and under certain conditions it is possible to observe both patterns in the mine.

\subsection{Chapter Summary}

This chapter discussed the patterns in the distribution of maximum, minimum induced principal stresses and safety factor in the roof of the development workings. Explanations on these patterns based on the resultant displacements and shear stress distributions have been given. The differences in the observed patterns when compared to the stress mapping technique have been identified and delineated. It was inferred that within the bounds of the assumptions made, both patterns may be observed in underground coal mines. 
(a)

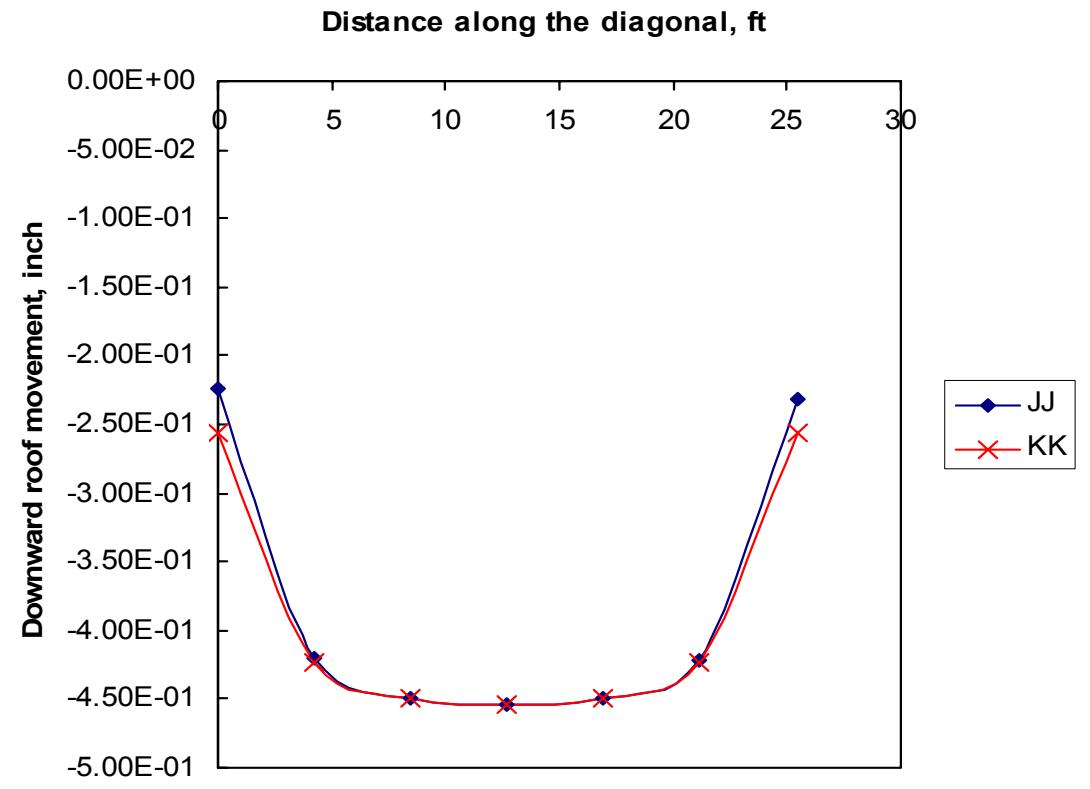

(b)

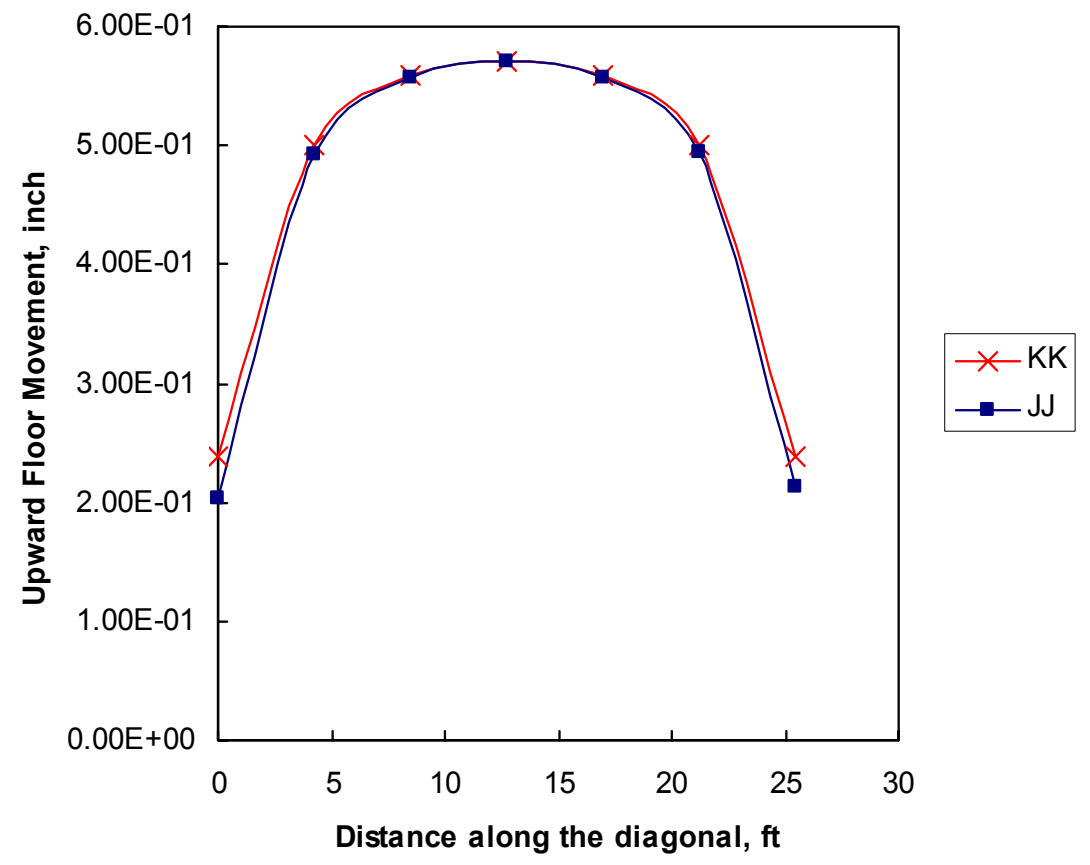

Figure 5.14. Vertical displacement in the (a) roof and (b) floor along diagonals $\mathrm{JJ}$ and $\mathrm{KK}$ in the immediate roof. 


\section{CHAPTER}

\section{INFLUENCE OF IN-SITU STRESS RATIOS ON THE ENTRY STABILITY}

\subsection{Introduction}

In-situ stress field is an extremely important factor contributing to ground control problems in the United States. It has been noted before that underground measurements in coal mines show large variations in the magnitudes of in-situ stresses. Though there are measurements that show the magnitude of vertical stress being larger than the horizontal stresses, there seems to have been little research effort in the past directed towards understanding the effects of low horizontal stresses and much of the research is focused on the effects of high in-situ horizontal stresses only. This is mainly because the failure process associated with high horizontal stress has some distinct characteristics that can easily be observed in the mine. The research efforts on this subject have now reached a stage where the mine operators can confidently predict or interpret the effects of high horizontal stresses and implement suitable measures to minimize or completely eliminate their effects.

The effect of low horizontal stresses on the rock failure when observed underground is not as discernable as the high horizontal stresses. In a low stress environment, the rock failure is complex and doesn't have any differentiating features that separate them from other possible causes. As a result, often they are overlooked and other causative factors like low support resistance, etc. are often explored.

In this chapter an attempt has been made to examine how different in-situ stress fields (both low and high) can affect the stability of development entries in underground coal mines. Since, the in-situ stress state at a point is given in terms of the vertical stress, maximum horizontal stress and minimum horizontal stress, the analysis considers the effect of these parameters expressed as the ratio of 
maximum horizontal to vertical stress, $\boldsymbol{k}$, and the ratio of maximum horizontal to minimum horizontal stress, $l$.

\subsection{Influence of In-situ Maximum Horizontal to Vertical Stress Ratio (k)}

Considering the wide range of variation in the ratio of maximum horizontal to vertical stress, $\boldsymbol{k}$, it is intuitive to investigate the influence of this factor on the stability of mine roof. The modeling results obtained for different combinations of input parameters explained in Chapter 3, show a consistent trend with regard to the effect of $\boldsymbol{k}$ on the average safety factors in the roof at different horizons. These results indicate that the average safety factor with change in $\boldsymbol{k}$ assumes the shape of a lognormal distribution curve, which means that the average stability of the roof improves with increasing $\boldsymbol{k}$ up to a certain value and then starts decreasing as shown in Figure 6.1 to Figure 6.5. The bed numbers in these figures correspond to the rock layers discussed in Chapter 3 and shown in Figure 3.2. The implication of this finding is that for every type of roof under some geo-mining conditions, there is a certain value of $\boldsymbol{k}$ at which the roof has maximum stability and for any other value (less or more than this) it will have lower stability.

The initial modeling plan was only for four $\boldsymbol{k}$ values and the results indicated maximum stability when its value was 0.75 . However, it was not clear whether this was the value at which the entry or intersection had maximum stability as the increment of $\boldsymbol{k}$ considered was rather large. Therefore, to get a full picture of the effect of $\boldsymbol{k}$ on the stability, models were run for additional $\boldsymbol{k}$ values to those described in chapter 3 . These models were for $\boldsymbol{k}$ equal to $0.5,1,1.25,1.75,2$ and 5 . This makes the total number of $\boldsymbol{k}$ values considered to be ten and provides a reasonably small increment to estimate the maximum stability location.

It was also noticed that the ratio of in-situ maximum horizontal to minimum horizontal stress, $\boldsymbol{l}$, does not affect the shape of the $\boldsymbol{k}$ effect curve though it might influence the location of the maximum safety factor. For this reason, the following analysis has been done for an $\boldsymbol{l}$ value of 1.5. Similar $\boldsymbol{k}$ effect was noticed for the insitu maximum horizontal stress angle and hence only $30^{\circ}$ value was considered. 
Given below are the results obtained at three cross-sections, AA, BB and CC in the entry and at cross-sections $\mathrm{JJ}$ and $\mathrm{KK}$ in the intersection shown in Figure 3.1.

\section{Section AA}

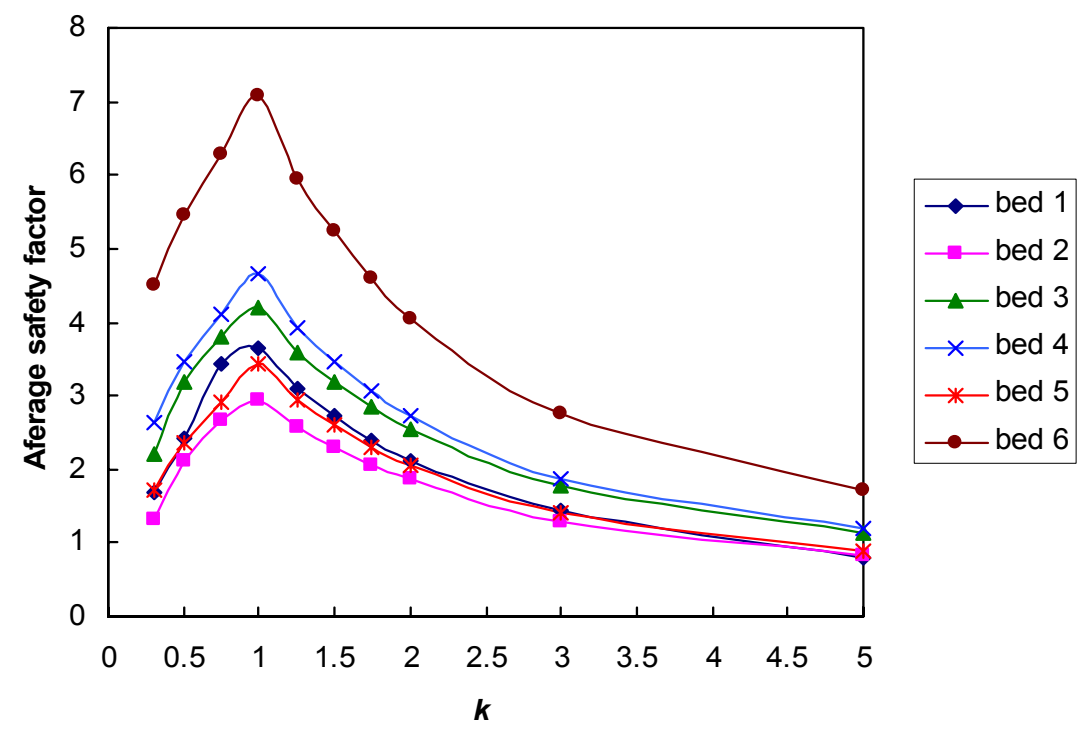

Figure 6.1. Effect of the ratio of maximum horizontal to vertical in-situ stress, $\boldsymbol{k}$ on the average safety factors of different beds at cross-section AA shown in Figure 3.1.

\section{Section BB}

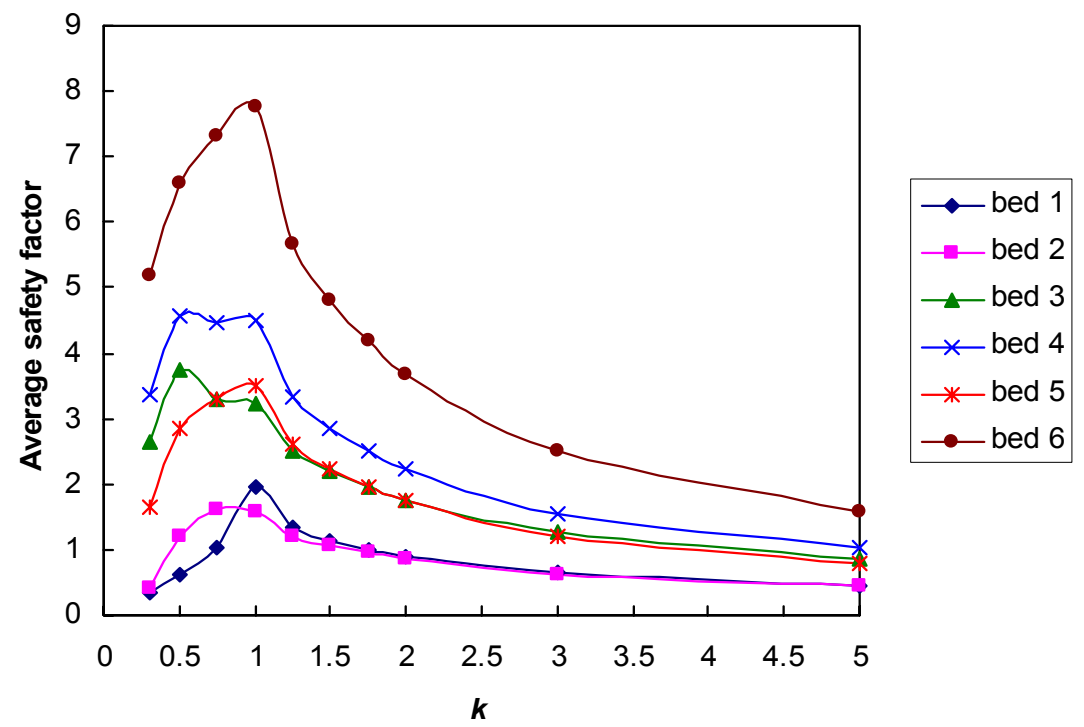

Figure 6.2. Effect of the ratio of maximum horizontal to vertical in-situ stress, $\boldsymbol{k}$ on the average safety factors of different beds at cross-section BB shown in Figure 3.1. 


\section{Section CC}

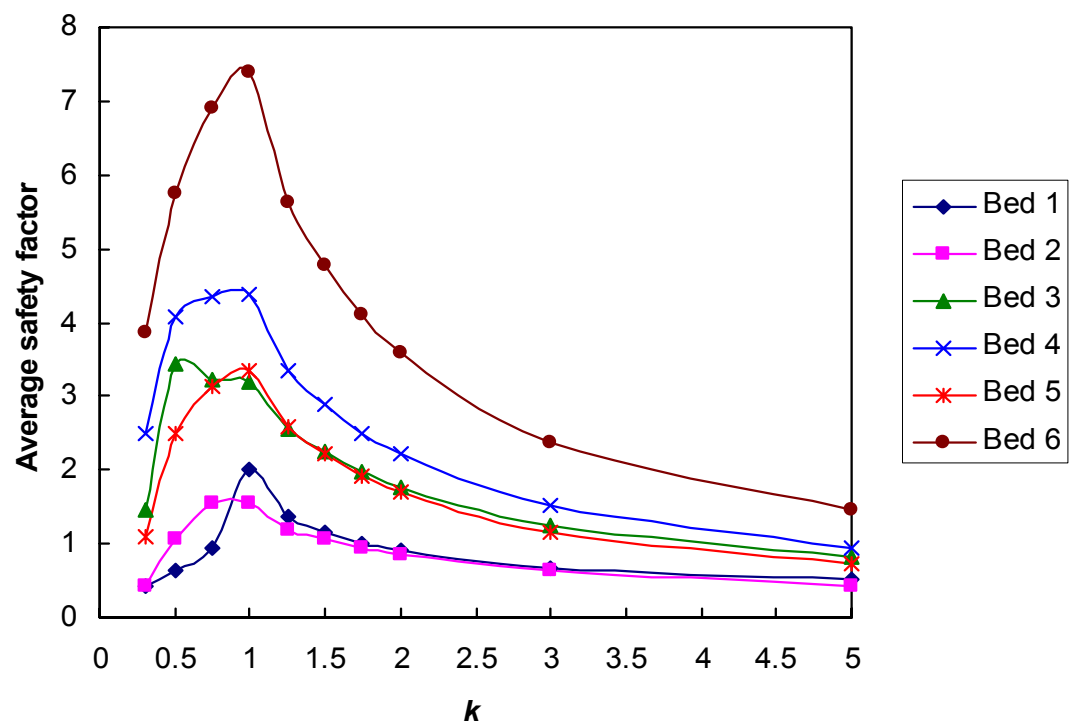

Figure 6.3. Effect of the ratio of maximum horizontal to vertical in-situ stress, $\boldsymbol{k}$ on the average safety factors of different beds at cross-section CC shown in Figure 3.1.

\section{Section JJ}

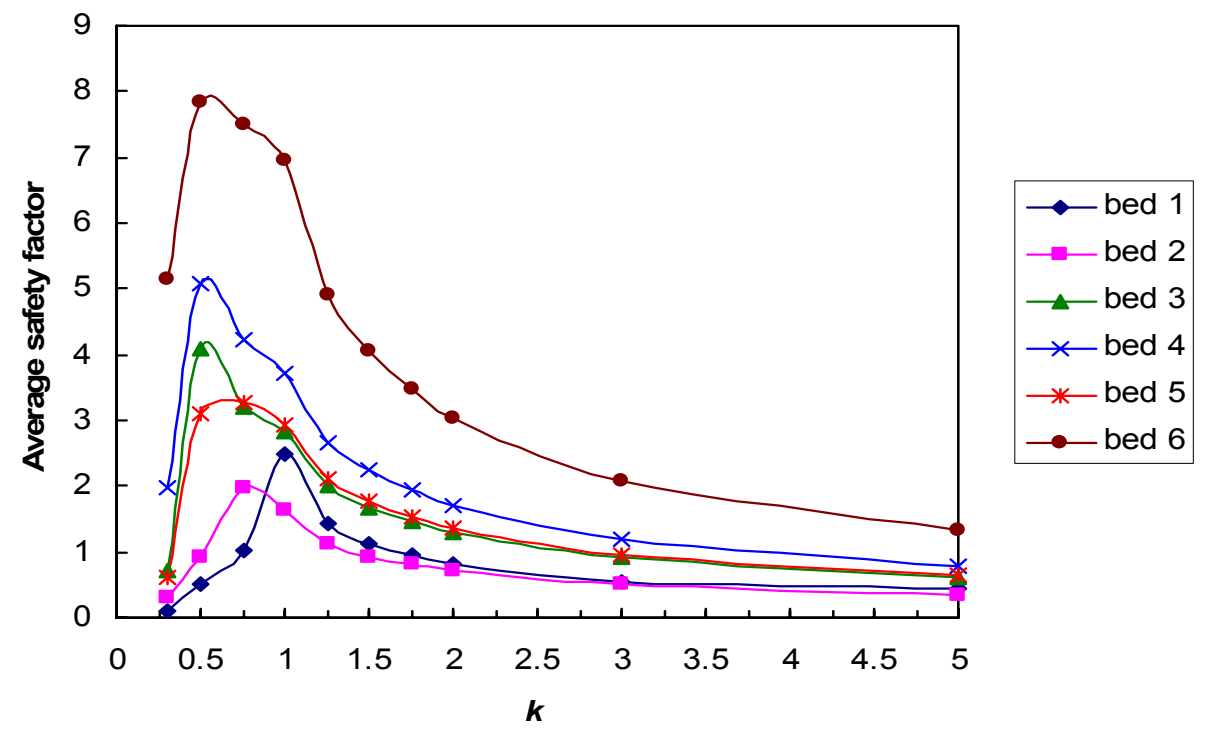

Figure 6.4. Effect of the ratio of maximum horizontal to vertical in-situ stress, $\boldsymbol{k}$ on the average safety factors of different beds at cross-section JJ shown in Figure 3.1. 


\section{Section KK}

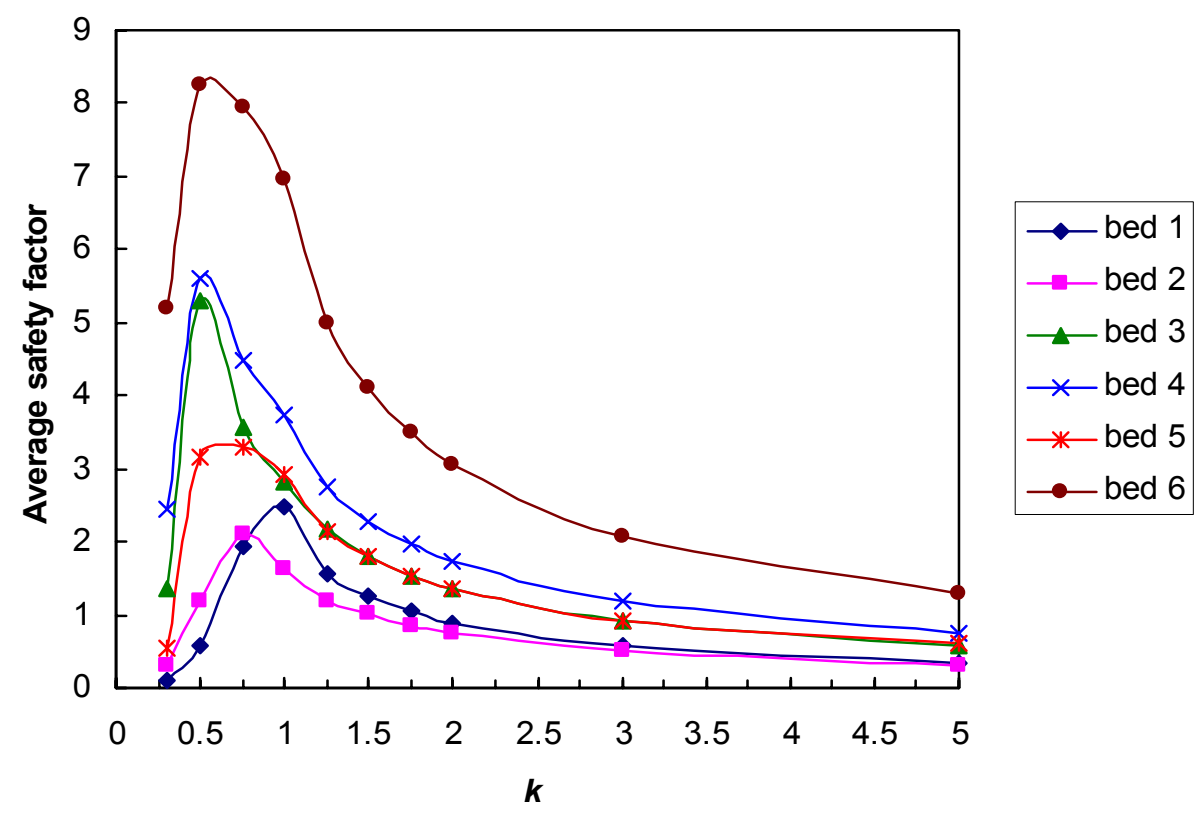

Figure 6.5. Effect of the ratio of maximum horizontal to vertical in-situ stress, $\boldsymbol{k}$ on the average safety factors of different beds at cross-section KK shown in Figure 3.1.

The following points emerge from this analysis:

\# The average stability of development workings increases with increasing $\boldsymbol{k}$ up to some value and then starts decreasing. The shape of this distribution resembles a lognormal distribution curve.

\# The peak of this curve is located somewhere between $\boldsymbol{k}=0.5$ and 1 .

I The shape of the distribution is approximately same for both the entry and the intersection.

\# The value of $\boldsymbol{k}$ at which maximum stability occurs is dependent on the ratio of in-situ maximum horizontal to minimum horizontal stress, in-situ maximum horizontal stress angle, location of the point in the roof and location of the cross-section.

a Very low horizontal stresses are equally unfavorable as very high horizontal stresses. 


\subsubsection{Why $k$ Effect?}

The next logical question that needs to be addressed is the reason why this particular shape is observed. This inquiry will also help us understand the mechanism of rock failure at very low as well as at very high horizontal in-situ stresses. For this purpose, the stress state at two points, one in the middle of section BB and the other in the middle of section JJ have been probed. The following Figures 6.6 and 6.7 show maximum and minimum principal stresses and also triaxial rock mass strength estimated using the Hoek-Brown rock mass failure criterion for different $\boldsymbol{k}$ values.

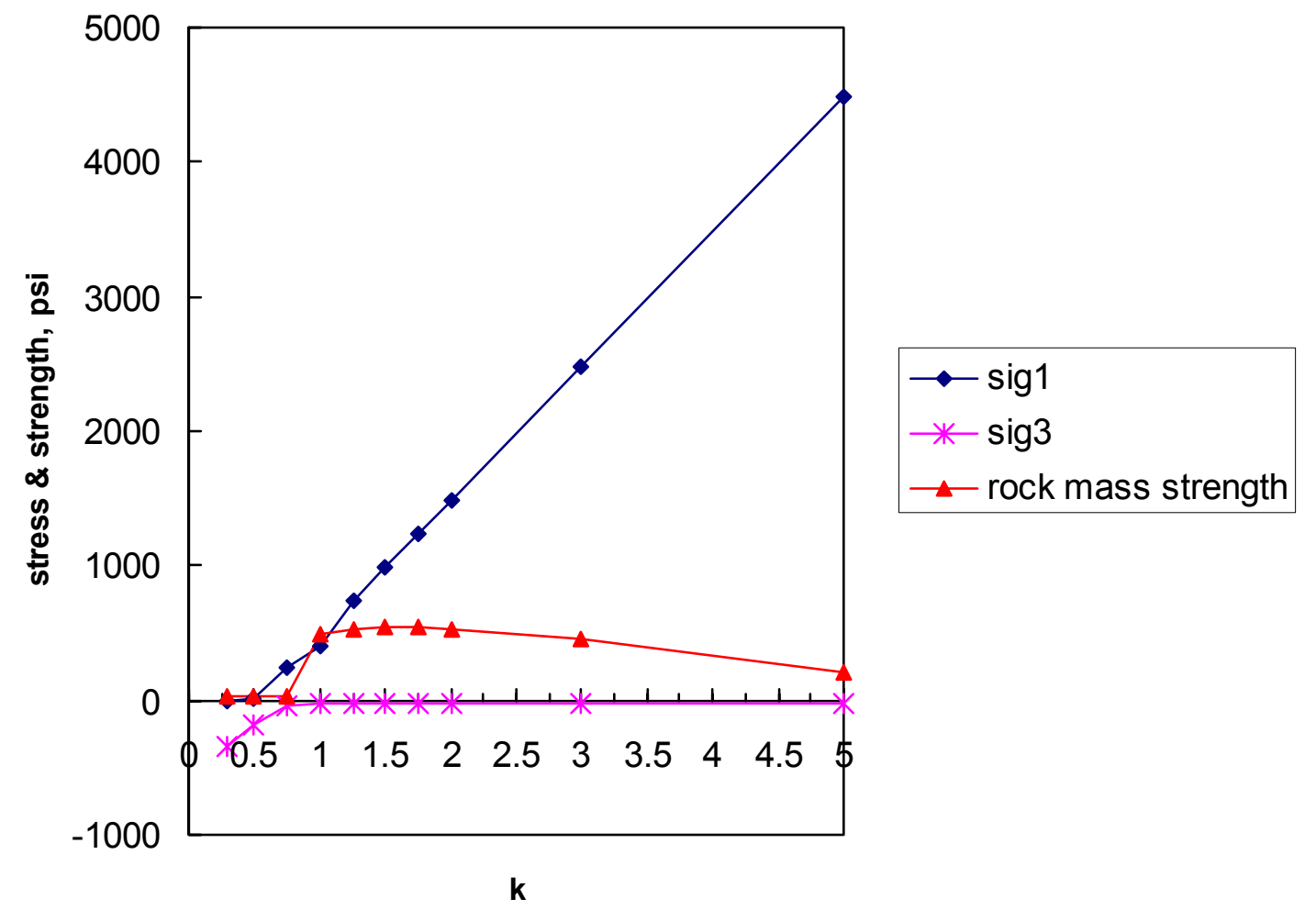

Figure 6.6. Maximum (sig1), minimum (sig3) principal stress and triaxial rock mass strength at the middle point in cross-section BB in the entry for different $\boldsymbol{k}$ values. 


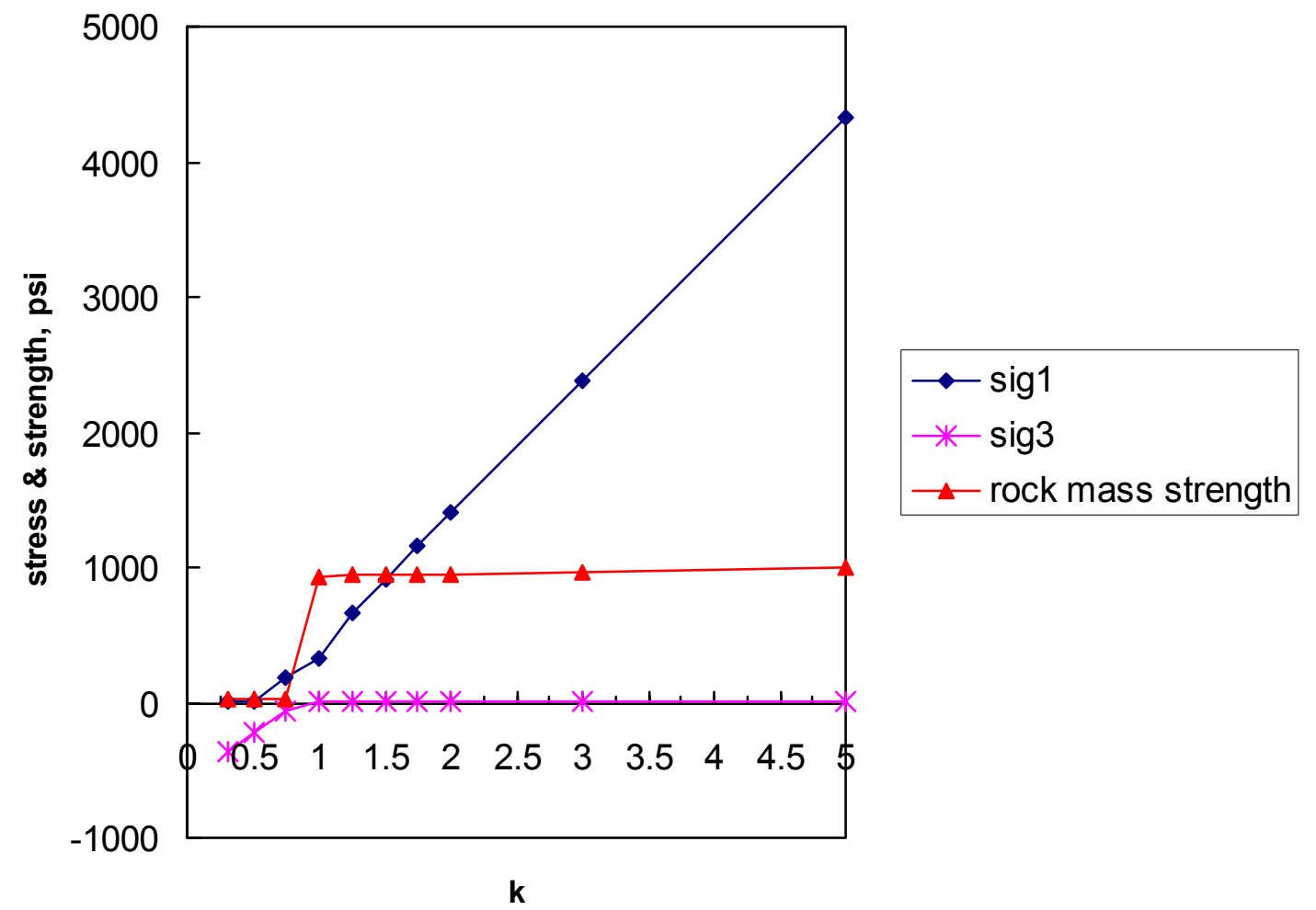

Figure 6.7. Maximum (sig1), minimum (sig3) principal stress and triaxial rock mass strength at the middle point in cross-section $\mathrm{JJ}$ in the intersection for different $\boldsymbol{k}$ values.

From figures 6.6 and 6.7 it may be noticed that the minimum principal stress is tensile in nature for $\boldsymbol{k}$ values below 1 and is more than the rock mass tensile strength. For this stress state, the rock fails in tension and hence the safety factors were low. Somewhere near $\boldsymbol{k}$ equal to 1 , the minimum principal stress becomes compressive or has very low tensile stress value. Near these points the maximum principal stress is also low and is less than the rock mass strength resulting in a stable roof. At high $\boldsymbol{k}$ values, the change in minimum principal stress is negligible while the maximum principal stress continues to increase. In this region, the rock mass strength doesn't change much as the minimum principal stress is not changing which causes shear failure of roof rock. This is reflected as low safety factors in this region too.

From this scrutiny it is apparent that the ratio of in-situ maximum horizontal to vertical stress changes the magnitude and nature of induced minimum principal 
stress which affects the rock mass strength resulting in the behavior observed above. Also, with changing $\boldsymbol{k}$ values the mode of rock failure changes from tensile to shear.

\subsubsection{Nature of Induced Stresses in the Immediate Roof}

It is commonly assumed that the induced stresses in the immediate roof are compressive for high horizontal in-situ stress fields. However, in one analysis [10] it was shown that some points in the immediate roof would be under tension even for high maximum horizontal to vertical stress ratios. Analysis in the present work also shows small tension in the immediate roof even for very high $\boldsymbol{k}$ values as shown in Figure 6.8. This plot shows the induced minimum principal stress in the immediate roof coal evaluated at different locations in the mesh. These results are for $\boldsymbol{k}=2, \boldsymbol{l}=$ 1.5 and $\theta=30^{\circ}$. The same trends were noticed for other combinations of input values. It is not clear whether this behavior is typical for the lithology and geo-mining parameters considered. Further research is required to verify this fact.

One comment about the induced stress nature in the roof is in order at this stage. As seen from Figure 6.8, the inference about the nature of stress would vary to some extent depending on the location of stress measurement points considered. It is different if one examines the results at the centroid of the element or at the integration points or the nodes. However, in the finite element method the results are most accurate at the integration points than at any location. Hence, the results obtained at these locations should reflect the actual nature of induced stresses. 


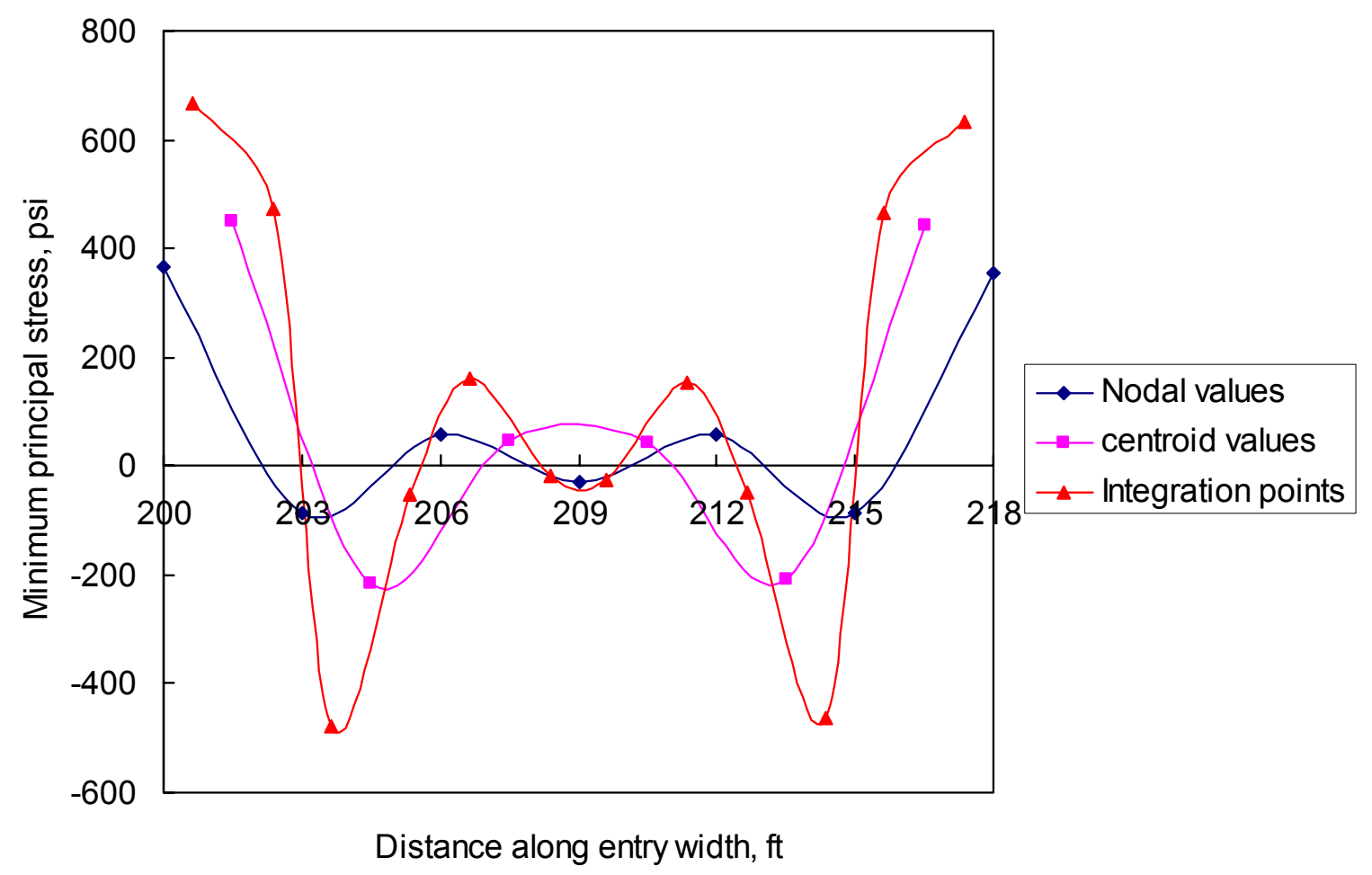

Figure 6.8. Minimum principal stress in the immediate roof coal evaluated at different locations in the mesh in the middle of the entry.

\section{3 Effect of In-situ Maximum Horizontal to Minimum Horizontal Stress Ratio (l)}

As discussed in chapter 2, the in-situ measurements also show wide variation in the ratio of in-situ maximum horizontal to minimum horizontal stress $(l)$ in the coal mines of the United States. Hence, an assessment of the influence of this factor on the stability of development workings has been made. To limit the amount of work, only three different values of $l, 1,1.5$ and 2 have been considered. The models were run for these $\boldsymbol{l}$ values for different $\boldsymbol{k}$ and $\theta$ values.

Average safety factors have been estimated for different beds in the roof at three cross-sections, $\mathrm{AA}, \mathrm{BB}$ and $\mathrm{CC}$ in the entry and two cross-sections, JJ and KK in the intersection shown in Figure 3.1. The variation of these safety factors is shown in Figure 6.9 through Figure 6.11 for different cross sections in the entry and Figure 6.12 and Figure 6.13 for the intersection. These figures show the safety factor 
distributions only for the first two beds in the roof and for an in-situ maximum horizontal stress angle of $30^{\circ}$. Similar trends were noticed in other beds and for different in-situ maximum horizontal stress angles.

(a)

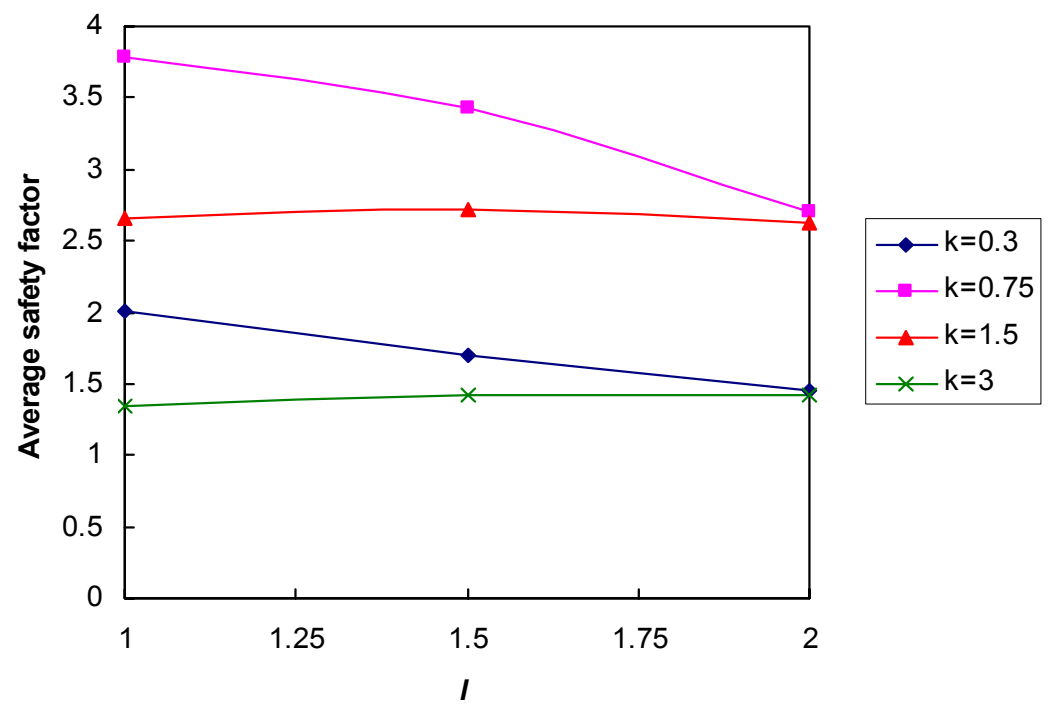

(b)

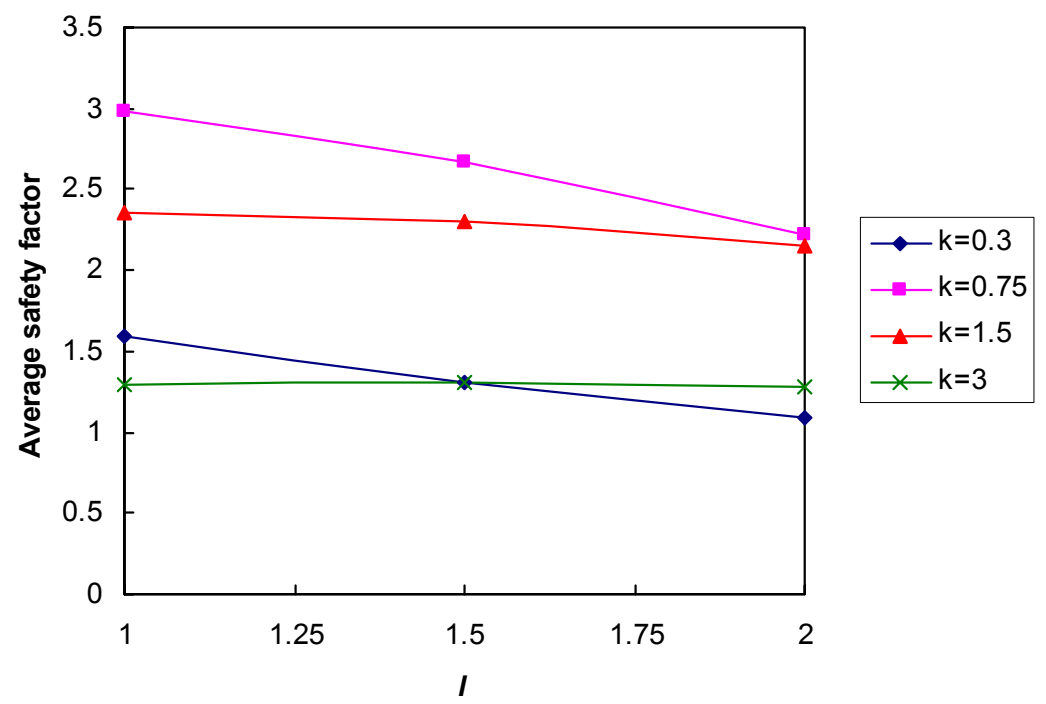

Figure 6.9. Change in average safety factors with $l$ for (a) bed 1 and (b) bed 2 at cross-section AA in the entry. 
(a)

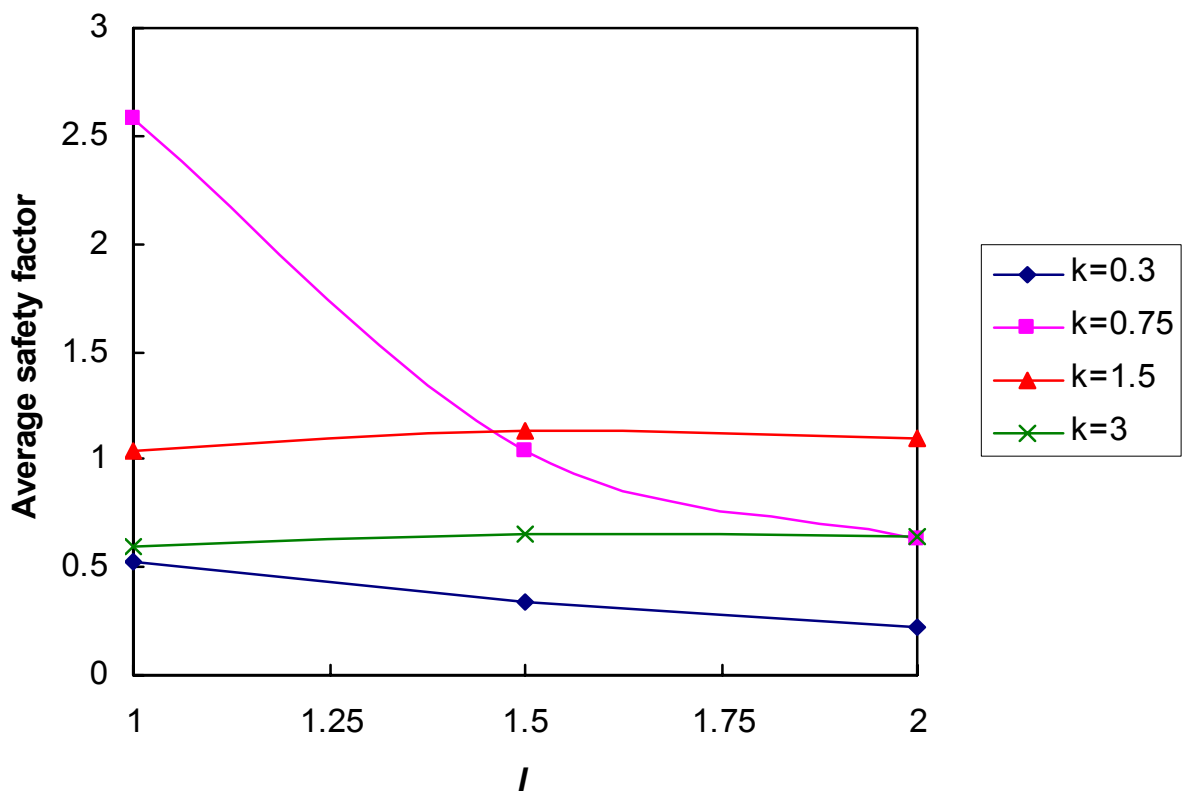

(b)

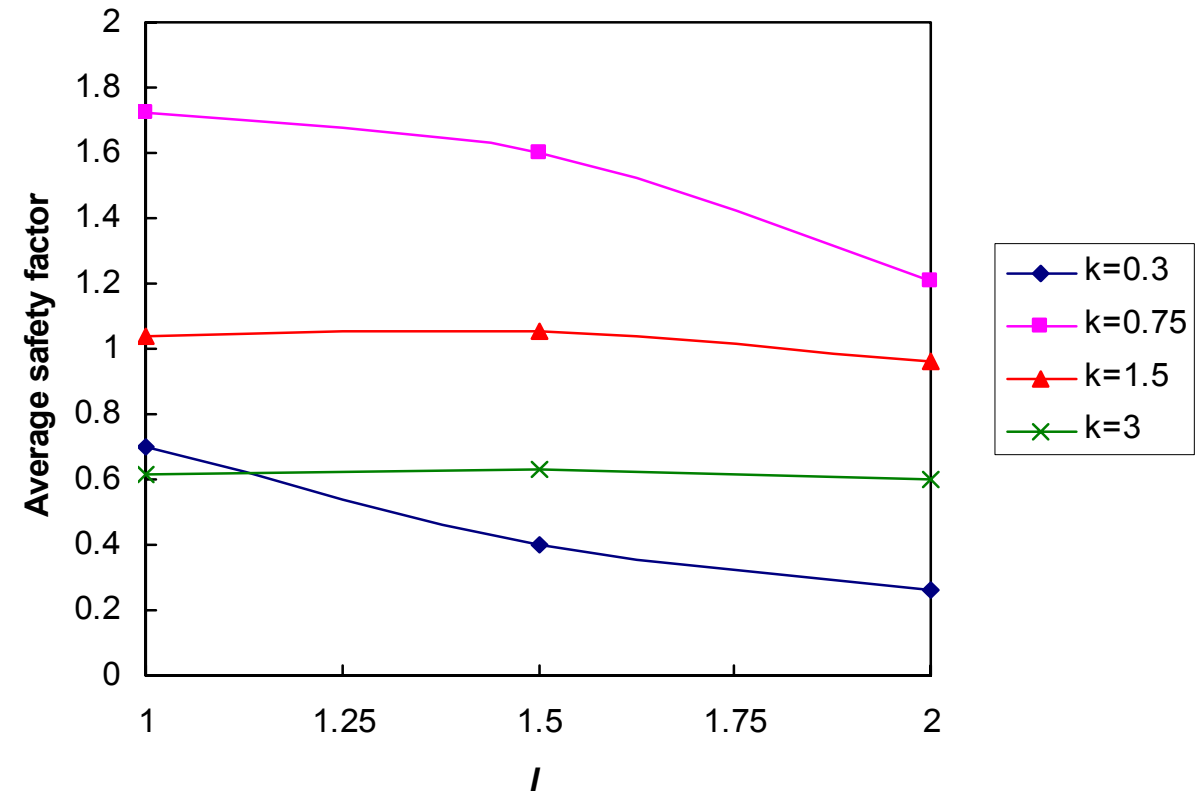

Figure 6.10. Change in average safety factors with $l$ for (a) bed 1 and (b) bed 2 at cross-section BB in the entry. 
(a)

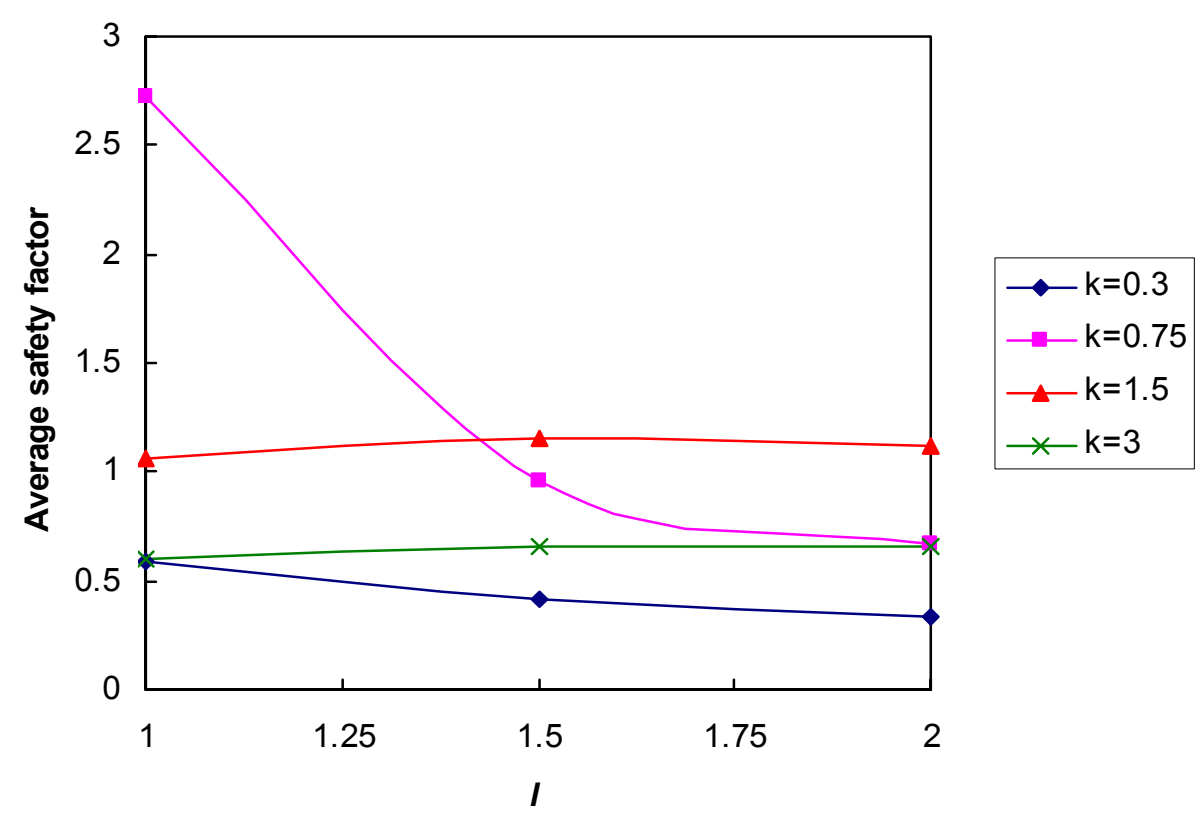

(b)

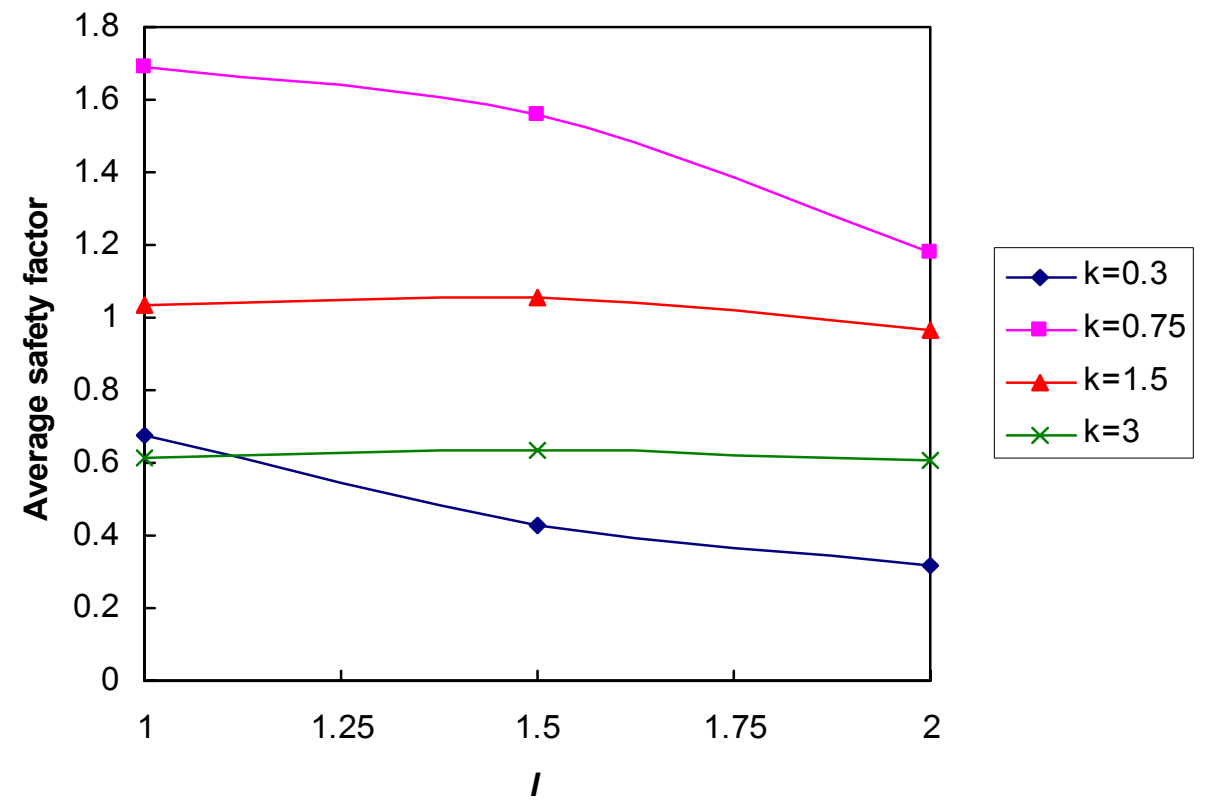

Figure 6.11. Change in average safety factors with $l$ for (a) bed 1 and (b) bed 2 at cross-section CC in the entry. 
(a)

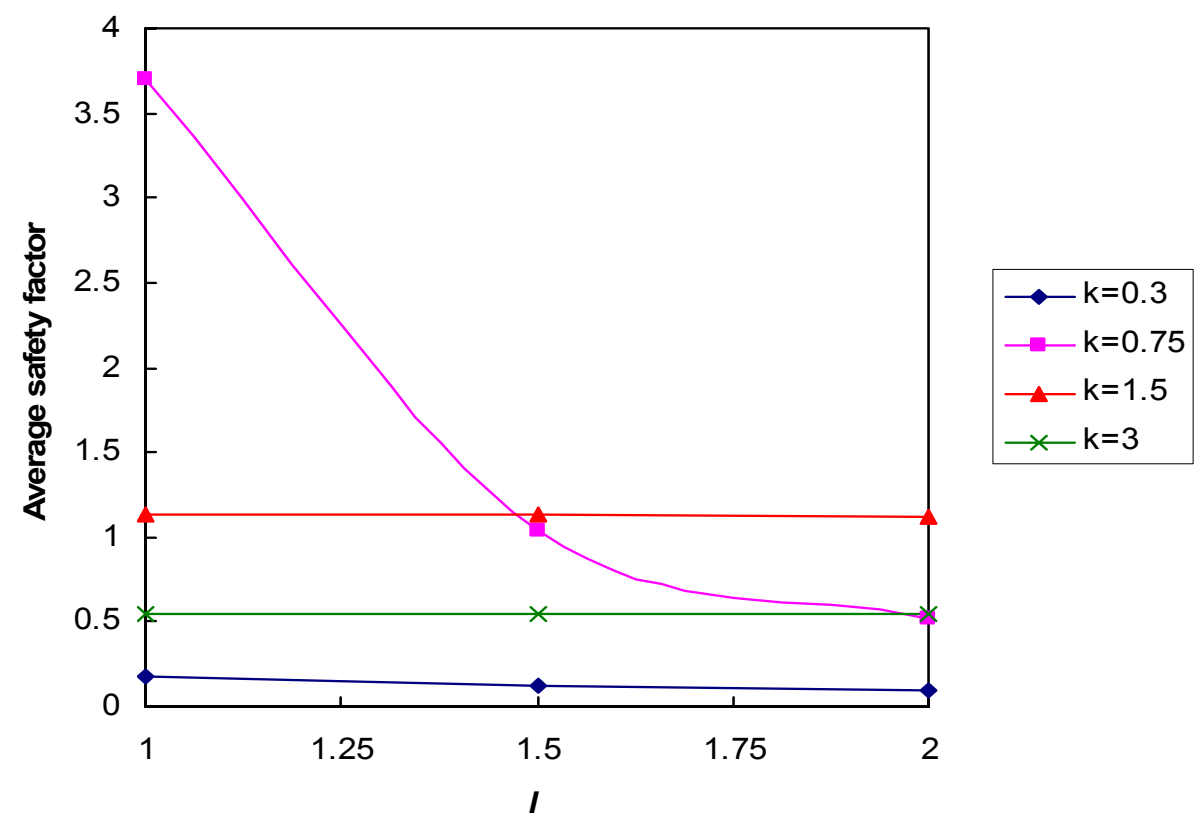

(b)

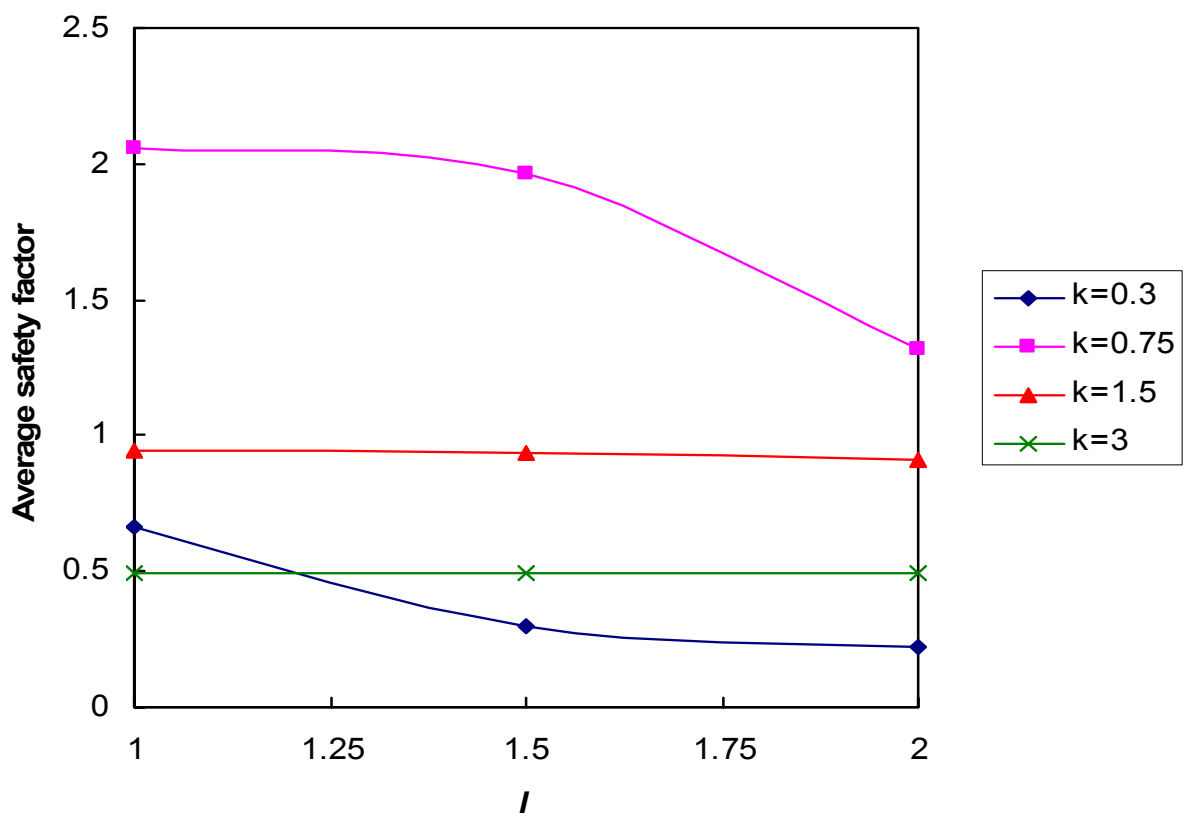

Figure 6.12. Change in average safety factors with $l$ for (a) bed 1 and (b) bed 2 at cross-section JJ in the intersection. 
(a)

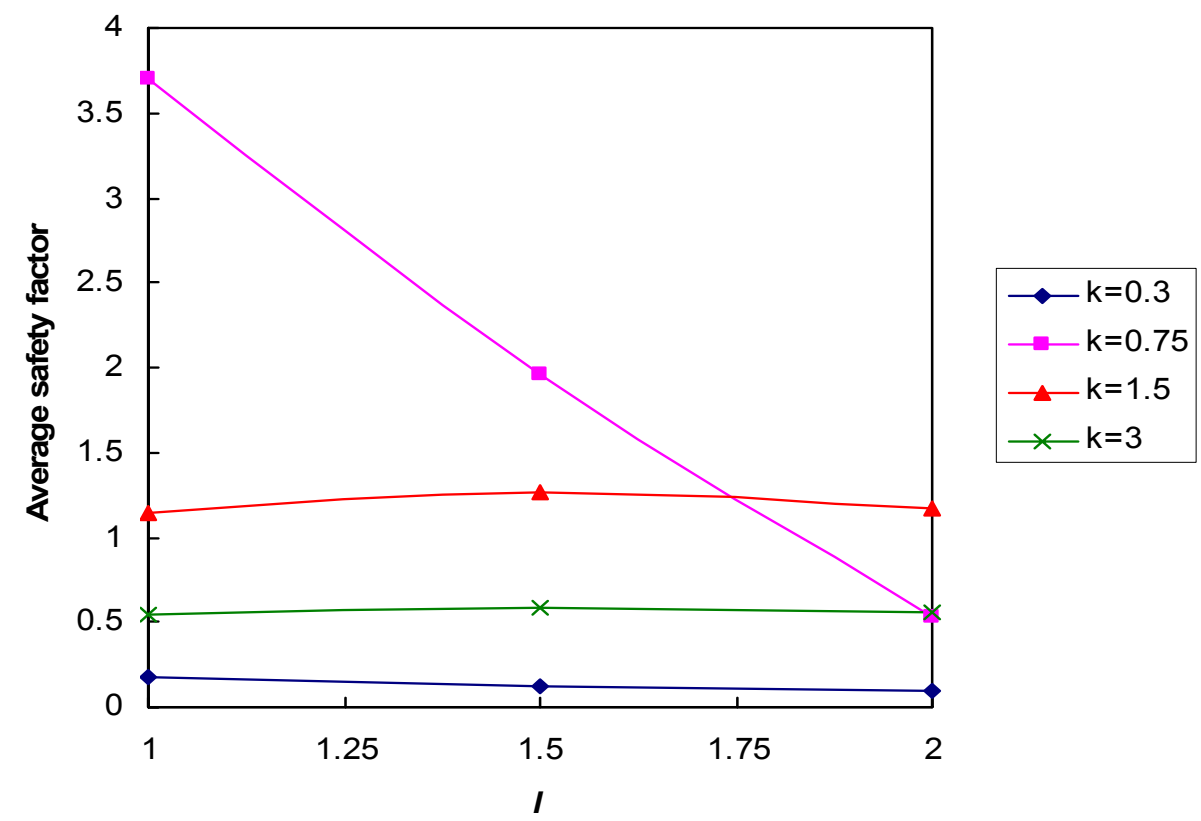

(b)

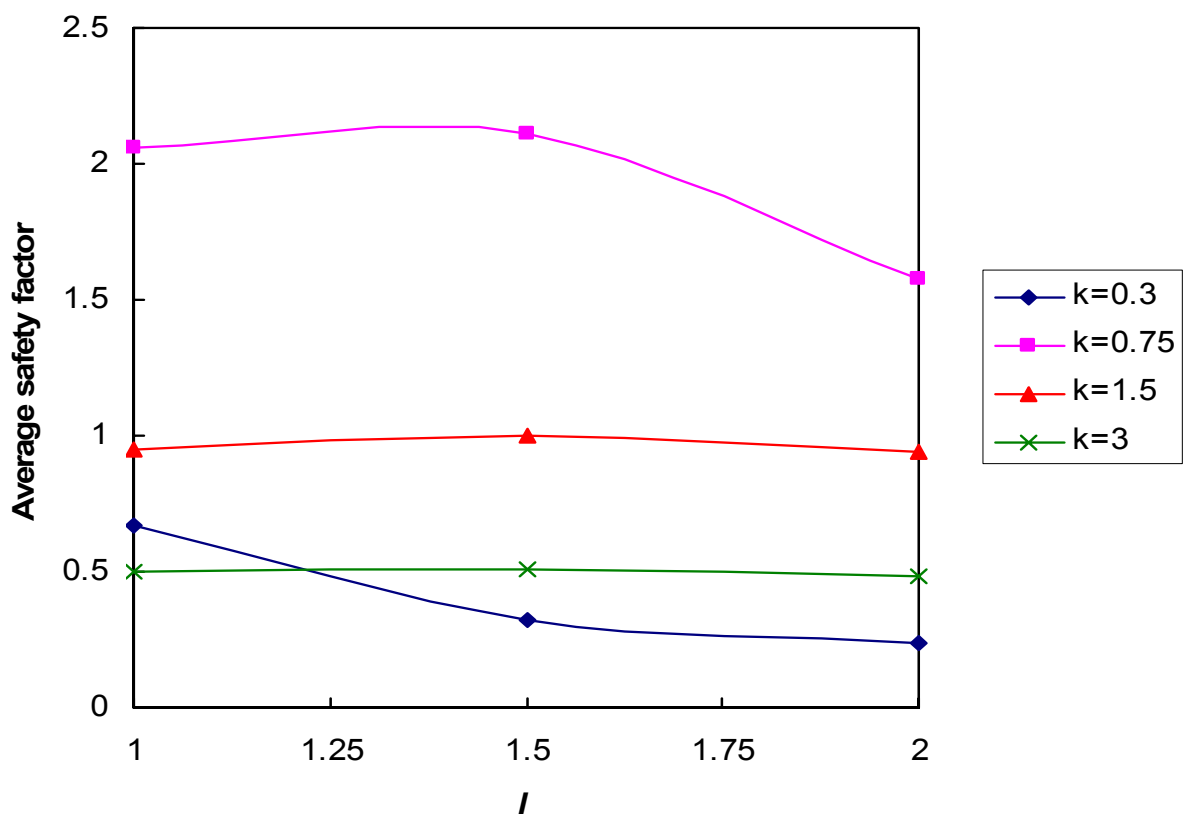

Figure 6.13. Change in average safety factors with $l$ for (a) bed 1 and (b) bed 2 at cross-section KK in the intersection. 
The following points are noticeable from these figures and from the analysis of results for the other combination of variables:

\# The effect of ratio $\boldsymbol{l}$ is more noticeable for $\boldsymbol{k}$ values less than 1 .

a Ratio $\boldsymbol{l}$ has little influence on the stability of roof for $\boldsymbol{k}$ greater than 1 .

\# The trend of $\boldsymbol{l}$ effect depends on the value of $\boldsymbol{k}$ and $\theta$, location of the bed in the roof and location of the cross-section.

Z In general, for a certain $\boldsymbol{k}$ value stability reduces with increasing $\boldsymbol{l}$.

\subsection{Chapter Summary}

The results obtained in this chapter clearly show the importance of both the ratio of in-situ maximum horizontal to vertical stress, $\boldsymbol{k}$ and the ratio of in-situ maximum horizontal to minimum horizontal stress, $l$ on the entry stability. Very low horizontal in-situ stresses can cause ground control problems as do very high horizontal in-situ stresses. For this reason, it is important to compare in-situ stress regimes among mines before transferring successful ground control strategies from one mine to another. This is because, with other things being similar, support techniques that are successful in one in-situ stress environment may be over or under designed in a different stress field. 


\section{CONCLUSIONS AND FUTURE RESEARCH}

The stability of an underground coal mine opening depends on many factors and the in-situ stress field is one among them. Though there are some good works available in the published literature as discussed in chapter 2, most of them are limited by the number of variable combinations considered. This thesis is an endeavor made to add a little more information on the effect of in-situ stresses on the roof stability of coal mine development excavations. The outcome of this research has been summarized below. Because of the limited scope of this thesis, many issues still remain to be explored. A brief outline of the possible areas for future research is also envisaged and given at the end of the chapter.

\subsection{Thesis Conclusions}

The following are the major conclusions drawn from the three dimensional finite element modeling and different analyses done in this thesis:

\# The application of in-situ stresses in the model by stress orientation or geometry orientation has the same effect on the induced principal stresses.

\# The Hoek-Brown rock failure criterion works well for US coal measure rocks, and the Mohr-Coulomb criterion with tension cut-off also provides comparable results.

I Broadly speaking, entries oriented in the direction of the maximum horizontal stress are in the most stable condition and those oriented at $90^{\circ}$ to $\sigma_{\mathrm{hmax}}$ are in the least stable condition. However, under certain conditions, the maximum and minimum stability could also be seen at other orientations.

Z The effect of $\theta$ on the intersection stability is different from its effect on the entry. In this case, the best conditions are seen at $0^{\circ}$ or $90^{\circ}$ and the worst at $45^{\circ}$. 
\# Orientation effects of $\sigma_{\mathrm{hmax}}$ on the conditions of the entry or the intersection depend on the values of ratio of maximum horizontal to vertical stress $(\boldsymbol{k})$, ratio of maximum horizontal to minimum horizontal stress $(l)$, location of the cross-section and location of the bed in the roof.

\# Based on this work, layout orientation charts for the entry and the intersection are developed and are shown in Figure 7.1 for ready reference. Though the design chart for the entry is already available, rational basis for this chart has been provided in this thesis. The validity of predictions was verified through three case studies.

Z One of the most surprising findings of the work is the higher increase in safety factor for low in-situ stress fields. It was found that the percentage of gain that could be realized with reorientation when $\boldsymbol{k}<1$ was much higher than when $\boldsymbol{k}$ $>1$. This gain was better seen in the conditions of the entry than in the intersection for any $\boldsymbol{k}$ value.

a Depending on the values of $\boldsymbol{k}, \boldsymbol{l}$, location of the cross-section and location of the bed in the roof, change in the average safety factor with reorientation could be significant or negligible.

I Distribution patterns of maximum and minimum principal stress and safety factor are developed and possible reasons for the apparent mismatch with stress mapping technique are discussed.

\# The effect of $\boldsymbol{k}$ on the entry or intersection stability has the shape of a lognormal distribution curve. Low in-situ horizontal stresses can have the same or even worse influence on the entry stability as high in-situ stresses. The entry stability also depends on the value of $l$.

\# While general design guidelines developed in this work may be sufficient for initial designs, they should not be considered as a substitute for detailed site specific studies as many variables can affect the actual improvement in the ground conditions as demonstrated in this work. 
(a) For entry or cross-cut
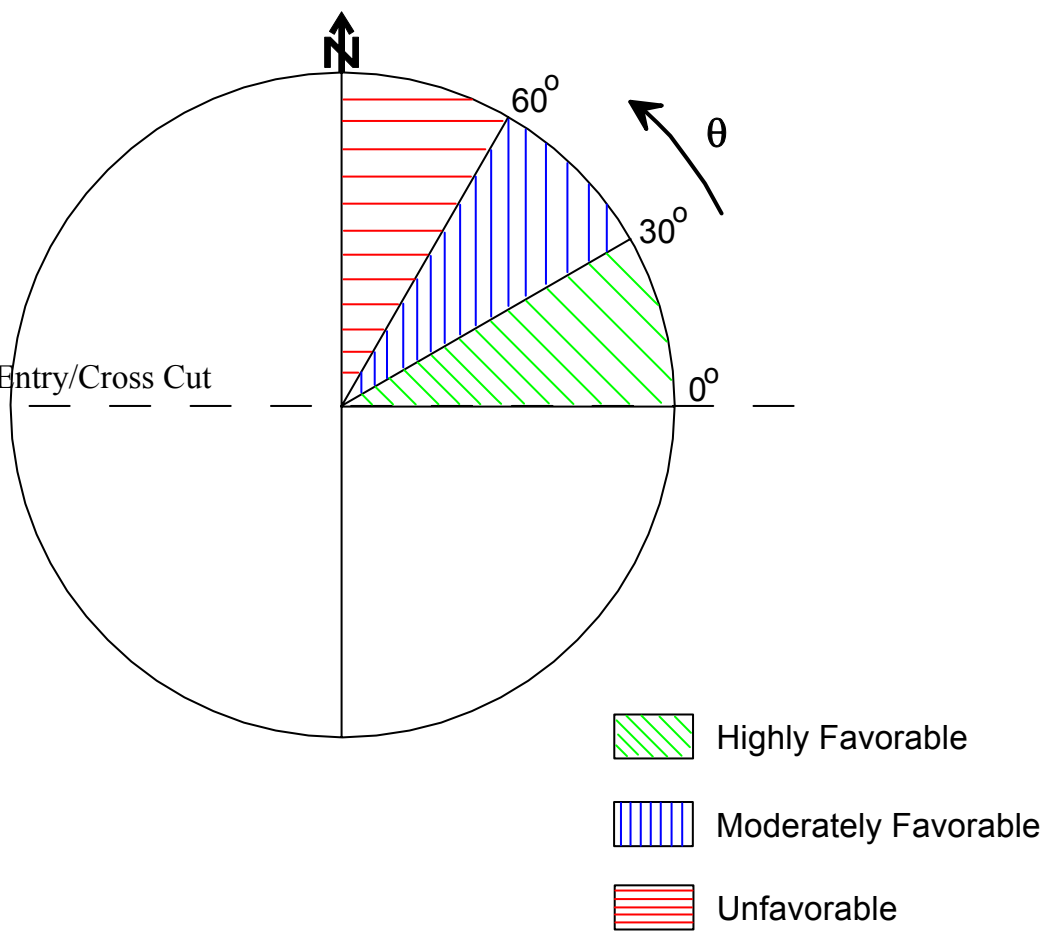

(b) For intersection

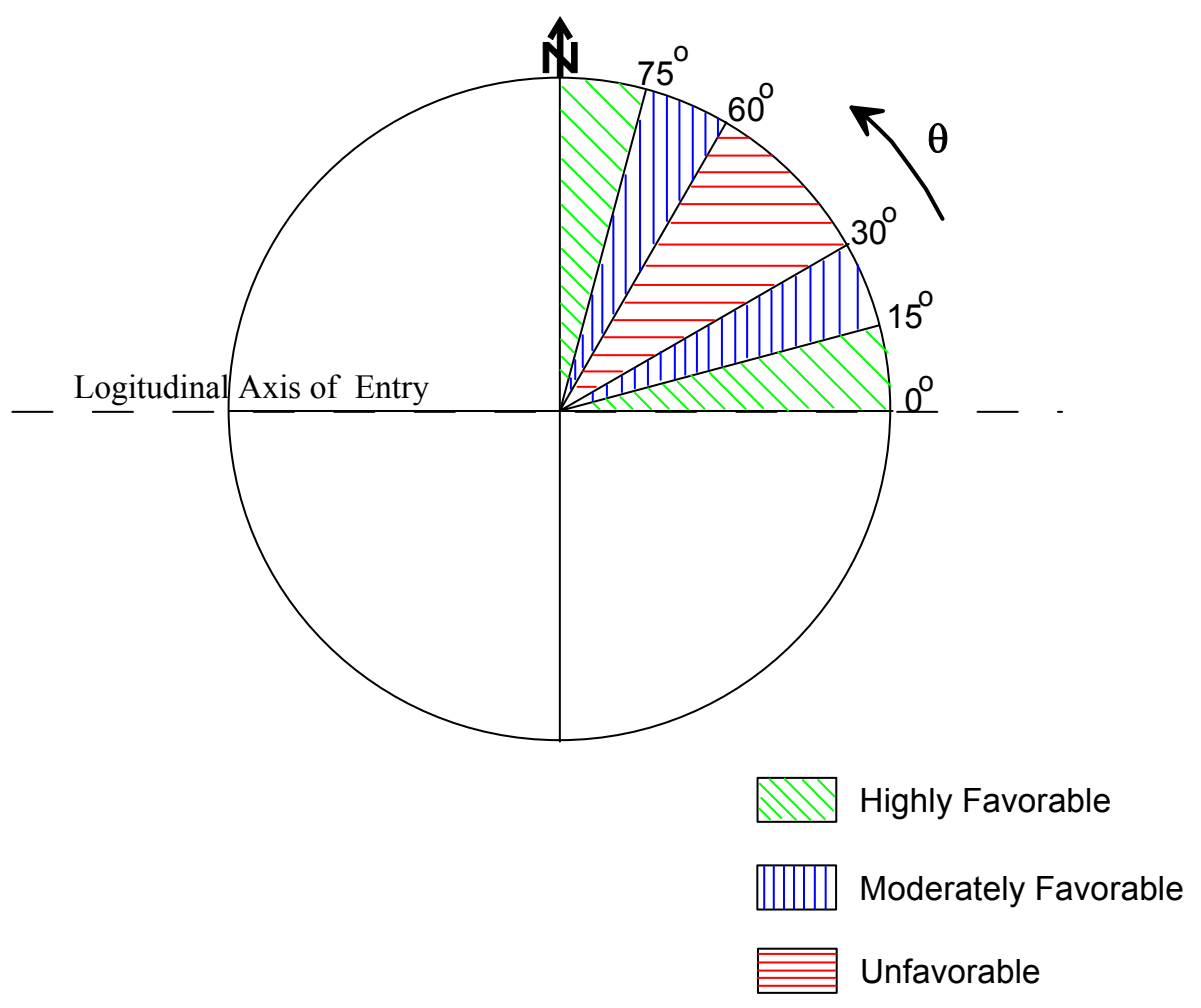

Figure 7.1. Layout orientations and associated ground conditions with respect to $\sigma_{\mathrm{hmax}}$ for (a) entry or crosscut and (b) intersection. 


\subsection{Future Research}

The following factors still need to be considered in order to develop a more comprehensive understanding of the effect of in-situ stresses on the coal mine roof stability.

\# Different entry widths and depth of covers.

\# Larger range of $\boldsymbol{k}$ and $\boldsymbol{l}$ values on smaller increments.

Z The effect of different lithologies.

\# Since the present work doesn't cover the interaction effects of multiple entries or the effect of angled crosscuts other than $90^{\circ}$, further work is required on this as well.

\# The effect of progressive failure and bedding planes on the response must also be incorporated.

\# Since more detrimental effects of horizontal stresses are seen on retreat workings, research should also be done on the effects of in-situ stresses on large extraction areas. 


\section{REFERENCES}

1. ABAQUS/Standard, version 6.3, user's manuals. ABAQUS, Inc., Pawtucket, Rhode Island, USA.

2. AHSEM, version 1.0d, help manuals. NIOSH, Pittsburgh Research Center, the U.S. Department of Health and Human Services, 2003 (available online at http://www.cdc.gov/niosh/mining).

3. Agapito, J. F. T., Mitchell, S. J., Hardy, M. P., and Hoskins, W. N. Determination of In Situ Horizontal Rock Stress on Both a Mine-Wide and District-Wide Basis (contract J0285020, Tosco Research Inc., and J.F.T. Agapito \& Associates). USBM OFR 143-80, 1980, 174 pp.

4. Aggson, J. R. Coal Mine Floor Heave in the Beckley Coalbed, An Analysis. USBM RI 8274, 1978, 32 pp.

5. Aggson, J. R. Stress-Induced Failures in Mine Roof. BuMines RI 8338, 1979, 16 pp.

6. Amadei, B., and Stephansson, O. Rock stress and its Measurement. Chapman and Hall, London, 1997, 490 pp.

7. Bauer, E. R. Cutter Roof Failure: Six Case Studies in the Northern Appalachian Coal Basin. USBM IC 9266, 1990, 18 pp.

8. Blevins, C. T. Coping With High Lateral Stress in an Underground Illinois Coal Mine. Paper in Proceedings of $2^{\text {nd }}$ Conf. on Ground Control in Mining, WV Univ. Morgantown, WV, 1982, pp. 137-141.

9. Blevins, C. T., and Dopp, D. Ground Control Experiences in A High Horizontal Stress Field at Inland Steel Coal Mine No.2. Paper in Proceedings of the $4^{\text {th }}$ Conf. on Ground Control in Mining, WV Univ., Morgantown, WV, 1985, pp 227-233.

10. Chen, H. J. Stress Analysis in Longwall Entry Roof Under High Horizontal Stress. Ph.D. dissertation, West Virginia University, 1999, 278 pp.

11. Dahl, H. D., and Parsons, R. C. Ground Control Studies in the Humphrey No. 7 Mine, Christopher Coal Div., Consolidation Coal Co. Soc. Min. Eng. AIME Trans., v. 252, June 1972, pp. 211-222. 
12. Dolinar, D. R., Aggson, J. R., and Hooker, V. E. In Situ Stress Distributions and Related Ground Control Problems. Paper in Ground Control in Roomand-Pillar Mining, Soc. Min. Eng. of AIME, 1982, pp. 35-40.

13. Dolinar, D. R., Mucho, T. P., Oyler, D. C., and Pablic, J. Advance and Relieve Mining: A Method to Mitigate the Effects of High Horizontal Stress on the Mine Roof. SME preprint 01-113. Littleton, CO: Society for Mining, Metallurgy, and Exploration, Inc. 2001.

14. Gale, W. J., and Blackwood, R. W. Stress distributions and rock failure around coal mine roadways. Int. Journal of Rock Mech. Min. Sciences and Geomech. Abstract, Vol. 24, No.3, 1987, pp.165-173.

15. Gale, W. J. Strata Control Utilising Rock Reinforcement Techniques and Stress Control Methods, in Australian Coal Mines. The Mining Engineer, Vol. 150, No. 352, Jan. 1991, pp. 247-253.

16. Gercek, H. Stability of Intersections in Room and Pillar Coal Mining. Ph. D. Thesis, Pennsylvania State Univ., 1982, 186 pp.

17. Hanna, K., Haramy, K. Y., and Conover, D. P. Effect of High Horizontal Stress on Coal Mine Entry Intersection Stability. Paper in Proceedings of the $5^{\text {th }}$ Conf. on Ground Control in Mining, WV Univ., Morgantown, WV, 1986, pp. 167-182.

18. Hill III, J. L. Cutter Roof Failure: An Overview of the Causes and Methods for Control. USBM IC 9094, 1986, 27 pp.

19. Hoek, E., and Brown, E. T. Underground Excavations in Rock. Institution of Min. Metall., London, 1980, 527 pp.

20. Hoek, E., Carranza-Torres, C.T., and Corkum, B. Hoek-Brown failure criterion - 2002 edition. Proc. North American Rock Mechanics Society meeting in Toronto in July 2002.

21. Jaeger, J. C., and Cook, N. G. W. Fundamental of Rock Mechanics. Chapman and Hall, London, 1979, 585 pp.

22. Jeremic, M. L. Coal Mine Roadway Stability in Relation to Lateral Tectonic Stress-Western Canada. Mining Engineering, June 1981, pp. 704-709. 
23. Kent, F. L. Factors affecting the stability of reinforced roadways in coal mines. Ph.D. Thesis, Camborne School of Mines, Univ. of Exeter, 1996, 339 pp.

24. Kripakov, N. P. Alternatives for controlling cutter roof in coal mines. Paper in Proceedings of the $2^{\text {nd }}$ Conf. on Ground Control in Mining, WV Univ., Morgantown, WV, 1982, pp. 142-151.

25. Lizak, J. B., and Sembourski, J. E. Horizontal Stresses and Their Impact on Roof Stability at the Nelms No. 2 Mine. Paper in Proceedings of the $4^{\text {th }}$ Conf. on Ground Control in Mining, WV Univ., Morgantown, WV, 1985, 7 pp.

26. Mark, C., and Mucho, T. P. Longwall Mine Design for Control of Horizontal Stress. Proc. BuMines Tech. Transfer Seminar on New Tech. for Longwall Ground Control, 1994, pp. 53-76.

27. Meyer, L. H. I., Coggan, J. S., and Stead, D. Three dimensional non-linear modeling of the effects of high horizontal stress on underground excavation face-end stability. Rock mechanics for Industry, ISBN 905809 0423, 1999, pp.147-152.

28. Meyer, L. H. I., Stead D., and Coggan, J. S. Three dimensional modeling of the effects of high horizontal stress on underground excavation stability. IRSM $9^{\text {th }}$ International Congress on Rock Mechanics, 1999, pp.411-416.

29. Middleton, G. V., Wilcock, P. R. Mechanics in the Earth and Environmental Sciences. Cambridge University Press, Australia, 1996, 496 pp.

30. Molinda, G. M., Mark, C., Bauer, E. R., Babich, D. R., and Pappas, D. M. Factors Influencing Intersection Stability in U.S. Coal Mines. Paper in Proceeding of $17^{\text {th }}$ Intl. Conf. on Ground Control in Mining, WV Univ., Morgantown, WV, 1998, pp. 267-275.

31. Mucho, T. P., Mark, C. Determining Horizontal Stress Direction Using Stress Mapping Technique. Paper in Proceeding of $13^{\text {th }}$ Intl. Conf. on Ground Control in Mining, WV Univ., Morgantown, WV, 1994, pp. 277-289.

32. Peng, S. S., and Chen, H. J. Stress Distributions in Three-Entry Development under High Horizontal Stress. Vol. 308, SME Transactions 2000, pp. 91-96 
33. Peng, S. S. Personal Communication.

34. Reinecker, J., Heidbach, O., and Mueller, B. The 2003 release of the World Stress Map, 2003 (available online at www.world-stress-map.org).

35. Sheorey, P. R. Empirical rock failure criteria. Balkema, Rotterdam, 1997,176 pp.

36. Su, W. H, and Peng, S. S. Cutter Roof and Its Causes. Soc. Min. Eng. AIME preprint 85-131, 1985, 5 pp.

37. Unal, E. Empirical Approach to Calculate Rock Loads in Coal Mine Roadways. Paper in Proceedings of the $5^{\text {th }}$ Conf. on Ground Control in Mining, WV Univ., Morgantown, WV, 1986, pp. 234-241.

38. Wang, F. D., Ropchan, D. M., and Sun, M. C. Structural Analysis of a Coal Mine Opening in Elastic Multilayered Material. BuMines RI 7845, 1974, 36 pp.

39. Wang, Y., and Stankus, J. Roof Control Under Conditions of Shallow Depth and High Horizontal Stress Field - A Case Study. Paper in Proceedings of the $17^{\text {th }}$ Intl. Conf. on Ground Control in Mining, WV Univ., Morgantown, WV, 1998, pp. 113-118.

40. Zoback, M. L., et al. Global Patterns of Tectonic Stress, Nature, 341, 1989, pp. 291-298. 